Marina da Silva Sanches

\title{
Política fiscal e dinâmica do produto: uma análise baseada em multiplicadores fiscais no Brasil
}

São Paulo 

Prof. Dr. Vahan Agopyan

Reitor da Universidade de São Paulo

Prof. Dr. Fábio Frezatti

Diretor da Faculdade de Economia, Administração e Contabilidade

Prof. Dr. José Carlos de Souza Santos

Chefe do Departamento de Economia

Prof. Dr. Ariaster Baumgratz Chimeli

Coordenador do Programa de Pós-Graduação em Economia 


\author{
Marina da Silva Sanches
}

\title{
Política fiscal e dinâmica do produto: uma análise baseada em multiplicadores fiscais no Brasil
}

\begin{abstract}
Dissertação de Mestrado apresentada ao Departamento de Economia da Faculdade de Economia, Administração e Contabilidade da Universidade de São Paulo como requisito parcial para a obtenção do título de Mestre em Ciências. Área de concentração: Teoria Econômica.
\end{abstract}

\author{
Universidade de São Paulo (USP) \\ Faculdade de Economia, Administração e Contabilidade \\ Programa de Pós-Graduação em Economia \\ Versão Corrigida
}

Orientadora: Prof ${ }^{\mathrm{a}}$ Dr$^{\mathrm{a}}$ Laura Barbosa de Carvalho

São Paulo 



\section{Sanches, Marina da Silva.}

Política fiscal e dinâmica do produto: uma análise baseada em multiplicadores fiscais no Brasil / Marina da Silva Sanches. - São Paulo, 2020.

$196 \mathrm{p}$.

Dissertação (Mestrado) - Universidade de São Paulo, 2020.

Orientador: Laura Barbosa de Carvalho.

1. Política fiscal. 2. Macroeconomia Pós-Keynesiana. 3. Multiplicadores fiscais. 4. Modelos Kaleckianos. 5. Benefícios Sociais. I. Universidade de São Paulo. Faculdade de Economia, Administração e Contabilidade. II. Título. 


\section{Agradecimentos}

Agradeço, em primeiro lugar, a Deus, por todas as bençãos, pela minha saúde, pela minha família e por todas as oportunidades. Há muito o que percorrer ainda, mas Sua presença é o que me fortalece e ilumina meu caminho.

Em seguida, agradeço às pessoas mais importantes da minha vida, meus queridos pais Roseli e Baltazar, que sempre me ofereceram, além de condições materiais, aspectos intangíveis para que eu alcançasse este êxito. Não foram poucos os momentos em que pensei em desistir por achar que eu não conseguiria superar as dificuldades do mestrado. Mas eles sempre estavam lá para me ajudar. Acompanharam minha jornada de perto, e celebraram comigo cada resultado positivo que eu tinha, em meio a tantas incertezas, ainda que fosse algo pequeno. Muito obrigada por todo o incentivo, seja por palavras ou por gestos. Agradeço a eles e a meus irmãos pelo carinho, pela paciência, pelo apoio incondicional, pela confiança em mim depositada, e por sempre me ajudarem em tudo o que faço na vida.

Obrigada a todos os amigos do IPE/USP, em especial aos do grupo de pesquisa de Macroeconomia das Desigualdades. As conversas na salinha do café e os momentos de descontração sempre me ajudavam a manter a cabeça no lugar nos momentos difíceis. Obrigada aos veteranos pela solidariedade ao ceder vários materiais de estudo e listas de exercícios, que foram fundamentais principalmente em meio ao ritmo pesado do primeiro semestre.

Agradeço imensamente à Universidade de São Paulo por me proporcionar uma formação de excelência para a pesquisadora que pretendo ser. Espero continuá-la no doutorado. Agradeço ao CNPq e à Fipe pelo meu financiamento. Agradeço ao Sergio Gobetti e ao Rodrigo Orair, que foram muito solícitos aos meus e-mails e me disponibilizaram os dados utilizados nesta pesquisa.

Sou grata também à Universidade de Brasília, onde obtive minha formação de economista. Especialmente à Professora Andrea Cabello, por todo o incentivo a seguir o caminho do mestrado. À minha amiga Flávia, que se formou comigo na UnB, obrigada pela amizade, pelas conversas sobre economia, por dividir suas experiências do mestrado e por sempre me incentivar a estudar.

Muito obrigada a todos os professores que contribuíram para minha formação de mestre, seja nas disciplinas ou na pesquisa. Agradeço especialmente aos professores do grupo de pesquisa de Macroeconomia das Desigualdades, pelo ambiente estimulante de nossas reuniões em grupo. Ao Professor Gilberto Tadeu Lima, que acompanhou todas as etapas de elaboração desta pesquisa, obrigada pelos ensinamentos em sala de aula e pela leitura 
atenta aos meus trabalhos, sempre contribuindo com valiosos comentários e conselhos. Ao Professor Fernando Rugitsky, agradeço pelas várias sugestões em etapas intermediárias de avaliação deste trabalho, principalmente no início, que foram fundamentais para o rumo que esta pesquisa tomou.

Agradeço especialmente à minha orientadora, Professora Laura Carvalho, que eu sempre admirei. Acompanhou de perto cada passo que eu dava, sempre me ensinando o melhor caminho e contribuindo com ideias novas. Sua orientação foi fundamental para o meu amadurecimento e despertou-me o interesse em seguir com o doutorado. Muito obrigada pela confiança em mim depositada, pela paciência e por todo o conhecimento transmitido. 


\section{Resumo}

Com base em um VAR Estrutural de Blanchard e Perotti (2002), estimamos, em nosso primeiro artigo, multiplicadores fiscais para os diferentes componentes das despesas do governo central brasileiro, bem como para diferentes subperíodos da amostra 1997-2017. Os resultados sugerem um multiplicador fiscal maior e mais persistente para a amostra inteira, que inclui a crise recente do país, do que para a amostra do período 1997-2014. A diferença emerge de apenas dois componentes: benefícios sociais e investimentos públicos, que geram os maiores efeitos multiplicadores. Com base nessas estimações, analisamos, em particular, os efeitos da substituição de investimentos públicos por subsídios a partir de 2011 e do corte de investimentos desde 2015. Alguns cenários alternativos, com outras formas de ajuste fiscal, serão construídos a partir dos multiplicadores estimados. Nos cenários em que a política fiscal desempenha um papel anticíclico, elevando os investimentos públicos, a crise brasileira recente teria sido bem menos severa e a recuperação da economia, bem mais rápida. Nós também contribuímos à literatura empírica de multiplicadores fiscais em nosso segundo artigo, no qual o foco é apenas nos multiplicadores de benefícios sociais. Embora haja um consenso na literatura em torno do grande efeito multiplicador dos investimentos públicos, não é o caso dos gastos com benefícios sociais, cujo impacto tem sido marginalmente explorado -e é similar ao impacto do investimento público em nosso estudo. Nós mostramos que para cada real gasto em benefícios sociais, há um impulso no PIB (em termos acumulados) maior na amostra inteira do que no exercício conduzido para a amostra pré-crise. Quando nós desagregamos o efeito sobre os componentes do PIB, nosso artigo sugere que existe um multiplicador acumulado relevante tanto para o consumo das famílias como para o investimento privado. Além disso, todos os componentes dos benefícios sociais, em menor ou maior grau, mostraram uma diferença entre a resposta na amostra que inclui a crise recente do país e na amostra pré-crise. Finalmente, nosso terceiro artigo contribui à literatura de modelos Kaleckianos e constrói um modelo teórico para explicar um dos nossos resultados anteriores: o maior impacto dos benefícios sociais sobre o produto na amostra que inclui a recessão recente. Nosso modelo inclui o endividamento das famílias - mais especificamente o endividamento dos trabalhadores que recebem renda dos benefícios sociais - que desempenha um significante efeito estabilizador na demanda agregada.

Palavras-chave: multiplicadores fiscais, investimento público, benefícios sociais, modelo Kaleckiano, endividamento. 



\section{Abstract}

Based on Blanchard and Perotti (2002)'s Structural VAR approach, we estimated, in our first paper, fiscal multipliers for different components of Brazilian federal government's expenditures, as well as for different sub-periods within the 1997-2017 sample. Results suggest a higher and more persistent expenditure multiplier in the full sample, which includes the country's current economic crisis, than in the period 1997-2014. The difference arises from only two components - social benefits and public investment - which generate the highest multiplier effects. Based on these estimations, we analyse, in particular, the effects of the substitution of public investment for subsidies from 2011 and of the investment cuts from 2015. Some alternative scenarios, with other ways of fiscal adjustment, will be built from the estimated multipliers. In the scenarios in which the fiscal policy plays an anti-cyclic role, increasing public investments, the recent Brazilian economic crisis would be much less severe and the economic recovery, so much faster. We also contribute to the fiscal multiplier empirical literature in our second paper, in which the focus is only on social benefits multipliers. Although there is a consensus in the literature that public investment has a great multiplier effect, it is not the case of the social benefits expenditures, whose impact has only been marginally exploited - and it is similar to the public investment impact in our study. We show that for each real spent on social benefits, there is a boost to GDP (in accumulated terms) which is greater in the whole sample than in the exercise carried out for the pre-crisis sample. Besides, when we disaggregate the effect on different GDP components, our paper suggests that there is a relevant accumulated multiplier effect both in terms of household consumption and private investment. Also, all social benefits components, to a smaller or larger extent, show a difference between the response in the sample that includes the country's current economic crisis and the pre-crisis sample. Finally, our third paper contributes to the Kaleckian models literature and builds a theoretical model to explain a possible channel for one of our previous results: the greater impact of social benefits on the output in the sample that includes the recent recession. Our model includes the household indebtedness - more specifically the indebtedness of the workers who receive income from social benefits - which performs a significant stabilizing effect in the aggregated demand.

Key-words: fiscal multipliers, public investment, social benefits, Kaleckian model, indebtedness. 



\section{Lista de ilustrações}

Figura 1 - Taxas de variação anual de componentes do gasto e da receita do governo central (\% a.a) obtidas por média geométrica em quatro subperíodos

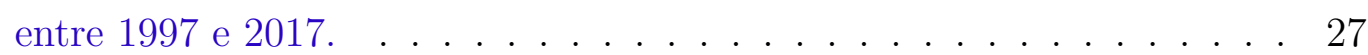

Figura 2 - Evolução do Investimento Público e dos Subsídios . . . . . . . . . . . . 28

Figura 3 - Evolução das Receitas e Despesas primárias . . . . . . . . . . . . . 28

Figura 4 - Evolução das despesas de Benefícios Sociais . . . . . . . . . . . . . 29

Figura 5 - Resposta acumulada do produto a um choque nas despesas totais . . . 51

Figura 6 - Resposta acumulada do produto a choque nos investimentos públicos . 52

Figura 7 - Resposta acumulada do produto a choque nos Benefícios Sociais . . . . 54

Figura 8 - Resposta do produto às despesas com pessoal, subsídios, demais despesas e à receita primária . . . . . . . . . . . . . . . . . . . 55

Figura 9 - Efeito no produto em cenários alternativos . . . . . . . . . . 66

Figura 10 - Efeito sobre o produto dos cortes de investimentos do governo central . 68

Figura 11 - Razão Dívida/PIB nos cenários . . . . . . . . . . . . . . . . . . . . 69

Figura 12 - Índice de preços de commodities . . . . . . . . . . . . . . . . . . . 84

Figura 13 - Resumo das estimações da elasticidade da receita encontradas nos estudos 91

Figura 14 - Taxas de variação calculadas por média geométrica dos Benefícios Sociais

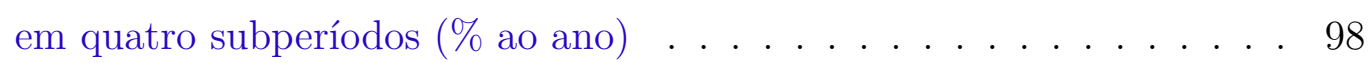

Figura 15 - Benefícios Sociais como $\%$ do PIB . . . . . . . . . . . . . . . . . . . 99

Figura 16 - Funções Impulso Resposta do produto a choques nos benefícios sociais (exercício mensal) . . . . . . . . . . . . . . . . 112

Figura 17 - Funções Impulso Resposta do produto a choques nos benefícios sociais (exercício trimestral) . . . . . . . . . . . . . . . . . 113

Figura 18 - Funções Impulso Resposta para o consumo das famílias . . . . . . . . . 119

Figura 19 - Funções Impulso Resposta para o consumo das famílias aos benefícios sociais em duas amostras . . . . . . . . . . . . . . . . . 120

Figura 20 - Funções Impulso Resposta para o investimento privado aos benefícios sociais em duas amostras . . . . . . . . . . . . . . . . . . 123

Figura 21 - Funções Impulso Resposta do produto aos benefícios sociais desagregados em duas amostras . . . . . . . . . . . . . . . . . . . . . . . 128

Figura 22 - Funções Impulso Resposta do consumo das famílias aos benefícios sociais desagregados em duas amostras . . . . . . . . . . . . . . . . . . . . 129

Figura 23 - Funções Impulso Resposta do investimento privado aos benefícios sociais desagregados em duas amostras . . . . . . . . . . . . . . . . 130

Figura 24 - Crédito consignado por categoria (variável estoque) . . . . . . . . . . . 147

Figura 25 - Crédito consignado por categoria (variável fluxo) . . . . . . . . . . . 148 
Figura 26 - Participação de cada categoria de trabalhador no crédito consignado total150 Figura 27 - Inadimplência no crédito consignado por categoria de trabalhador . . . 151 Figura 28 - Efeito multiplicador com alto e baixo grau de utilização . . . . . . . . 182 Figura 29 - Efeito de um aumento em $\beta^{u}$ e efeito multiplicador com alto e baixo grau de utilização . . . . . . . . . . . . . . . . . . . . . . 184 


\section{Lista de tabelas}

Tabela 1 - Multiplicadores fiscais estimados pré-crise / amostra inteira, respectivamente. . . . . . . . . . . . . . . . 51

Tabela 2 - Efeito dos cortes do investimento público e aumentos no subsídio 2011-

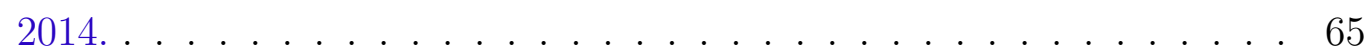

Tabela 3 - Efeito do corte de investimentos do governo central 2015-2017 sobre o produto. . . . . . . . . . . . . . . . . 67 67

Tabela 4 - Descrição dos Benefícios Sociais . . . . . . . . . . . . . . 97

Tabela 5 - Multiplicadores fiscais para o exercício do produto (impacto, pico e acumulado) . . . . . . . . . . . . . . . . . . 115

Tabela 6 - Multiplicadores fiscais estimados para o exercício do consumo das famílias 121

Tabela 7 - Multiplicadores fiscais estimados para o exercício do investimento privado125 



\section{Lista de abreviaturas e siglas}

\begin{tabular}{|c|c|}
\hline ARRA & American Recovery and Reinvestment Act \\
\hline $\mathrm{BCB}$ & Banco Central do Brasil \\
\hline BNDES & Banco Nacional de Desenvolvimento Econômico e Social \\
\hline $\mathrm{BPC}$ & Benefício de Prestação Continuada \\
\hline CLT & Consolidação das Leis do Trabalho \\
\hline CIDE & Contribuição de Intervenção no Domínio Econômico \\
\hline CSLL & Contribuição Social sobre o Lucro Líquido \\
\hline CODACE & Comitê de Datação de Ciclos Econômicos \\
\hline Cofins & Contribuição para o Financiamento para a Seguridade Social \\
\hline CPMF & Contribuição Provisória sobre Movimentação Financeira \\
\hline DLSP & Dívida Líquida do Setor Público \\
\hline DOLS & Dynamic Ordinary Least Squares \\
\hline $\mathrm{FBCF}$ & Formação Bruta de Capital Fixo \\
\hline FGTS & Fundo de Garantia do Tempo de Serviço \\
\hline FMI & Fundo Monetário Internacional \\
\hline GDP & Gross Domestic Product \\
\hline IPEA & Instituto de Pesquisa Econômica Aplicada \\
\hline IBGE & Instituto Brasileiro de Geografia e Estatística \\
\hline II & Imposto sobre Importação \\
\hline IFI & Instituição Fiscal Independente \\
\hline INSS & Instituto Nacional do Seguro Social \\
\hline $\mathrm{IOF}$ & Imposto sobre Operações Financeiras \\
\hline IPCA & Índice de Preços ao Consumidor Amplo \\
\hline
\end{tabular}


IPI Imposto sobre Produtos Industrializados

IR Imposto de Renda

LOAS Lei Orgânica da Assistência Social

MCMV Minha Casa Minha Vida

MQO Mínimos Quadrados Ordinários

OCDE Organização de Cooperação e de Desenvolvimento Econômico

OIT Organização Internacional do Trabalho

PAC Programa de Aceleração do Crescimento

Pasep Programa de Formação do Patrimônio do Servidor Público

PBF Programa Bolsa Família

PETI Programa de Erradicação do Trabalho Infantil

PIB Produto Interno Bruto

PIS Programa de Integração Social

PNAD Pesquisa Nacional por Amostra de Domicílios

POF Pesquisa de Orçamento Familiar

PSI Programa de Sustentação ao Investimento

RGPS Regime Geral da Previdência Social

RPPS Regime Próprio de Previdência Social

STVAR Smooth Threshold autoregressive vectors

SVAR Structural autoregressive vectors

TVAR Threshold autoregressive vectors

VAR Autoregressive Vectors 


\section{Lista de símbolos}

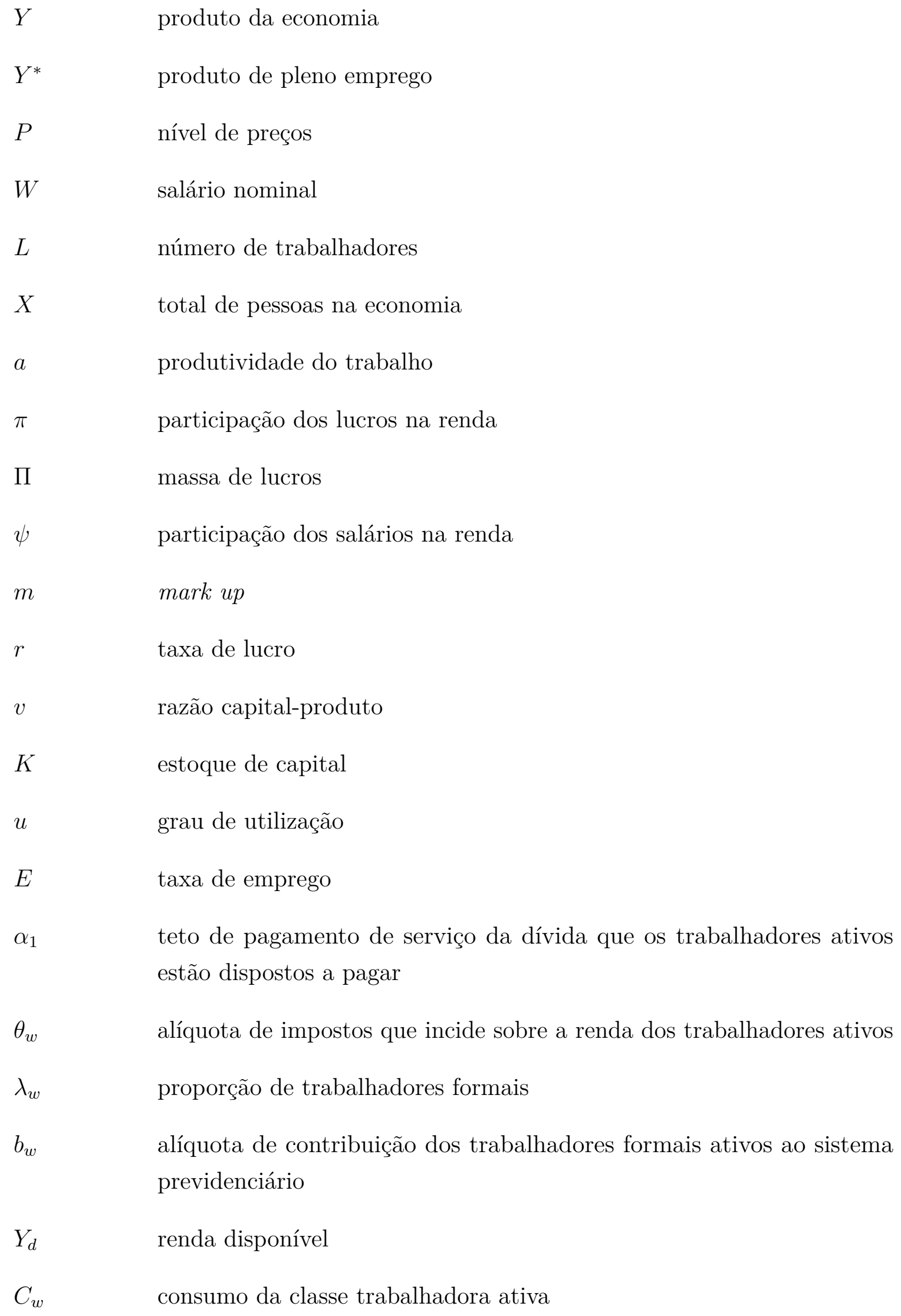




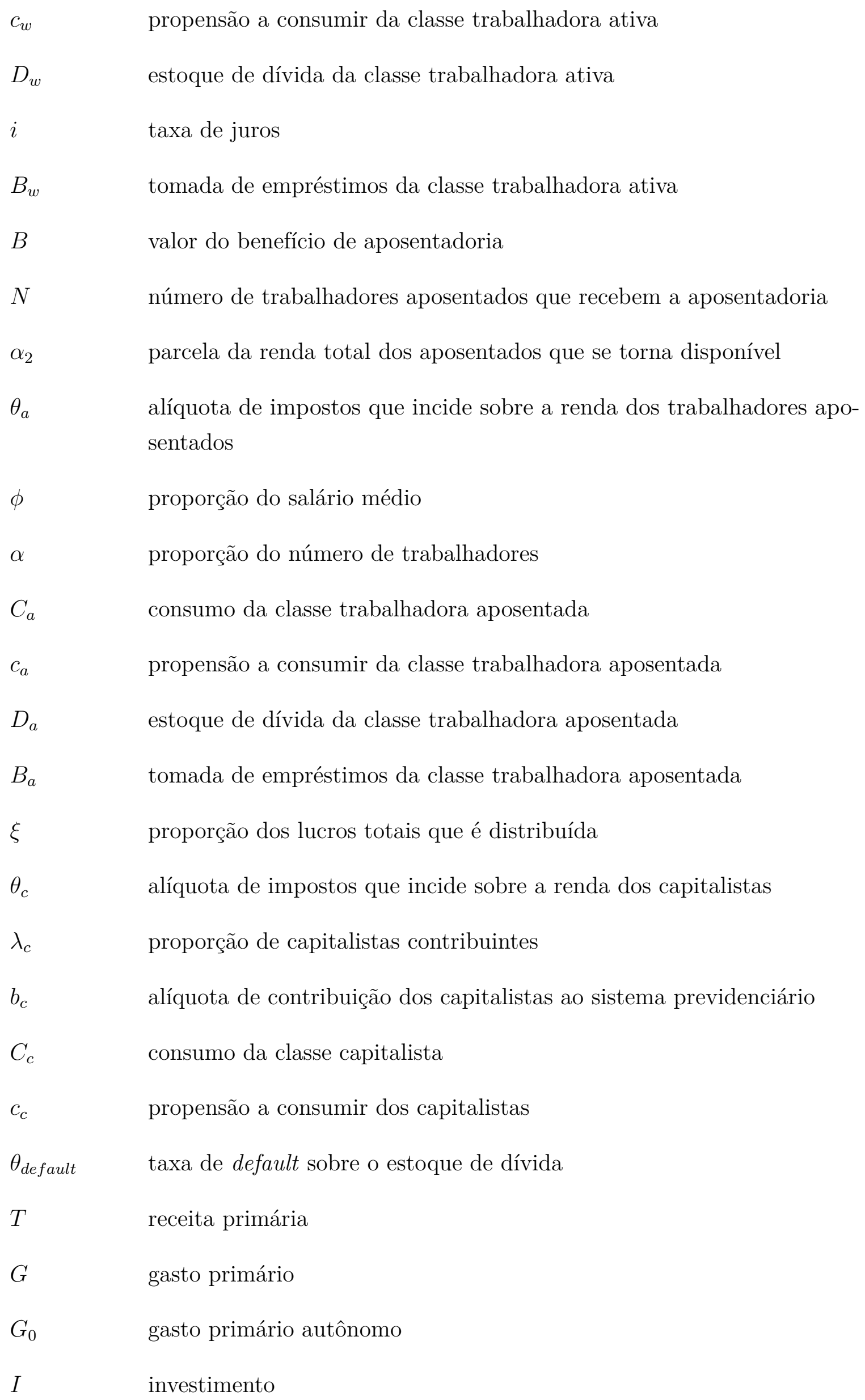


investimento autônomo

$\gamma_{u}$

$\beta_{1}$ sensibilidade do investimento ao grau de utilização

parâmetro de oferta/demanda de crédito para os aposentados que independe do ciclo econômico

parâmetro de oferta/demanda de crédito para os aposentados que é dependente do ciclo econômico

parâmetro de oferta/demanda de crédito para os ativos

parâmetro de oferta de crédito condicionado à distribuição de renda entre aposentados e ativos

propensão total a consumir dos trabalhadores ativos

sensibilidade da propensão total a consumir dos trabalhadores ativos em relação ao grau de utilização

sensibilidade da oferta/demanda de crédito para os trabalhadores aposentados em relação ao grau de utilização

sensibilidade da taxa de default ao grau de utilização 



\section{Sumário}

PRIMEIRO ARTIGO: A CONTRIBUIÇÃO DA POLÍTICA FISCAL PARA A CRISE BRASILEIRA RECENTE: UMA ANÁLISE BASEADA EM MULTIPLICADORES DE DESPESAS E RECEITAS PRIMÁRIAS DO GOVERNO CENTRAL NO PERÍODO 1997-2018 . . 23

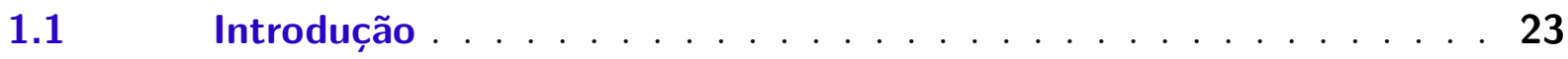

1.2 A história recente da política fiscal no Brasil: da expansão à consolidação . . . . . . . . . . . . . . . . . . . 25

1.3 A literatura empírica sobre multiplicadores fiscais . . . . . . . . 29

1.4 Dados e Metodologia . . . . . . . . . . . . . . . 38

$1.4 .1 \quad$ Dados . . . . . . . . . . . . . . . . . . . . 38

1.4 .2 Metodologia . . . . . . . . . . . . . . . . . 40

$1.5 \quad$ Resultados . . . . . . . . . . . . . . . . . . 48

1.5.1 Multiplicadores fiscais estimados . . . . . . . . . . . . . . 48

1.5.2 Aspectos teóricos e variáveis de controle . . . . . . . . . . . . . . . 57

1.6 Choques fiscais e impactos no produto . . . . . . . . . . . 64

1.6.1 O efeito da substituição do investimento público pelos subsídios no período 2011-2014 . . . . . . . . . . . . . . . . . . . 64 64

1.6.2 O efeito do ajuste fiscal de 2015-2017 . . . . . . . . . . . . . 67

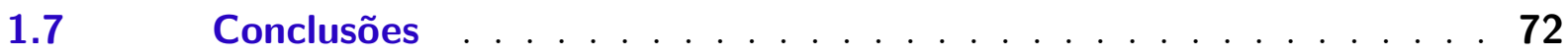

$1.8 \quad$ Apêndices do Primeiro Artigo . . . . . . . . . . . . . 84

$1.8 .1 \quad$ Apêndice A . . . . . . . . . . . . . . . . . 84

1.8.2 Apêndice B: Estimação da elasticidade da receita primária líquida com relação

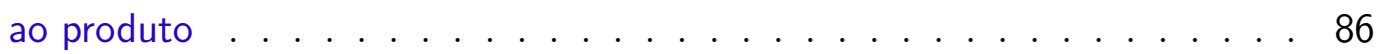

1.8.2.1 Método FMI (agregado) $\ldots \ldots \ldots \ldots \ldots$

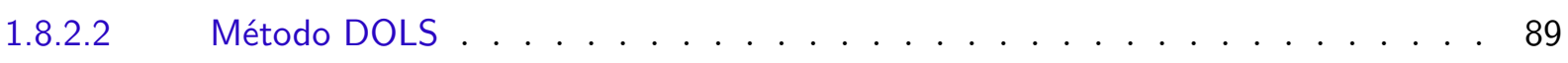

1.8.2.3 Método OCDE (desagregado) $\ldots \ldots \ldots \ldots \ldots$

2 SEGUNDO ARTIGO - OS EFEITOS ESTABILIZADORES DOS BENEFÍCIOS SOCIAIS: UMA ANÁLISE DE MULTIPLICADORES FISCAIS PARA O BRASIL NO PERÍODO 1997-2018 . . . . . . 93

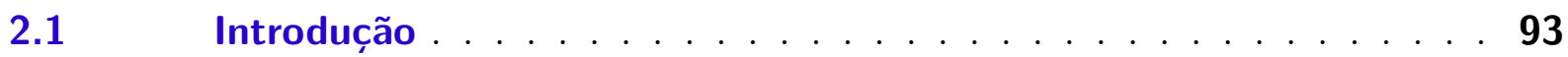

$2.2 \quad$ Benefícios Sociais no Brasil . . . . . . . . . . . . . . . . 95

$2.3 \quad$ A literatura sobre multiplicadores de benefícios sociais . . . . . . 100

$2.4 \quad$ Metodologia . . . . . . . . . . . . . . . . . . . . . 109

$2.5 \quad$ Resultados . . . . . . . . . . . . . . . . . . . 111 
2.5.1 O papel da crise econômica . . . . . . . . . . . . . . . 111

2.5.2 O efeito sobre diferentes componentes da demanda agregada . . . . . . . 118

2.5.3 Desagregação dos benefícios sociais . . . . . . . . . . . . . 127

2.6 Conclusão . . . . . . . . . . . . . . . . . . . . . . 131

3 TERCEIRO ARTIGO - O EFEITO DOS BENEFÍCIOS SOCIAIS NA RECESSÃO BRASILEIRA RECENTE: UM MODELO KALECKIANO COM ENDIVIDAMENTO DAS FAMÍLIAS . . . . . . . . . 141

$3.1 \quad$ Introdução . . . . . . . . . . . . . . . . . . . . 141

3.2 Motivação empírica . . . . . . . . . . . . . . . . . 143

$3.3 \quad$ Literatura relacionada . . . . . . . . . . . . . . . . . 152

$3.4 \quad$ Modelo . . . . . . . . . . . . . . . . . . . . 161

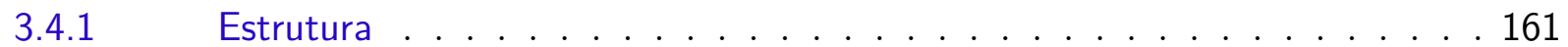

3.4.2 Inserção do crédito no modelo . . . . . . . . . . . . 166

3.4.3 Modelo simplificado . . . . . . . . . . . . . . . . . . . . . 170

3.4.4 Modelo com endogeneização da oferta de crédito . . . . . . . . . . . . 173

$3.5 \quad$ Conclusão . . . . . . . . . . . . . . . . . . . 186

3.6 Apêndice do Terceiro Artigo . . . . . . . . . . . . . 191 


\section{Primeiro Artigo: A contribuição da política} fiscal para a crise brasileira recente: uma análise baseada em multiplicadores de despesas e receitas primárias do governo central no período 1997-2018

\subsection{Introdução}

A explosão da dívida pública nos países ricos após a crise financeira global de 2008-9 e a impotência da política monetária em estimular economias com taxas de juros já próximas de zero trouxeram a política fiscal de volta ao centro da literatura macroeconômica internacional da última década (Ramey, 2019; Hagedorn et al, 2019). Com uma defasagem de alguns anos, o debate econômico brasileiro acerca das causas da desaceleração iniciada em 2011 e da recessão de 2015-16 também conferiu centralidade ao papel do expansionismo fiscal do pré-crise e/ou da consolidação fiscal que se seguiu para o fraco desempenho de nossa economia.

Ainda que diversos fatores exógenos, que vão desde o ciclo internacional dos preços de commodities aos impactos econômicos de curto prazo da Operação Lava Jato, possam explicar boa parte da trajetória recente de crescimento econômico brasileiro aproximadamente 50\% segundo estudo de Borges (2017) - são muitas as interpretações que atribuem a erros de política macroeconômica e, em particular, de política fiscal, a responsabilidade pela profundidade de nossa crise e lentidão da recuperação. De um lado, estão os que compreendem a crise atual como um "esgotamento fiscal do Estado", fruto da forte expansão de gastos sociais desde o contrato social de 1988 (Pessôa, 2017). De outro, autores como Orair e Gobetti (2017b) dão ênfase ao papel da substituição dos investimentos públicos diretos por subsídios fiscais a partir de 2011 e ao corte substancial nesses investimentos a partir de 2015 para a desaceleração e a recessão que se seguiu.

Tal como no debate internacional acerca da hipótese de austeridade fiscal expansionista (Alesina e Ardagna, 2010; FMI, 2010b), a análise do impacto das mudanças de composição e magnitude do Orçamento público brasileiro sobre o produto e a trajetória da dívida pública em relação ao PIB depende em boa medida da estimação dos multiplicadores fiscais para os diversos componentes do gasto e da receita. 
Capítulo 1. Primeiro Artigo: A contribuição da política fiscal para a crise brasileira recente: uma análise 24 baseada em multiplicadores de despesas e receitas primárias do governo central no período 1997-2018

Alguns autores descartam o papel da consolidação fiscal iniciada em 2015 para a recessão e a lenta recuperação que seguiu na economia brasileira por considerarem que o multiplicador fiscal em países emergentes é inferior ao das economias avançadas, tal como encontrado em Ilzetzki (2011) e Ilzetzki et al (2013), ou até nulo. No caso da América Latina, esta hipótese perdeu força após o estudo de Carrière-Swallow et al (2018), que analisou os ajustes fiscais implementados nesse grupo de países entre 1989 e 2016 e concluiu que os multiplicadores fiscais são muito similares aos encontrados para países desenvolvidos, levando à queda no produto, no consumo e no investimento privado após a consolidação. O estudo de Izquierdo et al (2019) mostrou que o investimento público, especificamente, assume um papel ainda mais relevante em países em desenvolvimento -com baixo estoque inicial de capital instalado em relação ao produto - onde há um efeito multiplicador significativamente maior, se comparado ao efeito em países que possuem um alto estoque de capital.

Por outro lado, Matheson e Pereira (2016) estimaram multiplicadores para o Brasil a partir de dois recortes temporais distintos e encontraram evidências de que os gastos públicos deixaram de ter efeito persistente e significante no produto desde a crise de 2009, ao contrário dos impostos e crédito dos bancos públicos. O resultado contradiz em parte o trabalho de Orair et al (2016), que estimou efeitos multiplicadores de investimentos públicos e benefícios sociais mais elevados e persistentes em períodos de recessão. Multiplicadores mais altos para investimentos públicos também foram encontrados por Pires (2011), Dutra (2016), Castelo Branco et al (2015) e Pires (2014).

Nesse contexto, o objetivo desse artigo é mensurar o impacto das alterações de composição e de magnitude do Orçamento público federal observadas nos últimos anos sobre o PIB brasileiro a partir de estimações atualizadas dos multiplicadores fiscais para diferentes tipos de gasto com base na metodologia de Blanchard e Perotti (2002). Em particular, serão quantificados os efeitos da substituição de investimentos públicos por subsídios a partir de 2011 e do corte de investimentos desde 2015 para o desempenho de nossa economia, bem como do crescimento dos benefícios sociais ao longo de todo o período de análise. Alguns cenários alternativos, de outras formas de ajuste fiscal, serão construídos a partir dos multiplicadores estimados. Para além de incluir o período 2015-2018 - crucial para a compreensão do papel da crise atual sobre os multiplicadores - na amostra que serviu de base para as estimações, esse artigo também se diferencia da literatura existente pela desagregação dos multiplicadores do gasto e utilização das séries ajustadas (e atualizadas) de despesas e receitas primárias de Orair e Gobetti (2017a), eliminando o ruído causado pela contabilidade criativa, entre outros aspectos descritos na seção 1.4 deste artigo.

O artigo conta com seis seções, além desta introdução. A seção 1.2 apresenta um breve histórico e contextualização da política fiscal adotada no período 1997-2018, com especial ênfase em seus pontos de inflexão. A seção 1.3 faz um breve resgate da literatura 
empírica de multiplicadores fiscais, com ênfase nos estudos para o Brasil. Os dados e a metodologia são explorados na seção 1.4. A seção 1.5, por sua vez, apresenta os resultados das estimações. Já a seção 1.6 analisa os efeitos da política fiscal adotada sobre o produto. Por fim, a seção 1.7 traz algumas conclusões.

\subsection{A história recente da política fiscal no Brasil: da expansão à consolidação}

Como observado em Orair e Gobetti (2017b), há dois importantes pontos de inflexão na política fiscal brasileira da última década. Após a forte expansão dos gastos sociais e do investimento público que vigorou entre 2006 e 2010, o período 2011-2014 é marcado pela política de diminuição de impostos e aumento de subsídios. O segundo ponto de inflexão ocorre em 2015, com o início da fase de consolidação fiscal pela via dos cortes de despesas.

Antes desses períodos, porém, de 2003 a 2005, ressalta-se que houve uma política econômica restritiva em termos fiscais e monetários. De acordo com Barbosa (2013), houve, por exemplo, elevação da meta de superávit primário para conter a dívida pública e conquistar os investidores pós-eleição de Lula. Esse tipo de política teve resultado rápido, com valorização cambial e diminuição da inflação, mas teve seu custo em termos de produto. No entanto, mais à frente, com a expansão dos mercados internacionais já em 2004 houve recuperação dos investimentos e das exportações - isso levou a um aperto monetário em razão da valorização cambial, e a política fiscal buscava a redução do endividamento e elevação do superávit primário.

Barbosa (2013) conclui que, considerando todo o período 2003-2005, o produto cresceu moderadamente e a inflação caiu, tendo em vista a valorização do câmbio, que se encontrava bastante desvalorizado diante das incertezas do ano de 2003. Esse período pode ser caracterizado, portanto, por políticas fiscal e monetária restritivas. Na política fiscal especificamente, a média anual do resultado primário do governo federal passou de 1.9\% do PIB, entre 1999 e 2002, para 2.5\%, entre 2003 e 2005. Trata-se de um ajuste fiscal de $0.6 \%$ do PIB. Pelo lado tributário, o governo implementou algumas medidas também no sentido contracionista com elevação tributária. É o caso, por exemplo, da ampliação da base de cálculo da Contribuição Social sobre o Lucro Líquido (CSLL) e maior alíquota para Contribuição para o Financiamento da Seguridade Social (COFINS) de instituições financeiras. Portanto, o período em questão foi caracterizado pela continuação do período anterior, com a adoção do tripé macroeconômico e com uma política fiscal parecida com a dos anos anteriores, cujo eixo era o corte de investimentos públicos e aumento da tributação.

Orair e Gobetti (2017b) chamam o período 1995-2005 de fase de consolidação fiscal, caracterizado por elevação progressiva das metas de primário, que passaram de $-0.2 \%$ do 
Capítulo 1. Primeiro Artigo: A contribuição da política fiscal para a crise brasileira recente: uma análise 26 baseada em multiplicadores de despesas e receitas primárias do governo central no período 1997-2018

PIB em 1995-1998, em média, para um superávit de cerca de 4\% do PIB. Vale lembrar que o período anterior, pós Plano Real, caracterizou-se pelo pensamento de que a política fiscal era a "guardiã", como indica Lopreato (2013), da estabilidade. Assim, uma política fiscal restritiva era importante para o resgate da credibilidade após anos difíceis de intensos desequilíbrios macroeconômicos. O programa incluiu não só o ataque à inércia inflacionária, como também disciplina fiscal bastante rígida ${ }^{1}$.

No primeiro período de expansão fiscal, de 2006 a 2010, a flexibilização significativa das metas fiscais, através, por exemplo, da exclusão das estatais federais da meta fiscal, levou a uma redução do resultado primário requerido de 4.25\% do PIB em 2004 para $2.63 \%$ do PIB em 2010². Para além dos efeitos da valorização real do salário mínimo, que tornou-se ainda mais expressiva a partir de meados dos anos 2000, destaca-se a expansão de programas sociais (e.g. Bolsa Família) e a ampliação de investimentos públicos com a chamada operação Tapa-Buracos em 2006 e, a partir de 2007, com o Programa de Aceleração do Crescimento (PAC). Após a crise de 2009, outras medidas estimulativas foram tomadas, como a redução das alíquotas do Imposto sobre Produtos Industrializados (IPI) sobre automóveis e a criação do programa Minha Casa Minha Vida (MCMV). Orair e Gobetti (2017b) afirmam que o que explica a rápida recuperação pós crise internacional é o favorecimento das categorias de gasto associadas a multiplicadores fiscais mais altos, como veremos adiante neste artigo.

No gráfico da Figura 1, observamos um crescimento positivo de todas as despesas no período, bem como da receita (em função do próprio crescimento econômico e do boom de commodities). O investimento público cresceu $28 \%$ ao ano, em média, no período 2006-2010, ante uma expansão de $8 \%$ ao ano nos benefícios sociais. O item de subsídios, que incluiu o efeito da expansão do crédito do BNDES no pós-crise de 2009, cresce $6.3 \%$ ao ano, em média.

No período 2011-2014, o eixo principal do expansionismo fiscal passou a ser o das desonerações e subsídios, como parte de uma estratégia de política econômica orientada ao estímulo à competitividade e à lucratividade do setor privado (Carvalho, 2018). Como a estratégia também envolvia uma redução substancial da taxa de juros, o período começa com um forte ajuste fiscal no ano de 2011 como tentativa de conter o processo inflacionário por uma substituição do afrouxamento fiscal por um afrouxamento monetário. Com o fracasso da política em estimular os investimentos privados, as exportações e a economia em geral, a consolidação fiscal inicial dá lugar a uma expansão fiscal com queda de receitas e expansão de subsídios.

$\overline{1 \text { De acordo com Orair e Gobetti (2017b) }}$, o ajuste fiscal foi caracterizado, no período 1995 a 2005, por aumento na carga tributária de 6.6 pontos percentuais (p.p) do PIB e redução de 1.3 p.p do PIB nos investimentos públicos, o que permitiu um aumento nos gastos com benefícios sociais.

2 Orair (2016) aponta que, entre 2005 e 2010, o resultado primário do governo geral caiu de $3.7 \%$ para $2.6 \%$ do PIB. Já a taxa de investimento cresceu 1.1 p.p do PIB; e a taxa de investimentos das estatais federais-que ficaram excluídas da meta fiscal- cresceu mais que 0.9 p.p do PIB. 
Figura 1 - Taxas de variação anual de componentes do gasto e da receita do governo central (\% a.a) obtidas por média geométrica em quatro subperíodos entre 1997 e 2017.

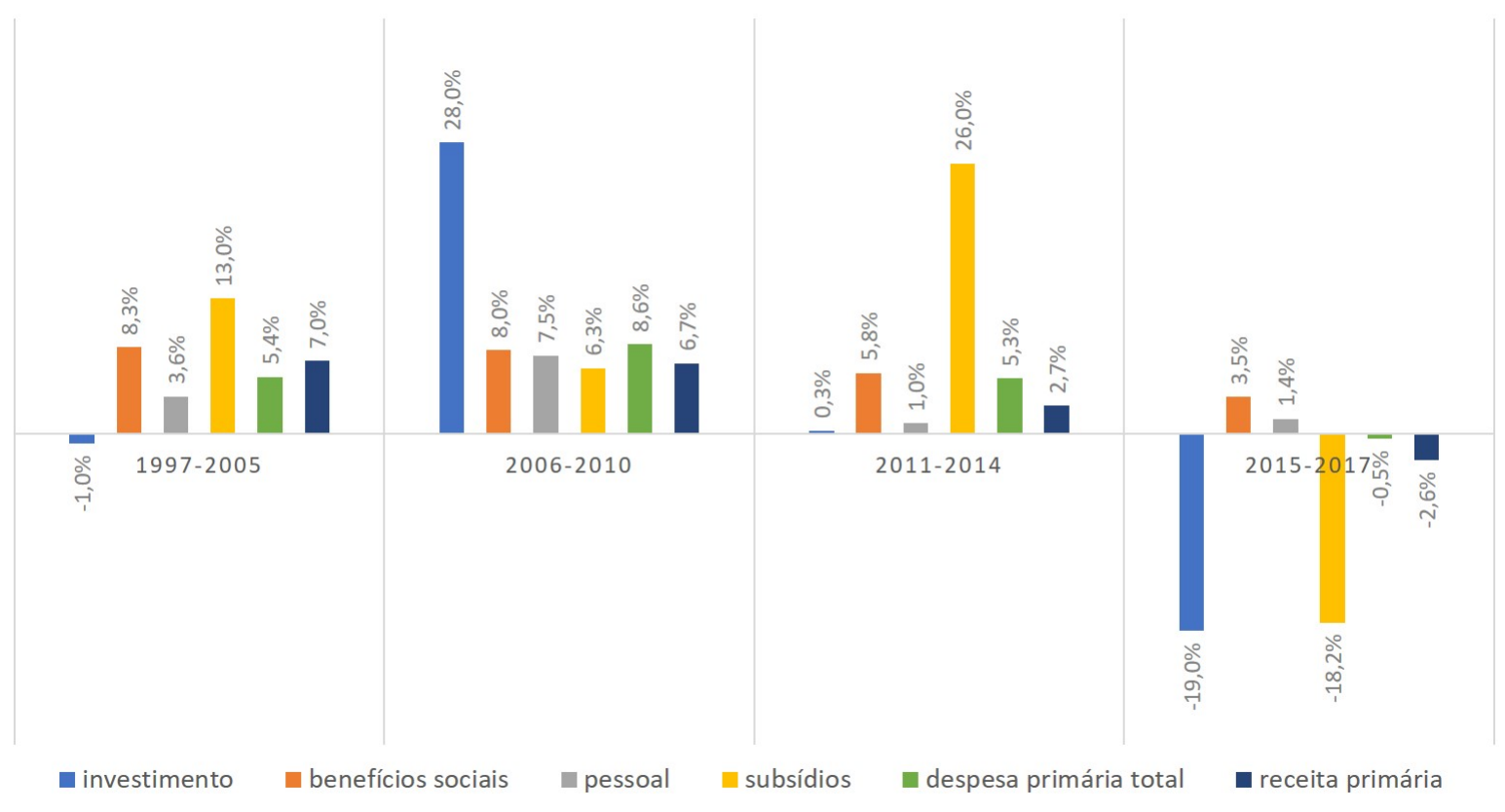

Fonte: Elaboração própria a partir dos dados de Orair e Gobetti (2017a).

Como aponta Carvalho (2018), nesse período foram adotadas políticas voltadas a desonerações, como o Plano Brasil Maior, a desoneração da folha de pagamento e da cesta básica; e ao crédito subsidiado. Os resultados são bastante conhecidos: o investimento privado não foi estimulado, pois apenas aumentava a taxa de lucro das empresas em um cenário de endividamento do ciclo expansivo do período anterior, além de beneficiar apenas setores muito específicos. Ademais, houve grande deterioração fiscal devido ao aumento de gastos com subsídios e à queda de crescimento das receitas - que se deve tanto às políticas de desoneração como à própria crise e à queda do nível de atividade.

O gráfico da Figura 1 mostra que as despesas com subsídios cresceram em torno de $26 \%$ ao ano no período 2011-2014, em detrimento do investimento público, cujo crescimento foi de apenas $0.3 \%$ ao ano. Nota-se também um crescimento menor da receita, de apenas $2.7 \%$ ao ano, causando uma deterioração crescente no resultado primário.

Nos gráficos da Figura 2, observa-se o que foi discutido nos parágrafos anteriores. Há uma queda nos investimentos públicos de 2002 para 2003, período de turbulência na economia brasileira e de uma disciplina fiscal rígida. A partir de 2006, entretanto, houve uma orientação da política fiscal aos investimentos. Em 2011, há uma reversão dessa trajetória, além de uma queda brutal em 2015. O gráfico também ilustra a evolução dos subsídios, que cresceram no período 2006-2010; mas é o período 2011-2014 que se destaca. Como proporção do PIB, como é mais adequado de se analisar, nossas conclusões anteriores não se alteram, pois o gráfico apresenta comportamento muito similar. Os 
Capítulo 1. Primeiro Artigo: A contribuição da política fiscal para a crise brasileira recente: uma análise 28 baseada em multiplicadores de despesas e receitas primárias do governo central no período 1997-2018

Figura 2 - Evolução do Investimento Público e dos Subsídios

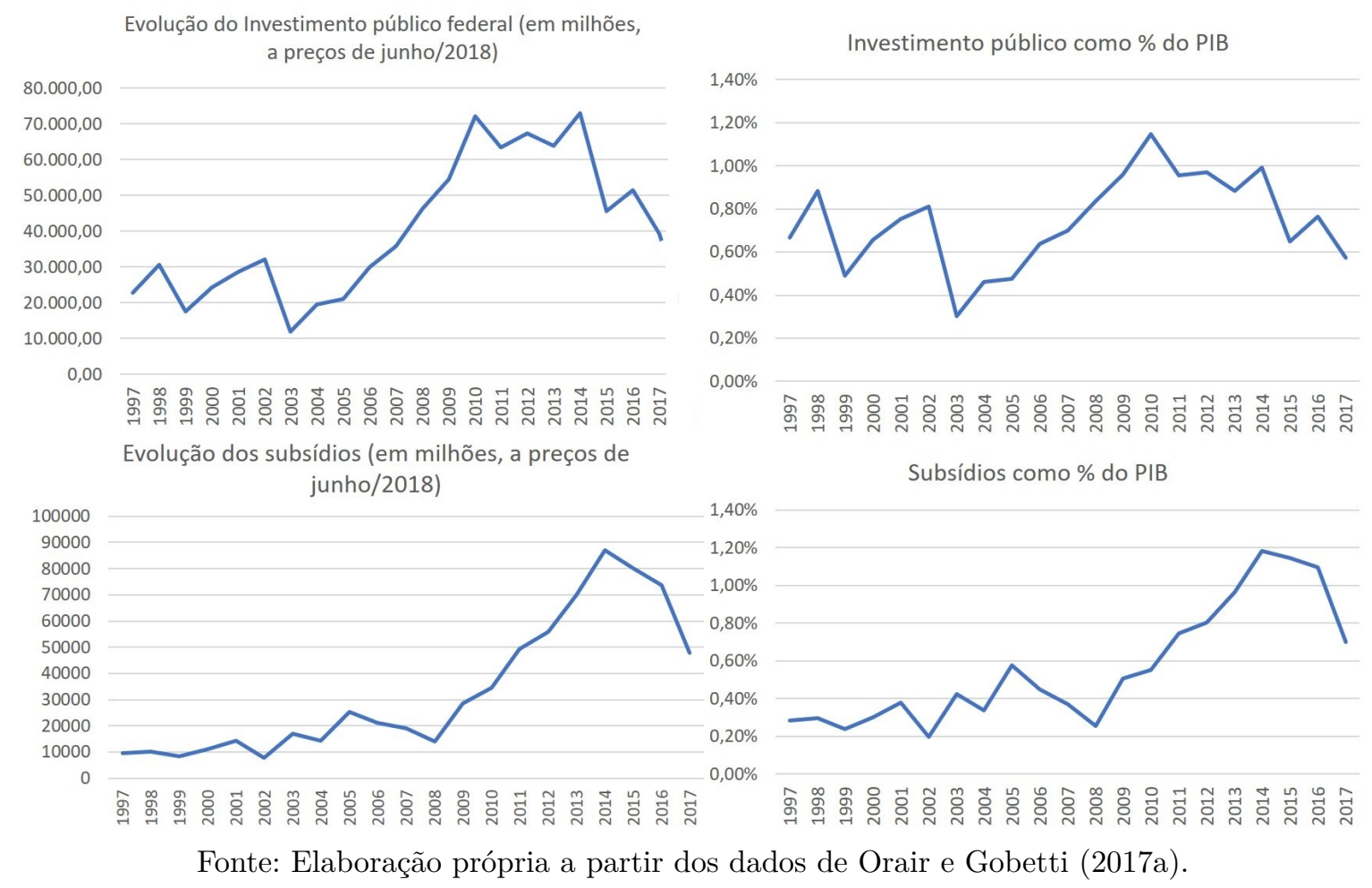

Figura 3 - Evolução das Receitas e Despesas primárias
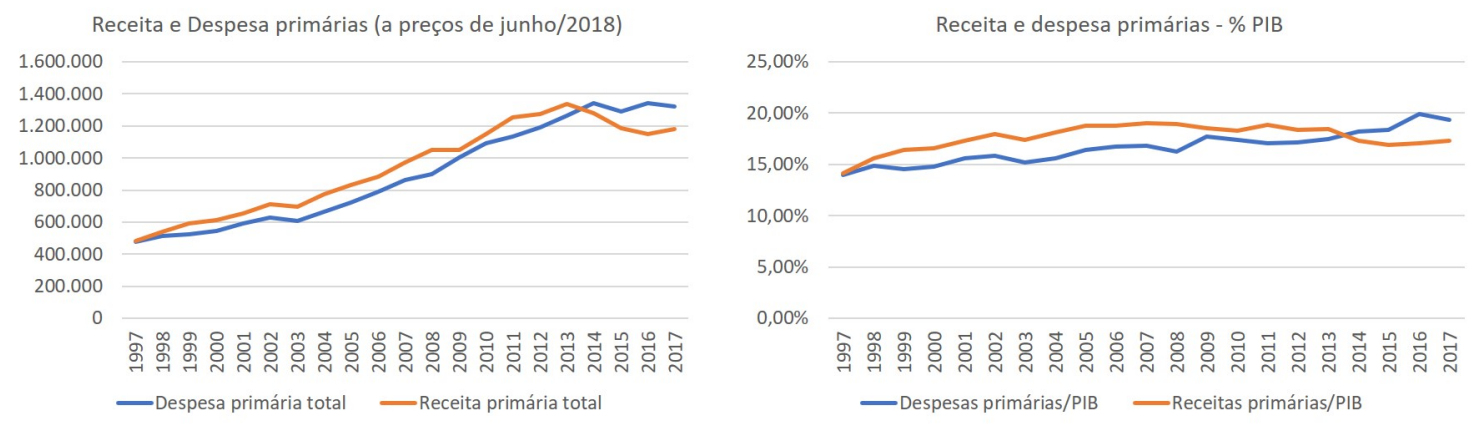

Fonte: Elaboração própria a partir dos dados de Orair e Gobetti (2017a).

gráficos da Figura 3 mostram a trajetória da receita e da despesa primárias no período inteiro. Enquanto a despesa primária manteve-se, a receita sofreu uma queda. Nossas conclusões não se alteram quando observamos o gráfico das receitas e despesas primárias em relação ao produto.

Após o primeiro ano de déficit primário, em 2014, o governo passa a adotar uma estratégia de ajuste fiscal baseada no corte de despesas. Dado o alto peso das despesas obrigatórias no Orçamento, a consequência foi um ajuste desproporcional em despesas discricionárias e, em particular, nos investimentos públicos. O gráfico da Figura 1 mostra a variação negativa dos subsídios e do investimento público no período 2015-2017. De 2014 para 2015, por exemplo, a queda no investimento público real do governo central foi de quase 40\%. Embora em 2016 o governo tenha adotado uma postura mais gradualista, com 
a aprovação da Emenda Constitucional 95 do "teto de gastos" o corte de investimentos públicos continua ocorrendo ano a ano desde então.

Como destaca Orair (2016) os investimentos públicos são sempre os primeiros candidatos a sofrerem cortes em episódios de consolidação fiscal, seja em virtude da visão de curto prazo dos governos, ou devido à rigidez legal e institucional dos outros gastos como benefícios sociais e pessoal. Algo que chama atenção no gráfico da Figura 1 é que a taxa de crescimento dos benefícios sociais permaneceu bastante estável ao longo dos períodos, o que mostra que tais despesas são rígidas. O gráfico da Figura 4 ilustra que esse tipo de despesa tem uma evolução crescente como proporção do PIB a cada ano, o que mostra um crescimento não só acentuado, como também bastante persistente. Como pode ser observado no Gráfico da Figura 1, a taxa de crescimento dos benefícios sociais permaneceu bastante estável ao longo dos quatro períodos analisados, como resultado do pacto de 1988 e seu caráter obrigatório. A taxa de crescimento anual dos benefícios sociais permaneceu à frente (ou muito próxima) da taxa de crescimento anual do produto em todos os períodos. Portanto, destacam-se dois pontos de especial interesse para este artigo.

Figura 4 - Evolução das despesas de Benefícios Sociais
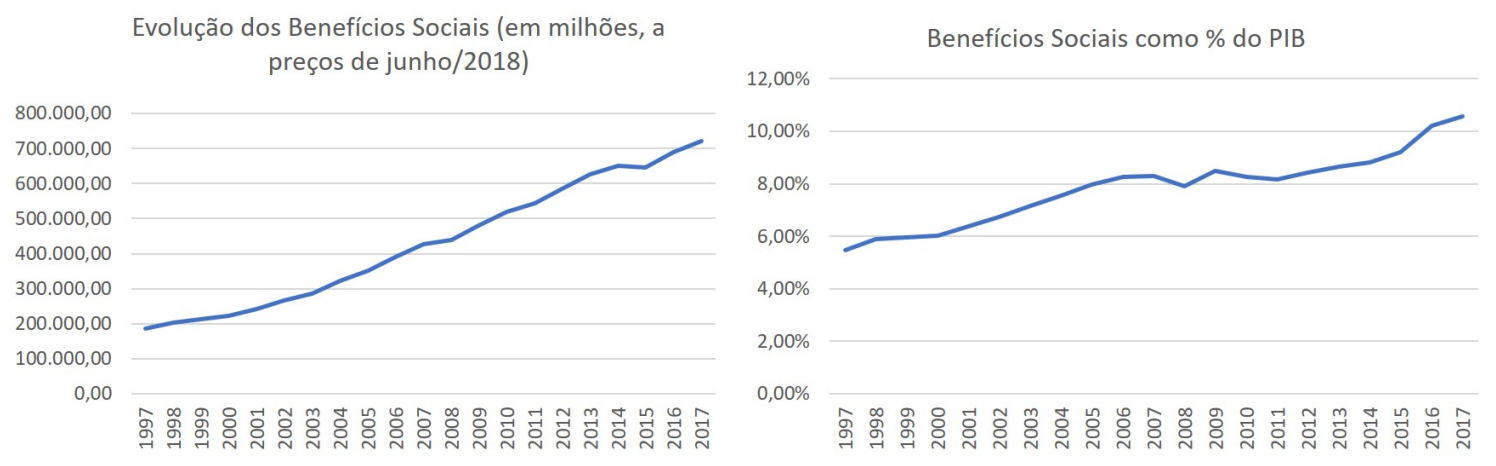

Fonte: Elaboração própria a partir dos dados de Orair e Gobetti (2017a).

Em primeiro lugar, queremos avaliar a estratégia de substituição do investimento público por subsídios no período 2011-2014 e as consequências disso em termos do produto. Em segundo lugar, temos principal interesse na narrativa do ajuste fiscal, que ganhou amplo destaque nos últimos anos e vêm sendo visto como imprescindível para a retomada do crescimento econômico após a recessão recente. Esses objetivos serão analisados à luz dos multiplicadores fiscais aqui estimados.

\subsection{A literatura empírica sobre multiplicadores fiscais}

A abordagem de modelos lineares do tipo VAR (vetores auto-regressivos) é a mais convencional $^{3}$ para a avaliação de multiplicadores fiscais, com ênfase no artigo seminal

3 Este tipo de estudo é o mais convencional em "country specific studies": "Since SVARs require only a minimum set of assumptions, the latter methodology is simple enough to apply to different data sets" (Borg, 2014, p.5). 
Capítulo 1. Primeiro Artigo: A contribuição da política fiscal para a crise brasileira recente: uma análise 30 baseada em multiplicadores de despesas e receitas primárias do governo central no período 1997-2018

de Blanchard e Perotti (2002) para a economia norte-americana. Tomando como base a metodologia por eles desenvolvida, diversos estudos incluíram novas variáveis endógenas, como a taxa de juros e de inflação (Perotti, 2004; Burriel et al, 2010; Ravnik e Zilic, 2011; Tenhofen et al, 2010; Lozano e Rodriguez, 2011; Mançellari, 2011 dentre outros) ou a dívida pública e a taxa de câmbio (Cavalcanti e Silva, 2010; Ilzetzki, 2011; Castro e Fernandez, 2011; Grudtner e Aragon, 2017; entre outros). Outras modificações foram feitas a partir de novas formas de identificação dos choques fiscais. Os resultados gerais encontrados na literatura estão relacionados a multiplicadores maiores para o caso de políticas monetárias acomodatícias que não pressionam muito os juros, como também ocorre para câmbio fixo. Para o caso da dívida pública, em geral os multiplicadores são menores para países com relação dívida-produto muito expressiva (Ilzetski et al, 2013). Há também estudos que calculam multiplicadores utilizando técnicas de dados em painel para conjunto de países ou de estados de um país, seja com um VAR ou com métodos de uma equação (Ilzetzki et al, 2013; Beetsma e Giuliodori, 2011; Valencia, 2015; Izquierdo et al, 2019; Silva et al, 2013; Carrière-Swallow et al, 2018; Bruckner e Tuladhar, 2010; Deleidi et al, 2019; Furceri e Zdzienicka 2012; Reeves et al, 2013; Konstantinou e Partheniou, 2019; Restrepo, 20204).

Geralmente, os artigos utilizam uma abordagem desagregada, seja verificando o impacto da política fiscal sobre diferentes componentes do PIB, tipicamente o consumo das famílias e os investimentos privados (Blanchard e Perotti, 2002; Tenhofen et al, 2010; Castro, 2003), seja em relação aos gastos e receitas do governo para os quais se estima os multiplicadores (Çebi, 2015; Unal, 2011; Burriel et al, 2010). A literatura que utiliza vetores auto-regressivos estruturais encontra multiplicadores de impacto no produto para as despesas governamentais positivos (Ramey, 2019) ${ }^{5}$, mas com diferentes magnitudes e persistência.

Um ponto importante é que os estudos mostram que multiplicadores de investimento público são geralmente mais altos e mais persistentes ${ }^{6}$ (Izquierdo et al, 2019; Tenhofen et

4 Em Restrepo (2020) há um estudo de multiplicadores fiscais de receita e despesa primárias, em termos agregados, para um conjunto de países da América Latina (Brasil, Chile, Colômbia, México, Peru, Paraguai, Uruguai, República Dominicana), além dos Estados Unidos. Neste artigo, são estimados VARs para os países individualmente, com aplicação da técnica de Blanchard e Perotti (2002) para cada um dos países.

5 Como em Blanchard e Perotti, 2002; Perotti, 2004; Burriel et al, 2010; Staniesic e Kasumovic, 2017; Tenhofen et al, 2010; Giordano et al, 2007; Fatás e Mihov, 2001; Mountford e Uhlig, 2009; Castro, 2003; Castro e Hernández de Cos, 2008; Çebi, 2015; Casero et al, 2010; Skrbic e Simovic, 2015; Ford, 2013; entre outros.

6 Apesar de ser uma conclusão muito comum nos estudos empíricos sobre o assunto, não é consenso. Perotti (2004), por exemplo, não encontra evidências de que o componente de investimento de fato gere respostas maiores em termos de produto. O autor encontrou que choques no consumo do governo geram respostas maiores no produto para cinco países da OCDE (mas esse resultado não vale para a Alemanha). Fatas e Mihov (2001) também encontraram, para o caso dos EUA, que as despesas do governo com consumo possuíram efeito maior que os investimentos no produto devido à forte resposta positiva do consumo privado. Já Borg (2014) ressalta a importância do investimento público para o longo prazo, que possui multiplicadores maiores e com maior persistência, mas é o consumo que possui maior importância como ferramenta contra-cíclica. De qualquer forma, há um consenso em torno da 
al, 2010; Garcia et al, 2013; Vdovychenko, 2018; Castro, 2003; Burriel et al, 2010; Lozano e Rodriguez, 2011; Borg, 2014; Benetrix e Lane, 2009; Ilzetzki et al 2013, Mançellari, 2011; Orair et al, 2016; Pires, 2011; Pires, 2014; Peres, 2006; Cattan, 2017; Dutra, 2016; Castelo Branco et al, 2015; Auerbach e Gorodnichenko, 2012; entre outros). A preocupação com os investimentos públicos em particular é justificada dada a sua importância para o produto da economia por meio de três formas, como afirma Cattan (2017), a partir do modelo de Dutt (2013): a) efeito direto, via multiplicador, sobre o aumento da demanda agregada; b) efeito indireto, que induz o investimento privado e, c) efeito indireto via aumento da produtividade da economia devido a mudanças tecnológicas. Portanto, o investimento público ganha papel de suma importância também no crescimento econômico de longo prazo, como destaca Aschauer (1989) ${ }^{7}$.

Izquierdo et al (2019) reforçam a importância do impacto do investimento público em termos de um significativo estímulo ao investimento e consumo privados. Os autores utilizaram o SVAR tradicional, com base em Blanchard e Perotti (2002); e também técnicas de uma só equação (projeção linear de Jordà (2005)); e encontraram que o multiplicador acumulado de investimento público torna-se maior e mais significante para os países europeus (e também para os estados dos Estados Unidos e para as províncias da Argentina) que possuem baixo estoque inicial de capital instalado como proporção do produto, se comparado ao multiplicador encontrado para os lugares com estoque de capital alto embora a resposta de impacto seja muito parecida nos dois grupos.

Deleidi et al (2019) encontram um alto efeito multiplicador do investimento público mesmo após cinco anos após o choque fiscal, o que evidencia a sua importância ao longo do tempo. O estudo é conduzido para um grupo de países europeus e os resultados mostram que os países com menor produto per capita possuem um efeito multiplicador ainda mais relevante. Além disso, há evidência de que a inclusão do período de crise (a partir de 2008) na amostra eleva o multiplicador.

Alguns estudos encontram que o multiplicador associado ao consumo do governo tem efeito imediato, mas que desaparece rapidamente; em contraste com o multiplicador de investimento, que possui mais persistência (Tenhofen et al, 2010; Garcia et al, 2013; Vdovychenko, 2018; Peres, 2006; Deleidi et al, 2019; Castro, 2003; Burriel et al, 2010; Lozano e Rodriguez, 2011; Borg, 2014; Benetrix e Lane, 2009; Ilzetski et al, 2013 ${ }^{8}$ ) entre

importância dos investimentos públicos, no curto e no longo prazos.

7 "The typical argument is that, unlike government consumption, public investment directly improves the economy's productive capacity by increasing the marginal product of private capital and labor. As time progresses, this generates positive effects both on private investment and private consumption"(Izquierdo et al, 2019, p.2).

8 Este estudo diz respeito a 44 países. Em geral, os autores encontram efeitos pequenos de um aumento de consumo do governo sobre o produto, particularmente para os países em desenvolvimento. Já para o caso de aumento do investimento público, o produto responde positivamente tanto no curto como no longo prazo. Neste caso, o multiplicador é maior para ambos os grupos de países, mas a diferença é maior para o grupo de países em desenvolvimento. 
Capítulo 1. Primeiro Artigo: A contribuição da política fiscal para a crise brasileira recente: uma análise 32 baseada em multiplicadores de despesas e receitas primárias do governo central no período 1997-2018

outros autores. Veremos que nossos resultados estão coerentes com a literatura nesse sentido.

Pelo lado da receita pública, os resultados encontrados na literatura para o multiplicador de receita são, em geral, consistentes com os aqui encontrados: geralmente apenas o de impacto é significativo e seu sinal é controverso. Além disso, são geralmente menores que os de gasto, pois seu efeito ocorre a partir da renda disponível, como em Blanchard e Perotti (2002) e Mountfourd e Uhlig (2009) - mas há exceções ${ }^{9}$. Intuitivamente, um choque positivo na receita deve significar um aumento de impostos e diminuição da renda disponível dos agentes destinada ao consumo e ao investimento privados de modo que o sinal do multiplicador é negativo - o produto diminui com o choque nas receitas.

Todavia, Tenhofen et al (2010) e Lozano e Rodriguez (2011), por exemplo, acham um sinal positivo para o multiplicador de receita, mas não estatisticamente diferente de zero - Castro e Hernandez de Cos (2008) também estimam um multiplicador de impacto positivo, porém o de longo prazo é negativo e significante. Outros autores encontram impactos negativos significativos no curto prazo e não significativos no longo, como Garcia et al (2013), Giordano et al (2007), Jemec et al (2013) e Skrbic e Simovic (2015). Afonso e Sousa (2009) encontram impacto nulo no curto prazo, ao passo que o de longo prazo é negativo e estatisticamente significativo. Em outros casos, o multiplicador de receita não é estatisticamente significante em todo o período (Stanisic e Kasumovic, 2017).

Mais recentemente, modelos não lineares vêm sendo utilizados na tentativa de diferenciar os multiplicadores fiscais durante as recessões e expansões econômicas: a política fiscal mostraria-se particularmente eficaz durante recessões (FMI, 2010a). Assim, as especificações econométricas passaram a atentar-se à possibilidade de existência desse tipo de não linearidade. Auerbach e Gorodnichenko (2012), Fazzari et al (2015), Konstantinou e Partheniou (2019); Baum e Koester (2011), Dufrénot et al (2016), Baum et al (2012), Poirier (2014), Cos e Moral Benito (2013), por exemplo, utilizam um modelo não linear, para calcular os multiplicadores. Tais estudos utilizam modelos do tipo VAR ou modelos de uma só equação ${ }^{10}$. O STVAR (Smooth Transition VAR) - ou o TVAR, com Threshold

9 "In general, many empirical papers find that tax multipliers are lower than spending ones in the short-term, which is consistent with the theoretical prediction that part of the higher disposable income stemming from tax cuts is saved. This is the case in Blanchard and Perotti (2002). However, some evidence suggests that in the longer term tax multipliers could be higher than spending multipliers" (Burriel et al, 2010, p.22-23). Um exemplo disso está em Matheson e Pereira (2016), que encontram um alto multiplicador acumulado de receita para o Brasil. Outro exemplo que vale a pena citar é Ilzetski (2011), que encontra multiplicadores acumulados de receita para países em desenvolvimento maiores se comparados aos dos países de alta renda. Além disso, o multiplicador de receita é maior que o de gasto para o grupo de países em desenvolvimento. A conclusão do autor é que "[...]tax policy is more effective at stimulating short-run output in developing countries" (Ilzetski, 2011, p.20).

10 A partir da extensão do estudo de Auerbach e Gorodnichenko (2012), a literatura não linear passou a empregar, além do VAR não linear, estimações via métodos de uma equação de forma a acomodar melhor as não-linearidades (Auerbach e Gorodnichenko, 2013). Mas há também estudos que utilizam métodos lineares. Este método é conhecido como projeção de Jordà (2005) e consiste na estimação de funções impulso-resposta para o cômputo dos multiplicadores fiscais, assim como no VAR. É estimada 
- usa a probabilidade de se estar em um determinado regime e assume que o valor do multiplicador depende do ciclo econômico, assumindo valores diferentes em uma recessão e em uma expansão. As estimativas dos multiplicadores de gastos públicos em recessões encontradas por estudos deste tipo geralmente são maiores que no caso de expansões. Destacam-se, novamente, os efeitos do investimento público sobre o produto, sobretudo em episódios de recessão.

O debate no Brasil é caracterizado por questões associadas à possível mudança do efeito multiplicador nos últimos anos (nos anos de crise); à sua magnitude em relação aos países desenvolvidos; e à questão do papel dos componentes do gasto. Neste contexto, um primeiro estudo importante é o de Peres e Ellery (2009) e Peres (2006), que usam a estrutura do SVAR linear com base no artigo seminal de Blanchard e Perotti (2002) para o Brasil de 1994 a 2005, com dados do governo central. O VAR de referência é estimado seguindo a metodologia aqui descrita, na seção 1.4, com a ordenação de Choleski "gastos, receitas e produto" a nível per capita. A série de gasto utilizada foi construída a partir de dados de fontes como Ministério da Fazenda e o do Planejamento e se referem a consumo de bens corrente e de capital (consumo mais investimento). A série de receita utilizada pelos autores é a receita corrente subtraída de transferências a pessoas, dos subsídios e do pagamento de juros. Os resultados encontrados são próximos aos estimados para a economia norte-americana e para os países da OCDE, sendo "tipicamente keynesianos": a resposta do produto é positiva diante de um choque nos gastos e negativa para o caso dos impostos, sendo que o multiplicador de gastos é maior que o de impostos, mas, ainda assim, possui pequena magnitude, cerca de 0.3 a 0.4 para os gastos e -0.2 para a receita, ambos com baixa persistência. Em seguida, um VAR com mais uma dimensão é estimado, desagregando os gastos totais em consumo e investimento público. A conclusão dos autores é que os efeitos de um choque nos investimentos públicos são mais persistentes e mais eficientes para elevar o produto, dados seus efeitos indiretos.

Cattan (2017) utiliza os dados mensais de Orair et al (2016) para avaliação da política fiscal, mas não calcula os multiplicadores. O autor estima funções impulso resposta a partir de um SVAR a la Blanchard e Perotti (2002) para a economia brasileira nas três esferas de governo, no período de 2002 a 2016; e encontra que o produto responde mais a choques no investimento público se comparada à resposta a choques no consumo do governo. Ademais, a resposta do produto a um choque na variável de subsídios é bastante baixa. O SVAR estimado possui seis dimensões: investimento público, consumo (engloba as categorias "benefícios sociais", "pessoal" e "outras despesas"), subsídios, receitas, produto e dívida líquida do setor público. No presente trabalho, será considerada maior desagregação,

uma equação de regressão do produto sobre variáveis de controle para lags das variáveis fiscais e do produto e sobre o choque fiscal. Exemplos incluem estimações lineares e não lineares (Konstantinou e Partheniou, 2019; Deileidi et al, 2019; Carrière-Swallow, 2018; Izquierdo et al, 2019; Ramey e Zubairy, 2015; Owyang et al, 2013; Alves, 2017). 
Capítulo 1. Primeiro Artigo: A contribuição da política fiscal para a crise brasileira recente: uma análise 34 baseada em multiplicadores de despesas e receitas primárias do governo central no período 1997-2018

tratando de forma diferenciada os componentes "benefícios sociais", "pessoal" e "outras despesas". Pires (2011) também usa um VAR linear - para o período de 1996 a 2011 - para as três esferas de governo, e conclui que o multiplicador do gasto público de consumo é menor que um (0.99), ao passo que o multiplicador de investimentos públicos é maior que a unidade (1.23), sendo mais persistente.

Já Cavalcanti e Silva (2010) incluem uma variável para a dívida pública (como recomendado por Favero e Giavazzi (2007)). Um SVAR com o vetor receitas públicas, gastos públicos e produto é estimado para a economia brasileira de 1995 a 2008, com dados do IPEA, para as três esferas de governo. A hipótese de identificação apoia-se na frequência dos dados, sendo bastante similar ao estudo de Peres (2006). Os autores concluem que o multiplicador diminui ao levar em consideração a dívida pública, ficando próximo de zero.

Na direção contrária, o estudo de Mendonça et al (2009) obtém resultados "nãokeynesianos": multiplicadores positivos para a receita e negativos para os gastos. Os autores realizam o estudo para a economia brasileira do período de 1995 a 2007 por meio de um SVAR com identificação de Mountford e Uhlig (2009), com dados da Secretaria do Tesouro Nacional, e do IPEA para a receita tributária líquida.

Outro estudo importante para o período recente, já mencionado na introdução, é o de Matheson e Pereira (2016), que utilizam um modelo SVAR linear para analisar o Brasil no período de 1999 a 2014, com dados trimestrais do Resultado Fiscal do Governo Central divulgados pela Secretaria do Tesouro Nacional. O modelo é estimado em oito dimensões, com o seguinte vetor de endógenas, empregando decomposição de Choleski: salário mínimo, gastos primários, crédito público ao setor privado, produto, crédito privado ao setor privado, índice de preços ao consumidor e receita primária. O resultado encontrado é que o produto responde pouco aos choques fiscais: o multiplicador para o gasto atinge 0.5, mas seu efeito é pouco persistente, tornando-se nulo já ao final do segundo ano após o choque. Já o multiplicador estimado para a receita pública é bastante pequeno nos períodos que imediatamente sucedem o choque. No entanto, a um prazo mais longo, tal multiplicador acumulado é positivo e alto (sua magnitude é em torno de 2, dado um corte de impostos). Apesar desse resultado, os autores analisam o pico de resposta do produto para a amostra inteira e para o período pré-crise global de 2008 e afirmam que tanto o multiplicador de gasto público como o de crédito público não foram significativos nos últimos anos (aproximando-se do zero), enquanto que o multiplicador de receita se manteve estável.

Resende (2019) estima, por meio de um VAR linear com dados trimestrais em que gastos são ordenados primeiro, multiplicadores para investimentos públicos, benefícios sociais (engloba as mesmas despesas utilizadas neste trabalho: benefícios previdenciários, BPC, Bolsa Família e abono e seguro-desemprego) e despesas com pessoal e encargos do governo federal para o período 1997-2018, utilizando séries de dados do Tesouro Nacional 
e outras fontes, como o portal Siga Brasil para os investimentos públicos. O multiplicador de impacto dos benefícios sociais é de 0.72 e chega a 4.37 após oito trimestres. Tais valores para o multiplicador de investimento público do governo central são de 2.37 (impacto) e 3.37 (acumulado em oito trimestres). Já despesas com folha de pagamento apresentaram um multiplicador de impacto em torno de 0.8 e o acumulado, de 2.48 , mas a função impulsoresposta não é estatisticamente diferente de zero. As demais despesas apresentaram um multiplicador muito pequeno. Destas despesas, a única que apresentou resposta significante a $95 \%$ ao longo do tempo foi a despesa com benefícios sociais. Como veremos, este estudo reforça o resultado de que os benefícios sociais possuem um elevado efeito multiplicador, de magnitude comparável ao efeito dos investimentos públicos.

De posse desses resultados, Resende (2019) calcula o impulso fiscal a cada ano, utilizando uma desagregação por tipos de despesa de forma a avaliar a política fiscal a partir da tentativa de expurgar o efeito do ciclo econômico, sob o ponto de vista do resultado fiscal estrutural. De acordo com a autora, a contração fiscal de 2015 foi mais severa do que a calculada pelo governo, e também a mais contracionista dentre todos os anos de contração fiscal, desde 1997. Comparando com o ajuste de 2011, entretanto, a contração fiscal de 2015 teve efeito menos prolongado no produto porque, apesar do grande corte em investimentos públicos em 2015, houve um pequeno aumento de despesas com pessoal e com transferências. Em 2011, contudo, tais despesas não atuaram para suavizar o impulso contracionista. Portanto, Resende (2019) sugere um efeito estabilizador por parte das despesas com benefícios sociais, que atuaram de forma a compensar o impulso fiscal contracionista promovido pelo ajuste fiscal concentrado do lado dos investimentos públicos. Em 2016, o impulso fiscal foi expansionista e marcado pela contribuição das transferências de renda.

Em um estudo recente, Restrepo (2020) estimou multiplicadores fiscais de despesa e receita primárias em termos agregados para um conjunto de países da América Latina, incluindo o Brasil, com uma aplicação do procedimento de Blanchard e Perotti (2002). O autor incluiu variáveis exógenas na estimação, com controle para efeito do preço de commodities - como um índice de termos de troca. Para o Brasil, foi estimado um SVAR linear com dados fiscais trimestrais do governo central com a amostra de 1997 a 2017 . O multiplicador de gastos primários estimado foi de 0.59 (pico) e de 0.81 (acumulado em oito trimestres); enquanto que o de receita atingiu os valores - 0.31 (pico/impacto) e -0.44 (acumulado em oito trimestres).

Inspirado em Auerbach e Gorodnichenko (2012), Orair et al (2016) utilizam um STVAR (Smooth Transition VAR) não linear a fim de estudar a relação da política fiscal com os ciclos econômicos para o Brasil, do período de 2002 a 2016, para as três esferas de governo utilizando os dados ajustados de Orair e Gobetti (2017a), em frequência mensal. Os resultados encontrados foram de que a resposta do produto aos choques nas despesas 
Capítulo 1. Primeiro Artigo: A contribuição da política fiscal para a crise brasileira recente: uma análise 36 baseada em multiplicadores de despesas e receitas primárias do governo central no período 1997-2018

no regime recessivo com aquisição de ativos fixos (investimento público) e com benefícios sociais, são elevadas e persistentes, com respostas maiores que a unidade, chegando a, respectivamente, 1.68 e 1.51. No acumulado de quatro anos, o multiplicador acumulado dos benefícios sociais chega a 8 em períodos de recessão e o do investimento público, a 6.8. Já o multiplicador do gasto com pessoal chega ao pico de 1.33. No regime expansivo, por outro lado, nenhum desses três multiplicadores (e também para os subsídios e demais despesas) foi estatisticamente significante, além de possuírem valores baixos. No mesmo sentido, Dutra (2016) parte de um STVAR e dos dados ajustados de Orair e Gobetti (2017a) para o governo central no período 1997-2016. O autor encontra multiplicadores maiores em períodos de recessão, tanto para o consumo do governo como para o investimento público.

Por outro lado, Grudtner e Aragon (2017) realizam uma aplicação do STVAR para a economia brasileira de 1999 a 2015, com dados trimestrais para as três esferas de governo, com um modelo parecido ao empregado por Orair et al (2016) - porém com algumas modificações, propostas em Ramey e Zubairy (2014), que tecem críticas à metodologia de Auerbach e Gorodnichenko (2012). Os autores utilizam dados de consumo do governo obtidos do IBGE. Os dados de investimento público e da receita líquida são provenientes do IPEA (de Santos et al (2010), em Grudtner e Aragon (2017)). A conclusão deste estudo é que os multiplicadores fiscais da despesa total não diferem de maneira significativa entre períodos de expansão e recessão.

Com conclusões parecidas às de Grudtner e Aragon (2017), Alves (2017) emprega procedimentos não lineares com base em métodos de uma equação (Projeção de Jordá) para estimar multiplicadores fiscais para a economia brasileira de 1999 a 2016, a partir dos dados trimestrais de despesa primária total do governo central, obtida de Orair e Gobetti (2017a), e da carga tributária líquida do IPEA (de Santos et al (2010), em Alves (2017)). Os resultados encontrados apontam para um multiplicador acumulado de despesa primária total maior em períodos de recessão. No entanto, apesar de esse resultado ser robusto a diversas especificações, o autor não encontra evidências de que, de fato, haja diferença significativa entre as etapas do ciclo econômico ${ }^{11}$.

Mendonça et al (2016) estimam multiplicadores fiscais para o Brasil de 1997 a 2014 com dados fiscais trimestrais de receita primária líquida e despesa primária obtidos do Ministério de Fazenda, por meio da aplicação de SVAR e do TVAR com base em Blanchard e Perotti (2002). O exercício é estendido para incluir, além das variáveis fiscais, taxa de

\footnotetext{
11 Alves (2017) dá mais um passo e desagrega os componentes do produto. O autor encontra uma maior resposta do consumo privado a choques nas despesas totais em períodos de recessão. Para o investimento, por outro lado, embora haja evidência de um multiplicador maior do que a unidade em períodos de recessão, os resultados não são tão robustos e são sensíveis à especificação do modelo. Para exportações e importações, não houve resposta significante. Em Grudtner e Aragon (2017) há a estimação desagregada para investimento público e consumo do governo. Os valores dos multiplicadores de consumo, tanto no impacto quanto no acumulado, são maiores para períodos de recessão. No caso do investimento público, o multiplicador é, em geral, maior em períodos de expansão. Entretanto, tais diferenças não são significativas.
} 
juros e inflação. O resultado encontrado é de multiplicadores fiscais para as despesas primárias totais baixos. Quando a amostra foi dividida entre os períodos completo e antes da crise de 2008, os resultados foram parecidos com os de Matheson e Pereira (2016): o multiplicador de despesa total foi menor para a amostra completa. Além disso, os resultados do modelo não linear, embora menos robustos, apontaram para multiplicadores de despesa total maiores em períodos de expansão (mas não significativos e muito baixos), contrariando boa parte da literatura que estima multiplicadores com métodos não lineares.

Dentre as estimações não lineares, há também o trabalho de Pires (2014), que calculou o multiplicador fiscal com um modelo VAR não linear com Mudança Markoviana de Regime para períodos de baixa volatilidade entre 1996 a 2012, sugerindo um multiplicador entre 1.4 e 1.7 para o investimento público (no caso do consumo do governo, o multiplicador não foi significativo) e em torno de -0.28 para a carga tributária líquida. Tanto Pires (2014), quanto Pires (2011) utilizam séries de consumo do governo do IBGE e séries do IPEA para a carga tributária líquida e para investimentos públicos.

Um segundo trabalho que emprega uma metodologia similar à de Pires (2014) é o de Castelo Branco et al (2015) para o período entre 1999 e 2012, para as três esferas de governo, com dados do IPEA para carga tributária líquida e formação bruta de capital fixo e do IBGE para consumo do governo. Os multiplicadores de gastos públicos são positivos, sendo: menor que a unidade no caso do multiplicador de gasto em consumo da administração pública; maior que a unidade (e com impacto persistente no produto real) no caso do multiplicador de investimento público. Já com relação a choques na carga tributária líquida, a resposta do produto é negativa e menor que a unidade, sendo menor que o multiplicador de gasto.

O presente estudo visa estimar o impacto das alterações mais importantes da política fiscal adotada no país nos últimos anos para a crise atual. Para isso, estimaremos a resposta do produto ao gasto e à receita com base nos dados de Orair e Gobetti (2017a), com o nível de desagregação proposto por Orair et al (2016), por meio de um modelo SVAR linear em duas amostras no período 1997-2018. Os dois recortes temporais permitirão lançar luz sobre uma eventual alteração dos efeitos multiplicadores após a crise iniciada em 2014, tal como realizado em Matheson e Pereira (2016) para a crise de 2009. Especificamente, trataremos dessa evidência no contexto da crise recente. Para isso, optamos pela estimação de um modelo SVAR linear em duas amostras a fim de isolar o efeito do momento específico de 2014 a 2018 e avaliar como os multiplicadores dos diferentes tipos de gasto se alteram nesse período. A estimação com um método não linear, portanto, não permitiria uma avaliação específica da crise recente.

Consideramos que a estimação desagregada, por tipos de despesa, é bastante importante a fim de termos uma ideia de quais são as despesas que possuem maior efeito na economia. Para além da desagregação entre consumo do governo e investimento 
Capítulo 1. Primeiro Artigo: A contribuição da política fiscal para a crise brasileira recente: uma análise 38 baseada em multiplicadores de despesas e receitas primárias do governo central no período 1997-2018 público, será dada maior relevância aos subsídios e aos benefícios sociais. O primeiro assumiu papel importante na política fiscal a partir de 2011, como vimos na seção 1.2. Os benefícios sociais, por sua vez, constituem um item fundamental do orçamento público, e seus efeitos multiplicadores são pouco explorados na literatura, como será apresentado no Capítulo 2 desta dissertação. A contribuição mais relevante deste artigo, entretanto, está na estimação da participação da política fiscal na crise brasileira recente, bem como na simulação de cenários alternativos. A desagregação por tipos de despesa permite o cálculo dos multiplicadores para cada um deles e, a partir disso, podemos estimar os efeitos da política fiscal adotada nos últimos anos no PIB, como faremos na seção 1.6.

\subsection{Dados e Metodologia}

\subsubsection{Dados}

O período analisado é de 1997 a 2018. Os dados de receita pública e de gasto público utilizados seguirão a base de Orair e Gobetti (2017a). Os autores montaram uma nova base de dados, de 1997 a 2018, em frequência mensal (acima da linha), a partir dos dados fornecidos pelo Tesouro Nacional, eliminando inconsistências e ruídos de natureza metodológica das estatísticas oficiais. No entanto, este trabalho utiliza os dados apenas para o governo central. Isto porque os autores têm os dados corrigidos apenas a partir de 2002 para o governo geral. Como um dos propósitos deste trabalho é analisar o ciclo econômico, optou-se pelos dados do governo central, para um período um pouco mais longo (desde 1997). Orair e Gobetti (2017a) enumeram três problemas das estatísticas obtidas da Secretaria do Tesouro Nacional, para o caso do governo central, com ordem crescente de gravidade:

a) Problemas relativos à composição de receitas e despesas, seja por mudanças metodológicas, erros ou mudanças contábeis. Neste caso, o resultado primário não é afetado, porém há prejuízos à análise desagregada. Por exemplo, há uma dupla contagem de ajuda financeira a estados e municípios, contabilizados tanto na despesa primária total quanto na repartição de receitas.

b) Operações intraorçamentárias que distorcem o montante de despesas e receitas, podendo ou não afetar o resultado primário. Há prejuízos na análise de crescimento de receitas e despesas. Um exemplo é a compensação do Tesouro à Previdência Social pela desoneração da folha de pagamento, que é uma despesa para o primeiro (fictícia) e uma receita para o segundo.

c) Problemas relacionados às manobras fiscais, que afetam tanto o resultado primário como a evolução das receitas e despesas. Um exemplo é o que ficou conhecido como "pedaladas fiscais"- em que despesas com subsídios e programas sociais foram pagas 
pelos bancos públicos mas apenas foram lançadas na contabilidade do Tesouro em $2015^{12}$, com o propósito de não afetar o resultado primário, uma vez que os bancos públicos não fazem parte do governo geral por uma questão conceitual. Outro exemplo de correção realizada pelos autores é retirar o impacto, seja como receita ou despesa, de resgates ou destinações de recursos ao Fundo Soberano e da capitalização (e cessão onerosa) da Petrobrás.

A despesa primária, por sua vez, é dividida em pessoal e encargos sociais, benefícios sociais (previdenciários e assistenciais), subsídios e despesas de custeio e capital, que são apuradas como resíduo. Desta forma, as despesas de custeio e capital incluem parte significativa das transferências intergovernamentais não categorizadas como transferência por repartição de receitas (transferências diretamente vinculadas a percentuais da receita, como os fundos de participação de estados e municípios - neste caso as transferências são segregadas das demais despesas).

Mais especificamente: "Os repasses a estados e municípios referentes à compensação pelas desonerações da Lei Kandir e ao complemento de recursos ao Fundo de Manutenção do Ensino Básico (Fundeb), que independem do volume arrecadado, foram deslocados do bloco das transferências para o bloco das despesas primárias, onde já eram classificados também os repasses para custeio dos programas de saúde, educação e assistências social, as transferências de capital para realização de investimentos etc". (Orair e Gobetti, 2017a, p.12). Em outras palavras, uma parte das transferências intergovernamentais (cerca de 1/3 mais especificamente) está diluída nas despesas primárias, diferentemente das transferências por repartição de receita, que são identificadas à parte e não entram no cálculo da receita do governo central (isto é, as receitas são líquidas de transferências). Para nossos propósitos, utilizamos apenas o governo central, de modo que as transferências de recursos para estados e municípios estão tanto no item "repartição de receitas", quanto diluídas nos demais itens, sobretudo "demais despesas" e "investimentos".

Em suma, os dados dividem os componentes do gasto público em: a) pessoal (remuneração e benefícios previdenciários dos funcionários públicos); b) benefícios sociais (benefícios de assistência social e previdência, exceto para funcionários públicos, mais seguro desemprego, abono salarial e benefícios dos programas Bolsa Família e Benefício de Prestação Continuada); c) aquisições de ativos fixos ou investimentos públicos, incluindo-se as transferências de capital para Estados e Municípios; d) subsídios (inclui subvenções aos fundos regionais, subsídios do programa Proagro, de auxílios à Conta de Desenvolvimento

12 A título de exemplo de "pedalada", Orair e Gobetti (2017a) explicam que, no resultado fiscal de 2015, o valor do subsídio ao Programa de Sustentação ao Investimento (PSI) foi de R \$ 30.3 bilhões, valor muito alto devido à quitação de $\mathrm{R} \$ 14.6$ bilhões em passivos do governo central com o BNDES. Tais passivos se referem a subsídios efetivamente concedidos ao setor privado em anos anteriores, sobretudo entre 2010 e 2014. A correção dos autores foi considerar essa despesa no ano em que efetivamente ocorreu: $\mathrm{R} \$ 1.3$ bilhão, em 2010, $\mathrm{R} \$ 2.2$ bilhões, em 2011, $\mathrm{R} \$ 2$ bilhões, em 2012, R $\$ 4.1$ bilhões, em 2013, e R $\$ 5.9$ bilhões, em 2014, em acordo com o Banco Central. 
Capítulo 1. Primeiro Artigo: A contribuição da política fiscal para a crise brasileira recente: uma análise 40 baseada em multiplicadores de despesas e receitas primárias do governo central no período 1997-2018

Energético, do Programa Minha Casa Minha Vida e também os subsídios implícitos dos empréstimos do Tesouro ao BNDES, além dos itens assim classificados pelo Tesouro); e) outras despesas (bens e serviços adquiridos pelo governo geral, incluindo Estados e Municípios, mais o resíduo das demais despesas). Já a receita ${ }^{13}$ utilizada é a líquida, que exclui as transferências (como as transferências para Estados e Municípios).

Para o produto agregado, a série obtida é a 4380, do Banco Central do Brasil (BCBDepec), que fornece o Produto Interno Bruto mensal, em valores correntes. Esta série é estimada com base em informações divulgadas da produção da indústria de transformação, do consumo de energia elétrica, da exportação de produtos primários e de índices de preços. As estimativas desses índices de volume são ajustadas aos dados de volume do PIB trimestral divulgado pelo IBGE. Essa escolha possui duas desvantagens: 1) utilização de uma série interpolada; 2) utilização do índice IPCA para deflacionar os dados do PIB. No entanto, há também vantagens: 1) possibilita o aumento do número de observações para a estimação; 2) o arcabouço institucional brasileiro é regulamentado pela Lei de Responsabilidade Fiscal, cujas metas e revisões são bimestrais. Assim, a utilização de dados mensais estaria em mais acordo com a hipótese de identificação, a ser explorada na seção 1.4.2. De qualquer forma, realizaremos os exercícios também com dados trimestrais.

Todas as séries de gasto, receita e produto foram deflacionadas com o índice de preços ao consumidor amplo (IPCA), obtido do Instituto Brasileiro de Geografia e Estatística (IBGE), a preços de junho de 2018, onde as séries terminam. Posteriormente, as séries foram dessazonalizadas a partir da rotina X-13 Arima do Eviews. E, finalmente, foram logaritmizadas. As séries têm um forte componente sazonal: o mês de dezembro, por exemplo, tem um salto em termos das despesas, em virtude do encerramento do exercício.

\subsubsection{Metodologia}

Como visto na revisão de literatura, grande parte dos trabalhos da literatura empírica sobre multiplicadores fiscais aplicam os modelos do VAR estrutural (ou SVAR). O método VAR é justificado pelo fato de que as variáveis de interesse são inter-relacionadas. A

13 Sobre os dados da receita, os componentes da receita primária líquida devem ter relação com o ciclo econômico para o cálculo da elasticidade da receita com relação ao produto, que será utilizada na estimação do SVAR. Desta forma, este trabalho segue as recomendações de Gobetti et al (2016): foram retirados os componentes da receita primária do governo central que possuem baixa correlação com a atividade econômica: receitas patrimoniais, concessões, permissões, dividendos, bem como receitas tributárias com pouca relação com o ciclo econômico ou que possuem caráter regulatório, contribuição previdenciária dos servidores públicos; imposto sobre operações financeiras (IOF), que sofre alterações frequentes de alíquotas; CIDE combustível, que possui base tributária muito específica; e CPMF, que foi extinta em 2007 e, de acordo com os autores, apresentou evolução bastante próxima da elasticidade unitária. Foram considerados, portanto, no cômputo da receita primária líquida: imposto sobre importação (II), impostos sobre produtos industrializados (IPI), imposto de renda (IR), contribuição para o financiamento para a seguridade social (Cofins), Programa de Integração Social (PIS) e Programa de Formação do Patrimônio do Servidor Público (Pasep), contribuição social sobre lucro líquido (CSLL), arrecadação previdenciária, contribuição de salário educação e outras receitas administradas pela Receita Federal. 
análise de função impulso-resposta permite calcular o quanto a variável produto responde, dado um choque na variável de gasto primário, por exemplo. A partir desta função, podemos calcular o multiplicador fiscal. O SVAR ficou bastante conhecido na literatura de multiplicadores fiscais por meio de Blanchard e Perotti (2002), que argumentam que a metodologia VAR é apropriada para a política fiscal pelo fato de que os lags de decisão e implementação das políticas fiscais implicam que, quando temos dados de alta frequência (mensais ou trimestrais), há muito pouca ou nenhuma resposta da política fiscal a choques inesperados no produto, contemporaneamente. Neste caso, o produto não afeta o gasto público contemporaneamente porque os formuladores de política pública levam mais tempo que um trimestre (ou um mês) para perceber o choque do produto e decidir os próximos passos na política fiscal, bem como apresentá-las ao legislativo. O propósito da identificação é isolar os choques exógenos, recuperando a forma estrutural dos choques, isto é, obter uma ortogonalização não-recursiva dos termos de erro.

O primeiro passo é estimar o VAR da forma reduzida. O vetor de variáveis endógenas utilizadas no modelo básico do presente estudo é tridimensional, sendo $x_{t}=\left[g_{t}, t_{t}, y_{t}\right]^{\prime} \mathrm{o}$ vetor de endógenas, onde $g_{t}, t_{t}, y_{t}$ são, respectivamente, as séries do gasto, da receita e do produto, em termos reais e logaritmizadas. Trata-se de um modelo VAR, tal como proposto por Sims (1980), onde cada variável é explicada por lags de si mesma e das demais variáveis do modelo, sendo capaz de capturar relações dinâmicas.

Conforme Lutkepohl (2005), a forma reduzida de um processo VAR(p) de dimensão K é dada por

$$
x_{t}=B_{1} x_{t-1}+(\ldots)+B_{P} x_{t-p}+u_{t}
$$

Onde $x_{t}$ é um vetor de variáveis observáveis endógenas com dimensão $(K x 1)$, onde $j=1, \ldots, p$, são matrizes de coeficientes da forma reduzida $(K x K)$ e $u_{t}$ é o vetor de resíduos da forma reduzida. O modelo também pode incluir uma constate e variáveis exógenas, como dummies e variáveis de tendência (Vdovychenko, 2018).

Para se obter a forma estrutural, o chamado "modelo AB" é utilizado, que descreve as relações entre os choques estruturais $\left(e_{t}\right)$ e os da forma reduzida $\left(u_{t}\right)$ (Lozano e Rodriguez, 2011):

$$
B e_{t}=A u_{t}
$$

neste modelo assume-se que os choques estruturais não são correlacionados entre si (a matriz de variância e covariância dos choques estruturais é diagonal).

A forma estrutural é obtida a partir da forma reduzida, pré-multiplicando pela matriz A (Lutkepohl, 2005), levando em conta a relação entre os choques:

$$
A x_{t}=A B_{1} x_{t-1}+(\ldots)+A B_{P} x_{t-p}+A u_{t}=A B_{1} x_{t-1}+(\ldots)+A B_{P} x_{t-p}+B e_{t}
$$

A matriz A reflete as relações contemporâneas entre as variáveis endógenas do vetor $x_{t}$. $\mathrm{O}$ SVAR parte dessa matriz para impor relações entre essas variáveis, de modo que possa 
Capítulo 1. Primeiro Artigo: A contribuição da política fiscal para a crise brasileira recente: uma análise 42 baseada em multiplicadores de despesas e receitas primárias do governo central no período 1997-2018

haver identificação do modelo ao isolar choques exógenos. Além disso, as matrizes A e B impõem restrições às relações contemporâneas dos resíduos da forma reduzida $B e_{t}=A u_{t}$. Quando a equação acima é resolvida para o vetor de variáveis $x_{t}$, obtém-se as funções impulso-resposta. Desta forma, o SVAR não é estimado diretamente. Estima-se o VAR em sua forma reduzida e, então, impõe-se restrições à matriz A na forma estrutural, na tentativa de se isolar choques de modo que as estimações não sejam viesadas e inconsistentes. Portanto, o objetivo da identificação é recuperar os choques estruturais a fim de se estimar os efeitos das mudanças exógenas não antecipadas na política fiscal (Peres e Ellery, 2009).

A identificação do modelo é obtida a partir da estratégia proposta por Perotti (2007), Blanchard e Perotti (2002) e Perotti (2004). O propósito da identificação é isolar os choques exógenos, recuperando a forma estrutural dos choques, isto é, obter uma ortogonalização não-recursiva dos termos de erro.

De acordo com Akpan a Atan (2015), Borg (2014), e Perotti (2004), existem algumas estratégias na literatura para a recuperação da parte exógena (ortogonal ou estrutural) dos termos de erro: a) o estudo de eventos (abordagem narrativa), que recupera os choques exógenos a partir do uso de variáveis dummy para capturar episódios específicos (como gastos de guerra ou episódios de medidas fiscais), como Romer e Romer (2010); Ramey e Shapiro (1998); Ramey (2011); b) o uso de restrições de sinais, como Mountford e Uhlig (2009); c) a imposição de restrições baseadas na teoria econômica e em aspectos institucionais, explorando os lags para tomada de decisão de política, como Blanchard e Perotti(2002) - que é utilizado neste artigo; d) o uso de ordem recursiva por meio de decomposição de Choleski, como Fatas e Mihov (2001), que ordenam as variáveis fiscais primeiro.

Ilzetzki et al (2013) enunciam duas abordagens para o problema de identificação: o SVAR (Blanchard e Perotti (2002)) e a abordagem narrativa. Na realidade, as estratégias recursiva e do SVAR são muito similares: o SVAR equivale à ordenação de Choleski em que os gastos são ordenados primeiro. A abordagem "c" exige imposição de restrições contemporâneas entre as variáveis, enquanto abordagem "d" impõe uma ordem causal. Caldara e Kamps (2008) mostram que a abordagem recursiva e a estrutural são bastante similares em termos de resultado. Uma crítica comum a este método é feita por Perotti (2004): o resultado é sensível à ordenação das variáveis. As críticas à abordagem "a" são no sentido de que há a dificuldade de se assegurar que o estudo de eventos resultará em choques de fato exógenos, além da dificuldade de se conseguir dados desses eventos. Como advertem Auerbach e Gorodnichenko (2012), essa abordagem demanda muitas informações, que muitas vezes não estão disponíveis e sua aplicação fica restrita a uma classe muito específica de choques fiscais - os choques de gastos militares. Além disso, conforme Peres (2006), reformas fiscais são geralmente precedidas de debate no parlamento e, portanto, antecipadas de modo que o choque não é puramente exógeno. Pires (2014) coloca que 
dificilmente a orientação de política ao crescimento econômico sistemático poderia se pautar em gastos militares.

Já a abordagem "b", embora não utilize relações contemporâneas entre as variáveis a priori, exige ordenação causal e estabelecimento de sinais às funções impulso-resposta pelo autor, que os escolhe com base na teoria econômica. Apesar de lidar com choques que possam ser antecipados, Perotti (2004) aponta que uma das desvantagens do método é encontrar efeitos fortemente condicionados ao que foi assumido, o que pode mascarar relações dinâmicas entre as variáveis. O resultado obtido por Mountford e Uhlig (2009), por exemplo, em um VAR para a economia norte-americana, é que um déficit fiscal ocasionado por aumento de gastos públicos tem, em geral, multiplicadores menores que os estimados por Blanchard e Perotti (2002), chegando a multiplicadores negativos após um certo período de tempo e a efeitos bastante adversos no investimento. Um déficit fiscal que use corte de impostos, por outro lado, tem multiplicadores menores nos primeiros trimestres, mas depois tornam-se maiores que os estimados pelo estudo de Blanchard e Perotti (2002).

Tendo em vista essas informações, e, embora críticas sejam feitas ao método "c", este é o método utilizado neste artigo dados nossos objetivos. Entre as críticas comuns a esse método, há a sensibilidade do multiplicador às elasticidades exógenas estimadas. Para amenizar um pouco isso, calculamos as elasticidades por dois métodos distintos e verificamos que os resultados não foram tão sensíveis. Outra crítica é dirigida ao fato de que a resposta do produto às variáveis fiscais é dependente do ciclo econômico - por isso a literatura sugere estimações não lineares. Para lidar com isso, fizemos o que foi sugerido por Mathenson e Pereira (2016), ao estimar duas amostras separadas: uma completa, incluindo a crise, e a outra pré-crise. Tendo em vista que nosso interesse é especificamente na recessão recente, esse método é conveniente. Há também outras questões, como inclusão de variáveis referentes à política monetária, como em Perotti (2004), e de dívida pública, como Favero e Giavazzi (2007). Trataremos destas questões incluindo controles de política monetária nos modelos estimados. Quanto à dívida pública, considerações serão feitas nas simulações dos cenários, na seção 1.6 .

O primeiro passo é estimar o VAR da forma reduzida. O vetor de variáveis endógenas utilizadas no modelo básico do presente estudo é tridimensional $x_{t}=\left[g_{t}, t_{t}, y_{t}\right]^{\prime}$, e o vetor dos resíduos $u_{t}=\left[u_{t}^{g}, u_{t}^{t}, u_{t}^{y}\right]^{\prime}$. Como vimos, a relação que descreve as relações contemporâneas entre $u$ e $e: B e_{t}=A u_{t}$. Os choques estruturais, ortogonais entre si e às demais variáveis, precisam ser recuperados. Para isso, impõe-se relações contemporâneas nos resíduos da forma reduzida (Giordano et al, 2007).

Os choques da forma reduzida, entretanto, não possuem significância econômica (Castro e Hernandez de Cos, 2008). Conforme Perotti (2007), os choques da forma reduzida (ou movimentos "surpresa") podem ser vistos como combinações lineares de três componentes: a) a resposta automática do gasto do governo e receita a mudanças no produto; 
Capítulo 1. Primeiro Artigo: A contribuição da política fiscal para a crise brasileira recente: uma análise 44 baseada em multiplicadores de despesas e receitas primárias do governo central no período 1997-2018

b) a resposta discricionária em razão de mudanças nas variáveis endógenas (Perotti dá o exemplo de mudanças nos impostos em resposta a uma recessão); c) choques discricionários aleatórios: os choques estruturais, que são não correlacionados entre si e não observáveis (precisamos recuperá-los). Desta forma:

$$
\begin{aligned}
& u_{t}^{g}=\alpha_{g y} u_{t}^{y}+\beta_{g t} e_{t}^{t}+e_{t}^{g} \\
& u_{t}^{t}=\alpha_{t y} u_{t}^{y}+\beta_{t g} e_{t}^{g}+e_{t}^{t} \\
& u_{t}^{y}=\gamma_{y t} u_{t}^{t}+\gamma_{y g} u_{t}^{g}+e_{t}^{y}
\end{aligned}
$$

Onde $u_{t}^{g}, u_{t}^{t}, u_{t}^{y}$ são os movimentos não esperados nas variáveis de gasto, receita e produto, respectivamente. Esses movimentos "surpresa" são os resíduos da forma reduzida, pois é a parte dos dados que não é explicada pelo VAR. Já $e_{t}^{g}, e_{t}^{t}, e_{t}^{y}$ são os choques estruturais não correlacionados entre si por suposição e refletem a parte dos movimentos-surpresa que é exógena, ou seja, que não depende de políticas e da evolução "normal" da economia (Coudret, 2013).

Os coeficientes $\alpha_{i j}$ refletem a resposta da variável i à variável j - os componentes "a" e "b" listados acima são captados pelos coeficientes . Já $\beta_{i j}$ medem a resposta contemporânea da variável i a um choque estrutural na variável j - isto é, o componente "c" (Lozano e Rodriguez, 2011; Perotti, 2007; Giordano et al, 2007; Borg, 2014).

Assim, a equação 1.4 diz que movimentos inesperados nos gastos ocorrem devido a movimentos inesperados do produto, via estabilizadores automáticos; a choques estruturais nas receitas por meio de resposta automática e a choques estruturais nos próprios gastos primários. A equação 1.5 possui interpretação similar. A equação 1.6 diz que os movimentos inesperados na renda ocorrem em resposta a movimentos-surpresa das variáveis fiscais e a choques exógenos (Peres e Ellery, 2009).

Nas equações acima, $e_{t}^{g}$ e $e_{t}^{t}$ são os choques estruturais fiscais, não correlacionados entre si, e refletem as mudanças discricionárias aleatórias, isto é, são os choques exógenos, que precisamos recuperar a partir da forma reduzida do VAR. Esses choques precisam ser exógenos para que o modelo possa ser identificado (isto é, para identificarmos a resposta do produto a um choque nos gastos, ou na receita, bloqueando a resposta da variável fiscal ao produto). Como ressaltam Giordano et al (2007) e Jemec et al (2013), precisamos estimar $e_{t}^{g}$ e $e_{t}^{t}$ a fim de estudar a resposta do produto a esses choques.

Conforme aponta Vdovychenko (2018), $\alpha_{g y}, \alpha_{t y}, \gamma_{y t}$ e $\gamma_{y g}$ não podem ser estimados sem viés devido à relação instantânea mútua entre o produto e as variáveis do gasto e da despesa. Em outras palavras, os resíduos da forma reduzida são correlacionados com os choques estruturais nas equações acima, de modo que os coeficientes obtidos por Mínimos Quadrados Ordinários (MQO) são viesados e inconsistentes. Por exemplo, se for estimada a equação da receita (equação 1.5), as estimativas não são consistentes porque o produto 
poderia responder contemporaneamente a choques na receita (Peres e Ellery, 2009). A identificação dos choques estruturais, portanto, não pode ser feita.

Para resolver isso, dois passos são colocados. Primeiro, parte-se da hipótese de identificação para dados de alta frequência (mensal ou trimestral): "it typically takes longer than a quarter for discretionary fiscal policy to respond to, say, an output shock" (Perotti, 2007, p.176) ${ }^{14}$. Os policymakers levam um certo tempo para perceber as mudanças no produto, tomar decisões acerca da política e aprová-las no legislativo para, então, implementá-las (Giordano et al, 2007) - isto remove o componente "b" acima, de modo que os coeficientes $\alpha$ apenas refletem o primeiro componente (a resposta de estabilizador automático).

Em segundo lugar, Perotti (2007) sugere o uso de informações externas ao modelo a fim de se estimar os coeficientes de $\alpha_{g y}$ e $\alpha_{t y}$, uma vez que o sistema acima possui endogeneidade, havendo relações mútuas entre as variáveis. Desta forma, não é possível estimar esses coeficientes de forma consistente porque os $u_{t}^{j}$ são correlacionados com $e_{t}^{i}$ (Giordano et al, 2007).

A interpretação é a seguinte: $\alpha_{g y}$ reflete a elasticidade contemporânea da despesa em relação ao produto e $\alpha_{t y}$ é a elasticidade contemporânea da receita com relação ao produto. Sabemos que os coeficientes $\alpha$ medem a resposta discricionária das variáveis fiscais a mudanças não esperadas no produto, bem como a resposta automática (Jemec et al, 2013). Dada a hipótese de identificação, não há resposta das variáveis fiscais ao produto de maneira discricionária de modo que essas elasticidades refletem apenas as respostas de estabilizador automático, pois o uso de dados mensais elimina o componente discricionário (Çebi, 2015). Desta forma, a hipótese de identificação parte da seguinte elasticidade:

$$
\alpha_{g y}=0
$$

Já a elasticidade da receita em relação ao produto foi estimada com base em dois métodos: o chamado "método FMI", tal como em Andreis (2014) e Maciel (2006), que é uma regressão com o uso de variáveis de dummy para controle de períodos, de outliers e de tendência. Gobetti et al (2016) estimam a elasticidade da receita por meio de Dynamic Ordinary Least Squares (DOLS), proposto por Stock e Watson (1993). Este método está relacionado ao fato de que as séries são não estacionárias, adicionando-se lags e leads da primeira diferença da variável independente, e busca corrigir possíveis problemas de viés nas estimativas MQO. Esse valor de elasticidade de longo prazo é do qual não se espera

14 Embora a maioria dos estudos utilize dados em frequência trimestral, optou-se, nesta pesquisa, utilizar dados mensais, como em Orair et al (2016) e Cattan (2017), que também usam os dados de Orair e Gobetti (2017a). No entanto, realizaremos o exercício trimestral como forma de teste de robustez. É importante observar também que, como colocado por Perotti (2004), embora os choques fiscais "reais" ocorram por ano, na prática existem várias revisões e mudanças que afetam a política fiscal em geral. 
Capítulo 1. Primeiro Artigo: A contribuição da política fiscal para a crise brasileira recente: uma análise 46 baseada em multiplicadores de despesas e receitas primárias do governo central no período 1997-2018

que haja desvio sistemático ao decorrer do tempo, como apontam Casalecchi e Barros $(2018)^{15}$. Sobre esta estimação, o Apêndice B detalha os procedimentos.

Mas esse procedimento ainda não é suficiente, pois ainda há problema de estimação tendo em vista que $u_{t}^{t}$ e $u_{t}^{g}$ são correlacionados. A partir dessas estimações separadas, obtêm-se as elasticidades exógenas e constroem-se os resíduos ciclicamente ajustados (que são os choques sem os efeitos do ciclo a fim de eliminarmos as respostas de estabilizador automático). Como deve haver causalidade dupla, realizamos esse ajuste cíclico (Restrepo, 2020). Assim, remove-se o componente "a", de forma a termos exogeneidade:

$$
\begin{aligned}
& u_{t}^{g, C A}=u_{t}^{g}-\alpha_{g y} u_{t}^{y}=\beta_{g t} e_{t}^{t}+e_{t}^{g} \\
& u_{t}^{t, C A}=u_{t}^{t}-\alpha_{t y} u_{t}^{y}=\beta_{t g} e_{t}^{g}+e_{t}^{t}
\end{aligned}
$$

Os choques estruturais $e_{t}^{g}$ e $e_{t}^{t}$ podem ser obtidos a partir da hipótese de ordenação das variáveis. Se o gasto vier primeiro, $\beta_{g t}=0$; se a receita vier primeiro, $\beta_{t g}=0$. A partir desta hipótese, torna-se possível estimar os choques estruturais por MQO.

Blanchard e Perotti (2002) apontam para o fato de que não há uma razão para se escolher $\beta_{g t}=0$ ou $\beta_{t g}=0$ a priori; isto é, a partir de um choque no gasto e na receita, não há justificativa teórica ou empírica para sustentar qual das variáveis irá reagir antes. Entretanto, Mendonça et al (2016) sustentam que, para o caso do Brasil ${ }^{16}$ particularmente, é recomendável que se escolha $\beta_{g t}=0$ e se estime o impacto contemporâneo dos gastos na receita $\beta_{t g}{ }^{17}$. Como a correlação entre $u_{t}^{g, C A}$ e $u_{t}^{t, C A}$ é muito pequena, Perotti (2007) assinala que a ordem não altera o resultado.

Inicialmente partiremos de $\beta_{g t}=0^{18}$; e estimaremos a regressão por MQO dos resíduos da receita ajustado sobre os resíduos da forma estrutural dos gastos, a fim de obter $\beta_{t g}$ (Burriel at al, 2010):

$$
\begin{gathered}
u_{t}^{g, C A}=u_{t}^{g}-\alpha_{g y} u_{t}^{y}=e_{t}^{g} \\
u_{t}^{t, C A}=u_{t}^{t}-\alpha_{t y} u_{t}^{y}=\beta_{t g} e_{t}^{g}+e_{t}^{t}
\end{gathered}
$$

15 Os valores obtidos para as elasticidades foram os seguintes: 1.25 (DOLS) e 1.2 (FMI) para a amostra inteira e 1.094 (DOLS) e 0.852 (FMI) para a amostra pré-crise. Utilizamos as elasticidades encontradas pelo "método FMI" porque as estimações pelo método DOLS são de longo prazo e, dado que estimamos os resultados para duas amostras, uma menor de 1997 a 2014, e a outra de 1997 a 2018, é interessante verificarmos as mudanças ocorridas nessa elasticidade. Foram estimados modelos com a elasticidade obtida pelo DOLS e as respostas do produto a choques nas variáveis ficais foram similares. Não houve alteração na função impulso resposta e nos multiplicadores para o caso do gasto. Para a receita, entretanto, houve mudança nos multiplicadores, mas tal alteração não foi tão expressiva.

16 "Our point is that the Brazilian government decides to spend without considering the possibility of collecting taxes" (Mendonça et al, 2016, p.10).

17 Há vários estudos que adotam essa especificação, como Perotti (2007), Tenhofen et al (2010), Castro e Fernandez (2011), Lozano e Rodriguez (2011), Burriel et al (2010), entre outros.

18 Os modelos também foram estimados também assumindo $\beta_{t g}=0$ (isto é, as decisões referentes às receitas ocorrem antes que as de gasto) e se mostraram robustos à especificação, com pouca variação nas funções impulso-resposta, como é usual na literatura. 
O propósito dessa regressão é obter as estimações de $e_{t}^{t}$ e $e_{t}^{g}$. Tais choques são "isolados" da influência do produto, pois foi retirado o componente de estabilizador automático. Isso, juntamente com a hipótese de identificação, permite tornar os choques exógenos, retirando os componentes "a" e "b" mencionados acima. Tendo em vista que $\alpha_{g y}=0$ e $\beta_{g t}=0$, temos:

$$
\begin{gathered}
u_{t}^{g, C A}=u_{t}^{g}=e_{t}^{g} \\
u_{t}^{t, C A}=u_{t}^{t}-\alpha_{t y} u_{t}^{y}=\beta_{t g} e_{t}^{g}+e_{t}^{t}
\end{gathered}
$$

Da equação 1.12, é possível recuperar $e_{t}^{g}$, utilizando-o para estimar a segunda por MQO (Burriel et al, 2010). A partir disso, obtemos variáveis instrumentais, os choques $e_{t}^{t}$ e $e_{t}^{g}$ para $u_{t}^{t}$ e $u_{t}^{g}$ na equação 1.14, tendo em vista a correlação dos regressores (resíduos da forma reduzida) com o termo de erro (choque estrutural). Assim $e_{t}^{t}$ e $e_{t}^{g}$ são utilizados como instrumentos pois sua correlação é baixa com $e_{t}^{y}$, devido ao uso dos resíduos ajustados ao ciclo.

$$
u_{t}^{y}=\gamma_{y t} u_{t}^{t}+\gamma_{y g} u_{t}^{g}+e_{t}^{y}
$$

Onde os instrumentos são estimados por:

$$
\begin{gathered}
e_{t}^{g}=u_{t}^{g, C A}=u_{t}^{g} \\
e_{t}^{t}=u_{t}^{t}-\alpha_{t y} u_{t}^{y}-\beta_{t g} e_{t}^{g}
\end{gathered}
$$

Cabe ressaltar que uma desvantagem desse método é que consideramos a elasticidade exógena estimada $\alpha_{t y}$ como constante no tempo (Boiciuc, 2015). Para amenizar isso, os modelos estimados para a janela amostral menor usarão uma elasticidade diferente da estimada para toda a amostra.

O último passo é colocar o modelo $\mathrm{AB}$ em matrizes e estimar as funções impulsoresposta, já com os coeficientes estimados. A análise da função impulso-resposta é importante pois, de acordo com Çebi (2015), permite a avaliação da força, persistência e timing da resposta do produto a choques nas variáveis fiscais. Este artigo analisará as funções impulso-resposta do produto a choques nas variáveis fiscais discricionárias. Essas funções são obtidas a partir das matrizes A e B e a partir dos coeficientes estimados pelo procedimento descrito nesta seção. Conforme Giodano et al (2007), Jemec et al (2013), Restrepo (2020) e Mançellari (2011), a diagonal da matriz B é formada pelo desvio-padrão dos choques estruturais. Ressalta-se ainda que, de acordo com Lutkepohl (2005), são necessárias $2 K^{2}-1 / 2 K(K+1)$ restrições para que o sistema seja identificado, onde $K$ é o número de variáveis endógenas (3 no nosso caso), o que implica em 12 restrições.

Temos, de fato, 12 restrições: os coeficientes estimados exogenamente $\alpha_{g y}$ e $\alpha_{t y}$ e por variáveis instrumentais $\gamma_{y g}$ e $\gamma_{y t}$; os coeficientes $\beta_{g t}$ e $\beta_{t g}$ (o primeiro é dado como zero e o segundo é estimado por MQO); os dois coeficientes "zero" da matriz A, pois "não parece razoável considerar movimentos-surpresa entre as variáveis fiscais, que estão sob o 
Capítulo 1. Primeiro Artigo: A contribuição da política fiscal para a crise brasileira recente: uma análise 48 baseada em multiplicadores de despesas e receitas primárias do governo central no período 1997-2018

controle do governo", como dizem Peres e Ellery (2009); e os demais zeros da matriz B, porque assume-se que os choques estruturais são ortogonais entre eles a fim de recuperar os choques exógenos (Adams e Wong, 2018).

\subsection{Resultados}

\subsubsection{Multiplicadores fiscais estimados}

O modelo básico é estimado ${ }^{19,20}$ com o vetor de variáveis endógenas $y_{t}=\left[g_{t}, t_{t}, y_{t}\right]^{\prime}$, com $g_{t}$ como o logaritmo da despesa total primária, $t_{t}$ como o logaritmo da receita primária e $y_{t}$ é logaritmo do produto. Serão estimados modelos para a amostra inteira, que vai de 1997 a 2018; e para a amostra pré-crise, de 1997 a 2014 - até março, porque, segundo a CODACE, no relatório de datação dos ciclos econômicos, a recessão teve início no segundo trimestre de 2014. Essa estratégia de estimação para averiguar eventuais alterações no multiplicador durante a crise é similar à de Mathenson e Pereira (2016) e à de Deleidi

19 Os testes de estacionariedade, cointegração, seleção de lags, autocorrelação, heterocedasticidade e estabilidade dos modelos estimados podem ser disponibilizados sob solicitação. Realizamos dois importantes testes para autocorrelação residual, o Portmanteau e o do multiplicador de Lagrange (teste LM). Os p-valores altos indicam que a hipótese nula - de que não há autocorrelação residual no respectivo lag - não pode ser rejeitada. O teste de heterocedasticidade foi também realizado, considerando-se os termos cruzados, e aponta para a ausência deste problema. Realizamos o teste de estabilidade, que indica que as raízes do polinômio característico do VAR estão dentro do círculo unitário e, portanto, o sistema não é explosivo. Os testes para normalidade residual também foram feitos (skewness, kurtosis e Jarque Bera), mas a hipótese nula de que os resíduos são normalmente distribuídos é rejeitada. Apesar desse resultado, há evidências de que os resíduos sejam aproximadamente normais quando desenhamos seu histograma, como em Cattan (2017).

20 Vamos fazer um breve comentário acerca de um "teste de endogeneidade" apresentado em Deleidi et al (2019). Como os autores estimam o multiplicador de investimento público para vários países em um painel, existem alguns casos em que não há dado trimestral, apenas anual. Desta forma, para estimar para um número maior de países, os autores utilizam dados anuais. Para os países que possuem dados trimestrais, é realizado um teste de endogeneidade para verificar se o investimento público responde ao produto dentro de um ano: "In order to detect whether public investment is influenced by the output level, we follow a procedure similar to that suggested by Born and Muller (2012). More specifically, we use quarterly data to test whether annual government investment is exogenous by evaluating whether the rate of growth of public investment responds to the rate of growth of GDP within the year (Deleidi et al, 2019; p.14). Isto é feito por meio de uma regressão da taxa de crescimento (primeira-diferença da variável em $\log$ ) do gasto sobre a taxa de crescimento do produto. Em seguida, um teste de Wald é realizado para testar a significância conjunta. Fizemos uma adaptação deste teste para o nosso caso: utilizamos dados mensais para verificar se há resposta dentro de um trimestre. Estimamos uma regressão da taxa de crescimento do gasto (ou componente) sobre a taxa de crescimento do produto, considerando três defasagens (um trimestre) e sobre a própria taxa de crescimento do gasto (também com três defasagens). A seguir, o teste de Wald testa se coeficientes da taxa de crescimento do produto são conjuntamente estatisticamente significativos. Tal teste foi realizado para cada componente do gasto. De fato, os testes confirmam que podemos considerar o gasto (e componentes) como exógenos, de modo que ele não responde dentro de um trimestre e, logo, dentro de um mês. A única exceção foi o investimento público na amostra menor, que mostrou indício de endogeneidade dentro de um trimestre (mas não dentro de um mês, quando consideramos apenas uma defasagem na regressão) dado que estamos utilizando o exercício mensal, não consideramos problema. Para a receita, como é de se esperar, encontramos que é bastante responsiva dentro de um trimestre (a 1\% de significância) e mesmo dentro de um mês (a $5 \%$ de significância) -por isso neste caso há a necessidade do ajuste cíclico com a elasticidade da receita em relação ao produto. 
et al (2019) e conveniente, pois a amostra ficaria muito pequena se utilizássemos apenas os dados para o período 2014-2018. Os efeitos dinâmicos do gasto público podem ser analisados utilizando o SVAR tridimensional, substituindo a variável de despesa total por seus componentes, assim como faz Çebi (2015). Os SVAR serão estimados com as variáveis em primeira-diferença ${ }^{21}$, dado que as séries são não estacionárias. O número de lags é escolhido com base nos critérios de informação ${ }^{22}$ e no teste de autocorrelação LM (Matteo et al, 2018).

Os gráficos apresentados fornecem a resposta acumulada do produto a um choque de um desvio-padrão na despesa total primária (ou em seus componentes/ou na receita), com intervalo de confiança de um e de dois desvios-padrão, calculados por Monte Carlo. A escolha do intervalo das bandas não tem uma justificativa formal ${ }^{23}$, mas significativa parte da literatura fornece a significância estatística usando uma banda de um desvio-padrão ${ }^{24}$.

De acordo com Spilimbergo et al (2009), existem quatro tipos de multiplicador: a) multiplicador de impacto, para análise do impacto de curto prazo da política fiscal: $\frac{\Delta Y(t)}{\Delta G(t)}$; b) multiplicador de horizonte, para calcular o multiplicador em um dado período: $\frac{\Delta Y(t+n)}{\Delta G(t)}$; c) multiplicador de pico, que representa o maior valor no período: $\max \frac{\Delta Y(t+n)}{\Delta G(t)}$;

$\overline{21}$ Como não houve evidência robusta de cointegração, bem como nosso interesse principal está nas relações de mais curto prazo entre as variáveis tendo em vista nosso objetivo de avaliar o papel da política fiscal anticíclica, estimamos modelos VAR, com as variáveis em primeira-diferença de forma a evitar relações espúrias. Foram realizados os testes de estacionariedade aumentado de Dickey-Fuller, de Phillips e Perron e KPSS, incluindo apenas intercepto e incluindo intercepto e tendência. Os três testes foram considerados a critério de desempate. A conclusão é que as séries são integradas de ordem 1 (I(1)). No entanto, trabalhos como Tenhofen et al (2010), Giordano et al (2007), Perotti (2004), Jemec et al (2013), Coudret (2013), entre outros, utilizam as variáveis em nível - mesmo na presença de raiz unitária. O exercício em nível não ficou adequado, mesmo quando controlamos com tendência, apresentando indícios de regressão espúria. Assim, os exercícios utilizaram as séries em primeira-diferença. Utilizamos as funções impulso-resposta acumuladas de forma a obtermos as respostas em nível, as quais utilizamos para obter a elasticidade de uma variável em relação à outra e, assim, os multiplicadores.

22 Quando se utilizam conjuntamente vários métodos de informação, a literatura recomenda que se escolha aquela defasagem que a maioria dos métodos aponta como sendo mais adequado (Lopes et al, 2012). De um modo geral, dos cinco critérios utilizados, três indicaram o uso de 5 ou 6 lags, e dois apontaram para o uso de 1 ou 2 lags. A estimação com poucos lags, 1 ou 2, não apresentou robustez adequada do sistema, com fortes indícios de autocorrelação residual e heterocedasticidade. Além disso, é mais apropriado incluir 5 ou 6 lags, tendo em vista que um choque de política fiscal possui certa persistência ao longo do tempo, e o que queremos avaliar é o efeito da política fiscal ao longo de certo período de tempo. A inclusão dessas defasagens se mostrou relevante pelo teste de exclusão de lags em todos os modelos. Além disso, tais defasagens apresentaram significância estatística na equação do VAR para os itens de gasto que possuem maior persistência no que se refere ao seu efeito sobre o produto (benefícios sociais e investimento público). Assim, todos os modelos foram estimados com 5 ou 6 defasagens.

23 Ramey (2011) afirma: "Although this is common practice in the government spending literature, it has no theoretical justification. Some have appealed to Sims and Zha (1999) for using 68\% bands. However, there is no formal justification for this particular choice. It should be noted that most papers in the monetary literature use 95\% error bands" (Ramey, 2011, p. 11).

24 como Blanchard e Perotti (2002), Fatàs e Mihov (2011), Tenhofen et al (2010), Matteo et al (2018), Perotti (2007), Caldara e Kamps (2012), Çebi (2015), Mountford e Uhlig (2009), Bachmann e Sims (2012), Benetrix e Lane (2009), Corsetti et al (2012), Castro e Fernandez (2011), Castro (2003), Mançellari (2011), Borg (2014), Burriel et al (2010), Ford (2013), Coudret (2013), Pereira e Sagalés (2009), Izquierdo et al (2019), dentre outros. 
Capítulo 1. Primeiro Artigo: A contribuição da política fiscal para a crise brasileira recente: uma análise 50 baseada em multiplicadores de despesas e receitas primárias do governo central no período 1997-2018 d) multiplicador cumulativo, para um prazo mais longo: $\frac{\sum_{i=1}^{n} \Delta Y(t+i)}{\sum_{i=1}^{n} \Delta G(t+i)}$.

A importância de se calcular o multiplicador de impacto é que ele permite uma avaliação da política fiscal em termos de resposta imediata do produto a um choque na variável fiscal para lidar com uma crise, por exemplo. O multiplicador cumulativo, por sua vez, é importante para verificarmos o impacto de um choque discricionário aleatório, uma vez que a economia requer um tempo para absorver todo o choque inicial (Ilzetzki et al, 2013). O multiplicador cumulativo é igual à razão entre a resposta acumulada do produto e a resposta acumulada da variável que sofreu o choque e mede a mudança cumulativa no produto após uma mudança cumulativa no gasto do governo em um dado horizonte temporal (Lozano e Rodriguez, 2011; Borg, 2014; Burriel et al, 2010; Tenhofen et al, 2010; Restrepo, 2020). O multiplicador acumulado, também chamado de multiplicador integral, é ressaltado por Restrepo (2020), que refaz o estudo de Blanchard e Perotti (2002) com o objetivo de estimar, além do multiplicador de pico - já encontrado - o multiplicador integral. O autor ressalta que: "According to Ramey and Zubairy (2018), the cumulative multiplier may be a better representation when the effects of fiscal policy build over time" (Restrepo, 2020, p.9). O multiplicador acumulado é tipicamente maior que o de impacto e o de pico. É raramente reportado nos estudos, embora seja a medida mais apropriada, de acordo com Spilimbergo et al (2009).

Para chegar ao multiplicador, é necessário dividir a elasticidade pela participação média das despesas primárias (ou receitas primárias) totais no produto. Como as variáveis estão em logaritmo, as funções impulso resposta nos fornecem as elasticidades do produto (Y) em relação à variável que sofreu o choque $(\mathrm{X})$ :

$$
\xi_{Y, X}=\frac{\frac{\Delta Y}{Y}}{\frac{\Delta X}{X}}=\frac{\Delta Y}{Y} \frac{X}{\Delta X}=\frac{\Delta Y}{\Delta X} \frac{X}{Y}
$$

Conforme Pires (2014), como $\frac{\Delta Y}{\Delta X}$ é a definição do multiplicador, que reflete a mudança na variável produto dado o aumento de uma unidade na variável fiscal, tem-se:

$$
\frac{\Delta Y}{\Delta X}=\frac{\xi_{Y, X}}{\frac{X}{Y}}
$$

A Tabela 1 a seguir sumariza os nossos principais resultados para os multiplicadores, com os valores para as amostras pré-crise (1997-2014) e amostra inteira (1997-2018).

O gráfico da Figura 5 apresenta a função impulso-resposta do produto a choques na variável de despesas primárias totais. O multiplicador de impacto é estatisticamente significante, o que demonstra que o impacto de curto prazo da política fiscal é significativo. Tanto para a amostra completa como para a amostra pré-crise, notamos que as respostas são estatisticamente significantes na maioria dos períodos quando consideramos um intervalo de um desvio-padrão. Para o cômputo dos multiplicadores, calculamos a participação média das despesas (e de cada tipo de despesa primária) no produto, em acordo com a 


\begin{tabular}{|l|l|l|l|}
\hline Tipo de Gasto & $\begin{array}{l}\text { Multiplicador } \\
\text { impacto } \\
\mathrm{t}=1)\end{array}$ & $\begin{array}{l}\text { Multiplicador de pico (o } \\
\text { respectivo período em que } \\
\text { ocorre é indicado por "t") }\end{array}$ & $\begin{array}{l}\text { Multiplicador acu- } \\
\text { mulado (15 ou 25 } \\
\text { meses a depender } \\
\text { da persistência })\end{array}$ \\
\hline $\begin{array}{l}\text { Despesa primária } \\
\text { total }\end{array}$ & $0.33 / 0.375$ & $0.33(\mathrm{t}=1) / 0.375(\mathrm{t}=1)$ & $0.58 / 0.59$ \\
\hline Receita primária & $-0.15 /-0.37$ & $-0.0129(\mathrm{t}=6) / 0.0784(\mathrm{t}=8)$ & $-0.21 /-0.18$ \\
\hline $\begin{array}{l}\text { Investimento pú- } \\
\text { blico }\end{array}$ & $1.5 / 1.4$ & $1.5(\mathrm{t}=1) / 2.4(\mathrm{t}=7)$ & $1.42 / 3.6$ \\
\hline Benefícios sociais & $0.7 / 0.77$ & $1.2(\mathrm{t}=2) / 1.25(\mathrm{t}=5)$ & $1.9 / 2.9$ \\
\hline Pessoal & $0.01 / 0.1$ & $0.088(\mathrm{t}=2) / 0.1(\mathrm{t}=1)$ & $-0.7 /-1$ \\
\hline Subsídios & $-0.08 / 0.14$ & $0.114(\mathrm{t}=4) / 0.176(\mathrm{t}=7)$ & $-0.49 / 0.057$ \\
\hline Demais despesas & $0.34 / 0.38$ & $0.34(\mathrm{t}=1) / 0.38(\mathrm{t}=1)$ & $-0.07 /-0.008$ \\
\hline
\end{tabular}

Tabela 1 - Multiplicadores fiscais estimados pré-crise / amostra inteira, respectivamente.

equação 1.18. O resultado está disponível na Tabela 1. O multiplicador cumulativo de longo prazo foi calculado para um determinado período de acordo com a persistência de cada tipo de despesa ${ }^{25}$. Ressalta-se que não há muita diferença para os dois períodos no valor do multiplicador da despesa primária total; nem no padrão da função impulso-resposta.

Figura 5 - Resposta acumulada do produto a um choque nas despesas totais

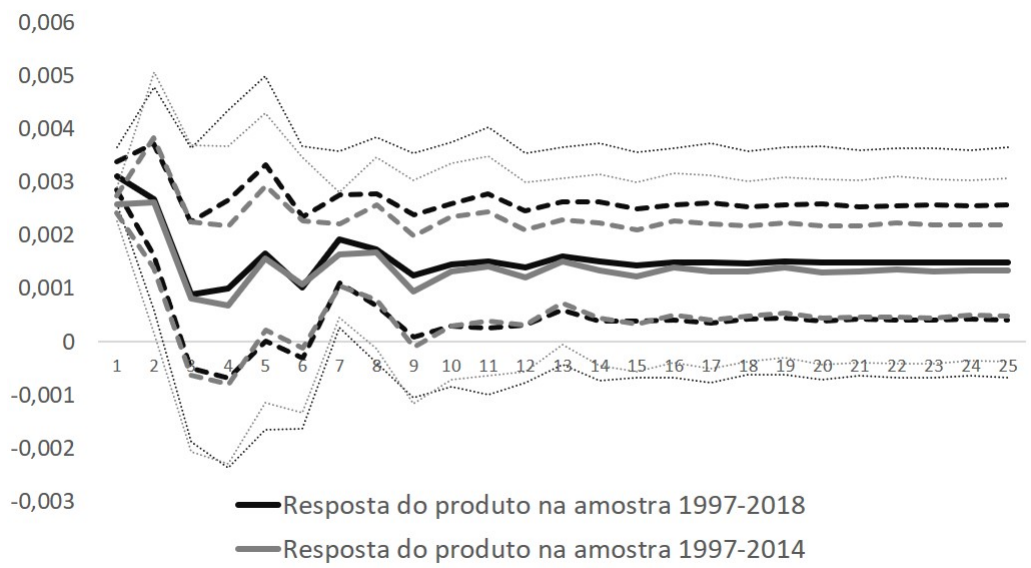

Fonte: Elaboração própria a partir dos dados de Orair e Gobetti (2017a) e do Banco Central. As linhas tracejada e pontilhada correspondem, respectivamente, ao intervalo de um e de dois desvios-padrão, isto é, níveis de confiança de $68 \%$ e $95 \%$.

Com relação à resposta do produto ao investimento público, quase todas as respostas são estatisticamente diferentes de zero para a amostra completa a $95 \%$ de confiança, exceto

$\overline{25}$ Por exemplo, para o caso da despesa primária total foi escolhido um período de 15 meses após o choque inicial. A justificativa para a escolha de 15 períodos para o cálculo do multiplicador cumulativo apoia-se em Garcia et al (2013): "The long-run multiplier is defined as the cumulative multiplier when $J->\infty$, but in practice is used the number of periods needed for the multiplier to stabilize at its long-run value. In this paper, 24 periods are used as all multipliers stabilize after that number of quarters" (Garcia et al, 2013, p.11). 
Capítulo 1. Primeiro Artigo: A contribuição da política fiscal para a crise brasileira recente: uma análise 52 baseada em multiplicadores de despesas e receitas primárias do governo central no período 1997-2018

Figura 6 - Resposta acumulada do produto a choque nos investimentos públicos

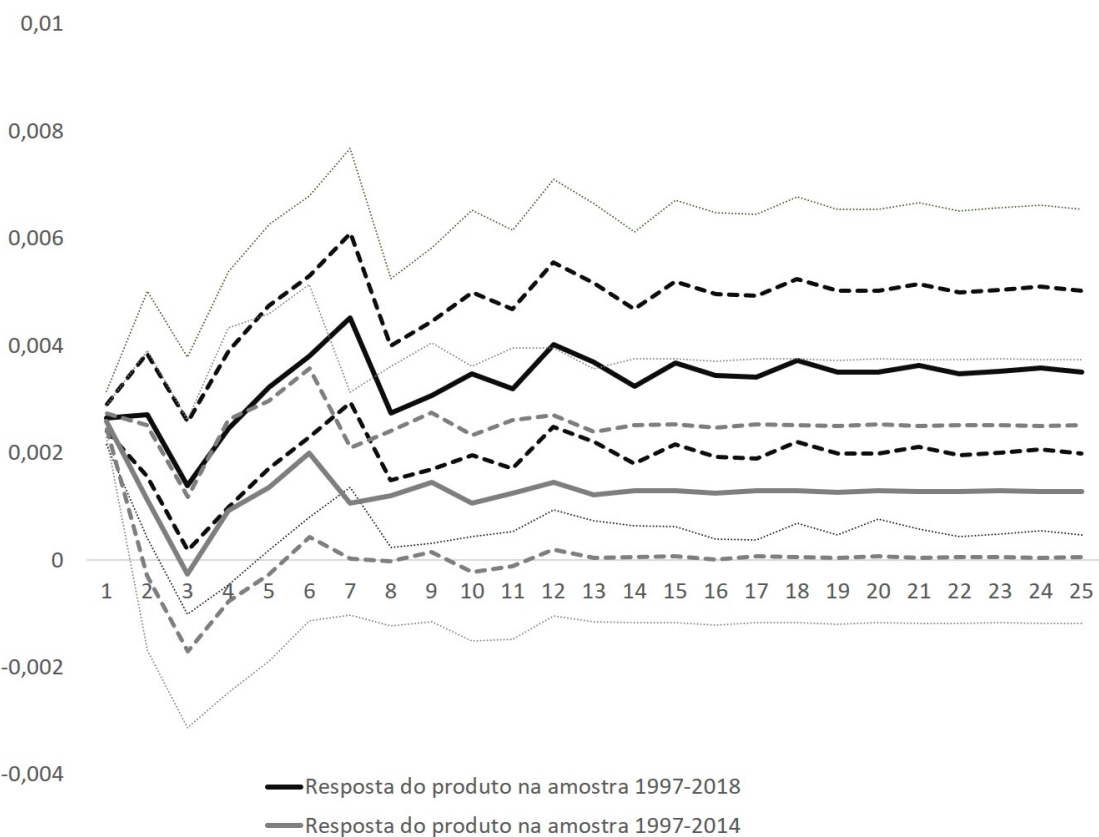

Fonte: Elaboração própria a partir dos dados de Orair e Gobetti (2017a) e do Banco Central. As linhas tracejada e pontilhada correspondem, respectivamente, ao intervalo de um e de dois desvios-padrão, isto é, níveis de confiança de $68 \%$ e $95 \%$.

para o terceiro e quarto meses após o choque, como pode ser visto no gráfico da Figura $6^{26}$. O multiplicador de impacto é considerado alto (maior que a unidade): 1.4. Já o cumulativo, após 25 meses, vale em torno de 3.6, um valor bastante alto: a cada um real gasto em investimento público, obtêm-se como renda gerada 3.6 reais em um período de 25 meses. Destacamos que o cumulativo foi calculado para um período maior tendo em vista a maior persistência do multiplicador de investimento público - o que é encontrado, em geral, na literatura. O multiplicador de pico do investimento para a amostra inteira, que ocorre no período 7 , chega a 2.4 , aproximadamente.

Para a amostra pré-crise, embora o multiplicador de impacto seja um pouco maior (1.5), o acumulado ao longo de 25 períodos após o choque inicial vale 1.42 - valor bem menor que o observado na amostra completa (3.6) para o mesmo número de períodos, o que também indica uma diferença importante desse tipo de multiplicador para o período que engloba a crise de 2014-2017. Em termos percentuais, portanto, há um aumento de quase

$\overline{26}$ O exercício para o investimento público foi realizado com a inclusão de algumas dummies. Foram utilizadas dummies que capturassem outliers e períodos específicos da economia brasileira: foram incluídas as dummies descritas no apêndice B, como dumdate99, dum08, dummy08, uma dummy para capturar os efeitos da crise também em 2009; bem como uma tendência; além de uma dummy que capturasse o último mês e os primeiros dois meses de cada ano, que apresentaram variações mais bruscas, mesmo na série já dessazonalizada. Outros controles para outliers foram utilizados (como para 2002, 2010, 2013). O exercício sem as dummies mudou muito pouco os valores da função impulso-resposta. No entanto, o exercício com a inclusão destas variáveis melhorou a significância. Além disso, as dummies se mostraram significantes a $10 \%$ ou a $5 \%$. Logo, os resultados para o investimento público foram robustos à inclusão de tendência e de dummies, tanto na amostra completa quanto na menor. 
154\% no multiplicador acumulado de investimento público na amostra completa em relação à amostra pré-crise. A significância da resposta da amostra pré-crise é menor: a função impulso-resposta acumulada é significante a $68 \%$ na maioria dos períodos, mas não é a 95\%. Já para a amostra inteira há significância mesmo considerando um intervalo de dois desvios-padrão (ao nível de 95\%). Os intervalos de confiança ficam separados se, ao invés de considerarmos a banda usual na literatura, de um desvio-padrão, considerarmos uma banda de 0.8 desvios-padrão. Neste caso, os intervalos de confiança ficam separados a partir do sétimo período e a diferença de resposta entre as amostras torna-se estatisticamente significante, ao nível mencionado.

O Gráfico da Figura 7 apresenta a resposta do produto a choques de um desvio padrão nos benefícios sociais ${ }^{27}$. A resposta é estatisticamente significante em todos os períodos para a amostra completa. Para a amostra pré-crise, a resposta é também significante considerando um intervalo de um desvio-padrão. Embora os multiplicadores de impacto para os benefícios sociais sejam próximos, o multiplicador cumulativo ao final de 25 meses é de 2.914, o que demonstra certa persistência, para o caso da amostra completa; e é bem menor na amostra pré-crise, de 1.9. Isso indica algo que percebemos ao olhar para o gráfico abaixo: a resposta acumulada do produto aos benefícios sociais é bem maior no caso da amostra inteira. Similarmente ao caso do investimento público, os intervalos de confiança ficam separados se considerarmos, ao invés de uma banda de um desvio-padrão, como é usual na literatura, uma banda de 0.8 desvios-padrão, no acumulado da função 28 . Mas reforça-se que a resposta do produto é estatisticamente significante para o nível de 95\% para quase todos os períodos no caso da amostra completa - isso não ocorre para a amostra pré-crise. O multiplicador acumulado cresceu na amostra completa em relação à amostra pré-crise cerca de 53\%, um aumento bem expressivo apesar de ser menor que o verificado para os investimentos públicos. Portanto, há evidência de que o multiplicador seja mais alto na amostra que inclui a crise para os benefícios sociais e para o investimento público.

Quanto à despesa com pessoal, subsídios, demais despesas e à receita primária, em geral apenas o multiplicador de impacto é estatisticamente significante. Os demais períodos, entretanto, não têm significância, tanto para a amostra completa como para a amostra pré-crise. Ainda assim, como afirma Coudret (2013), mesmo que não haja significância

$\overline{27}$ Assim como para o investimento público, para este exercício foi estimada uma versão com dummies para controle de outliers e de períodos específicos. A estimação mudou de forma muito marginal os valores das funções impulso-resposta, e não alterou os valores dos multiplicadores. A significância do modelo, porém, ficou um pouco melhor. Além disso, as dummies se mostraram significantes, sobretudo as variáveis para controle da crise de 2008/2009 (nas duas amostras). Por este motivo, o modelo foi estimado com as dummies, para ambas as amostras. No entanto, sua ausência não alterou os valores dos multiplicadores. Para as despesas com pessoal, subsídios, demais despesas e receitas, as funções impulso-resposta mudaram pouco e continuaram a ser não significantes com a inclusão de dummies no exercício. Assim, optou-se por manter a estimação sem essas variáveis para esses casos.

28 Isto também vale para o exercício trimestral. 
Capítulo 1. Primeiro Artigo: A contribuição da política fiscal para a crise brasileira recente: uma análise 54 baseada em multiplicadores de despesas e receitas primárias do governo central no período 1997-2018

Figura 7 - Resposta acumulada do produto a choque nos Benefícios Sociais

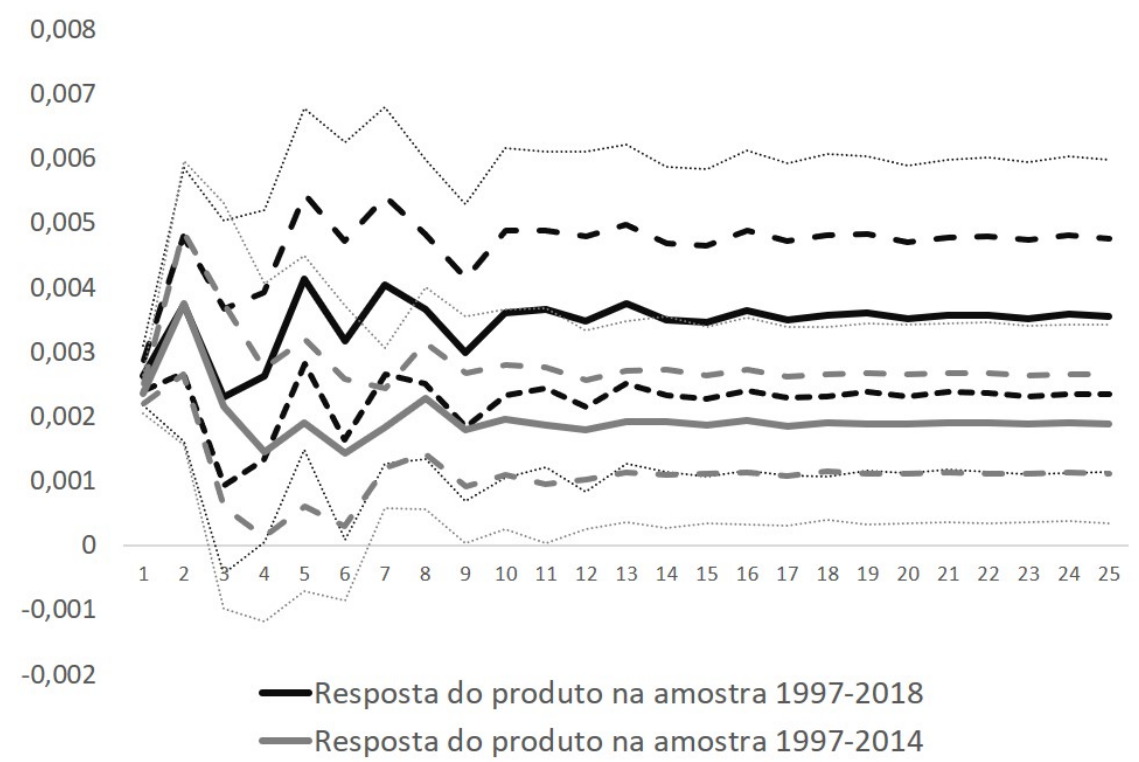

Fonte: Elaboração própria a partir dos dados de Orair e Gobetti (2017a) e do Banco Central. As linhas tracejada e pontilhada correspondem, respectivamente, ao intervalo de um e de dois desvios-padrão, isto é, níveis de confiança de $68 \%$ e $95 \%$.

na função impulso-resposta - algo que é comum em modelos VAR - o modelo ainda pode ser útil para nos informar ao menos os prováveis sinais dos parâmetros (Kennedy, 2002). Destaca-se que, para esses grupos de despesas, não há tanta diferença na função impulso-resposta entre as duas amostras (exceto no impacto), como foi observado no caso das despesas com benefícios sociais e investimentos públicos. O gráfico da Figura 8 ilustra a função impulso-resposta para essas despesas e para o caso da receita. Como antes, a linha preta representa a resposta na amostra inteira (1997-2018) e a cinza na amostra pré-crise (1997-2014).

Nas estimações para toda a amostra, nossos resultados reportados na Tabela 1 e nos gráficos sugerem que os componentes de investimento público e de benefícios sociais possuem multiplicadores de magnitude mais elevada e com maior persistência, enquanto que pessoal, demais despesas e subsídios têm multiplicador de impacto positivo e estatisticamente significante para amostra inteira, mas não no longo prazo, captado pela função impulso-resposta acumulada. Notamos que, de fato, existem diferenças entre os multiplicadores na amostra inteira e na amostra pré-crise, mas não para todo tipo de gasto. As funções impulso-resposta e os multiplicadores acumulados para o caso dos investimentos públicos e benefícios sociais na amostra inteira são bastante diferentes - são maiores e mais persistentes - que na amostra pré-crise. Note-se que esses multiplicadores durante a crise podem ser ainda maiores, dado que estamos apenas considerando a diferença entre a amostra pré-crise e a amostra completa.

Nossos resultados reforçam, portanto, os encontrados por Orair et al $(2016)^{29}$,

29 No caso do estudo de Orair et al (2016), o componente do pessoal possui multiplicador elevado na 
Figura 8 - Resposta do produto às despesas com pessoal, subsídios, demais despesas e à receita primária
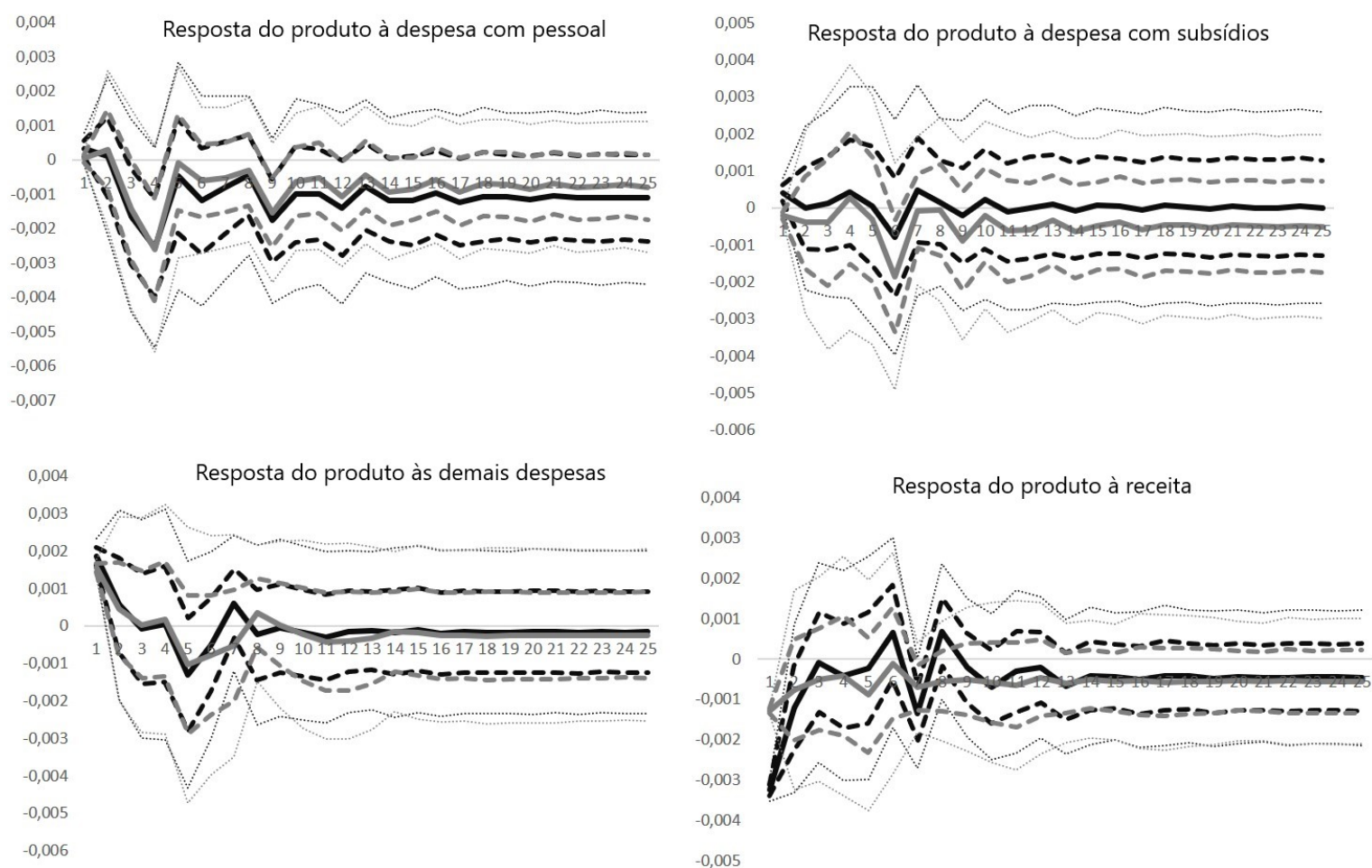

Fonte: Elaboração própria a partir dos dados de Orair e Gobetti (2017a) e do Banco Central. As linhas tracejada e pontilhada correspondem, respectivamente, ao intervalo de um e de dois desvios-padrão, isto é, níveis de confiança de $68 \%$ e $95 \%$.

bem como os de Pires (2011), que sustenta que o investimento público possui efeito um pouco maior e mais persistente sobre o produto em relação ao consumo do governo, com multiplicadores de 1.23 e 0.99, respectivamente. Já Pires (2014) encontra multiplicadores entre 1.4 e 1.7 para o investimento público e multiplicadores não significativos para o consumo do governo. No caso deste estudo, na amostra inteira, o multiplicador de impacto para os investimentos públicos foi de 1.4; e para os gastos de consumo (pessoal e demais despesas) os multiplicadores foram estatisticamente significantes somente no primeiro mês - resultados parecidos com os encontrados por Pires.

Quanto ao impacto das receitas no produto, os resultados encontrados estão de acordo com a literatura em geral: geralmente apenas o de impacto é significativo. Encontramos um multiplicador negativo, que é esperado, tendo em vista que um choque positivo nas receitas deve diminuir a renda disponível para consumo e investimento,

recessão, juntamente com investimento público e benefícios sociais. No entanto, deve-se lembrar que o presente trabalho apenas engloba o governo federal, enquanto Orair et al (2016) tratam das três esferas de governo. De acordo com os autores: "Os resultados corresponderam em geral ao esperado segundo a literatura empírica internacional, sobretudo para os investimentos, mas surpreenderam em relação ao patamar do multiplicador das despesas de pessoal, acima da unidade e um pouco inferior ao dos benefícios sociais. Como hipótese, atribuímos isso ao fato de que a despesa de pessoal tenha crescido principalmente na esfera municipal, onde os salários são mais baixos [...]" (Orair et al, 2016, p.56). 
Capítulo 1. Primeiro Artigo: A contribuição da política fiscal para a crise brasileira recente: uma análise 56 baseada em multiplicadores de despesas e receitas primárias do governo central no período 1997-2018

impactando o produto. Nossas estimativas estão próximas às de Peres (2006) e Pires (2014), que encontram, respectivamente, - 0.2 e -0.28. Ressalta-se que esse multiplicador é bem menor - sobretudo em termos acumulados - que, por exemplo, o de investimentos públicos e o de benefícios sociais, o que pode sugerir que os efeitos de estímulo ao produto via redução de impostos são bem menores do que os efeitos de políticas que priorizem os dois tipos de gastos mencionados. O presente estudo difere, nesse sentido, do de Matheson e Pereira (2016), que acham um alto multiplicador de receita em termos acumulados de magnitude comparável ao nosso multiplicador acumulado estimado para os benefícios sociais. Além disso, os autores encontram um multiplicador acumulado próximo de zero para a despesa ${ }^{30}$.

Nossos resultados também diferem dos encontrados por Matheson e Pereira (2016) no que diz respeito à possível dependência do multiplicador fiscal em relação ao ciclo econômico. Este estudo encontrou que o multiplicador fiscal de pico da despesa total primária diminuiu na amostra inteira, em relação à amostra pré-crise de 2008, enquanto o multiplicador associado à receita manteve-se estável ${ }^{31}$. Nossos resultados estimados para a crise recente revelam que, embora o multiplicador fiscal da despesa total não tenha se alterado entre a amostra pré-crise e a amostra completa, há dois tipos de despesas que possuem a particularidade de ter um maior efeito multiplicador durante a recessão, em

30 Os autores sugerem algumas causas para esse resultado: "First, in the context of a binding primary surplus target, surprise increases in government spending in a given quarter will likely generate consolidation measures later on. Second, the nature of spending increases matter. Public investment, which typically entails larger and more persistent multipliers, is exceptionally low in Brazil; thus shocks to St [spending] may be dominated by current spending, particularly transfers which have a short lived impact (working as a demand boost which fuels inflation and expectations of future monetary tightening)"(Matheson e Pereira, 2016, p. 7). Aqui temos outro contraste com nosso estudo, que estimou altos multiplicadores para as despesas associadas às transferências/benefícios sociais.

31 O estudo, além disso, estima multiplicadores associados ao crédito público, o qual também diminuiu na amostra completa. A conclusão dos autores é a seguinte: "this may be a consequence of inefficiencies in public spending increases (mostly pensions), impact on debt levels (traditional crowding out effect and expectation of a sharp adjustment need in the future), and possibly the crowding out of private bank activity (which market share declined continuously since 2011)" (Matheson e Pereira, 2016, p.9). Resultados parecidos foram obtidos por Mendonça et al (2016), que encontraram multiplicadores de despesas totais menores para a amostra completa, em relação à amostra pré-crise de 2008. A explicação fornecida por Mendonça et al (2016) é parecida com a de Matheson e Pereira (2016): "First, as highlighted earlier, the public debt level creates a downward bias in the multipliers, while the low degree of the trade openness creates an upward bias [...]. Conversely, in Brazil, the context of the high interest rate intensifies the impact of government expenditures on GDP growth, although the specifications of the SVAR with monetary policy variables are not robust" (Mendonça et al, 2016, p.26). Ainda, os autores atribuem o baixo valor do multiplicador à combinação de um elevado nível do gasto total em relação ao PIB com sua tendência crescente, devido a transferências sociais de caráter obrigatório: "Therefore, protected by the Federal Constitution and laws, a combination of a growing number of beneficiaries, a sizable correction in the value of the benefits, and enlarged income transfer programs can be considered relevant factors to explain the upward trend in the government expenditures. In our perspective, the counter-cyclical fiscal policies that were put in practice recently would add some impetus to such tendencies, so the unexpected fiscal shock caused by the government in line with countercyclical policies would influence the output less than expected" (Mendonça et al, 2016, p.28). Vale lembrar que tanto Matheson e Pereira (2016) como Mendonça et al (2016) não desagregam os componentes da despesa total para estimar o multiplicador fiscal de cada um deles. 
termos acumulados (apesar de, no impacto, seus efeitos são parecidos) - daí a importância da desagregação das despesas primárias. No entanto, cabe qualificar que Matheson e Pereira (2016) investigaram a mudança de efeito multiplicador para o caso da crise de 2008/2009, que foi muito diferente da crise mais recente, iniciada em 2014, nosso objeto aqui. Enquanto na crise de 2008 o produto caiu por dois trimestres consecutivos, e já no segundo trimestre de 2009 a economia voltou a crescer (Carvalho, 2018) ${ }^{32}$; a crise mais recente foi caracterizada por ser uma das mais profundas recessões, com queda do produto real entre 2014 e 2016, bem como pela mais lenta recuperação de nossa história.

Além disso, frisamos a relevância da análise do efeito multiplicador ao longo do tempo, e não apenas no período de pico (ou de impacto). Restrepo (2020), por exemplo, argumenta que as conclusões acerca do multiplicador fiscal são bastante sensíveis a depender da definição utilizada. O artigo replica o estudo de Blanchard e Perotti (2002) (que utiliza como definição o multiplicador de pico), realizado para a economia norte-americana no período 1960 a 1997, e chega à conclusão de que o multiplicador de gasto primário é, em termos acumulados, menor que o de pico. Já o multiplicador acumulado em oito trimestres para a receita é muito maior que o multiplicador em termos de pico. O autor defende a importância de se estimar o multiplicador acumulado de forma a se avaliar os efeitos da política fiscal ao longo do tempo, e não apenas em determinado ponto temporal.

\subsubsection{Aspectos teóricos e variáveis de controle}

Os resultados explorados neste artigo sugerem a importância das condições de demanda agregada na determinação do produto, tendo em vista que encontramos evidências de que um estímulo de demanda por meio do gasto público - via investimentos públicos e gastos sociais - tem o poder de gerar renda, especialmente em situação de recessão. Nesta lógica, destacam-se dois autores que nos dão suporte teórico. Para Kalecki (1942), a distribuição de renda é elemento central. Em seu arcabouço teórico, a propensão marginal a consumir dos salários é superior à dos lucros. A distribuição de renda entre capitalistas e trabalhadores torna-se variável fundamental que influencia diretamente o consumo e o investimento.

Keynes (1937) explica que, dada a propensão marginal a consumir e as condições para investir em um cenário de incerteza marcado por decisões cruciais, não há razão para que o nível de emprego seja igual ao nível de pleno emprego. Neste contexto, o princípio da demanda efetiva parte da ideia de que as condições de demanda determinam o produto. Como o emprego dos fatores de produção não segue a lógica neoclássica segundo a qual a distribuição é dada pela produtividade marginal dos fatores de produção, a distribuição de renda torna-se variável importante na determinação da renda. A propensão a consumir

32 Carvalho (2018) pontua que parte desse bom desempenho de recuperação pode ser atribuída a políticas que já vinham sendo implementadas antes da crise, como aumento das transferências sociais, no salário mínimo e nos investimentos públicos. 
Capítulo 1. Primeiro Artigo: A contribuição da política fiscal para a crise brasileira recente: uma análise 58 baseada em multiplicadores de despesas e receitas primárias do governo central no período 1997-2018

média e o investimento (acumulação de capital) determinam, conjuntamente, o nível de emprego.

Nossos resultados estão em consonância com as teorias desenvolvidas a partir da existência de capacidade ociosa, em que a demanda agregada assume papel fundamental no crescimento econômico. O investimento público possui um alto efeito multiplicador, seja em cenário de crise ou não (porém sobretudo na recessão), e poderia atuar de forma a incentivar o investimento privado, sendo complementar a ele, e não concorrente. Similarmente, a distribuição de renda para classes com maior propensão a consumir por meio do gasto com os benefícios sociais conferem dinâmica à economia, especialmente em situações de insuficiência de demanda. Ao dinamizar o consumo, o investimento é estimulado porque seu principal determinante é o próprio nível de atividade econômica. A renda gerada por esses gastos por meio do multiplicador ajuda a suprir a insuficiência de demanda em um cenário de crise, estimulando o processo produtivo e induzindo o consumo das famílias e o investimento. Em Kalecki (1943), seu conhecido artigo "Political aspects of full employment", há uma explícita defesa da importância desses dois tipos de gastos públicos, o investimento público e o gasto relacionado ao subsídio do consumo em massa, na condução de uma política econômica cujo objetivo é o aumento do emprego e renda:

"If the Government undertakes public investment (e.g. builds schools, hospitals, and highways) or subsidises mass consumption (by family allowances, reduction of indirect taxation, or subsidies to keep down the prices of necessities), if, moreover, this expenditure is financed by borrowing and not by taxation (which could affect adversely private investment and consumption), the effective demand for goods and services may be increased up to a point where full employment is achieved. Such Government expenditure increases employment, be it noted, not only directly but indirectly as well, since the higher incomes caused by it result in a secondary increase in demand for consumption and investment goods". (Kalecki, 1943, p.322).

Note que, ao falar de efeitos indiretos, Kalecki (1943) trata dos efeitos multiplicadores desses dois tipos de gasto em particular.

O princípio da demanda efetiva é a base de modelos Pós-Keynesianos, cujo objeto de estudo é analisar questões macroeconômicas em um cenário de subutilização da capacidade instalada. Especialmente os modelos denominados Neo-Kaleckianos, cujo desenvolvimento na literatura foi bastante proeminente nos anos 1980 e 1990, abordam o crescimento econômico liderado pela demanda sob o ponto de vista da avaliação do impacto da distribuição funcional da renda sobre a demanda efetiva em economias com subutilização da capacidade instalada e competição imperfeita (Amadeo, 1986; Taylor, 1985; Bhaduri e Marglin, 1990). 
Lavoie (2014) resume o funcionamento desses modelos propondo quatro aspectos fundamentais: 1) o investimento deve depender do grau de utilização da capacidade instalada; 2) os preços são definidos exogenamente como uma margem (mark up) sobre o custo unitário de produção, refletindo uma estrutura oligopolista da economia. A partir da definição do nível de preços, define-se, por consequência, a distribuição funcional da renda de maneira exógena; 3) a propensão marginal a consumir associada aos salários é maior que a dos lucros; 4) o grau de utilização da capacidade instalada deve ser menor que a unidade (deve haver capacidade ociosa, não havendo restrição pelo lado da oferta).

Tendo em vista essas informações, o modelo que utilizamos como plano de fundo é baseado em um arcabouço teórico que leva em consideração a insuficiência de demanda efetiva e a existência de capacidade ociosa na economia. Uma observação importante é que o nível de inferência dos resultados explorados neste estudo é limitado. Diversos fatores afetam o PIB além da política fiscal. Do ponto de vista da análise dos multiplicadores, porém, encontramos que os gastos com benefícios sociais e com investimento público são importantes fatores responsáveis por gerar emprego e renda, especialmente em períodos de recessão. Para amenizar um pouco esse alcance limitado, propomos alguns controles econométricos escolhidos à luz do que ocorreu na economia brasileira, bem como do que nosso arcabouço teórico sugere.

Foram feitas algumas extensões dos exercícios da seção anterior de forma a endereçar um possível problema de variável omitida, com a inclusão de variáveis de controle. Essas variáveis foram escolhidas de forma a considerar quais fatores poderiam afetar o produto, além da política fiscal, dentro de um arcabouço de modelos de crescimento neo-Kaleckianos; e também do ponto de vista do que ocorreu na economia brasileira durante o período estudado. Como o pilar de tais modelos é a questão distributiva, e sua relação com o crescimento econômico, sua aplicação no contexto deste artigo é adequada. Cada componente da demanda agregada total será considerado para que se justifique a influência destas variáveis no produto.

Para o consumo, o arcabouço teórico neo-Kaleckiano o considera função da renda corrente e da propensão a consumir. Neste contexto, a distribuição de renda assume papel central, tendo em vista as diferentes propensões a consumir dos trabalhadores e dos capitalistas. Carvalho e Rugitsky (2015) apontam para duas principais extensões de tal formulação. A primeira leva em conta a distribuição de renda pessoal: trabalhadores que possuem menores salários têm maior propensão a consumir. Desta forma, uma distribuição favorável a esses trabalhadores possui impacto positivo na propensão média a consumir (Carvalho e Rezai, 2015). A segunda extensão leva em conta o papel do crédito. A expansão do crédito - sobretudo entre 2003 e 2009 - contribuiu para a inclusão financeira da base da pirâmide e funcionou como uma alavanca para o consumo e para a demanda agregada, ao menos no curto prazo. Isto porque a um prazo mais longo, deve haver um efeito concentrador 
Capítulo 1. Primeiro Artigo: A contribuição da política fiscal para a crise brasileira recente: uma análise 60 baseada em multiplicadores de despesas e receitas primárias do governo central no período 1997-2018

de renda pela via do fluxo de pagamento de juros da classe de maior propensão a consumir - os trabalhadores - para os capitalistas, cuja propensão a poupar é maior. Isto impacta negativamente na demanda agregada e, consequentemente, há efeitos estagnacionistas. Portanto, as políticas distributivas e de acesso ao crédito tiveram grande relevância na economia brasileira nos anos 2000. Isto será levado em conta em nosso modelo teórico do Capítulo 3.

Além disso, consideraremos os fatores que afetam o investimento e a acumulação de

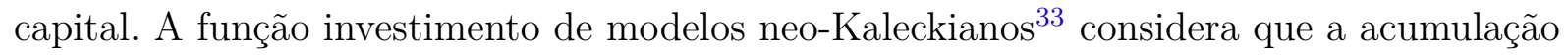
de capital depende positivamente de um termo exógeno - que reflete o otimismo das firmas - do grau de utilização da capacidade instalada e da taxa de lucro. Neste contexto, o câmbio é uma variável relevante. Uma desvalorização cambial, por exemplo, deve afetar o investimento por meio de três canais, conforme explicitam Carvalho e Rugitsky (2015): deve haver aumento das exportações líquidas e, consequentemente, maior grau de utilização; dada a menor competitividade externa com a queda das importações, as firmas ajustam seus mark ups e elevam a participação dos lucros na renda e as margens de lucro; há diminuição do consumo e do grau de utilização pela via do efeito negativo nos salários reais.

Em particular, o estudo econométrico de Dos Santos et al (2016) revela que o investimento no Brasil, ou FBCF (formação bruta de capital fixo) em máquinas e equipamentos, depende da taxa de câmbio real e dos preços de commodities ${ }^{34}$. Os autores encontraram que uma desvalorização cambial desestimula o investimento, ao invés de estimulá-lo por meio da maior demanda externa. Em Carvalho e Rugitsky (2015) há uma possível explicação dentro do arcabouço neo-Kaleckiano: o efeito de desvalorização cambial sobre os salários reais deprime o consumo e diminui o grau de utilização - este efeito seria maior que o efeito positivo sobre o grau de utilização gerado pela demanda externa e por maiores taxas de lucro e ganhos de competitividade. Há outras explicações, como o encarecimento de insumos importados, o efeito da restrição externa nas firmas que possuem dívida em moeda estrangeira, a possibilidade de as firmas aumentarem as margens de lucro sem contrapartida de investimento, a baixa elasticidade-preço dos produtos primários exportados e a dependência de importações que não possuem equivalente nacional (Carvalho e Rugitsky, 2015; Dos Santos et al, 2016). Desta forma, incluiremos a taxa de câmbio como controle nos exercícios.

Já o efeito do preço das commodities sobre a formação bruta de capital fixo -

33 Esta função investimento é chamada na literatura de Kalecki-Steindl.

$34 \mathrm{O}$ estudo também revela que o investimento depende positivamente da FBCF do governo, sugerindo que o investimento público possui caráter complementar, e não concorrente, ao investimento privado. Uma observação adicional importante é que Dos Santos et al (2016) diferencia o investimento total em FBCF em máquinas e equipamentos e em construções. O primeiro é mais reativo ao ambiente e ciclo econômicos. Já o segundo tipo apresenta maior estabilidade devido à maior participação das famílias e do governo. 
encontrado em Dos Santos et al (2016) - é positivo. Carvalho e Rugistky (2015) apontam para duas explicações: 1) há um estímulo à parte autônoma do investimento porque os altos preços de commodities animam o espírito animal ao sinalizarem um crescimento da demanda externa por exportações; 2) o aumento de preço das commodities seria capaz de elevar o grau de utilização e a taxa de lucro das firmas, estimulando o investimento em vários setores, dada a importância dos produtos primários na estrutura produtiva brasileira. Ademais, o aumento desses preços alivia a restrição externa do fluxo de caixa individual das firmas ao aumentar o fluxo de divisas estrangeiras para o país.

Uma das interpretações da aceleração do crescimento da economia brasileira nos anos 2000 está ligada ao cenário externo. Em especial, a demanda chinesa por exportações brasileiras de commodities teria ajudado o país a alcançar altas taxas de crescimento do produto. Tal impulso de demanda é visto no índice de preços de commodities, obtido do Fundo Monetário Internacional ${ }^{35}$ : os preços começaram a subir de forma significativa a partir de 2002, como indica o gráfico da Figura 12, apresentado no Apêndice A.

Dada a importância do cenário internacional para explicar a dinâmica da economia brasileira, tanto no período de boom de commodities - o qual foi responsável por parte do crescimento econômico brasileiro nos anos 2000 - quanto no período posterior, sobretudo a partir de 2011, cujo cenário externo não favorável atuou de forma negativa na economia brasileira (Borges, 2017; Carvalho, 2018), foi colocada uma variável de controle que expressasse o preço das commodities. A justificativa teórica da inclusão desta variável, bem como da taxa de câmbio, como controle no exercício econométrico, está relacionada à sua influência na dinâmica do produto por meio de seus efeitos acima mencionados sobre o investimento e o consumo.

Outra variável de controle testada foi da taxa de juros, de forma a contemplar a política monetária. Sua importância teórica em modelos neo-Kaleckianos está relacionada ao efeito de redistribuição de renda entre classes - como é bastante enfatizado em modelos que incorporam endividamento das famílias - e também pela via do impacto direto sobre o investimento ${ }^{36}$.

35 Trata-se da variável "All Commodity Price Index, $2016=100$, includes both Fuel and Non-Fuel Price Indices", obtida do FMI.

36 Em Hein (1999) e Hein (2010), por exemplo, a taxa de juros impacta a demanda agregada por meio de redistribuição de renda entre classes e por meio da dependência do investimento em relaçãa ao custo do crédito. Em Hein (1999), essa redistribuição de renda é alterada quando há uma alteração na taxa básica de juros, fixada pelo Banco Central, e ocorre entre capitalistas produtivos e financeiros e, também, entre capitalistas e trabalhadores por meio da dependência do mark up das firmas da taxa de juros. Quanto mais elástico o mark up em relação à taxa de juros, mais os salários reais são afetados tendo em vista o aumento dos preços e da participação dos lucros na renda. A taxa de juros também afeta a demanda agregada pelo canal do investimento, a partir de uma extensão da função de Bhaduri e Marglin (1990), incorporando o fato de que um aumento da taxa de juros significa um aumento do custo do crédito. O impacto final de um aumento da taxa de juros sobre o grau de utilização e a taxa de crescimento do produto depende da propensão a poupar da classe rentista que recebe a renda dos juros, da sensibilidade do investimento a variações do custo do crédito, da razão entre endividamento e capital, bem como da variação do mark up em relação à taxa de juros e da sensibilidade da função 
A versão com controle para política monetária foi estimada em duas formas. Incluiu-se a variável de taxa de juros Selic acumulada no mês anualizada, em termos reais (descontada pela inflação medida pelo IPCA), como variável exógena nos modelos VAR. O resultado está na Tabela 1.2 do Apêndice A. A segunda forma inclui como controle a taxa de juros Selic acumulada no mês (sem ser anualizada), em termos reais (descontada pela inflação de cada mês, medida pelo IPCA). O resultado está na Tabela 1.1 (Apêndice A). Os resultados da especificação que controlou para a taxa de câmbio real efetiva ${ }^{37}$ estão disponíveis na Tabela 1.3 do Apêndice A. Já a Tabela 1.4 apresenta os resultados para os multiplicadores estimados quando controlamos os exercícios pelos preços de commodities.

Quando incluímos a taxa de juros anualizada em termos reais, no caso dos benefícios sociais, a mudança no multiplicador é bastante mínima em ambas as amostras; enquanto que para o investimento público a alteração é um pouco maior, mas também é pequena. O multiplicador de 1.42 (acumulado) torna-se 1.1 quando controlamos para a taxa de juros real anualizada na amostra pré-crise. Na amostra completa, o multiplicador de 3.6 reais torna-se 3.28. De qualquer forma, a diferença de pouco mais de 2 reais é mantida. Seu coeficiente foi negativo na equação do produto em todas as estimações, mas somente na amostra pré-crise houve significância, a $10 \%^{38}$. O índice da taxa de câmbio exibiu coeficiente positivo na equação do produto, mas não foi estatisticamente significativo em nenhum caso. Tal variável foi significante a $10 \%$ apenas na equação da receita, com coeficiente positivo. Desta forma, foi realizado um exercício com a inserção de uma variável capaz de captar os efeitos do cenário externo sobre o produto, o índice de preços internacionais de commodities.

Preço de commodities mostrou-se bastante significante, ao contrário das outras variáveis de controle. Seu coeficiente foi positivo e significante a $5 \%$ em quase todas as estimações, na equação do produto e na da receita. Em alguns poucos casos, foi a $10 \%$. O resultado está no Apêndice A, Tabela 1.4. Para o investimento público, na amostra maior houve maior alteração em relação à amostra menor. Em particular, o multiplicador acumulado do investimento público para a amostra inteira ficou 0.48 mais baixo, passando a valer 3.12 reais, enquanto o da amostra menor caiu ligeiramente, para um pouco abaixo de 1.4 (1.32). Mesmo assim, as diferenças entre as amostras foram mantidas, em certo grau ${ }^{39}$.

investimento à participação dos lucros na renda. Em Hein (2010) há um modelo parecido com uma extensão ao longo prazo, na qual o equilíbrio de longo prazo torna-se tanto mais instável quanto maior a propensão a poupar da classe rentista e quanto maior a elasticidade do investimento com relação ao custo do crédito e à disponibilidade de fundos próprios para investir.

37 As séries do índice da taxa de câmbio real efetiva, da taxa de juros selic acumulada no mês anualizada e da taxa de juros selic acumulada no mês foram obtidas do Banco Central do Brasil.

38 A inclusão da taxa de juros real acumulada no mês apresentou coeficiente negativo na equação do produto para a amostra menor, e positivo na amostra maior - em quase todas as estimações. No entanto, tal variável não foi estatisticamente significativa em nenhum dos casos.

39 Em particular, a diferença de magnitude de $154 \%$ passa a ser de $136 \%$ para o multiplicador acumulado do investimento público; e a diferença de $53 \%$ é praticamente mantida, chegando a $57 \%$, para o multiplicador acumulado do benefício social. 
Para os benefícios sociais, a mudança foi bastante marginal. Os demais tipos de gasto e a receita continuaram exercendo efeito multiplicador não significativo no acumulado.

Por fim, a Tabela 1.5 do Apêndice A apresenta os resultados para os exercícios em que incluímos três controles, ao mesmo tempo: taxa de juros anualizada (que se mostrou mais relevante em termos de significância), índice de preços de commodities e índice de taxa de câmbio. O único controle que apresentou significância foi o índice de preços de commodities. Seu coeficiente foi positivo na equação do produto, significante a $5 \%$, em todas as estimações. Nota-se que a Tabela 1.5 exibe resultados para os multiplicadores bastante similares à Tabela 1.4, que foi construída pela estimação dos modelos apenas com o índice de preços de commodities como variável exógena, refletindo que tal controle predomina quando incluímos os três de uma vez. Isso mostra, mais uma vez, a relevância do cenário externo para a economia brasileira. Assim como na Tabela 1.4, observamos menores multiplicadores para o investimento público na Tabela 1.5, mas as diferenças entre as amostras permanecem. Como dito anteriormente apesar de o alto efeito multiplicador do investimento público já ter sido bastante tratado na literatura empírica, o impacto dos benefícios sociais não é muito estudado. A Tabela 1.5 mostra que os multiplicadores acumulados, na amostra inteira, para o investimento público e para os benefícios sociais são praticamente iguais, o que reforça a semelhança entre esses dois multiplicadores.

Desta seção, podemos concluir que as estimações se mostraram robustas às especificações, de modo que os valores dos multiplicadores - tanto em termos de impacto como no acumulado - pouco mudaram ${ }^{40}$.

$\overline{40}$ Foi estimada também a versão trimestral, com a série do PIB trimestral obtida do IBGE e com os dados fiscais trimestralizados. No caso trimestral, estimou-se duas versões: uma com o deflacionamento do produto via IPCA, e a outra utilizando o deflator do PIB. Algumas dummies, explicadas anteriormente, foram incluídas em caso de significância. Embora em alguns casos o valor exato dos multiplicadores tenha mudado, o comportamento da função impulso-resposta foi semelhante: nos casos em que as respostas não foram significantes (despesas com pessoal, subsídios, demais despesas e receita), no exercício trimestral continuaram a não ser significativas. Já no caso do investimento público e dos benefícios sociais, as funções foram estatisticamente significativas a $95 \%$ para os 8 trimestres estimados. Ressalta-se também que as diferenças entre as amostras continuaram no caso do benefícios sociais e, embora em menor grau, para o investimento público. Desta forma, o exercício para os benefícios sociais mostrou maior robustez nesse aspecto. Todavia, como visto na nota de rodapé número 20 , preferimos utilizar o exercício mensal para o caso do investimento público (na amostra menor), por apresentar melhores resultados no "teste de endogeneidade" de Deleidi et al (2019). Com os dados deflacionados utilizando o IPCA, para os benefícios sociais, o valor do multiplicador de impacto foi em torno de 1 nas duas amostras e o acumulado foi de 1.65 na amostra pré-crise e 3 na amostra completa. Com os dados do produto deflacionados pelo deflator implícito, o multiplicador de impacto atingiu valores perto da unidade nas duas amostras. O acumulado foi em torno de 3.1 na pré-crise e 4.5 na completa. Para o investimento público: no caso do deflacionamento pelo IPCA, o valor do multiplicador de impacto é de 1.7 para a amostra pré-crise e 1.9 para a completa. $\mathrm{O}$ acumulado assume os valores 2.5 e 3.3, respectivamente. Com o deflacionamento do produto pelo deflator implícito, como é mais adequado, o acumulado é de 3.6 para a amostra pré-crise e de 4.5 para a amostra completa. O multiplicador de impacto também assume valores maiores neste caso, sendo em torno de 2 nas duas amostras. Como visto, os valores são sensíveis a pequenas alterações, como utilizar outro deflator. Segundo Çebi (2015), embora isto ocorra, o importante é ver em quais casos o multiplicador é alto (maior que a unidade) ou baixo. Em nosso caso, o importante é verificar se a alta magnitude e as diferenças entre amostras são preservadas. Nos demais tipos de gastos, embora houvesse diferenças nos 
Capítulo 1. Primeiro Artigo: A contribuição da política fiscal para a crise brasileira recente: uma análise 64 baseada em multiplicadores de despesas e receitas primárias do governo central no período 1997-2018

\subsection{Choques fiscais e impactos no produto}

A desagregação das despesas primárias é fundamental a fim de termos uma visão dos efeitos multiplicadores das diferentes despesas primárias e, com base nisso, estudar a política fiscal do período recente. Em particular, a pertinência da desagregação dos tipos de despesa para este trabalho será explorada nesta seção. Realizaremos ${ }^{41}$ dois exercícios de simulação: a estimação do efeito da "substituição dos investimentos públicos pelos subsídios" a partir de 2011, como descrito na seção 1.2; e o efeito do corte de investimentos públicos realizado entre 2015 e 2017. Para tanto, seguiremos Gechert e Rannenberg (2015), que avaliam o impacto dos esforços de consolidação fiscal na Grécia utilizando multiplicadores fiscais por eles estimados em outro artigo (Gechert e Rannenberg (2014)) a partir da análise da variação anual das séries fiscais originais ${ }^{42}$.

\subsubsection{O efeito da substituição do investimento público pelos subsídios no período 2011-2014}

Nosso exercício aqui é, com base nos multiplicadores acumulados em um ano para os investimentos públicos e para os subsídios, estimar o efeito acumulado de 2011-2014 dos cortes ou aumentos ilustrados na tabela abaixo sobre o produto. Para este exercício, foi utilizado o multiplicador acumulado de 12 meses para a amostra pré-crise para as simulações do produto em 2011, 2012 e 2013; e o multiplicador acumulado de 12 meses encontrado para a amostra que inclui 2014 em diante para a estimação do produto em 2014 e em 2015. A tabela abaixo (Tabela 2) multiplica a variação em milhões de reais pelo multiplicador encontrado de forma a verificar o efeito no produto. A variação é acumulada para verificarmos o efeito acumulado ao longo do período 2011-2014 no produto, como fazem Gechert e Rannenberg (2015). Para o caso do investimento público, esse

valores exatos dos multiplicadores, a função impulso-resposta não se mostrou significativa, como dito anteriormente.

41 Para isso, utilizaremos os multiplicadores acumulados para o período de 12 meses, que são similares aos estimados para 15 ou para 25 meses porque chegam a um valor de estado estacionário, conforme o efeito do choque inicial se dissipa. No caso da amostra inteira: 3.37 para investimentos públicos, 2.63 para benefícios sociais, -1.05 para pessoal, 0.06 para subsídios, 0.01 para demais despesas, -0.19 para receitas e 0.58 para as despesas totais. Para a amostra pré-crise, temos um multiplicador de 1.384 para investimentos públicos, 1.89 para benefícios sociais, -0.68 para pessoal, -0.47 para subsídios, -0.05 para demais despesas, -0.21 para as receitas e 0.57 para as despesas totais.

42 Embora os valores dos cortes/aumentos exatos das séries do choque estimado no SVAR e do choque efetivamente ocorrido na série original sejam diferentes, os gráficos, aqui omitidos, apresentam comportamento muito similar. Os choques estimados e os observados estão, em geral, próximos, o que nos aponta que utilizar dados mensais (e, portanto, supor choques mensais), não é algo tão fora da realidade. O uso da série original não é um grande problema no caso dos investimentos públicos e no caso dos gastos de consumo do governo (pessoal e demais despesas), tampouco no caso de subsídios, porque esses gastos são decisões determinadas diretamente pela política fiscal, como notam Gechert e Rannenberg (2015). No caso dos benefícios sociais, entretanto, possivelmente o esforço de consolidação fiscal é subestimado no caso da série pura, porque esta série é afetada pelo próprio ciclo econômico. Vale notar que, ainda assim, os benefícios sociais possuem um forte elemento discricionário, como indicam Orair e Gobetti (2017b). 
multiplicador vale em torno de 1.38 nos anos 2011 a 2013 e 3.37 em 2014 e em 2015. Para os subsídios, -0.47 em 2011-2013 e 0.06 em 2014 e em 2015. Nota-se que ambos são menores para a amostra pré-crise se comparados à amostra inteira: o de investimento é menor em magnitude, enquanto o de subsídios é negativo neste caso e positivo, mas muito próximo a zero, para a amostra inteira.

\begin{tabular}{|l|l|l|l|l|}
\hline Ano & $\begin{array}{l}\text { Variação no } \\
\text { investimento } \\
\text { público em reais } \\
\text { (Acumulada) }\end{array}$ & $\begin{array}{l}\text { Efeito no Pro- } \\
\text { duto Acumulado } \\
-\quad \text { investimento } \\
\text { público }\end{array}$ & $\begin{array}{l}\text { Variação nos sub- } \\
\text { sídios em reais } \\
\text { (Acumulada) }\end{array}$ & $\begin{array}{l}\text { Efeito no Pro- } \\
\text { duto Acumulado } \\
- \text { subsídios }\end{array}$ \\
\hline 2011 & $-8.681,30$ & $-12.015,5$ & $14.788,46$ & $-6.950,57$ \\
\hline 2012 & $-4.863,45$ & $-6.731,3$ & $21.158,77$ & $-9.944,62$ \\
\hline 2013 & $-8.152,55$ & $-11.283,7$ & $35.163,26$ & $-16.526,73$ \\
\hline 2014 & 904,61 & $3.048,3$ & $52.553,26$ & $3.153,2$ \\
\hline
\end{tabular}

Tabela 2 - Efeito dos cortes do investimento público e aumentos no subsídio 2011-2014.

Por exemplo, como mostra a Tabela 2, o corte no investimento público do início do período, de mais de 8 bilhões de reais é traduzido em um custo em termos de produto de mais de 12 bilhões de reais, dado que cada corte de 1 real no investimento representa uma queda do produto de quase 1.4 reais, em um período de um ano. Já para o caso dos subsídios observa-se, ao contrário do caso dos investimentos, variações predominantemente positivas.

O fato de a estratégia do governo, a partir de 2011, ser muito focada em subsídios ao setor privado, com a crença de que este poderia ser um motor de crescimento econômico capaz de estimular os investimentos privados revelou-se fracassada, como vimos na seção 1.2. Esse fato não surpreende quando estimamos o exercício aqui realizado: os efeitos multiplicadores dos investimentos públicos sobre o produto são muito superiores em termos de geração de renda se comparados aos dos subsídios.

Como nossos multiplicadores acumulados para esses dois tipos de despesa são muito diferentes, uma pergunta importante a ser feita é: e se a variação acumulada no período, que é sempre positiva no caso dos subsídios neste período, fosse destinada aos investimentos públicos? Para isso, abatemos o impacto da variação em reais acumulada do produto a cada ano dos subsídios, que efetivamente ocorreu; e adicionamos esse novo impacto, caso esse gasto fosse destinado aos investimentos públicos (que não ocorreu, sendo apenas uma simulação caso os recursos dos subsídios fossem canalizados para o investimento público, o que chamamos de "cenário alternativo 1"). O cenário alternativo 2, por sua vez, também considera que o aumento dos subsídios não ocorreu e, juntamente com isso, supõe um aumento dos investimentos públicos à taxa média ao ano observada no período 2006-2010, calculada no Gráfico da Figura 1. 
Capítulo 1. Primeiro Artigo: A contribuição da política fiscal para a crise brasileira recente: uma análise 66 baseada em multiplicadores de despesas e receitas primárias do governo central no período 1997-2018

Figura 9 - Efeito no produto em cenários alternativos

130,00

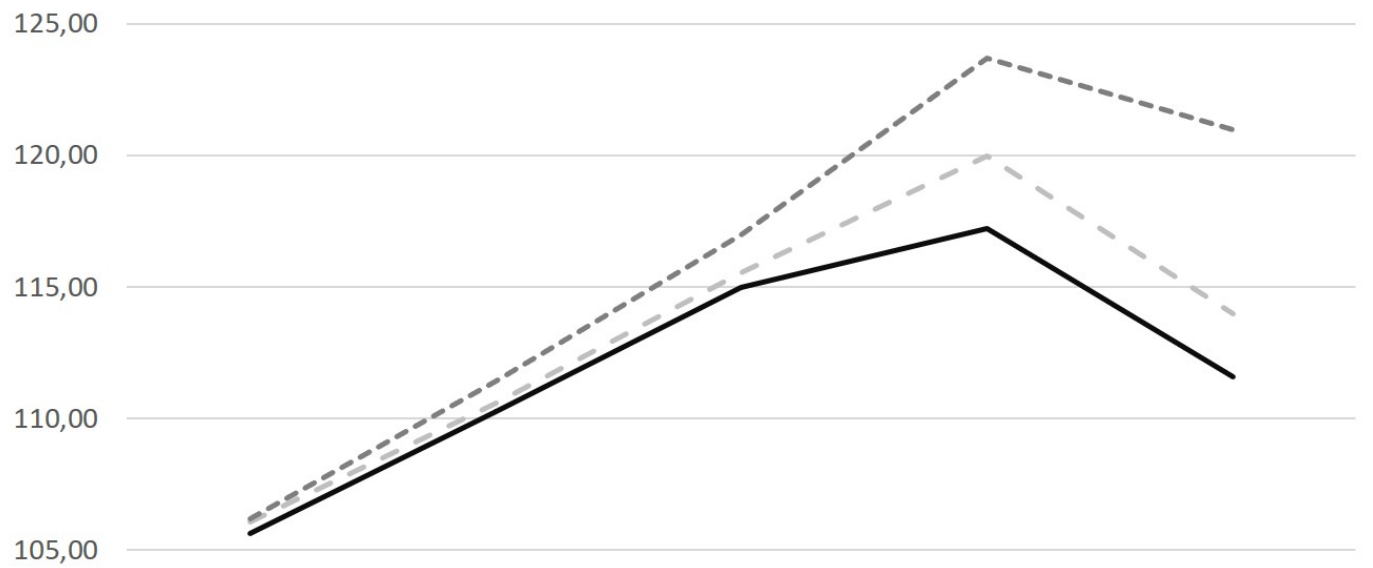

100,00

95,00

$20112012 \quad 2013 \quad 2015$

- Produto observado - - Produto no cenário alternativo $1^{*}$ - --Produto no cenário alternativo $2 * *$

Fonte: Elaboração própria. * O cenário alternativo 1 refere-se ao cenário em que os recursos destinados aos subsídios entre 2011 e 2014 são canalizados ao investimento público. **O cenário alternativo 2 refere-se ao caso em que os investimentos públicos crescem no período 2011-2014 à taxa anual observada durante o período 2006-2010.

De 2011 a 2014, a média geométrica da taxa de crescimento do indicador do produto no período foi de, efetivamente, $4 \%$ ao ano. No cenário alternativo 1 , essa taxa seria de quase $4.7 \%$ ao ano, ao passo que no cenário 2 seria pouco mais de $5.4 \%$. O período de 2013 para 2014 é o que mais possui diferença entre os cenários em termos de taxa de variação. De 2013 para 2014 a taxa de crescimento efetiva do indicador do produto foi de $1.96 \%$. No caso do cenário 1 seria de $3.8 \%$ e, no cenário 2, de $5.7 \%$. Considerando que o choque de 2014 ainda produz efeito acumulado em 2015, estendemos o exercício até 2015. A taxa média de crescimento do indicador do produto foi de $2.2 \%$ ao ano de 2011 a 2015 . Nos cenários alternativos 1 e 2, essa taxa seria de $2.65 \%$ e $3.9 \%$ ao ano, respectivamente. O Gráfico da Figura 9 acima ilustra esse efeito, considerando 2010 como o ano-base. Em 2014, o produto estava $17 \%$ acima do nível do ano-base (2010). Esse patamar é $2.76 \%$ inferior ao que seria observado no cenário 1 (em que o produto estaria a quase $20 \%$ acima do nível de 2010) e $6.46 \%$ menor ao que seria observado no caso do cenário alternativo 2 com o produto a $23.7 \%$ acima do nível de 2010 . 


\begin{tabular}{|l|l|l|l|l|}
\hline Ano & 2014 & 2015 & 2016 & 2017 \\
\hline Total & $73.048,03694$ & $45.667,03124$ & $51.598,65046$ & $39.241,84536$ \\
\hline Corte & $9.057,162733$ & $-27.381,00571$ & $5.931,619221$ & $-12.356,8051$ \\
\hline Corte Acumulado & - & $-27.381,00571$ & $-21.449,38649$ & $-33.806,19158$ \\
\hline $\begin{array}{l}\text { Efeito estimado acu- } \\
\text { mulado no produto }\end{array}$ & - & $-92.267,8$ & $-72.279,6$ & $-113.919,2$ \\
\hline
\end{tabular}

Tabela 3 - Efeito do corte de investimentos do governo central 2015-2017 sobre o produto.

\subsubsection{O efeito do ajuste fiscal de 2015-2017}

A Tabela 3 mostra o valor do investimento em milhões de reais (linha "total") em cada ano e, na linha "corte", a variação de um ano para outro. Notamos a variação fortemente negativa de 2014 para 2015 (de quase 40\%), como já antecipado na seção 1.2. O "corte acumulado" acumula esses choques. Como o ajuste fiscal foi realizado em 2015, o ano de 2014 não entrará na estimação e está na tabela apenas para comparação ${ }^{43}$. De posse do multiplicador acumulado em um ano para a amostra completa (3.37), estimamos o efeito acumulado no produto. Ao final de 2017, o custo do ajuste fiscal nos investimentos públicos corresponde a cerca de $20 \%$ do total da queda acumulada no produto, de 2015 a 2017, ceteris paribus. Por outro lado, embora o corte de subsídios seja similar ao corte de investimentos públicos, tal corte não foi tão prejudicial- o efeito negativo acumulado estimado no produto em 2017 foi de apenas $0.45 \%$ da queda acumulada total do produto.

Se o ajuste fiscal fosse feito do lado dos impostos, por exemplo, o custo do ajuste em termos de produto seria bem menor, pois o multiplicador acumulado de receita é de apenas -0.18. Se multiplicarmos a linha "corte acumulado" da Tabela 3 por -0.18 , o efeito negativo cumulativo no produto é muito menor que o aumento proporcionado pelo maior gasto em investimentos públicos: vale, em termos acumulados até $2017,1.14 \%$ do valor total da queda acumulada no produto. Com relação às despesas, juntos, os cortes acumulados no período das despesas "subsídios", "demais despesas" e "pessoal" respondem a apenas $2.8 \%$ da queda total acumulada do produto, aproximadamente, ceteris paribus. Se considerarmos o conjunto de despesas como um todo, utilizando o multiplicador acumulado para despesas primárias totais, o efeito sobre o produto da queda acumulada das despesas totais no período corresponde a $2.3 \%$ da queda total acumulada do PIB no período. A partir dos nossos multiplicadores fiscais calculados, realizamos quatro cenários possíveis.

O Gráfico da Figura 10 projeta quatro cenários e sugere que o produto teria caído menos caso não houvesse cortes nos investimentos públicos. Toma-se como base 100 o ano de atividade econômica imediatamente anterior ao aprofundamento da crise (2014). Os

43 Nossa análise desta seção vai até 2017, pois dispomos de dados até junho de 2018, o que dificulta a estimação do corte/aumento anual no ano de 2018. Ressalta-se, porém, que a estimação do multiplicador levou em conta este período de 2018 (de janeiro até junho). 
Capítulo 1. Primeiro Artigo: A contribuição da política fiscal para a crise brasileira recente: uma análise 68 baseada em multiplicadores de despesas e receitas primárias do governo central no período 1997-2018

Figura 10 - Efeito sobre o produto dos cortes de investimentos do governo central

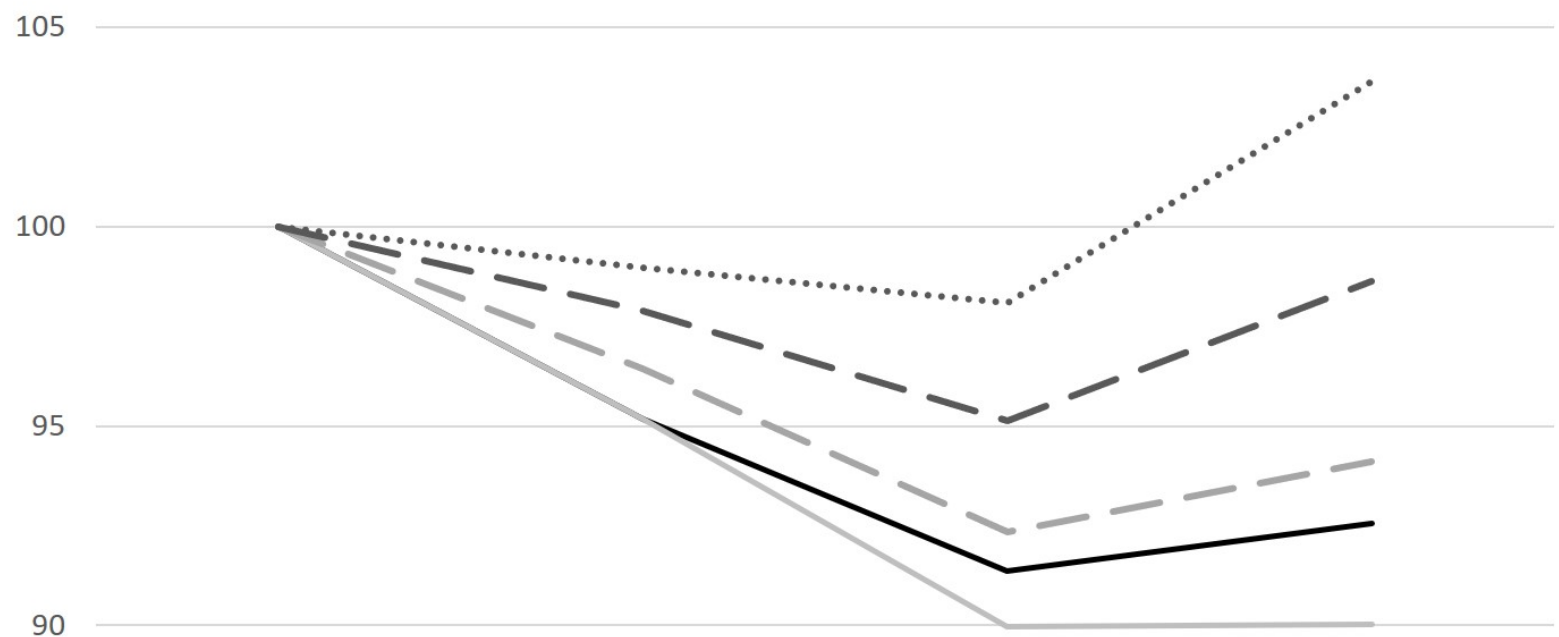

85

80

2014

- Produto observado

.....Produto no cenário $2 * *$

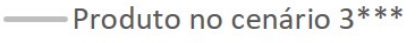

Produto no cenário $4 * * * *$

Fonte: Elaboração própria. *O cenário 1 refere-se ao caso com manutenção dos investimentos públicos no mesmo patamar de 2014. ${ }^{* *} \mathrm{O}$ cenário 2 considera uma situação em que o investimento público mantém sua taxa de crescimento de $28 \%$ ao ano, observada em 2006-2010, de 2011 até 2017, a partir do nível de 2010. ${ }^{* * *} \mathrm{O}$ cenário 3 supõe que as despesas com benefícios sociais se mantiveram no patamar de 2014. **** $\mathrm{O}$ cenário 4 considera uma situação em que o governo reage à crise aumentando o investimento público à taxa de $28 \%$ ao ano no período de recessão, a partir do nível de 2013.

valores indicam que a taxa de variação média do indicador do produto no período de 20152017 foi, efetivamente, de $-2.5 \%$ ao ano. No cenário sem cortes de investimentos (cenário 1), essa taxa teria sido de $-2 \%$ ao ano. No cenário 2 consideramos que o investimento público manteve seu ritmo de crescimento à taxa observada em 2006-2010 ao longo dos anos seguintes, incluindo o período da crise- neste caso a taxa de variação média do produto seria positiva, de $1.2 \%$ ao ano. No cenário 4, em que o governo aumenta o investimento público à mesma taxa observada no período 2006-2010 somente ao perceber a crise, isto é, apenas a partir de 2014, esta taxa seria de $-0.7 \%$ ao ano. De 2014 para 2015, quando verificamos queda abrupta do indicador do produto (de $4.8 \%$ ), a queda seria de $3.5 \%$, de $1 \%$ e de $2 \%$ nos cenários 1, 2 e 4, respectivamente. Já a variação positiva do indicador do produto de 2016 para 2017, apesar de estar longe de uma recuperação, indica, efetivamente, 
Figura 11 - Razão Dívida/PIB nos cenários

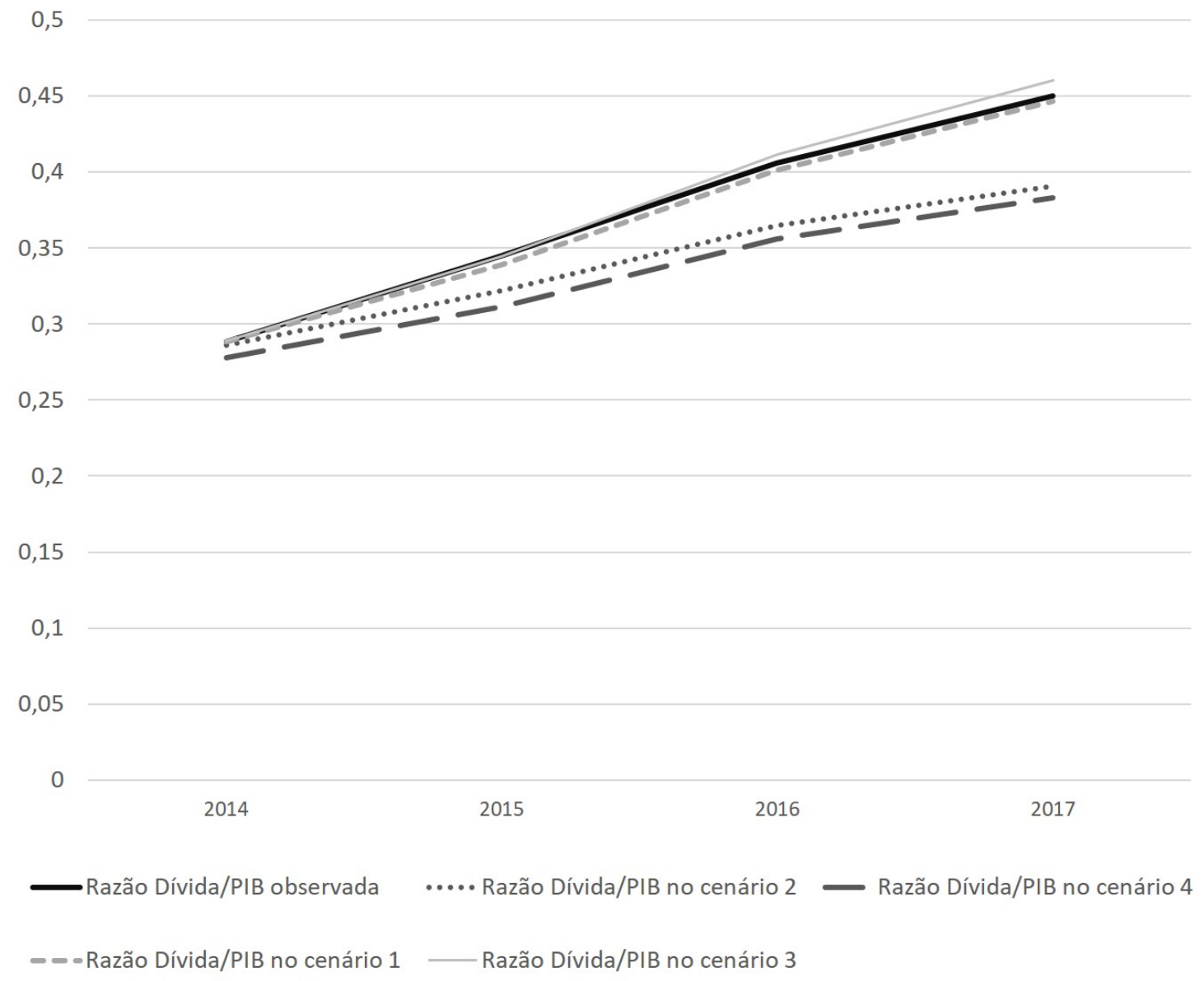

Fonte: Elaboração própria.

variação de $1.32 \%$. Essa variação positiva seria de $1.92 \%$ no cenário 1, de $5.6 \%$ no cenário 2 e de $3.7 \%$ no cenário 4 , o que mostra o grande efeito multiplicador em um cenário de uma política fiscal voltada à expansão do investimento público.

Vale notar que, como as despesas associadas aos benefícios sociais - que incluem programas sociais e previdência - são rígidas e, portanto, não são passíveis de um foco muito expressivo de corte, sua variação acumulada no período foi positiva, apesar do corte no ano de 2015. Como o multiplicador de benefícios sociais é alto e, dado que o ajuste não se deu por esses gastos, sua expansão pode ter contribuído para que a crise não se aprofundasse ainda mais. Ao considerar uma situação em que a variação positiva nos anos de 2016 e 2017 nos benefícios sociais não tivesse ocorrido, o cenário 3 do Gráfico 10, a taxa de variação média do produto no período 2015-2017 teria sido -3.4\% ao ano, frente ao $-2.5 \%$ ao ano, realmente ocorrido. A variação positiva de 2016 para 2017 seria ainda menor do que foi, de apenas $0.06 \%$.

Como o ponto 100 no Gráfico da Figura 10 representa o ano anterior ao aprofundamento da crise nos diferentes cenários (2014), ao final do período - em 2017 - o produto estava 7.4\% abaixo do nível anterior, em 2014. No cenário sem aumento dos benefícios 
Capítulo 1. Primeiro Artigo: A contribuição da política fiscal para a crise brasileira recente: uma análise 70 baseada em multiplicadores de despesas e receitas primárias do governo central no período 1997-2018 sociais, o nível do produto seria $2.53 \%$ menor (e o produto estaria a quase $10 \%$ abaixo do nível de 2014), ao passo que no caso do cenário sem cortes de investimentos do governo central (e tudo o mais constante) o nível do produto estaria $1.6 \%$ acima do que realmente ocorreu (e estaria a 5.8\% abaixo do nível de 2014). Já no caso em que o investimento público continuasse a se expandir à taxa observada nos anos 2006-2010 (de 28\% ao ano) nos anos posteriores, haveria completa recuperação, com o produto a $3.62 \%$ acima do nível de 2014, conforme o Gráfico 10 indica - e estaria a 11\% acima do PIB verdadeiro. Neste caso, haveria completa recuperação e o produto ainda estaria acima do nível de 2014. Se o governo reagisse ao início da crise, em 2014, aumentando o investimento público à taxa de $28 \%$ ao ano, o produto estaria apenas $1.37 \%$ abaixo do nível de 2014 , o que indica uma recuperação muito mais rápida que no caso observado, e a $6 \%$ acima do PIB observado.

O gráfico da Figura 11 mostra a razão entre Dívida Líquida do Setor Público (DLSP) Interna ${ }^{44}$ do Governo Federal junto com o Banco Central, e o produto em cada cenário $^{45}$. Assume-se que a taxa de juros real implícita sobre a dívida se manteve constante nos cenários. Do gráfico, é possível inferir que no cenário 2, com a taxa de crescimento dos investimentos públicos a $28 \%$ ao ano desde 2011, embora a relação Dívida-PIB esteja crescendo, estaria abaixo da observada. Nota-se uma pequena mudança de inclinação da curva, resultante do alto efeito multiplicador do investimento público sobre o produto, a despeito de um aumento significativo nos gastos primários. Ao final de 2017, a dívida seria correspondente a $39 \%$ do PIB, frente a $45 \%$ no caso observado.

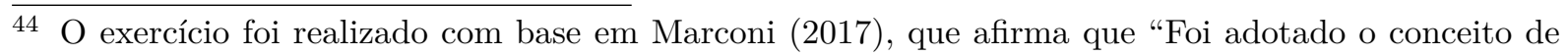
dívida interna líquida, pois essa é aquela pressionada imediatamente quando há um déficit no setor público" (Marconi, 2017, p.26), tendo em vista que nosso objetivo é avaliar possíveis cenários da relação Dívida/PIB com base em mudanças nos gastos e receitas primárias, considerando todos os demais fatores que afetam a dívida - como ajustes cambiais- constantes.

45 Quando não há variação patrimonial, a evolução da dívida pode ser decomposta em dois termos: o déficit primário no período corrente e o pagamento de juros sobre a dívida acumulada até o ano anterior (Souza Júnior e Santos, 2017). Desta forma: $\Delta D_{t}=\left(G_{t}-T_{t}\right)+r D_{t-1}$. Onde consideramos as variáveis em termos reais: $r$ é a taxa real de juros implícita sobre a DLSP, $\Delta D_{t}$ é a variação da dívida $D_{t}-D_{t-1}$ e $G_{t}-T_{t}$ é a diferença entre gasto primário e receita primária (definido como déficit primário). Para a realização do exercício, o valor inicial da simulação foi considerando o ano de 2010 , obtido da série da Dívida Líquida do Setor Público do Governo Federal e Banco Central, disponibilizada pelo Banco Central. Esta série foi deflacionada pelo IPCA. Calculou-se qual seria o deficit primário em cada cenário, adicionando-se os novos gastos com investimento público nos cenários 1 , 2 e 4, e retirando os gastos com benefícios sociais no cenário 3. A série correspondente de receita primária de cada cenário foi obtida a partir da estimação da elasticidade da receita com relação ao produto. A taxa de juros implícita acumulada em 12 meses sobre a DLSP referente à dívida sob o critério utilizado neste exercício foi obtida do Banco Central, em termos nominais, e transformada em termos reais descontando a inflação medida pela variação do IPCA a cada ano. O IPCA foi obtido do IBGE. Para estimar a receita primária, foi utilizada a elasticidade da receita com relação ao produto, parte do próprio exercício de estimação dos SVAR. O valor da elasticidade utilizada foi de 1.2, calculada por MQO: para um aumento de $1 \%$ no PIB, há uma elevação nas receitas primárias de $1.2 \%$. Uma observação adicional é que para os anos anteriores a 2014 (no caso do cenário 2), pré-crise, assumiu-se uma elasticidade de $1.0944 \%$, conforme calculada no apêndice B - esta elasticidade estimada é a mais próxima encontrada da literatura em geral, como mostra o quadro da Figura 13. Além disso, para o cenário 2, o efeito multiplicador estimado entre 2011 e 2013 foi feito utilizando o multiplicador acumulado para um ano encontrado no exercício para a amostra pré-crise, de 1.384; para os anos a partir de 2014, foi utilizado o multiplicador da amostra inteira, de 3.37. 
Algo que chama a atenção na Figura 11 é que, no cenário 1, em que o investimento público ficou estável (ao mesmo nível de 2014), sem cortes, a razão dívida-PIB estaria muito pouco abaixo da observada, mas sua inclinação não sugere indícios de estabilização. Sua inclinação é, na realidade, bem parecida com a linha do caso observado. O efeito multiplicador do investimento público seria mais alto, compensando o impacto na dívida. Apesar disso, o gráfico sugere que o cenário 1 teria um comportamento menos estável que no cenário 4, quando os investimentos públicos aumentaram $28 \%$ ao ano, desde o ano de início da crise. No cenário 4, apesar de um aumento inicial na razão dívida-PIB, este aumento é amenizado a partir de 2016, quando há uma leve mudança de inclinação em relação à curva observada. Isto sugere que, no cenário 4, a despeito do aumento do gasto público primário, haveria indícios de estabilização na dívida pública, tendo em vista o aumento do PIB pelo efeito multiplicador, e consequentemente da receita primária. A razão dívida-produto neste caso seria de $38.29 \%$ no cenário 4, frente a $44.61 \%$ no cenário 1 e $45 \%$ no caso observado.

No cenário 3, em que os benefícios sociais não aumentaram nos anos de crise, a relação dívida-PIB fica muito próxima à observada, inicialmente. Entretanto, observa-se que a linha está muito inclinada a partir de 2016, sugerindo que a razão dívida-PIB começa a aumentar rapidamente e, ao final de 2017, percebe-se o início de uma tendência de elevação. Ao final de 2017, a razão dívida-PIB é de $46 \%$ (maior que a observada). Embora os gastos primários tenham diminuído, o produto diminuiu significativamente, como mostrado no gráfico da Figura 10, o que contribui para a desestabilização da relação dívida-PIB.

Pode-se concluir a partir deste exercício que, se o governo tivesse aumentado o investimento público à taxa observada entre 2006-2010, de $28 \%$ ao ano, por meio de uma política anticíclica já no início da crise, em 2014 (o cenário 4), o produto estaria bem mais próximo da recuperação já ao final de 2017, se compararmos com o observado. Neste caso, a relação dívida-PIB, embora tenha aumentado, estaria abaixo da observada durante todo o período de crise, como indica o gráfico da Figura 11, e apresenta indícios de estabilização - a despeito do aumento dos gastos primários - ao reverter um pouco sua inclinação a partir de 2016, o que não ocorre com o cenário observado. Além disso, uma política pautada na expansão dos investimentos públicos desde 2011 também seria capaz de manter uma relação dívida-PIB mais baixa e mais estável, mesmo aumentando bastante o gasto primário. Estes resultados estão em consonância com o estudo de Marconi (2017), que projeta a relação dívida-PIB, no mesmo critério aqui utilizado, no caso em que o governo estabelece uma meta de taxa de investimento público que cresce continuamente de 2018 a 2020. O autor encontra que, em 2021, a relação dívida-PIB já apresentaria sinais de estabilização, mesmo com um aumento dos gastos em investimento.

O exercício aqui realizado supôs que a taxa de juros implícita sobre a dívida é 
Capítulo 1. Primeiro Artigo: A contribuição da política fiscal para a crise brasileira recente: uma análise 72 baseada em multiplicadores de despesas e receitas primárias do governo central no período 1997-2018

igual à observada, em cada cenário. É importante considerar o quão maior a taxa de juros teria que ser para que a razão dívida/PIB chegasse ao que foi realmente observado (para cada um dos cenários). Desta forma, calculamos o quanto a taxa de juros implícita sobre a dívida teria que ter se elevado para que a razão dívida-PIB nos cenários fosse igual à observada, de modo que, para valores maiores que essa taxa de juros calculada, a trajetória da dívida-PIB seria maior que a observada ${ }^{46}$. No cenário 2 , a taxa de juros implícita em termos reais teria que ser cerca de 4.5 pontos percentuais maior que a observada, em 2017; 4.9 pontos maior em 2016; 7 pontos maior em 2015; 7.3 pontos maior em 2014; 2.4 pontos menor em 2013; 1.2 pontos menor em 2012 e 2 pontos menor em 2011. No cenário 4, a nova taxa de juros seria 3.8 pontos percentuais maior que a observada em 2017; 4 em 2016; 7.3 em 2015 e 4.13 em 2014. Desta forma, se a taxa de juros tivesse aumentado em pelo menos estes valores, a trajetória da relação Dívida-PIB não seria mais tão favorável. Nos cenários 1 e 3, essa variação seria bem menor, tendo em vista que a relação Dívida-PIB está bastante próxima da observada. No cenário 1, a taxa de juros implícita seria 1.9 pontos percentuais maior que no caso observado em 2015; 0.49 pontos percentuais menor em 2016 e 0.29 pontos menor em 2017. Já no cenário 3, a taxa de juros teria que ser 1.5 pontos percentuais menor que a observada em 2016 e 1.1 pontos percentuais menor no ano de 2017.

\subsection{Conclusões}

A partir da estimação de um VAR estrutural baseado na metodologia de Blanchard e Perotti (2002) com variáveis fiscais mensais do governo central brasileiro para o período 1997-2018, esse trabalho encontrou um multiplicador mais elevado e persistente das despesas primárias federais sobre o produto para a amostra que inclui a crise de 2014-2017 se comparada à amostra pré-crise 1997-2014. Estimações desagregadas por componente do gasto sugerem que esse resultado é explicado pelo efeito dos investimentos públicos e dos benefícios sociais. Se o multiplicador elevado e persistente dos investimentos públicos já é bastante estabelecido na literatura nacional e internacional, o resultado para os benefícios sociais só havia aparecido em Orair et al (2016) e em Resende (2019). Nesse sentido, o crescimento expressivo e estável nesse item do gasto público desde o pacto social de 1988, que sobreviveu em boa medida ao ajuste fiscal iniciado em 2015 por seu caráter obrigatório, pode ter evitado flutuações muito maiores do PIB brasileiro ao longo desse período e, em particular, na crise atual.

Nossa contribuição está em, para além de analisar especificamente o papel da crise econômica recente no efeito multiplicador das despesas e receitas primárias, construir

\footnotetext{
46 A taxa de juros implícita sobre a dívida líquida interna do governo federal foi de, em termos reais, $3.48 \%$ ao ano em 2010, $6 \%$ em 2011, $3 \%$ em 2012, $4.8 \%$ em 2013, $7.3 \%$ em 2014, $9 \%$ em 2015, $4.9 \%$ em 2016 e $7.3 \%$ em 2017.
} 
cenários alternativos à forma de consolidação fiscal observada no período. Nossas estimações indicam que a forma em que ocorre a expansão ou o ajuste fiscal importa, e muito, para a dinâmica do produto. Em particular, simulamos o efeito de duas alterações significativas na política fiscal na última década sobre o PIB brasileiro: primeiro, a perda de peso dos investimentos públicos em prol de uma expansão de subsídios entre 2011 e 2014; segundo, o corte substancial de investimentos públicos a partir de 2015. Caso toda a expansão observada de subsídios tivesse sido direcionada para os investimentos públicos diretos entre 2011 e 2014, o PIB brasileiro teria crescido 4.7\% ao ano ao invés dos $4 \%$ observados no período. Ao final do período analisado, em 2014, o PIB no cenário em que os recursos dos subsídios são destinados aos investimentos públicos estaria $2.76 \%$ acima do PIB observado, e a $6.46 \%$ acima do PIB que efetivamente ocorreu no cenário em que os investimentos públicos continuassem crescendo à taxa anual observada no período 2006-2010.

Nossas estimações indicam que os cortes de investimentos públicos foram responsáveis por aproximadamente $20 \%$ da perda de produto observada no país desde 2014, em termos acumulados, considerando tudo o mais constante. No cenário sem cortes de investimentos do governo central, o nível do produto ao final do período analisado (2017) estaria $1.6 \%$ acima do nível que realmente ocorreu, enquanto que o PIB estaria a quase $6 \%$ acima do PIB verdadeiro no cenário expansionista em que o governo aplica uma política anticíclica orientada à expansão dos investimentos públicos a partir de 2014, à taxa anual média de crescimento do período 2006-2010, de 28\%. Já no cenário em que esta taxa de $28 \%$ é mantida a partir de 2011, a crise teria sido bem menos severa e o PIB estaria a $11 \%$ acima do PIB observado. O papel dos benefícios sociais também deve ser destacado, pois seu crescimento estável contribuiu para que seu alto efeito multiplicador impedisse uma crise mais profunda: o produto ao final de 2017 estaria a 2.53\% abaixo do que realmente ocorreu caso não houvesse crescimento desse tipo de despesa nos anos de 2016 e 2017.

O exercício de estimação da dívida pública mostrou que nos cenários em que foram adotadas políticas expansionistas focadas na expansão do investimento público, a razão dívida pública-PIB estaria abaixo do patamar observado, com indícios de maior estabilização a partir de 2016, quando há uma pequena mudança de inclinação na linha do gráfico, caracterizando um indício de que a dívida poderia se estabilizar em um horizonte temporal próximo. Assim, mesmo com um aumento do gasto primário, haveria uma elevação do crescimento econômico pelo efeito multiplicador que contribuiria para a elevação da receita primária. O resultado final é uma diminuição do déficit primário com relação ao produto, bem como um menor patamar da razão Dívida-PIB, considerando que a taxa de juros implícita sobre a dívida permaneceu constante, igual à observada, em cada cenário.

Uma limitação de nosso estudo é que analisamos esses cenários alternativos apenas do ponto de vista do efeito multiplicador exercido pelo gasto público, considerando tudo o mais constante. No entanto, há diversos outros fatores que afetam o produto, que não 
Capítulo 1. Primeiro Artigo: A contribuição da política fiscal para a crise brasileira recente: uma análise 74 baseada em multiplicadores de despesas e receitas primárias do governo central no período 1997-2018

sejam ligados à política fiscal. De forma a endereçar esta questão, ao menos parcialmente, escolhemos alguns controles econométricos com base em sua relevância para o modelo teórico que sustenta nossos argumentos, bem como em sua importância para a economia brasileira. Os resultados foram robustos e estas especificações. Contudo, as conclusões devem ser vistas com cautela, visto que analisamos cenários do que ocorreria na economia brasileira somente no tocante ao efeito multiplicador fiscal, sendo, portanto, uma análise de caráter parcial.

Cumpre salientar que, pela própria natureza de um exercício de construção de cenários, lidamos com situações contrafactuais. Nesse sentido, reconhecemos que uma segunda limitação do nosso estudo é que há a possibilidade de que os próprios multiplicadores estimados dependam da composição do orçamento, isto é, do próprio nível do gasto em questão. Ou ainda, tenham efeitos diferentes a um prazo mais longo. Com relação a este último problema, consideramos que nossos exercícios são projetados especificamente para o período da crise e, logo, nosso objetivo não é construir cenários para um prazo muito longo. Em relação ao problema da possível dependência do nível do gasto, apesar de haver a possibilidade de os multiplicadores serem sensíveis à composição do orçamento, consideramos que o efeito do investimento público e dos benefícios sociais, por exemplo, é tão relevante do ponto de vista do efeito multiplicador que, mesmo que este efeito dependa do próprio nível do gasto (sobretudo no caso do investimento público, que sofreu maiores alterações, com grandes cortes a partir de 2015), ainda deva ser bastante alto.

Ademais, nossos resultados possivelmente estão subestimados, pois o multiplicador somente para o período da crise deve ser ainda maior. O real efeito do ajuste fiscal deve ser mais custoso em termos de produto, tendo em vista que utilizamos multiplicadores estimados para a amostra inteira e não apenas para o período de crise. Esse trabalho ajuda, portanto, a quantificar o impacto de fatores internos, associados à política econômica, para a desaceleração vivida pela economia brasileira a partir de 2011 e para a crise que se seguiu. Os resultados encontrados servem também para subsidiar as discussões acerca do novo regime fiscal implementado em 2016 e de outras regras fiscais vigentes, que têm penalizado desproporcionalmente os investimentos públicos em períodos de crise.

\section{Referências do Primeiro Artigo}

ADAMS, A.; WONG, M. Quantifying fiscal multipliers in New Zealand: the evidence from SVAR Models. Reserve Bank of New Zealand Analytical Note Series, n.5, 2018.

AFOnSO, A.; SOUSA, R. The Macroeconomic Effects of Fiscal Policy in Portugal: a Bayesian SVAR Analysis. NIPE Universidade do Minho Working Paper, n.3, 2009.

AKPAN, U.; ATAN, J. Macroeconomic Effects of Fiscal Policy Shock in Nigeria: A SVAR Approach. International Journal of Business and Economics Research, v.4, n.3, p.109-120, 
2015.

ALESINA, A.; ARDAGNA, S. Large Changes in Fiscal Policy: Taxes versus Spending. In: BROWN J. R. Tax Policy and the Economy, v.24, p. 35-68, 2010.

ALVES, R. O impacto da política fiscal sobre a atividade econômica ao longo do ciclo econômico: evidências para o Brasil. Dissertação de Mestrado. Instituto de Pesquisas Econômicas. Universidade de São Paulo, 2017.

AMADEO, E. The role of capacity utilization in long-period analysis. Political Economy, v.2, n.2, p.147-185, 1986.

ANDREIS, A. Balanço Orçamentário Estrutural no Brasil: a política fiscal no Brasil é pró ou anticíclica no período pós plano real? Finanças Públicas, XIX Prêmio Tesouro Nacional, 2014.

ANDREIS, A. O comportamento da política fiscal brasileira no período pós-plano real e suas implicações. Dissertação de Mestrado -Universidade do Vale do Rio dos Sinos, 2016.

ASCHAUER, D. A. Is public expenditure productive? Journal of Monetary Economics, v. 23, n. 2, pp. 177-200, 1989.

AUERBACH, A.; GORODNICHENKO, Y. Measuring the output responses to fiscal policy. American Economic Journal: Economic Policy, v.4, n.2, p. 1-27, 2012.

AUERBACH, A.; GORODNICHENKO, Y. Fiscal multipliers in recession and expansion. In: ALESINA, A.; GIAVAZZI, F. Fiscal policy after the financial crisis. University of Chicago Press, 2013.

BACHMANN, R.; SIMS, E. Confidence and the Transmission Mechanism of Government Spending Shocks. Journal of Monetary Economics, v.59, p.235-249, 2012.

BARBOSA, N. Dez anos de política econômica. In: SADER, E (Org.). Lula e Dilma: dez anos de governos pós-neoliberais. Editora Boitempo, 2013.

BAUM, A.; KOESTER, G. The impact of fiscal policy on economic activity over the business cycle - evidence from a threshold VAR analysis. Discussion Paper Series Economic Studies - Deutsche Bundesbank, n.3, 2011.

BAUM, A.; POPLAWSKI-RIBEIRO, M.; WEBER, A. Fiscal multipliers and the state of the economy. IMF Working paper, n.12/286, 2012.

BEETSMA, R.; GIULIODORI, M. The effects of government purchases shocks: review and estimates for the EU. The Economic Journal, v.121, p.4-32, 2011.

BENETRIX, A.; LANE, P. The Impact of Fiscal Shocks on the Irish Economy. The Economic and Social Review, v. 40, n. 4, p. 407-434, 2009.

BHADURI, A.; MARGLIN, S. Unemployment and the real wage: the economic basis for 
Capítulo 1. Primeiro Artigo: A contribuição da política fiscal para a crise brasileira recente: uma análise 76 baseada em multiplicadores de despesas e receitas primárias do governo central no período 1997-2018 contesting political ideologies. Cambridge Journal of Economics, v.14, n.4, p.375-393, 1990. BLANCHARD, O.; PEROTTI, R. An empirical characterization of the dynamic effects of changes in government spending and taxes on output. Quarterly Journal of Economics, v.117, n.4, p. 1329-1368, 2002.

BOICIUC, I. The effects of fiscal policy shocks in Romania. A SVAR Approach. Procedia Economics and Finance, v.32, p.1131 - 1139, 2015.

BORG, I. Fiscal Multipliers in Malta. Central Bank of Malta Working Papers, n.06, 2014.

BORGES, B. Debate dos impactos da nova matriz econômica: a visão de que há exagero. Conjuntura Econômica, 2017.

BRUCKNER, M.; TULADHAR, A. Public Investment as a Fiscal Stimulus: Evidence from Japan's Regional Spending During the 1990s. IMF Working Paper, n.110, 2010.

BURRIEL, P.; CASTRO, F.; GARROTE, D.; GORDO, E.; PAREDES, J.; PEREZ, J. Fiscal policy shocks in the euro area and the US an empirical assessment. Fiscal Studies, v.31, n.2, p. 251-285, 2010.

CALDARA, D.; KAMPS, C. What are the effects of fiscal shocks? A VAR-based comparative analysis. European Central Bank Working Paper Series, n.877, 2008.

CALDARA, D.; KAMPS, C. The analytics of SVARs: a unified framework to measure fiscal multipliers. Board of Governors of the Federal Reserve System (U.S.) Finance and Economics Discussion Series, n.20, 2012.

CARRIÈRE-SWALLOW, Y.; DAVID, A.; LEIGH, D. The macroeconomic effects of fiscal consolidation in emerging economies: evidence from Latin America. International Monetary Fund. IMF Working Papers, n.142, 2018.

CARVAlHO, L. Valsa Brasileira. Do boom ao caos econômico. Editora Todavia, 2018.

CARVALHO, L.; REZAI, A. Personal income inequality and aggregate demand. Cambridge Journal of Economics, 2015.

CARVALHO, L.; RUGITSKY, F. Growth and distribution in Brazil the 21st century: revisiting the wage-led versus profit-led debate. Working paper series. Department of Economics FEA/USP, n.25, 2015.

CASALECCHI, A.; BARROS, G. A variação da receita em resposta à atividade econômica. Instituição Fiscal Independente, nota técnica n.19, 2018.

CASERO, P.; CERDEIRO, D.; TREZZI, R. Estimating the Fiscal Multiplier in Argentina. Policy Research Working Paper - The World Bank., n. 5220, 2010.

CASTElO-BRAnCO, M. A.; LIMA, E. C. R.; PAUlA, L. F. Mudanças de Regime e Multiplicadores Fiscais no Brasil entre 1999-2012: uma avaliação empírica. Anais do XLIII 
Encontro Nacional de Economia da Anpec, 2015.

CASTRO, F. The macroeconomic effects of fiscal policy in Spain. Documento de Trabajo Banco de Espana, n.0311, 2003.

CASTRO, F.; FERNANDEZ, L. The Effects of Fiscal Shocks on the Exchange Rate in the Spain. Documentos de Trabajo - Bank of Spain, n.1121, 2011.

CASTRO, F.; HERNANDEZ DE COS, P. The economic effects of fiscal policy: The case of Spain. Journal of Macroeconomics, v. 30, n.3, p. 1005-1028, 2008.

CATTAN, R. Política fiscal e crescimento econômico: uma análise do período de metas de inflação no Brasil. Dissertação de Mestrado. Unicamp, 2017.

CAVALCANTI, M.; SILVA, N. Dívida pública, política fiscal e nível de atividade: Uma abordagem var para o brasil no período 1995-2008. Economia Aplicada, v.14, n.4, p.391-418, 2010.

ÇEBI, C. Government Spending Multiplier in Turkey. Central Bank of the Republic of Turkey (Turkiyes Cumhuriyet Merkez Bankasi) Working Paper, n.15, 2015.

CORSETTI, G.; MEIER, A.; MUELLER, G. J. What determines government spending multipliers? Economic Policy, v.27, n.72, p. 521-565, 2012.

COS, P. H. de; MORAL-BENITO, E. Fiscal multipliers in turbulent times: the case of Spain. Banco de España Working Papers, n.1309, 2013.

COUDRET, N. Fiscal Multipliers in the Netherlands A Structural VAR Approach. Master Thesis in Policy Economics. Erasmus School of Economics, 2013.

DELEIDI, M.; IAFRATE, F.; LEVRERO, E. Public investment fiscal multipliers: an empirical assessment for European countries. Structural Change and Economic Dynamics, v.52, p.354-365, 2019.

DOS SANTOS, C.; MODENESI, A.; SQUEFF, G.; VASCONCELOS, L.; MORA, M.; FERNANDES, T.; MORAES, T.; SUMMA, R.; BRAGA, J. Revisitando a dinâmica trimestral do investimento no Brasil: 1996-2012. Revista de Economia Política, v.36, n. 1 (142), p. 190-213, 2016.

DUFRÉNOT, G.; JAMBOIS, A.; JAMBOIS, L.; KHAYAT, G. Regime-Dependent Fiscal Multipliers in the United States. Open Economies Review, v. 27, n.5, p. 923-944, 2016.

DUTRA, F. Multiplicadores fiscais no Brasil: estimativas a partir de Modelos STVAR. Trabalho de conclusão. Universidade Federal do Rio Grande do Sul, 2016.

DUTT, A. Government spending, aggregate demand, and economic growth. Review of Keynesian Economics, v.1, n. 1, p. 105-119, 2013.

FATAS, A.; MIHOV, I. The Effects of Fiscal Policy on Consumption and Employment: 
Capítulo 1. Primeiro Artigo: A contribuição da política fiscal para a crise brasileira recente: uma análise 78 baseada em multiplicadores de despesas e receitas primárias do governo central no período 1997-2018

Theory and Evidence. CEPR Discussion Paper - Centre for Economic Policy Research (London), n.2760, 2001.

FAVERO, C.; GIAVAZZI, F. Debt and the effects of fiscal policy. Federal Reserve Bank of Boston Working Paper, n.4, 2007.

FAZZARI, S.; MORLEY, J.; PANOVSKA, I. State-dependent effects of fiscal policy. Studies in Nonlinear Dynamics and Econometrics, v.19, n.3, p. 285-315, 2015.

FMI. Fiscal monitor: Balancing fiscal policy risks. Technical report, World Economic and Financial Surveys. Washington, DC, 2010a.

FMI. Will it hurt? Macroeconomic effects of fiscal consolidation. World Economic Outlook, p.93-124, 2010b.

FORD, E. The effects of fiscal policy on output in Belize. Master of Science (Dissertation). University of the West of England, 2013.

FURCERI, D.; ZDZIENICKA, A. The Effects of Social Spending on Economic Activity: Empirical Evidence from a Panel of OECD Countries. Fiscal Studies, Institute for Fiscal Studies, v.33, n.1, p.129-152, 2012.

GARCIA, J.; LEMUS, A.; MRKAIC, M. Fiscal Multipliers in the ECCU. IMF Working Paper, n.13/117, 2013.

GECHERT, S.; RANNENBERG, A. Are Fiscal Multipliers Regime-Dependent? A Meta Regression Analysis. IMK working paper, n.139, 2014.

GECHERT, S.; RANNENBERG, A. The costs of Greeces fiscal consolidation. Vierteljahrshefte zur Wirtschaftsforschung, v.84, n.3, p. 47-59, 2015.

GIORDANO, R.; MOMIGLIANO, S.; NERI, S.; PEROTTI, R. The effects of fiscal policy in Italy: Evidence from a VAR model. European Journal of Political Economy, v.23, p.707-733, 2007.

GIORnO, C.; RICHARDSOn, P.; ROSEVEARE, D.; NOORD, P. Potential output, output gaps and structural budget balances. OECD Economic Studies, n. 24, 1995.

GOBETTI, S.; GOUVEA, R.; SCHETTINI, B. Resultado fiscal estrutural: um passo para a institucionalização de políticas anticíclicas no Brasil. Texto para discussão IPEA, n.1515, 2010 .

GOBETTI, S.; DUTRA, F.; ORAIR, R. Resultado estrutural, ciclos econômicos e os desafios para avaliar o desempenho fiscal. XXII Prêmio Tesouro Nacional 2017, 2016.

GRUDTNER, V.; ARAGON, E. Multiplicador dos gastos do governo em períodos de expansão e recessão: evidências empíricas para o Brasil. Revista Brasileira de Economia, v.71, n.3, p.321-345. 2017. 
HAGEDORN, M.; MANOVSKII, I.; MITMAN, K. The fiscal multiplier. National Bureau of Economic Research Working Paper Series. Working Paper 25571, 2019.

HAGEMANN, R. The structural budget balance: the IMF's methodology. IMF, 1999.

HEIN, E. Interest Rates, Income Shares, and Investment in a Kaleckian Model. Political Economy. Review of Political Economy and Social Sciences, Issue 5, p. 5-22, 1999.

HEIN, E. The rate of interest as a macroeconomic distribution parameter: Horizontalism and Post-Keynesian models of distribution of growth. Institute for International Political Economy Working Paper, n.7/2010, 2010.

ILZETZKI, E. Fiscal Policy and Debt Dynamics in Developing Countries. Policy Research Working Paper World Bank, n.5666, 2011.

ILZETZKI, E.; MENDOZA, E.; VEGH, C. How Big (Small?) Are Fiscal Multipliers? Journal of Monetary Economics, v.60, p.239-254, 2013.

IZQUIERDO, A.; LAMA, R.; MEDINA, J.; PUIG, J.; RIERA-CRICHTON, D.; VEGH, C.; VULETIN, G. Is the public investment multiplier higher in developing countries? An empirical investigation. National Bureau of Economic Research Working paper series, n.26478, 2019 .

JEMEC, N.; KASTELEC, A.; DELAKORDA, A. How do fiscal shocks affect the macroeconomic dynamics in the slovenian economy? Delovni Zvezki Banke Slovenije Banck of Slovenia Working Paper, 2013.

JORDÀ, O. Estimation and inference of impulse responses by local projections. American Economic Review, v.95, n.1, p.161-182, 2005.

KALECKI, M. A theory of profits. The Economic Journal, v.52, n. 206/207, p.258-267, 1942.

KALECKI, M. Political aspects of full employment. Political Quarterly, 1943.

KENNEDY, P. Sinning in the basement: What are the rules? the ten commandments of applied econometrics. Journal of Economic Surveys, v.16, n.4, p.569-589, 2002.

KEYNES, J. The general theory of employment. The Quarterly Journal of Economics. Oxford University Press, v.51, n.2, p.209-223, 1937.

KOnStAntinOU, P.; PARTHEnIOU, A. The Effects of Government Spending Over the Business Cycle: A Disaggregated Analysis for OECD and Non-OECD Countries. Quarterly Review of Economics and Finance, 2019.

LAVOIE, M. Post-Keynesian Economics: new foundations. [S.l.]: Edward Elgar Publishing, 2014 .

LOPES, M.; MOLLO, M.; COLBANO, F. Metas de inflação, regra de Taylor e neutralidade 
Capítulo 1. Primeiro Artigo: A contribuição da política fiscal para a crise brasileira recente: uma análise 80 baseada em multiplicadores de despesas e receitas primárias do governo central no período 1997-2018

da moeda: uma crítica pós-keynesiana. Revista de Economia Política, v.32, n.2, p.282-304, 2012 .

LOPREATO, F. L. Caminhos da política fiscal no Brasil. Editora Unesp, 2013.

LOZANO, I.; RODRIGUEZ, K. Assessing the macroeconomic effects of fiscal policy in Colombia. Journal of Financial Economic Policy, v.3, n.3, p.206-228, 2011.

LÜTKEPOHL, H. New Introduction to Multiple Time Series Analysis. Springer, 2005.

MACIEL, P. Proposta à regra fiscal brasileira: orientação pelos ciclos econômicos. XI Prêmio do Tesouro Nacional, 2006.

MANÇELLARI, A. Macroeconomic effects of fiscal policy in Albania: a SVAR approach. Working paper, Bank of Albania, n.05 (28), 2011.

MARCEL, M.; TOKMAN, M; VALDÉS, R.; BENAVIDES, P. Structural Budget Balance: Methodology and Estimation for the Chilean Central Government 1987- 2001. Estudios de Finanzas Públicas, n. 1, 2002.

MARCONI, N. Uma meta para o investimento público com equilíbrio fiscal. Conjuntura Econômica, 2017.

MATHESON, T.; PEREIRA, J. Fiscal multipliers for Brazil. International Monetary Fund. IMF Working papers, n.79, 2016.

MATTEO, D.; VINCENZO, D.; MAZZUCATO, M.; AGNOLUCCI. Fiscal Multipliers: a SVAR approach for the US. Associazione Italiana per la Storia dell'Economia Politica (STOREP), 2018.

MELLO, L.; MOCCERO, D. Brazil's fiscal stance during 1995-2005. OECD Economics Department Working Papers, n.485, 2006.

MENDONÇA, D.; MARÇAL, E.; HOLLAND, M. Is fiscal policy effective in Brazil? An empirical analysis. Working paper series, São Paulo School of Economics, 2016.

MENDONÇA, M.; MEDRANO, L.; SACHSIDA, A. Avaliando os efeitos da política fiscal no Brasil: resultados de um procedimento de identificação agnóstica. Texto para Discussão IPEA, n.1377, 2009.

MOUNTFORD, A.; UHLIG, H. What are the effects of fiscal policy shocks? Journal of Applied Econometrics, v.24, n.6, p.960-992, 2009.

NEWEY, W.; WEST, K. A simple, positive semi-definite, heteroskedasticity and autocorrelation consistent covariance matrix. Econometrica, v.55, n.3, p.703-708, 1987.

ORAIR, R. Investimento público no Brasil: trajetórias e relação com o regime fiscal. Texto para discussão - Instituto de Pesquisa Econômica Aplicada (IPEA), n.2215, 2016.

ORAIR, R.; GOBETTI, S. Resultado primário e contabilidade criativa: reconstruindo as 
estatísticas fiscais acima da linha do governo geral. Texto para discussão - IPEA, n.2288, 2017 a.

ORAIR, R.; GOBETTI, S. Brazilian fiscal policy in perspective: from expansion to austerity. Encontro Nacional ANPEC, 2017b.

ORAIR, R.; SIQUEIRA, F.; GOBETTI, S. Política fiscal e ciclo econômico: uma análise baseada em multiplicadores do gasto público. XXI Prêmio do Tesouro Nacional, 2016.

OWYANG, M.; RAMEY, V.; ZUBAIRY, S. Are government spending multipliers greater during periods of slack? American Economic Review: Papers $\mathscr{G}$ Proceedings, v. 103, n.3, p. 129-134, 2013.

PEREIRA, A.; SAGALÉS, O. Long-term effects of fiscal policies in Portugal. College of William and Mary - Working Paper, n.35, 2009.

PERES, M. Os efeitos dinâmicos da política fiscal sobre a atividade econômica: um estudo para o caso brasileiro. Dissertação de Mestrado - Universidade de Brasília, 2006.

PERES, M.; ELLERY, R. Efeitos dinâmicos dos choques fiscais do governo central no pib. Pesquisa e Planejamento Econômico, v.39, n.2, p.159-206, 2009.

PEROTTI, R. Estimating the effects of fiscal policy in OECD countries. IGIER Working Paper, n.276, 2004.

PEROTTI, R. In search of the transmission mechanism of fiscal policy. NBER Macroeconomics Annual, v.22, 2007.

PESSÔA, S. Debate dos impactos da nova matriz econômica: a visão mais crítica. Conjuntura Econômica, 2017.

PIRES, M. Controvérsias recentes sobre multiplicadores fiscais. Anais do VII Encontro Internacional da Associação Keynesiana Brasileira, 2011.

PIRES, M. Política fiscal e ciclos econômicos no Brasil. Economia Aplicada, v.18, n.1, p.69-90, 2014.

POIRIER, R. Fiscal Multipliers in Portugal using a Threshold Approach. NOVA-School of Business and Economics Working paper, 2014.

RAMEY, V. Identifying Government Spending Shocks: It's All In the Timing. Quarterly Journal of Economics, v.126, n.1, p.1-50, 2011.

RAMEY, V. Ten years after the financial crisis: what have we learned from the Renaissance in fiscal research? Journal of Economic Perspectives, v.33, n.2, p.89-114, 2019.

RAMEY,V.; SHAPIRO, M. Costly Capital Reallocation and the Effects of Government Spending. Carnegie-Rochester Conference Series on Public Policy, v.48, n.1, p.145-94, 1998. 
Capítulo 1. Primeiro Artigo: A contribuição da política fiscal para a crise brasileira recente: uma análise 82 baseada em multiplicadores de despesas e receitas primárias do governo central no período 1997-2018

RAMEY, V.; ZUBAIRY, S. Government Spending Multipliers in Good Times and in Bad: Evidence from U.S. Historical Data. National Bureau of Economic Research Working Paper, n.20719, 2014.

RAMEY, V.; ZUBAIRY, S. Are government spending multipliers state dependent? Evidence from Canadian historical data. National Bureau of Economic Research Working Paper, 2015.

RAVNIK, R.; ZILIC, I. The use of SVAR analysis in determining the effects of fiscal shocks in Croatia. Financial Theory and Practice, v. 35, n.1, p.35-58, 2011.

REEVES, A.; BASU, S.; MCKEE, M.; MEISSNER, C.; STUCKLER, D. Does investment in the health sector promote or inhibit economic growth? Globalization and Health, v.43, n.9, 2013.

RESENDE, C. Impulso fiscal: Uma abordagem de multiplicadores fiscais com aplicação para a economia brasileira. Dissertação de Mestrado. Escola de Economia de São Paulo. Fundação Getulio Vargas, 2019.

RESTREPO, J. How big are fiscal multipliers in Latin America? IMF Working Paper, n.17, 2020.

RIBEIRO, L. Sobre arrecadação e atividade econômica. Nota técnica FGV IBRE, 2016.

ROMER, C.; ROMER, D. The macroeconomic effects of tax changes: Estimates based on a new measure of fiscal shocks. American Economic Review, v.100, n.3, p.763-801, 2010.

SANTOS, C.; MACEDO E SILVA, A.; RIBEIRO, M. Uma metodologia de estimação da carga tributária líquida brasileira trimestral no período 1995-2009. Economia Contemporânea, v.14, n.2, p.209-236, 2010.

SILVA, R.; CARVALHO, V.; RIBEIRO, A. How Large are Fiscal Multipliers? A Panel-Data VAR Approach for the Euro Area. FEP Working Papers, n.500, 2013.

SIMS, C. Macroeconomics and reality. Econometrica, n.48, p.1-48, 1980.

SIMS, C.; ZHA, T. Error bands for impulse responses. Econometrica, v.6, n.5, p.1113-1155, 1999.

SKRBIC, M.; SIMOVIC, H. The size and determinants of fiscal multipliers in Western Balkans: comparing Croatia, Slovenia and Serbia.EFZG Working Paper Series, n.15-10, 2015.

SOUZA JÚNIOR, J.; SANTOS, F. Simulações da trajetória da dívida bruta do governo geral (2017 a 2037). Texto para Discussão, Instituto de Pesquisa Econômica Aplicada (IPEA), n.2303, 2017.

SPILIMBERGO, A.; SYMANSKI, S.; SCHINDLER, M. Fiscal multipliers. Technical report. IMF Staff Position Note, 2009. 
STANIESIC, D.; KASUMOVIC, B. Fiscal Multipliers for Bosnia and Herzegovina. Graduate Institute of International and Development Studies Working Paper, n.23, 2017.

STOCK, J.; WATSON, M. A Simple Estimator of Cointegrating Vectors in Higher Order Integrated Systems. Econometrica, v.61, n.4, pp. 783-820, 1993.

TAYLOR, L. A stagnationist model of economic growth. Cambridge Journal of Economics, v.9, n.4, p.383-403, 1985.

TENHOFEN, J.; WOLFF, G.; HEPPKE-FALK, K. The Macroeconomic Effects of Exogenous Fiscal Policy Shocks in Germany: A Disaggregated SVAR Analysis. Journal of Economics and Statistics (Jahrbuecher fuer Nationaloekonomie und Statistik), v.230, n.3, p.328-355, 2010.

UNAL, U. Rethinking the Effects of Fiscal Policy on Macroeconomic Aggregates: A Disaggregated SVAR Analysis. Florida International University - Economics Research Working Paper Series, n.12, 2011.

VALENCIA, F. Fiscal multipliers in Mexico. IMF Mexico Selected Issues. IMF Country Report, n.15/314, p.4-9, 2015.

VDOVYCHENKO, A. How does fiscal policy affect gdp and inflation in Ukraine? Visnyk of the National Bank of Ukraine, n. 244, p. 25-43, 2018. 
Capítulo 1. Primeiro Artigo: A contribuição da política fiscal para a crise brasileira recente: uma análise 84 baseada em multiplicadores de despesas e receitas primárias do governo central no período 1997-2018

\subsection{Apêndices do Primeiro Artigo}

\subsubsection{Apêndice A}

Figura 12 - Índice de preços de commodities

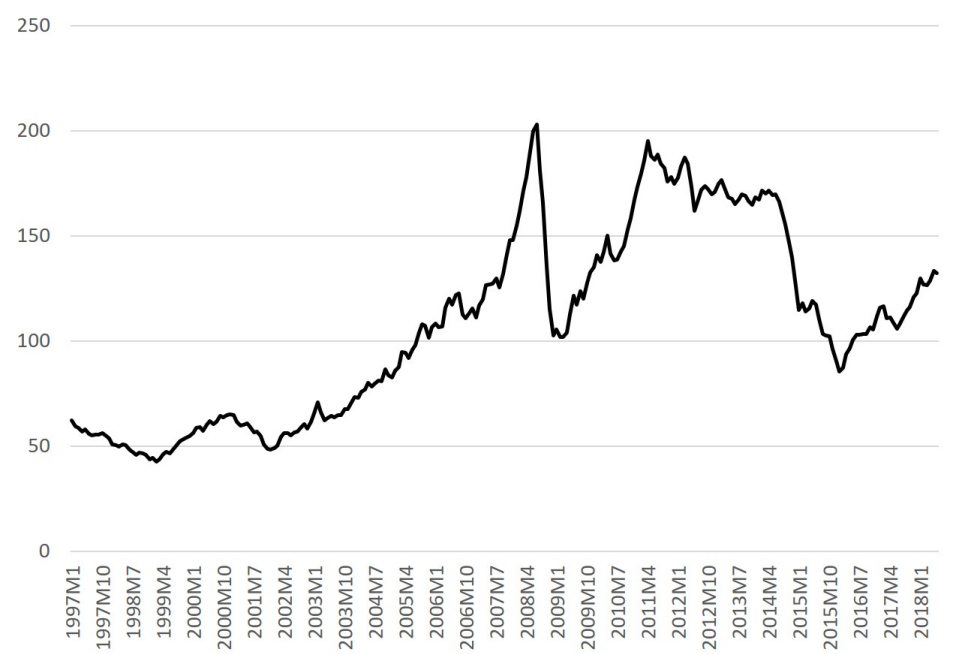

Fonte: Elaboração própria a partir dos dados do Fundo Monetário Internacional. *2016=100.

Tabela 1.1- Multiplicadores pré-crise / amostra inteira. Controle: taxa selic.

\begin{tabular}{|l|l|l|l|}
\hline Tipo de Gasto & $\begin{array}{l}\text { Multiplicador } \\
\text { impacto } \\
\mathrm{t}=1)\end{array}$ & $\begin{array}{l}\text { Multiplicador de pico (o } \\
\text { respectivo período em } \\
\text { que ocorre é indicado por } \\
\text { "t") }\end{array}$ & $\begin{array}{l}\text { Multiplicador } \\
\text { acumulado (15 } \\
\text { ou 25 meses a } \\
\text { depender da } \\
\text { persistência) }\end{array}$ \\
\hline $\begin{array}{l}\text { Despesa primá- } \\
\text { ria total }\end{array}$ & $0.33 / 0.37$ & $0.33(\mathrm{t}=1) / 0.37(\mathrm{t}=1)$ & $0.58 / 0.57$ \\
\hline Receita primária & $-0.19 /-0.38$ & $-0.03(\mathrm{t}=6) / 0.072(\mathrm{t}=6)$ & $-0.27 /-0.23$ \\
\hline $\begin{array}{l}\text { Investimento pú- } \\
\text { blico }\end{array}$ & $1.5 / 1.4$ & $1.5(\mathrm{t}=1) / 2.16(\mathrm{t}=7)$ & $1.41 / 3.35$ \\
\hline Benefícios sociais & $0.82 / 0.75$ & $1.25(\mathrm{t}=2) / 1.14(\mathrm{t}=5)$ & $2 / 2.9$ \\
\hline Pessoal & $0.03 / 0.09$ & $0.1(\mathrm{t}=2) / 0.09(\mathrm{t}=1)$ & $-0.67 /-1.15$ \\
\hline Subsídios & $-0.1 / 0.14$ & $0.085(\mathrm{t}=4) / 0.14(\mathrm{t}=1)$ & $-0.54 /-0.08$ \\
\hline Demais despesas & $0.33 / 0.39$ & $0.33(\mathrm{t}=1) / 0.39(\mathrm{t}=1)$ & $-0.1 / 0.02$ \\
\hline
\end{tabular}


Tabela 1.2- Multiplicadores pré-crise / amostra inteira. Controle: taxa selic anualizada.

\begin{tabular}{|l|l|l|l|}
\hline Tipo de Gasto & $\begin{array}{l}\text { Multiplicador } \\
\text { impacto (em } \\
\mathrm{t}=1)\end{array}$ & $\begin{array}{l}\text { Multiplicador de pico (o } \\
\text { respectivo período em } \\
\text { que ocorre é indicado por } \\
\text { "t") }\end{array}$ & $\begin{array}{l}\text { Multiplicador } \\
\text { acumulado } 15 \\
\text { ou 25 meses a } \\
\text { depender da } \\
\text { persistência) }\end{array}$ \\
\hline $\begin{array}{l}\text { Despesa primá- } \\
\text { ria total }\end{array}$ & $0.33 / 0.37$ & $0.33(\mathrm{t}=1) / 0.37(\mathrm{t}=1)$ & $0.54 / 0.58$ \\
\hline Receita primária & $-0.17 /-0.37$ & $-0.005(\mathrm{t}=6) / 0.081(\mathrm{t}=6)$ & $-0.17 /-0.19$ \\
\hline $\begin{array}{l}\text { Investimento pú- } \\
\text { blico }\end{array}$ & $1.4 / 1.35$ & $1.4(\mathrm{t}=1) / 2.11(\mathrm{t}=7)$ & $1.1 / 3.28$ \\
\hline Benefícios sociais & $0.82 / 0.81$ & $1.28(\mathrm{t}=2) / 1.21(\mathrm{t}=5)$ & $2 / 3$ \\
\hline Pessoal & $0.065 / 0.12$ & $0.15(\mathrm{t}=2) / 0.12(\mathrm{t}=1)$ & $-0.65 /-1.1$ \\
\hline Subsídios & $-0.12 / 0.14$ & $0.052(\mathrm{t}=4) / 0.14(\mathrm{t}=1)$ & $-0.6 /-0.09$ \\
\hline Demais despesas & $0.31 / 0.36$ & $0.31(\mathrm{t}=1) / 0.36(\mathrm{t}=1)$ & $-0.34 /-0.3$ \\
\hline
\end{tabular}

Tabela 1.3- Multiplicadores pré-crise / amostra inteira. Controle: taxa de câmbio.

\begin{tabular}{|l|l|l|l|}
\hline Tipo de Gasto & $\begin{array}{l}\text { Multiplicador } \\
\text { impacto } \\
\mathrm{t}=1)\end{array}$ & $\begin{array}{l}\text { Multiplicador de pico (o } \\
\text { respectivo período em } \\
\text { que ocorre é indicado por } \\
\text { "t") }\end{array}$ & $\begin{array}{l}\text { Multiplicador } \\
\text { acumulado } \\
\text { ou 25 meses a } \\
\text { depender da } \\
\text { persistência) }\end{array}$ \\
\hline $\begin{array}{l}\text { Despesa primá- } \\
\text { ria total }\end{array}$ & $0.33 / 0.38$ & $0.33(\mathrm{t}=1) / 0.38(\mathrm{t}=1)$ & $0.59 / 0.61$ \\
\hline Receita primária & $-0.17 /-0.38$ & $-0.007(\mathrm{t}=6) / 0.08(\mathrm{t}=6)$ & $-0.21 /-0.23$ \\
\hline $\begin{array}{l}\text { Investimento pú- } \\
\text { blico }\end{array}$ & $1.6 / 1.5$ & $1.6(\mathrm{t}=1) / 2.3(\mathrm{t}=7)$ & $1.41 / 3.5$ \\
\hline Benefícios sociais & $0.78 / 0.82$ & $1.26(\mathrm{t}=2) / 1.2(\mathrm{t}=5)$ & $1.94 / 2.92$ \\
\hline Pessoal & $0.02 / 0.1$ & $0.12(\mathrm{t}=2) / 0.1(\mathrm{t}=1)$ & $-0.6 /-1$ \\
\hline Subsídios & $-0.07 / 0.15$ & $0.15(\mathrm{t}=4) / 0.17(\mathrm{t}=4)$ & $-0.4 /-0.009$ \\
\hline Demais despesas & $0.34 / 0.38$ & $0.34(\mathrm{t}=1) / 0.38(\mathrm{t}=1)$ & $-0.05 / 0.022$ \\
\hline
\end{tabular}


Capítulo 1. Primeiro Artigo: A contribuição da política fiscal para a crise brasileira recente: uma análise 86 baseada em multiplicadores de despesas e receitas primárias do governo central no período 1997-2018

Tabela 1.4- Multiplicadores pré-crise / amostra inteira. Controle: preço de commodities.

\begin{tabular}{|l|l|l|l|}
\hline Tipo de Gasto & $\begin{array}{l}\text { Multiplicador } \\
\text { impacto }(\mathrm{em} \\
\mathrm{t}=1)\end{array}$ & $\begin{array}{l}\text { Multiplicador de pico (o } \\
\text { respectivo período em } \\
\text { que ocorre é indicado por } \\
\text { "t") }\end{array}$ & $\begin{array}{l}\text { Multiplicador } \\
\text { acumulado } \\
\text { ou 25 meses a } \\
\text { depender da } \\
\text { persistência) }\end{array}$ \\
\hline $\begin{array}{l}\text { Despesa primá- } \\
\text { ria total }\end{array}$ & $0.35 / 0.39$ & $0.35(\mathrm{t}=1) / 0.39(\mathrm{t}=1)$ & $0.65 / 0.68$ \\
\hline Receita primária & $-0.18 /-0.4$ & $-0.06(\mathrm{t}=6) / 0.019(\mathrm{t}=6)$ & $-0.33 /-0.38$ \\
\hline $\begin{array}{l}\text { Investimento pú- } \\
\text { blico }\end{array}$ & $1.5 / 1.4$ & $1.5(\mathrm{t}=1) / 2.1(\mathrm{t}=7)$ & $1.32 / 3.12$ \\
\hline Benefícios sociais & $0.8 / 0.8$ & $1.2(\mathrm{t}=2) / 1.24(\mathrm{t}=5)$ & $2 / 3$ \\
\hline Pessoal & $0.02 / 0.14$ & $0.12(\mathrm{t}=2) / 0.14(\mathrm{t}=1)$ & $-0.57 /-0.7$ \\
\hline Subsídios & $-0.11 / 0.12$ & $0.17(\mathrm{t}=4) / 0.26(\mathrm{t}=7)$ & $-0.25 / 0.35$ \\
\hline Demais despesas & $0.36 / 0.38$ & $0.36(\mathrm{t}=1) / 0.38(\mathrm{t}=1)$ & $0.1 / 0.0023$ \\
\hline
\end{tabular}

Tabela 1.5 -Multiplicadores pré-crise / amostra inteira. Com os três controles.

\begin{tabular}{|l|l|l|l|}
\hline Tipo de Gasto & $\begin{array}{l}\text { Multiplicador } \\
\text { impacto } \\
\mathrm{t}=1)\end{array}$ & $\begin{array}{l}\text { Multiplicador de pico (o } \\
\text { respectivo período em } \\
\text { que ocorre é indicado por } \\
\text { "t") }\end{array}$ & $\begin{array}{l}\text { Multiplicador } \\
\text { acumulado (15 } \\
\text { ou meses a } \\
\text { depender da } \\
\text { persistência) }\end{array}$ \\
\hline $\begin{array}{l}\text { Despesa primá- } \\
\text { ria total }\end{array}$ & $0.37 / 0.4$ & $0.37(\mathrm{t}=1) / 0.4(\mathrm{t}=1)$ & $0.73 / 0.75$ \\
\hline Receita primária & $-0.25 /-0.43$ & $-0.09(\mathrm{t}=6) / 0.01(\mathrm{t}=6)$ & $-0.46 /-0.42$ \\
\hline $\begin{array}{l}\text { Investimento pú- } \\
\text { blico }\end{array}$ & $1.55 / 1.46$ & $1.55(\mathrm{t}=1) / 2.17(\mathrm{t}=7)$ & $1.16 / 3.05$ \\
\hline Benefícios sociais & $0.78 / 0.77$ & $1.22(\mathrm{t}=2) / 1.27(\mathrm{t}=5)$ & $1.96 / 3.04$ \\
\hline Pessoal & $0.09 / 0.19$ & $0.17(\mathrm{t}=2) / 0.19(\mathrm{t}=1)$ & $-0.65 /-1$ \\
\hline Subsídios & $-0.06 / 0.17$ & $0.3(\mathrm{t}=4) / 0.17(\mathrm{t}=4)$ & $-0.05 / 0.39$ \\
\hline Demais despesas & $0.41 / 0.4$ & $0.41(\mathrm{t}=1) / 0.4(\mathrm{t}=1)$ & $0.4 / 0.22$ \\
\hline
\end{tabular}

\subsubsection{Apêndice B: Estimação da elasticidade da receita primária líquida com relação ao produto}

Para além de ser importante na estimação dos modelos VAR, a elasticidade da receita com relação ao produto é fundamental no exercício da razão Dívida/PIB nos cenários. De acordo com Andreis (2016), a elasticidade da receita em relação ao produto é estimada com base em duas abordagens. A primeira segue a metodologia do balanço 
orçamentário estrutural do FMI, desenvolvida por Hagemann (1999), que trata a receita primária de forma agregada. A segunda forma de estimação é com base na metodologia da OCDE, de Giorno et al (1995), que trata a receita de forma desagregada. Para cada grupo de receita, estima-se a sua elasticidade com relação à sua base de incidência e, posteriormente, a elasticidade da base de incidência em relação ao hiato do produto.

Os componentes da receita primária líquida devem ter relação com o ciclo econômico para o cálculo da elasticidade. Desta forma, este trabalho segue as recomendações de Gobetti et al (2016): foram retirados os componentes da receita primária do governo central que possuem baixa correlação com a atividade econômica ${ }^{47}$ : receitas patrimoniais, concessões, permissões, dividendos, bem como receitas tributárias com pouca relação com o ciclo econômico ou que possuem caráter regulatório: contribuição previdenciária dos servidores públicos; Imposto sobre Operações Financeiras (IOF), que sofre alterações frequentes de alíquotas; CIDE combustível, que possui base tributária muito específica; e CPMF, que foi extinta em 2007 e, de acordo com os autores, apresentou evolução bastante próxima da elasticidade unitária. Foram considerados, portanto, no cômputo da receita primária líquida: Imposto sobre Importação (II), Impostos sobre Produtos Industrializados (IPI), Imposto de Renda (IR), Contribuição para o Financiamento para a Seguridade Social (Cofins), Programa de Integração Social (PIS) e Programa de Formação do Patrimônio do Servidor Público (Pasep), Contribuição Social sobre Lucro Líquido (CSLL), arrecadação previdenciária, contribuição de salário educação e outras receitas administradas pela Receita Federal.

\subsubsection{Método FMI (agregado)}

Os modelos estimam a resposta da receita primária líquida em relação ao produto, em termos reais, dessazonalizados e em logaritmo. Como as variáveis estão em logaritmo, a interpretação de elasticidade é direta, como apontam Marcel et al (2002).

Apesar de as séries da receita líquida e do produto serem não estacionárias pelo teste ADF, optou-se por estimar as regressões em nível de forma que as relações de longo prazo entre as variáveis não fossem perdidas. Para que não haja relações espúrias é importante que as séries sejam integradas de mesma ordem e cointegradas. Desta forma, foram realizados os testes de Engle Granger e de Johansen. Os resultados apontam para a existência de cointegração.

Foram estimadas várias equações. Conforme os controles foram introduzidos, foi-se observando o ajuste do modelo. Foram realizados testes de autocorrelação serial (LM) e de heterocedasticidade $(\mathrm{ARCH})$, bem como foram computadas as medidas de erros

$\overline{47}$ Como Gobetti et al (2016) afirmam: "ou estão relacionadas centralmente a outros fatores e precisam ser analisadas separadamente, como no caso dos royalties de petróleo e dos dividendos recebidos das empresas estatais" (Gobetti et al, 2016, p.35). 
Capítulo 1. Primeiro Artigo: A contribuição da política fiscal para a crise brasileira recente: uma análise 88 baseada em multiplicadores de despesas e receitas primárias do governo central no período 1997-2018

RMSE (Root Mean Squared Error), MAE (Mean Absolute Error) e MAPE (Mean Absolute Percent Error), além dos coeficientes de Akaike, Schwarz e HQ. Optou-se pelos modelos com ausência de autocorrelação serial e heterocedasticidade, com coeficientes significativos, maior grau de aderência e com os menores erros ${ }^{48}$.

Foram utilizadas variáveis dummy para controlar quebras estruturais e outliers, em acordo com Andreis (2014), Maciel (2006) e Andreis (2016). A variável dummy "dumdate99" foi introduzida de forma a controlar as mudanças ocorridas no modo de operar da economia brasileira em razão da adoção do "tripé macroeconômico". Tal variável assume valor 1 de janeiro de 1999 em diante e 0 nos demais. A justificativa para a introdução dessa variável é que a dinâmica orçamentária do governo se alterou, como explica Andreis (2016). A partir de 1999 torna-se recorrente o aparecimento de superávit primário fiscal. Ainda, a dinâmica se altera novamente após 2012. A partir de 2014 observa-se uma queda da receita primária líquida em relação à despesa, seja pela própria manifestação da desaceleração econômica, ou pelas políticas de desoneração tributária implementadas no período. Desta forma, introduziu-se uma variável dummy para controlar as mudanças de ciclo verificadas a partir de 2012, como sugere Andreis (2016): "dumdate12" assume valor 1 a partir do terceiro trimestre de 2012 e zero nos demais meses. Nota-se que houve mudança de padrão na tendência do produto, que começa a desacelerar nesse período, tendendo à estagnação, e, posteriormente, com queda no período a partir de 2014.

As demais variáveis dummy foram introduzidas de forma a controlar a presença de outliers: "dum10" representa um período no qual o aquecimento da economia brasileira significou um aumento significativo das receitas primárias líquidas em 2010 e vale 1 para o segundo semestre de 2010; "dum02" assume o valor 1 para os últimos quatro meses de 2002; "dum13" assume 1 para os três últimos meses para o ano de 2013 e "dum15" vale 1 para o período dos últimos quatro meses de 2015, quando houve queda acentuada da receita. Também foi colocada na regressão um termo de tendência visto que as séries do produto e da receita primária líquida são não estacionárias, porém cointegradas.

Levou-se em conta, além dos fatores acima expostos, a crise internacional de 2008, cujo efeito foi bastante transitório na economia brasileira, uma vez que houve recuperação logo em seguida. Assim optou-se pela introdução da variável dummy de forma a controlar os efeitos da crise de 2008 de duas formas: pela introdução da variável "dum08" e da variável "dummy08". A variável "dum08" assume 1 no período nos últimos quatro meses de 2008, e zero nos demais períodos - esse tipo de controle é adotado por Andreis (2014).

48 A equação "final" resultante desse processo foi: logreceitaprimáriareal $=c(1)+c(2)$ logpibreal + $c(3)$ dumdate99 $+c(4)$ dumdate $12+c(5) d u m 10+c(6) @$ trend $+c(7) d u m 02+c(8) d u m 08+c(9) d u m 13+$ $c(10) d u m 15+c(11) d u m m y 08$. Esta foi a equação estimada para a amostra inteira. Para a amostra pré-crise, foi estimada praticamente a mesma regressão, mas sem dummy "dum15". Tal equação também foi estimada com a variável do logaritmo do PIB com defasagem, como sugerem Maciel (2006) e Gobetti et al (2010), mas não houve mudanças significativas na magnitude da elasticidade, nem em termos de ajuste do modelo. 
Por outro lado, a literatura sugere o controle da crise de 2008 também por uma dummy que seja 1 a partir de 2008 até o final da amostra, e zero nos períodos anteriores (que chamaremos de "dummy08"). Dentre os estudos que consideram que é necessário tratar os períodos pré e pós-crise de 2008 de forma separada está o de Ribeiro (2016). O autor não utiliza variável dummy, mas estima a elasticidade da receita em duas amostras, pré e pós-crise, por meio de uma abordagem de cointegração, que será discutida adiante. Já Casalecchi e Barros (2018), em nota técnica da Instituição Fiscal Independente (IFI), calcularam a elasticidade da receita considerando uma interação da variável do produto com a dummy da crise de 2008, que assume valor 1 a partir do quarto trimestre de 2008 até o final do período considerado (2018), bem como incluíram esta dummy na regressão. Diante disto, optou-se por estimar a elasticidade da receita considerando ambos os controles.

Entre os estudos para o Brasil que consideraram a metodologia do FMI, estão o de Andreis (2014), para 1997 a 2013; Andreis (2016), para 1997 a 2015; e Maciel (2006), para 1999 a 2005. Os autores encontram valores para as elasticidades de, respectivamente: 1.084; 1.11 e 1.026. Utilizando o mesmo procedimento, Marcel et al (2002) encontram a elasticidade de 1.05 para a economia chilena, para o período de 1987 a 2001.

Casalecchi e Barros (2018) estimam uma regressão de MQO para três grupos de receitas: receitas tributárias, receitas previdenciárias e receitas mais sujeitas à variação com o ciclo. Entre essas últimas, incluem-se os tributos sobre a renda do trabalho, sobre a folha de pagamento, sobre a renda corporativa, sobre importação e sobre ganhos de capital, além de tributos indiretos, isto é, são os grupos considerados na receita primária líquida neste trabalho. Os resultados das estimativas são, respectivamente para os grupos: $1.11 ; 1.0$ e 1.13.

Desta forma, as estimativas do presente estudo ficaram próxima das da literatura: 1.09 para a equação que estima a elasticidade da receita incluindo os controles: damdate99, dumdate12, dum10, trend, dum02, dum08, dum13 e dum 15. E de 1.2 para uma equação similar, mas que trata a crise de 2008 com a variável dummy08, como explicado nos parágrafos acima. Trata-se de uma regressão que inclui os seguintes controles : dumdate99, dumdate12, trend, dum02, dummy08, dum13 e dum15.

\subsubsection{Método DOLS}

Gobetti et al (2016) estimam a elasticidade da receita por meio de Dynamic Ordinary Least Squares (DOLS), proposto por Stock e Watson (1993). Os dados são para o governo central, também utilizados neste trabalho, mas os autores acrescentam estados e municípios. Este método está relacionado ao fato de que as séries são não estacionárias, adicionando-se lags e leads da primeira diferença da variável independente. Assim, trata-se de um método que busca corrigir possíveis problemas de viés nas estimativas MQO. Os 
Capítulo 1. Primeiro Artigo: A contribuição da política fiscal para a crise brasileira recente: uma análise 90 baseada em multiplicadores de despesas e receitas primárias do governo central no período 1997-2018

autores alertam para o uso da correção dos erros-padrão, de Newey e West (1987). A elasticidade da receita de longo prazo é calculada, portanto, por uma regressão DOLS do logaritmo da receita primária líquida sobre o logaritmo do produto, com um lag e um lead, de forma a cumprir o critério da parcimônia. Esse valor de elasticidade de longo prazo é do qual não se espera que haja desvio sistemático ao decorrer do tempo e seu cálculo é importante em razão de sazonalidade nos dados, como apontam Casalecchi e Barros (2018).

Gobetti et al (2016) estimam a elasticidade de longo prazo para o período de 1997 a 2016 e encontram, após ajustes nas séries, o coeficiente de 1.2372. Tais ajustes compreendem o "taxcorrection", que consiste em harmonização das séries de receita supondo que a legislação tributária fosse a mesma ao longo de todo o período (tais correções foram de particular importância no período de oneração de 1997 a 2004 e de desonerações, de 2007 a 2016). Além disso, os autores corrigiram as séries de forma a retirar as receitas atípicas, como as do Refis. Já Casalecchi e Barros (2018), que também fazem os ajustes nas séries de forma a captar as receitas recorrentes, calculam a elasticidade para as receitas recorrentes de tributos sensíveis ao ciclo e chegam ao resultado de que, no período anterior à crise de 2008, de 1997 a 2008, a elasticidade era de 1.23 e, após 2008, de 0.95. Essa queda é atribuída sobretudo à menor participação da indústria no produto .

Ribeiro (2016) também estima um DOLS de 2000 a 2016, utilizando a série "receitas recorrentes" do IBRE e chega à conclusão de que a elasticidade é de 1.162. Quando o exercício é dividido em duas amostras, o resultado é de 1.686 para o período pré-crise de 2008 e de 1.009 no período posterior, também revelando uma queda da elasticidade da receita nos últimos anos.

Dada a existência de cointegração entre as variáveis, os autores sugerem o uso de um mecanismo de correção de erros a fim de encontrarem as elasticidades de curto prazo. Gobetti el al (2016) encontram 1.0844 e Casalecchi e Barros (2018), 1.36 (pré e pós crise) para as receitas recorrentes ajustáveis ao ciclo para os valores da elasticidade de curto prazo.

\subsubsection{Método OCDE (desagregado)}

Ao contrário das metodologias anteriores, este trabalho não irá estimar a elasticidade por este método por razões práticas (de disponibilidade de dados). A metodologia utiliza a receita de forma desagregada, de acordo com Giorno et al (1995). Para o Brasil destacam-se dois estudos. Mello e Moccero (2006) dividem as receitas em quatro grupos e acham os seguintes resultados: a) imposto sobre a renda pessoal: elasticidade de 2.7 (enquanto que a média da OCDE é de 1.26); b) seguridade social: 0.67 (próxima à média da OCDE, de $0.71)$;c) imposto sobre renda de pessoa jurídica: 1.17 (abaixo da média da OCDE, de 1.5) e d) impostos indiretos, de elasticidade unitária. 
Peres (2006) também encontra elasticidades desagregadas, dividindo a receita em oito categorias, e considerando que as receitas que têm pouca relação com o ciclo tenham elasticidade zero. Tais categorias englobam comércio exterior, produção industrial, renda das empresas, renda dos indivíduos, movimentação financeira, faturamento e folha de pagamentos. Essas elasticidades são ponderadas pela participação do respectivo componente na receita total. Depois, soma-se as elasticidades ponderadas e o autor chega à elasticidade da receita ao produto de 2.0322 .

Figura 13 - Resumo das estimações da elasticidade da receita encontradas nos estudos

\begin{tabular}{|c|c|c|c|c|c|c|c|c|c|}
\hline & $\begin{array}{l}\text { Peres } \\
(2006)\end{array}$ & $\begin{array}{l}\text { Maciel } \\
(2006)\end{array}$ & $\begin{array}{l}\text { Andreis } \\
(2014)\end{array}$ & $\begin{array}{l}\text { Andreis } \\
\text { (2016) }\end{array}$ & is $\begin{array}{l}\text { Gobetti } \\
\text { et al } \\
(2016)\end{array}$ & $\begin{array}{l}\text { Ribeiro } \\
\text { (2016) }\end{array}$ & \multicolumn{2}{|c|}{$\begin{array}{l}\text { Casalecchi } \\
\text { e Barros } \\
\text { (2018) }\end{array}$} & $\begin{array}{l}\text { Casalecchi } \\
\text { e Barros } \\
\text { (2018) }\end{array}$ \\
\hline $\begin{array}{l}\text { Elasticidade } \\
\text { da receita }\end{array}$ & 2.0322 & 1.026 & 1.084 & 1.11 & $\begin{array}{l}1.23 \\
\text { (longo } \\
\text { prazo)/ } \\
1.0844 \\
\text { (curto } \\
\text { prazo) }\end{array}$ & 1.162 & $\begin{array}{l}1.23 \\
2008 \\
\text { pós-20 } \\
1.12 \\
\text { prazo) }\end{array}$ & $\begin{array}{l}\text { pré- } \\
0.95 \\
08 / \\
\text { curto }\end{array}$ & 1.13 \\
\hline Metodologia & OCDE & FMI & FMI & FMI & DOLS & DOLS & DOLS & & MQO \\
\hline Período & $\begin{array}{l}1994- \\
2005\end{array}$ & $\begin{array}{l}1999- \\
2005\end{array}$ & $\mid \begin{array}{ll}1997 & - \\
2013 & -\end{array}$ & $\begin{array}{l}1997 \\
2015\end{array}$ & $-\mid \begin{array}{ll}1997 & - \\
2016\end{array}$ & $\begin{array}{l}2000- \\
2015\end{array}$ & $\begin{array}{l}1997- \\
2018\end{array}$ & & $\begin{array}{l}1998 \\
2018\end{array}$ \\
\hline & \multicolumn{2}{|c|}{$\begin{array}{l}\text { Casalecchi } \\
\text { Barros (2018) }\end{array}$} & \multicolumn{2}{|c|}{ Este Estudo } & Este Estudo & \multicolumn{2}{|c|}{ Este estudo } & \multicolumn{2}{|c|}{ Este estudo } \\
\hline $\begin{array}{l}\text { Elasticidade } \\
\text { da receita }\end{array}$ & \multicolumn{2}{|l|}{0.68} & \multicolumn{2}{|l|}{0.8522} & 1.0944 & \multicolumn{2}{|c|}{1.1997} & \multicolumn{2}{|c|}{1.247} \\
\hline Metodologia & \multicolumn{2}{|l|}{ MQO } & \multicolumn{2}{|l|}{ FMI } & DOLS & \multicolumn{2}{|l|}{ FMI } & \multicolumn{2}{|l|}{ DOLS } \\
\hline Período & \multicolumn{2}{|c|}{$1998-2008$} & \multicolumn{2}{|c|}{ 1997-2014 } & 1997-2014 & \multicolumn{2}{|c|}{$1997-2018$} & \multicolumn{2}{|c|}{$1997-2018$} \\
\hline
\end{tabular}

Fonte: Elaboração própria.

Utilizaremos as elasticidades estimadas tanto pelo DOLS como pelo método FMI a fim de verificarmos robustez. No entanto, de início, escolhemos utilizar as estimativas do método FMI, tendo em vista que as estimativas do DOLS são para um prazo mais longo. A tabela exposta na Figura 13 sumariza os resultados encontrados na literatura e neste estudo. 



\section{Segundo Artigo - Os efeitos estabilizadores dos benefícios sociais: uma análise de mul- tiplicadores fiscais para o Brasil no período $1997-2018$}

\subsection{Introdução}

De acordo com a Organização Internacional do Trabalho (OIT), apenas 27\% da população mundial possui adequada cobertura de proteção social, enquanto que mais de 50\% não possui sequer uma rede mínima de seguridade, a despeito do significante avanço na extensão de redes de proteção social pelos países, desde o século passado ${ }^{1}$. Para além da questão fundamental relacionada aos direitos humanos, os benefícios sociais possuem importante impacto social e econômico. Há vários estudos que evidenciam que os gastos sociais (gastos em educação, saúde e, sobretudo, em proteção social) são capazes de diminuir a desigualdade de renda, bem como atuam de forma a amenizar a pobreza (Sanchez e Perez, 2018; Claus et al, 2012; Bhorat et al, 2017; Ospina, 2010; Haile e Zarazúa, 2018; Holzner, 2011; Ocampo e Arteaga, 2016; Wagle, 2016; Ulu, 2018; Niehues, 2010; Kozuharov e Petkovski, 2018; Vazquez, et al 2012). Se por um lado a literatura vem se debruçando sobre as questões associadas aos impactos socioeconômicos dos gastos sociais, por outro, os seus efeitos macroeconômicos têm sido pouco explorados. Em particular, os efeitos multiplicadores de renda sobre o produto desse tipo específico de despesa primária não têm recebido muita atenção.

A literatura sobre multiplicadores fiscais expandiu significativamente desde a Crise Global de 2008. Essa literatura inicialmente estimou multiplicadores associados à despesa primária total, bem como à receita, como em Blanchard e Perotti, 2002. A partir daí, e sobretudo mais recentemente, os autores passaram a adotar uma abordagem mais desagregada. Em particular, quando desagregamos os diferentes tipos de gastos, a literatura usualmente encontra um efeito multiplicador no PIB maior e mais persistente para o investimento público, em detrimento do consumo do governo (Tenhofen et al, 2010; Garcia et al, 2013; Çebi, 2015; Vdovychenko, 2018; Peres, 2006; Castro, 2003; Burriel et al, 2010; Lozano e Rodriguez, 2011; Borg, 2014; Benetrix e Lane, 2009; Ilzetski et al 2013, Orair et al, 2016; Pires, 2011; Pires, 2014, Mançellari, 2011; entre outros autores).

1 Dado disponível em www.ilo.org/global/topics/social-security/lang-en/index.htm. Esses dados se referem aos seguintes gastos: "access to health care and income security, particularly in cases of old age, unemployment, sickness, invalidity, work injury, maternity or loss of a main income earner". 
Capítulo 2. Segundo Artigo - Os efeitos estabilizadores dos benefícios sociais: uma análise de multiplicadores fiscais para o Brasil no período 1997-2018

O maior interesse nos efeitos multiplicadores associados aos gastos sociais especificamente emergiu depois da crise global de 2008 (Galdon, 2013), quando o American Recovery and Reinvestment Act (ARRA) foi implementado nos Estados Unidos. Em particular, o papel das transferências sociais foi enfatizado. Contudo, apenas poucos estudos focaram na estimação do efeito dos gastos com proteção social (ou benefícios sociais) na economia - que englobam transferências de renda, como seguro-desemprego e cash transfers; bem como a seguridade social. Blanchard e Perotti (2002) e Perotti (2004), que são estudos que serviram de base para a literatura em geral, tratam as transferências como um componente a ser subtraído da receita total, uma estratégia que foi seguida por muitos autores (Tenhofen et al, 2010; Lozano e Rodriguez, 2011; Peres, 2006; Peres e Ellery, 2009; Alves, 2017; Mendonça et al, 2016; Grudtner e Aragon, 2017; Jemec et al, 2013; Castro e Fernandez, 2011; Burriel et al, 2010; Giordano et al, 2007; Borg, 2014; Skrbic e Simovic, 2015; entre outros), mas que tem sido criticada por outros (Gáldon, 2013; Gechert et al, 2018; Baum e Koester, 2011; Pereira e Wemans, 2013). Essas críticas, que serão detalhadas na seção 2.3, vão na direção do fato de que, apesar da grande importância dos gastos sociais, que ocupam um expressivo espaço dentro do Orçamento público em muitos países, pouco tem se falado de seus efeitos multiplicadores, a despeito dos numerosos estudos.

No Brasil, a crise econômica enfrentada pelo país recentemente e o atual desafio fiscal, caracterizado por um expressivo aumento do déficit primário do governo federal e da dívida pública nos últimos anos, estimulou o debate sobre as formas de ajuste fiscal e seus impactos sobre o crescimento econômico. De um lado, estão os que fazem o diagnóstico de que as despesas obrigatórias associadas aos benefícios sociais garantidos pela Constituição de 1988 - que criou um regime de assistência e previdência social mais inclusivo - é que seriam responsáveis pelo colapso fiscal e a crise seria fruto desse esgotamento (Pessôa, 2014; Almeida et al, 2015; Pessôa, 2017). De outro, estão os que questionam essa visão, afirmando que apenas uma parte do crescimento de tais despesas obrigatórias é devida à Constituição. Haveria, assim, uma parcela do crescimento estrutural das despesas primárias associada aos reajustes reais de salário mínimo, que fornece o piso para o valor dos benefícios (Pires e Borges, 2019).

Entre os que defendem formas alternativas de ajuste fiscal, que não seja centrado no diagnóstico que culpabiliza as despesas obrigatórias, o papel do investimento público é destacado, por ser um tipo de despesa governamental com alto efeito multiplicador (Orair e Gobetti, 2017b; Orair et al, 2016; Orair, 2016). Todavia, mesmo deste lado do debate, falta tratar da importância dos benefícios sociais, especificamente, na sustentação da demanda agregada e seu papel na crise econômica, tendo em vista que há evidências de que seu efeito multiplicador é até mesmo comparável ao do investimento público (Orair et al, 2016; Resende, 2019).

Se o efeito multiplicador do investimento público, que é geralmente maior e mais 
persistente do que das demais despesas primárias, já é bem conhecido e documentado também na literatura em âmbito nacional (Orair et al, 2016; Pires, 2011; Pires, 2014; Peres, 2006; Cattan, 2017; Dutra, 2016; Castelo Branco et al, 2015; entre outros), são poucos os estudos que tratam dos benefícios sociais. No Brasil, destaca-se o estudo de Orair et al (2016), que estimam multiplicadores para este tipo de despesa de magnitude elevada, sobretudo em recessões. Desta forma, na literatura sobre multiplicadores - tanto nacional quanto internacional - há um relativo consenso em torno dos investimentos públicos, mas não para os benefícios sociais.

A rede de proteção social desempenha papel relevante na manutenção da estabilização da renda disponível e da demanda agregada. Países com estabilizadores automáticos mais fortes mostram maior resiliência em crises (Dolls et al, 2010). Não só o papel de estabilizador automático (como é o caso do seguro-desemprego) deve ser enfatizado, como também das políticas discricionárias voltadas aos benefícios sociais. Embora no Brasil o papel de estabilizador automático dos gastos sociais seja questionado, apresentando relativa independência das transferências do ciclo econômico (Gobetti et al, 2010), a manutenção dos benefícios sociais - cuja boa parte são despesas rígidas garantidas pela Constituição Federal e, portanto, não passíveis de cortes em programas de ajuste - pode evitar o aprofundamento de uma situação de crise.

Dado que em meio ao ajuste fiscal essas despesas continuaram crescendo por serem obrigatórias (ao contrário de investimentos públicos), que papel elas podem ter tido em exacerbar ou evitar uma queda maior do PIB? O artigo pretende analisar o efeito desse tipo de despesa no produto especificamente no cenário da crise recente. Para isso, o artigo conta com quatro seções, além desta introdução. A seção 2.2 desagrega a variável dos benefícios sociais e analisa sua evolução ao longo do tempo. A seção 2.3 apresenta uma revisão de literatura com os estudos que focam nos multiplicadores fiscais associados a transferências sociais. A seção 2.4 apresenta a metodologia. Por fim, as seções 2.5 e 2.6 apresentam os resultados e as conclusões, respectivamente.

\subsection{Benefícios Sociais no Brasil}

De acordo com estimativas realizadas por Pires e Borges (2019), a despesa primária do governo federal passou de $12.7 \%$ do PIB em 1986 para 19.5\% em 2016. Em termos do PIB potencial, houve incremento de 5.9 pontos percentuais entre 1988 e 2016 . Os autores mostram que o item que gera esse crescimento estrutural são as despesas com previdência e assistência social. O crescimento desse tipo de despesa se deve não apenas ao envelhecimento da população, mas sobretudo a um aumento no valor médio dos benefícios. De acordo com as estimativas do artigo, a política de reajuste de salário mínimo praticada desde 1995, com o controle da inflação, explica parte desse aumento do valor médio dos 
Capítulo 2. Segundo Artigo - Os efeitos estabilizadores dos benefícios sociais: uma análise de multiplicadores fiscais para o Brasil no período 1997-2018

benefícios previdenciários entre 1988 e 2016. Ao levar em conta também os benefícios de caráter assistencial, do aumento de 5.9 pontos percentuais do gasto primário do governo central entre 1988 e 2016, 1.9 pontos percentuais devem-se a políticas de reajuste de salário mínimo, cujo incremento, entre 1988 e 2016, foi de $62 \%$ de seu valor real. As despesas criadas pela Constituição responderiam por 1.5 pontos percentuais. Uma parte menor (0.5 p.p) é explicada por reajustes reais de benefícios previdenciários acima de um salário-mínimo.

Portanto, o crescimento estrutural das despesas com benefícios sociais não se deve apenas à Constituição, mas a reajustes reais relevantes no valor do piso desses benefícios (pelo salário mínimo), que ocorreu em todos os governos após a estabilização. Os autores frisam que, embora a Constituição tenha relação com esses reajustes reais, ela apenas definiu um piso real, determinando sua preservação do poder de compra ao longo do tempo. Logo, um dos elementos principais da dinâmica desses gastos são os reajustes de salário-mínimo. A característica de despesa mais "rígida", não passível de tantos cortes como é o caso do investimento público, pode ter conferido aos benefícios sociais um possível efeito de evitar um aprofundamento da recessão recente.

Além de seu possível efeito estabilizador na crise, os benefícios sociais possuem um importante impacto distributivo. De acordo com um estudo do Ipea (2011), os gastos sociais -seja com saúde, educação ou previdência e assistência - são importantes para compensar as deficiências da estrutura tributária do país, caracterizada por forte regressividade, sobretudo nas camadas mais pobres e intermediárias.

A Tabela 4, representada a seguir, apresenta a variável "benefícios sociais" em seus componentes, com uma breve descrição. A expansão da transferência de renda direta no Brasil iniciou-se, em grande medida, com a promulgação da Constituição de 1988 e foi reforçada na década de 1990, com a aprovação da Lei Orgânica de Assistência Social (LOAS), a qual instituiu o Benefício de Prestação Continuada (BPC) e a aposentadoria rural. Em 2004, a transferência de renda direta no Brasil atinge nível sem precedentes com o Programa Bolsa Família (PBF) (Tupy e Toyoshima, 2013). A taxa média de variação dos benefícios sociais total, ilustrada no gráfico da Figura 14, permaneceu à frente -ou próxima- à taxa média anual de crescimento do produto.

A aposentadoria ${ }^{2}$, pelo seu caráter de pagamento obrigatório, é o componente que mais apresentou estabilidade nas taxas de variação ao longo dos subperíodos. Há uma tendência crescente bastante persistente em virtude não apenas do envelhecimento da população, mas do aumento do valor médio dos benefícios - como indicam Pires e Borges (2019) - que ocorreu por alguns canais, como o fortalecimento do salário mínimo e elevação do valor do piso previdenciário.

$\overline{2}$ A aposentadoria tratada neste artigo é referente ao Regime Geral da Previdência Social (RGPS) e inclui as esferas urbana e rural. 


\begin{tabular}{|c|c|}
\hline $\begin{array}{l}\text { Programa Bolsa Famí- } \\
\text { lia }(\mathrm{PBF})\end{array}$ & $\begin{array}{l}\text { "O Bolsa Família é um programa federal destinado às famílias em } \\
\text { situação de pobreza e extrema pobreza, com renda per capita de até } \\
\mathrm{R} \$ 154 \text { mensais, que associa à transferência do benefício financeiro do } \\
\text { acesso aos direitos sociais básicos - saúde, alimentação, educação e as- } \\
\text { sistência social. Através do Bolsa Família, o governo federal concede } \\
\text { mensalmente benefícios em dinheiro para famílias mais necessitadas" } \\
\text { - Descrição disponível em "www.bolsafamilia.datasus.gov.br". }\end{array}$ \\
\hline Aposentadoria & $\begin{array}{l}\text { Os benefícios de Aposentadoria são regulamentados pelo Regime } \\
\text { Geral de Previdência Social (RGPS). Trata-se de uma renda men- } \\
\text { sal calculada com base nos salários de contribuição do segurado e } \\
\text { de acordo com as regras de cálculo dadas pela legislação vigente. } \\
\text { Abrangem as aposentadorias, as pensões por morte, os auxílios, } \\
\text { o salário-família e o salário-maternidade (Boletim estatístico da } \\
\text { previdência social, 2015). Já a aposentadoria rural não requer con- } \\
\text { tribuição (embora o termo seja "aposentadoria", sua natureza é } \\
\text { mais assistencial) e consiste em um salário mínimo mensal, basta o } \\
\text { indivíduo provar que esteve em atividades rurais por ao menos } 15 \\
\text { anos (Souza, 2011). }\end{array}$ \\
\hline Benefício de Prestação & O BPC é um tipo de benefício assistencial, regulamentado pela Lei \\
\hline Continuada (BPC) & $\begin{array}{l}\text { Orgânica da Assistência Social - LOAS, que garante um salário } \\
\text { mínimo mensal a idosos com } 65 \text { anos ou mais de idade e a pessoas } \\
\text { portadoras de deficiência incapacitadas para o trabalho, sem a } \\
\text { obrigatoriedade de contribuições. O valor da renda familiar mensal } \\
\text { per capita dos beneficiários deve ser inferior a um quarto do salário } \\
\text { mínimo. (Boletim estatístico da previdência social, 2015). }\end{array}$ \\
\hline Seguro-desemprego & $\begin{array}{l}\text { "[...]tem por objetivo, além de prover assistência financeira temporá- } \\
\text { ria ao trabalhador desempregado em virtude de dispensa sem justa } \\
\text { causa, inclusive a indireta, auxiliá-lo na manutenção e busca de } \\
\text { emprego, promovendo para tanto, ações integradas de orientação, } \\
\text { recolocação e qualificação profissional". Descrição disponível em } \\
\text { "www.trabalho.gov.br/seguro-desemprego". }\end{array}$ \\
\hline Abono Salarial & $\begin{array}{l}\text { "O benefício do Abono Salarial assegura o valor de um salário } \\
\text { mínimo anual aos trabalhadores brasileiros que recebem em média } \\
\text { até dois salários mínimos de remuneração mensal de empregadores } \\
\text { que contribuem para o Programa de Integração Social (PIS) ou } \\
\text { para o Programa de Formação do Patrimônio do Servidor Público } \\
\text { (PASEP)". Descrição disponível em "www.trabalho.gov.br/abono- } \\
\text { salarial/". }\end{array}$ \\
\hline
\end{tabular}

Tabela 4 - Descrição dos Benefícios Sociais 
Capítulo 2. Segundo Artigo - Os efeitos estabilizadores dos benefícios sociais: uma análise de 98 multiplicadores fiscais para o Brasil no período 1997-2018

Figura 14 - Taxas de variação calculadas por média geométrica dos Benefícios Sociais em quatro subperíodos (\% ao ano)

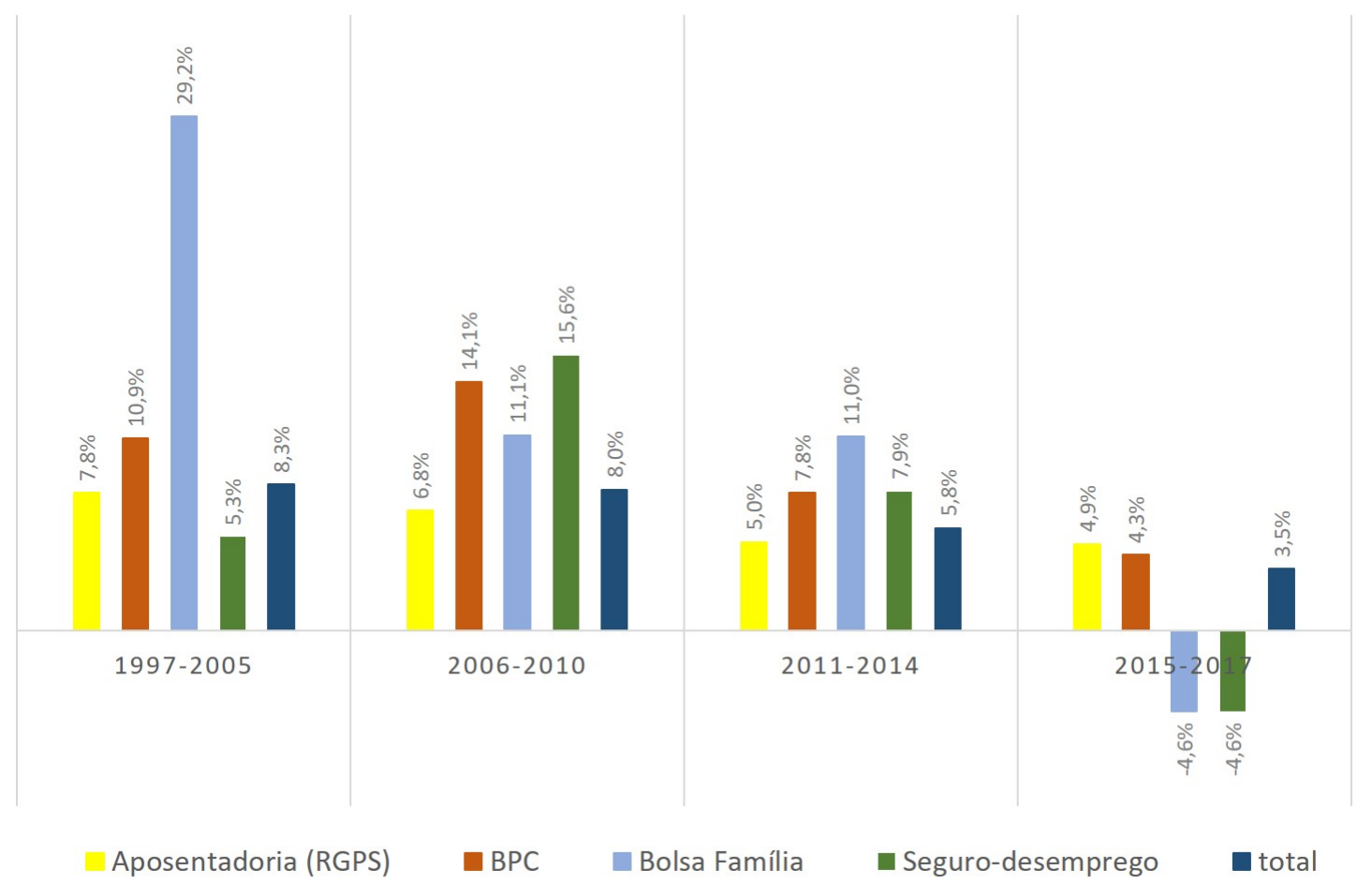

Fonte: Elaboração própria a partir dos dados de Orair e Gobetti (2017a).

O BPC é um programa de caráter assistencial, estabelecido na Constituição de 1988 e implementado a partir de 1995 (Souza, 2011). Assim como a Aposentadoria, o BPC possui relativa estabilidade, tendo em vista que seu provimento está previsto na Constituição, o que lhe confere algum grau de independência política significante. Sobre isso, há uma diferença importante em relação ao Bolsa Família, como notam Medeiros et al (2008): por estar previsto em Constituição, o BPC não pode ser alterado tão facilmente e o programa não está sujeito às vulnerabilidades de ajustes fiscais, cortes de gastos e contingenciamentos, e medidas de curto prazo em geral, como está o Bolsa Família.

Entretanto, nota-se que há destaque para o crescimento das despesas com o BPC no período 2006-2010, de $14 \%$ ao ano, ante a uma variação bem menor, embora ainda positiva, de $4.3 \%$ nos anos de recessão e ajuste fiscal 2015-2017. Ainda assim, há certa estabilidade. No caso do PBF, há um crescimento expressivo ao ano nos subperíodos anteriores a 2015, com posterior variação negativa nos anos de 2015 a 2017. Essa variação foi negativa em todos nos anos deste período, com maior corte no ano de 2014 para 2015, de pouco mais de 7\%. Portanto, os dados confirmam que o PBF está mais vulnerável a medidas de cortes de gastos.

Já o seguro-desemprego (somado com abono salarial) destaca-se por sua grande variação positiva no período 2006-2010, de pouco mais de $15 \%$ ao ano, em função dos efeitos associados ao estabilizador automático na crise de 2009 -em particular, destaca-se a 
variação alta e positiva de 2008 para 2009, de 25\%. No entanto, sua variação média anual foi negativa justamente no momento da crise: de 2014 para 2015 houve um corte bastante expressivo, de 15\%. Ainda assim, a variação média por ano dos benefícios sociais totais foi positiva no período de ajuste fiscal, pela manutenção de despesas obrigatórias, como a aposentadoria e o BPC.

Figura 15 - Benefícios Sociais como \% do PIB

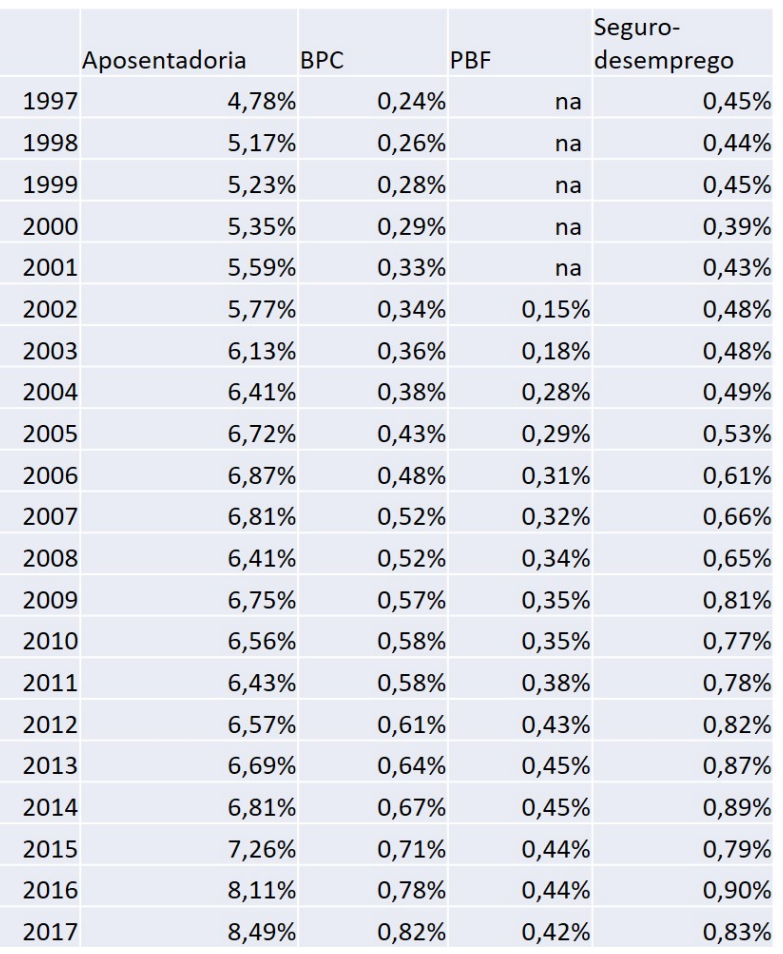

Fonte: Elaboração própria a partir de dados de Orair e Gobetti (2017a) e do IBGE.

A tabela acima, representada na Figura 15, apresenta as despesas associadas a cada item dos benefícios sociais apresentados na Tabela 4 como proporção do PIB de forma a termos alguma ideia de sua evolução ao longo do tempo. Nota-se aqui, novamente, o crescimento acentuado e sem muita oscilação das despesas relacionadas à Aposentadoria e BPC como proporção do PIB. As despesas com seguro-desemprego apresentam maior variação no tempo, em termos de \% do PIB. Já o PBF teve um crescimento na participação no produto bastante considerável desde sua criação.

De acordo com Denes et al (2016), o Programa Bolsa Família (PBF) foi criado em 2003, instituído em 2004 e unificou a gestão e a execução de alguns programas federais que já existiam, como o Programa de Renda Mínima vinculada à Educação ("Bolsa Escola Federal"), o Programa Nacional de Acesso à Alimentação ("Cartão Alimentação"), o Programa Nacional de Renda Mínima vinculado à Saúde ("Bolsa Alimentação"), o Programa Auxílio Gás, e, a partir de 2005, o Programa de Erradicação do Trabalho Infantil (PETI). Soares et al (2007) atribuem dois principais objetivos ao PBF: aliviar a situação das famílias no curto prazo, proporcionando-lhes uma renda; e combater a 
Capítulo 2. Segundo Artigo - Os efeitos estabilizadores dos benefícios sociais: uma análise de 100 multiplicadores fiscais para o Brasil no período 1997-2018

pobreza intergeracional por meio do cumprimento de condicionalidades relacionadas à educação e saúde, por exemplo.

Além dessa unificação, o programa foi também bastante ampliado, como sugere a alta taxa de crescimento por ano (de quase 30\%) observada no gráfico da Figura 14 acima, para o primeiro subperíodo (nossos dados começam em 2002, considerando os programas anteriores ao PBF). Landim Junior (2009), por exemplo, encontra um aumento substancial na porcentagem da população beneficiada pelo PBF em todos os estados, ao comparar os anos de 2004, 2005 e 2006, bem como um aumento no repasse anual per capita dos municípios de cada estado. Carvalho (2018) destaca que, enquanto em janeiro de 2004 o PBF atendia 3.6 milhões de famílias, em 2010 esse número chegava a 12.8 milhões. Em agosto de 2017, o número de famílias beneficiárias do programa era de 13.5 milhões.

\subsection{A literatura sobre multiplicadores de benefícios sociais}

Como já foi dito na Introdução, a literatura sobre multiplicadores fiscais expandiu significativamente desde a Crise Global de 2008. Em estudos para um único país, a metodologia mais convencional utilizada são modelos do tipo VAR linear (vetores autoregressivos) para estimar o impacto de um choque exógeno nas despesas públicas ou nas receitas governamentais sobre o nível de atividade econômica, seguindo Blanchard e Perotti (2002). Com base nesta metodologia, alguns estudos incluíram outras variáveis, como inflação e taxa de juros (Perotti, 2004; Burriel et al, 2010; Ravninik e Zilic, 2011; Tenhofen et al, 2010; Lozano e Rodriguez, 2011; Mançellari, 2011) ou dívida pública e taxas de câmbio (Cavalcanti e Silva, 2010; Ilzetski, 2011; Castro e Fernandez, 2011). Uma conclusão bastante comum dessa literatura é que os investimentos públicos se destacam por apresentarem multiplicadores mais altos e mais persistentes (Tenhofen et al, 2010; Garcia et al, 2013; Deleidi et al 2019; Vdovychenko, 2018; Peres, 2006; Castro, 2003; Burriel et al, 2010; Lozano e Rodriguez, 2011; Borg, 2014; Benetrix e Lane, 2009; Ilzetski et al 2013, Orair et al, 2016; Pires, 2011; Pires, 2014, Mançellari, 2011; entre outros).

Todavia, é comum que os artigos não estimem multiplicadores específicos para despesas associadas a transferências de renda (como programas de seguro-desemprego) e à seguridade social. Blanchard e Perotti (2002) e Perotti (2004) tratam as transferências como um elemento a ser subtraído da receita. A partir daí, a maioria dos autores seguiu a mesma estratégia. Muitos estudos consideram, dentro da despesa primária, os gastos do governo com consumo e investimento público. As receitas primárias, por sua vez, são tratadas de forma líquida, no sentido de que são subtraídas as transferências privadas, seja para seguridade social e/ou subsídios ao setor privado (Blanchard e Perotti, 2002; Tenhofen et al, 2010; Lozano e Rodriguez, 2011; Peres, 2006; Peres e Ellery, 2009; Alves, 2017; Grudtner e Aragon, 2017; Mendonça et al, 2016; Jemec et al, 2013; Castro e Fernandez, 
2011; Burriel et al, 2010; Giordano et al, 2007; Borg, 2014; Skrbic e Simovic, 2015; entre outros).

Pereira e Wemans (2013) afirmam que:

"Initial studies applying the structural VAR methodology to fiscal policy adopted a very aggregate definition of budgetary variables, considering only taxes net of transfers, on the one hand, and public expenditure (fundamentally consumption and public investment), on the other. These definitions were used in a great deal of the subsequent work in this field. It is, however, plausible that the various headings that make up these aggregates have distinctive influences on economic activity" (Pereira e Wemans, 2013, p.10).

Há trabalhos que não retiram o componente de transferências dos dados de gasto total - como Coudret (2013), por exemplo. Porém, também não realizam a estimação desagregada de modo a dar maior importância aos gastos do governo associados aos benefícios sociais.

Baum e Koester (2011) fazem uma crítica aos estudos que não levam em consideração as transferências sociais:

"Seminal studies such as BP (2002) and Perotti (2004) define public spending very narrowly as government investment plus government consumption, and public revenues as general government revenues (excluding social security) minus transfers. Although many papers follow this definition [...], we argue that it is not well-suited for an analysis of fiscal policy in Germany, since social insurance accounts on average for more than $40 \%$ of total revenues and for a large part of overall public spending. Furthermore, economic stimulation is often explicitly pursued via the social security system" (Baum e Koester, 2011, p. 13).

Para o caso do Brasil, os benefícios sociais são gastos muito relevantes, tanto do ponto de vista quantitativo - correspondem a quase $46 \%$ da receita total primária na amostra utilizada neste trabalho, e a $48 \%$ do total de gastos primários, bem como a $8 \%$ do PIB (em termos de média) - quanto qualitativo, como mostrado por Orair et al (2016), que estimaram multiplicadores altos e de magnitude comparável aos de investimento público, sobretudo em períodos de recessão.

Gechert et al (2018) afirmam que, a despeito dos numerosos estudos sobre multiplicador fiscal, o gasto social não tem recebido sua devida importância:

"In recent years there has been a tremendous surge in the literature on the size of fiscal multipliers. While many papers have focused on the effects of federal 
Capítulo 2. Segundo Artigo - Os efeitos estabilizadores dos benefícios sociais: uma análise de multiplicadores fiscais para o Brasil no período 1997-2018

and local public procurement, employment and investment spending and tax shocks, the impact of changes in social security contributions and benefits has received only little attention. This seems surprising given the fact that social security systems have grown substantially in OECD countries after the Second World War and account for about half of the overall budget in countries like Germany" (Gechert et al, 2018, p.2).

Como já mencionado na introdução, o maior interesse em multiplicadores de transferências surgiu após a crise de 2008, quando foi implementado nos Estados Unidos o American Recovery and Reinvestment Act (ARRA), que consistiu em um estímulo fiscal cujo efeito multiplicador estimado seria maior que a unidade (Council of Economic Advisers, 2009). Em particular, o papel das transferências governamentais ganhou destaque. De acordo com Galdón (2013):

"If we want to understand what has been the effect of fiscal policy in the last decade, we can not neglate the fact that $75 \%$ of the extra spending provided in the ARRA is used to increase transfer payments, including unemployment benefits or social security. I find that transfers played a big role in stabilizing output and, especially, private consumption" (Gáldon, 2013, p.2).

Gáldon (2013) parte da metodologia desenvolvida por Blanchard e Perotti (2002), fazendo uma extensão de forma a incorporar a volatilidade da amostra. Após estimar multiplicadores para o gasto total do governo, o autor chega à conclusão de que o multiplicador estimado por ele para o período da crise de 2008 não foi tão alto porque, em um primeiro momento, foram excluídas as transferências governamentais da estimação:

"We should thus not neglect the role of transfers once we analyze the effects of fiscal policy in the United States which account for a $14.3 \%$ of total output at the end of 2012" (Gáldon, 2013, p.21).

Logo, sobretudo a partir da crise de 2008, os estudos passaram a dar maior ênfase aos gastos associados a transferências - ainda assim, são poucos os autores que estimam, de forma desagregada, os efeitos desse tipo de gasto no PIB. Na metodologia VAR linear a la Blanchard e Perotti (2002), a mais convencional técnica aplicada a multiplicadores fiscais, alguns estudos encontram um papel bastante relevante associado ao gasto com transferências sociais, estimando multiplicadores próximos ou maiores que a unidade, em termos de impacto $^{3}$ (Gechert et al, 2018; Gáldon, 2013; Adams e Wong, 2018), apesar de, algumas vezes, o multiplicador acumulado não ser tão relevante (Adams e Wong, 2018) ${ }^{4}$; ou

3 "[transfers are] well target to households that are liquidity-constrained" (Adams e Wong, 2018, p.17).

4 Os autores encontram multiplicadores mais baixos no longo prazo (acumulados) e atribuem a menor reação do produto ao aumento da inflação e da taxa de juros, propondo algum tipo de crowding out. 
mesmo o impacto agregado do gasto primário total ser pequeno (e até negativo) - como em Gáldon (2013). Em outros casos, o multiplicador de transferências fica bastante próximo da unidade no impacto e diminui ao longo do tempo, mas ainda permanece positivo em termos acumulados (Pereira e Wemans, 2013).

Na direção contrária aos efeitos significativos das transferências no produto, há artigos que partem desta mesma metodologia e encontram multiplicadores de transferências positivos, mas muito baixos - tanto em termos de impacto quanto acumulado. Geralmente, tais estudos estimam multiplicadores associados a despesas de consumo do governo, a corte de impostos diretos e, principalmente, a investimentos públicos, bem mais expressivos que os de transferências (Huseyin e Ayse, 2017; Sarangi e Bonin, 2017; Bova e Klyviene, 2019; Pereira e Wemans, 2013; Silva et al, 2013 ${ }^{5}$.). Em alguns casos, há um multiplicador alto para as transferências, mas ainda assim outros tipos de gastos são igualmente importantes ou superiores em termos de efeito multiplicador no produto (Pereira e Wemans, 2013; Fatás e Mihov, 20016 ; Pereira e Sagalés, 2009); enquanto que em outros, embora o multiplicador para o gasto total seja positivo, para gastos com assistência social há um multiplicador menor que zero e não significativo (Claus et al, 2006; Bruckner e Tuladhar, 2010).

Há autores que partem de outros métodos, como o "método narrativo" (mas que também utiliza VAR ${ }^{7}$ ), como é o caso de Romer e Romer (2016), com base em Romer e Romer $(2010)^{8}$, e encontram uma resposta significante e expressiva do consumo, sobretudo

5 Os autores atribuem a seguinte explicação: "One explanation is that transfers work as automatic stabilizers and, in the very short-run, may exhibit a strong negative correlation with output (reverse causality); stabilization role becomes less pronounced as time passes" (Silva et al, 2013, p.16).

6 Cabe destacar que Fatás e Mihov (2001) identificam as transferências como uma das ferramentas mais efetivas para estimular o produto, além dos impostos e dos salários pagos pelo governo.

7 Romer e Romer (2016) avaliam o impacto dos benefícios sociais no produto utilizando uma regressão da variação do logaritmo do produto sobre as variáveis de gasto com benefícios sociais; e também utilizando um VAR. Nas especificações, algumas variáveis de controle são utilizadas, como controle para política monetária e para preços do petróleo. O método narrativo, como é chamado pelos autores, consiste na análise dos dados para os Estados Unidos no período 1952-1991, identificando as mudanças nos gastos com benefícios sociais por meio de análises de documentos do Congresso, por exemplo. O objetivo é excluir as possíveis respostas contracíclicas do gasto social, limitar a análise ao aumento do benefício aos usuários já existentes, em vez de considerar possíveis variações relacionadas ao aumento do número de beneficiários, e, também, considerar separadamente gastos sociais permanentes e temporários. Variações para repor perda de poder de compra associada à inflação, por exemplo, são vistas com bons olhos pelos autores, porque tais variações refletem aumentos para um mesmo beneficiário. A especificação do VAR segue a literatura em geral: gastos são ordenados primeiro de forma que os gastos com benefícios sociais podem afetar as demais variáveis no VAR (impostos, nível de preços e consumo), mas não são afetados por elas dentro de um mês.

8 Gechert et al (2018) ressaltam que o método narrativo exposto em Romer e Romer (2010) é uma alternativa ao tradicional Blanchard e Perotti (2002), mas que não há consenso na literatura sobre qual método seria melhor, tendo, ambos, desvantagens: "The main variants in the literature are the narrative approach of Romer and Romer (2010) (RR henceforth) and the Blanchard and Perotti (2002) (BP henceforth) structural $\operatorname{VAR}(S V A R)$ approach. RR identify size, timing and motivation of legislative changes with a relevant budgetary impact via legislative texts and other historic documents and create a shock series from the bottom-up. BP cyclically adjust headline budgetary figures via imposing estimated elasticities of budgetary components and lags in the reactions of budget planners to output shocks. While narrative approaches have been considered to give a more reliable and comprehensible identification, they may be more prone to measurement error and incomplete information. Thus, there is still no 
Capítulo 2. Segundo Artigo - Os efeitos estabilizadores dos benefícios sociais: uma análise de multiplicadores fiscais para o Brasil no período 1997-2018

no impacto, a um aumento permanente nos benefícios sociais. No entanto, é o lado da receita que possui maior efeito multiplicador ao longo do tempo, sendo também mais persistente - uma possível explicação atribuída pelos autores é a grande resposta da taxa de juros a aumentos no gasto com os benefícios, que é bem maior se comparada à resposta desta variável a choques associados a cortes de impostos. Em Alesina et al (2017), há um resultado parecido para um painel de países da OCDE, com metodologia similar à de Romer e Romer (2016): consolidações fiscais baseadas em elevações impostos são mais custosas em termos de produto do que as baseadas em cortes de gastos - seja de gastos de consumo do governo ou de transferências. Por outro lado, em Gechert et al (2018), que empregam uma metodologia similar ao método narrativo de Romer e Romer (2010) para o gasto social na Alemanha com a estimação de um VAR com base em Mertens e Ravn (2014), há o resultado de que o multiplicador estimado é mais alto e mais persistente para o gasto social do que para as contribuições sociais (impostos que financiam esse gasto) ${ }^{9}$. Os resultados em nada diferem dos encontrados pelo método de Blanchard e Perotti (2002), também empregado pelos autores.

Há estudos que empregam métodos de análise em painel para vários países (ou regiões de um país) no cômputo dos multiplicadores fiscais em geral, seja por meio de VARs ou de métodos de só uma equação (Silva et al, 2013; Furceri e Zdzienicka 2012; Reeves et al, 2013; Ilzetski et al, 2013; Beetsma e Giuliodori, 2011; Valencia, 2015; Izquierdo et al, 2019; Carrière-Swallow et al, 2018; Deleidi et al, 2019; Konstantinou and Partheniou, 2019). No caso específico dos benefícios sociais, Furceri e Zdzienicka (2012) encontram um multiplicador acumulado positivo para um grupo de países da OCDE, embora menor que a unidade, para o gasto social (que inclui despesas com saúde, seguro-desemprego, aposentadoria, entre outras). As despesas com seguro-desemprego e saúde são as mais relevantes do ponto de vista do multiplicador (sendo próximo de 2 e de 1 , respectivamente). Ao desagregar os componentes da demanda, os autores encontram uma resposta positiva e significante do consumo a choques no gasto social, sobretudo determinada pelos gastos com saúde e seguro-desemprego. Do lado do investimento privado, no entanto, há uma resposta não significativa deste componente a choques nos benefícios sociais. Apesar desse resultado, um aumento do gasto com saúde é capaz de estimular o investimento privado de forma positiva e estatisticamente significante.

Em Reeves et al (2013) há um multiplicador estimado positivo e alto para um grupo de países europeus ${ }^{10}$. O estudo é feito para os "gastos sociais" desagregados, incluindo

consensus about the least biased strategy (Caldara and Kamps 2017)" (Gechert et al, 2018, p.2-3).

9 A explicação fornecida pelos autores é a seguinte: "Given that benefits are likely pro-poor while contributions are paid by middle and upper income classes, it seems plausible that benefit shocks have a stronger aggregate demand effect. Moreover, some benefits are in-kind and will have a direct GDP effect" (Gechert et al, 2018, p.19).

10 Neste artigo, há a utilização de modelo em painel de efeitos fixos para países europeus - ao invés do VAR usualmente empregado, por se tratar de um grande número de países. "Vector autoregressive models have been applied to quarterly data for small numbers of countries, but for annual data with 
várias categorias, como educação, saúde e proteção social (que, por sua vez, inclui itens como aposentadoria e seguro-desemprego). O multiplicador para o gasto com proteção social, no modelo base, foi em torno de 3.

A literatura que estima VAR também encontra casos em que o investimento público possui um papel relevante e significativo na geração de renda, mas sem muita persistência, de forma que os benefícios sociais tornam-se uma variável-chave para o estímulo ao produto, pois são responsáveis por efeitos mais duradouros e significativos (Hollmayr e Kuckuck, 2018).

Ainda na nessa linha de estimação por VAR, alguns autores passaram a empregar metodologias não lineares, como VAR com Threshold - sobretudo após o estudo de Auerbach e Gorodnichenko (2012), que encontram multiplicadores fiscais mais altos em períodos de recessão - de modo a enfatizar a dependência do efeito multiplicador da fase do ciclo econômico. Nesta abordagem, os benefícios sociais seriam particularmente importantes por sua capacidade de sustentar o consumo das famílias durante episódios de recessão (Dufrénot et al, 2016; Konstantinou and Partheniou, 2019¹1; Baum e Koester, 2011 ${ }^{12}$; Silva et al, 2013 ${ }^{13}$; Orair et al, 2016). Gechert e Rannenberg (2014), por meio de uma análise de meta-regressão baseada em vários estudos empíricos que empregam VAR (ou estimações por equações), encontram que, em regime de recessão, o multiplicador acumulado de transferências seria sensivelmente maior e estaria entre 2 e 3 , sendo maior que o de receitas e gastos de consumo do governo, e até mesmo superior ao de investimento público. Em um cenário de expansão, por outro lado, tal multiplicador seria menor que 0.5.

Para estimar o multiplicador das transferências, alguns autores tratam do componente de estabilizador automático. Gechert et al (2018), Gáldon (2013), Claus et al (2006), Adams e Wong (2018), Pereira e Wemans (2013), Baum e Koester (2011), Bova e Klyviene (2019) e Hollmayr e Kuckuck (2018), por exemplo, estimam a elasticidade dos gastos com transferências com relação ao produto. Em particular, os artigos geralmente utilizam a elasticidade ponderada do componente de seguro-desemprego, que é o mais tradicional estabilizador automático, para colocar na estimação do SVAR e obter os multiplicadores (Pereira e Wemans, 2013) ${ }^{14}$. Em outros artigos, há a ordenação de Choleski em que o

larger numbers of countries fixed effects models are more consistent" (Reeves et al, 2013).

11 Neste artigo, o grande efeito positivo sobre o consumo das famílias durante recessões como resposta a um choque positivo nos benefícios sociais ocorre tanto para países da OCDE como para a amostra de países não pertencentes ao grupo. Entretanto, somente para os países da OCDE esse efeito positivo também ocorre em expansões.

12 Apesar de Baum e Koester (2011) frisarem a importância da inclusão das transferências nos gastos totais para a estimação, eles não realizam uma análise desagregada para verificar o impacto isolado dos benefícios sociais e verificam apenas o efeito das transferências via gasto total.

13 Este artigo estima VAR linear para subamostras que caracterizam períodos de recessão e de expansão.

14 "Regarding social transfers, it is considered that only the expenditure related to unemployment responds to cyclical developments, which is an assumption commonly used in the procedures of cyclical adjustment of budgetary series. In fact, although social transfers not related to unemployment, but which involve means testing, may bear a relationship with economic activity, such a relationship within the quarter 
Capítulo 2. Segundo Artigo - Os efeitos estabilizadores dos benefícios sociais: uma análise de multiplicadores fiscais para o Brasil no período 1997-2018

gasto vem primeiro (incluindo os gastos associados a transferências). Como os gastos são ordenados primeiro, assume-se que os choques fiscais são discricionários de modo que exclui-se a possibilidade de resposta contemporânea (dentro de um mês ou de um trimestre) do gasto com transferências ao produto (Orair et al, 2016; Huseyin e Ayse, 2017; Cattan, 2017; Pereira e Sagalés, 2009; Silva et al, 2013). Na realidade, o procedimento de identificação de Blanchard e Perotti (2002) apoia-se em uma ordenação de Choleski em que o gasto vem primeiro, mas possui certa flexibilidade em relação à ordenação de Choleski direta, pois permite que se estime apenas a elasticidade de um dos componentes das transferências (seguro-desemprego), como foi dito anteriormente ${ }^{15}$.

Em Eskesen (2009), embora o autor não inclua transferências sociais em sua estimação (por uma questão de disponibilidade de dados), sugere a importância de se considerar esse tipo de gasto no desenho de política. Do lado dos gastos, há a recomendação de políticas capazes de sustentar a demanda agregada, orientando os gastos para quem tem maior propensão a consumir. Particularmente, o autor cita "targeted cash transfers" como forma de expandir uma rede de proteção social e desenhar uma política fiscal capaz de estimular o produto.

is difficult to sustain" (Pereira e Wemans, 2013, p.33). Em Hollmayr e Kuckuck (2018): "In view of the tax and transfer system in Germany, it is plausible to assume that, on the expenditure side, only unemployment insurance benefit payments made when unemployment commences (unemployment benefit I) will be affected contemporaneously in the same quarter by GDP changes. Other spending categories that generally also depend on macroeconomic developments, such as basic allowance benefits (such as unemployment benefit II) or pension insurance expenditure, respond with something of a lag (the latter with a lag of more than a year, via the pension adjustment formula)" (Hollmayr e Kuckuck, 2018, p.10). Um outro exemplo é dado por Gechert et al (2018): "Social security expenditures, including transfers are also partly elastic to the cycle, in particular unemployment benefits (-3.3, with a share of $10.47 \%$ in total benefits) and earnings-related benefits (-0.64, share: 23.49\%), with the remainder assumed inelastic. Hence, the weighted average elasticity of social spending amounts to -0.50" (Gechert et al, 2018, p.15).

15 Fatás e Mihov (2001) por exemplo, utilizam uma ordenação de Choleski em que os gastos de consumo e investimento do governo são ordenados primeiro, seguidos de variáveis de consumo e investimento privados, das transferências e da receita. Esta forma de decomposição de Choleski ficou conhecida na literatura por forma recursiva, e pressupõe que o efeito contemporâneo da receita e das transferências sobre o produto é zero. Desta forma, este método de identificação considera um forte elemento de estabilizador automático nas transferências. Assim, o produto influencia contemporaneamente essas variáveis, mas o contrário não ocorre. Blanchard e Perotti (2002) fornecem uma possibilidade de estimação mais flexível neste sentido: permite que se estime apenas a elasticidade de um dos componentes das transferências (seguro-desemprego), como fazem Galdon (2013), Adams e Wong (2018), Pereira e Wemans (2013), Baum e Koester (2011), e Hollmayr e Kuckuck (2018); ou mesmo ordenar este tipo de gasto primeiro, de modo que se considera que este gasto é majoritariamente discricionário, como fazem Orair et al (2016) e Cattan (2017) para o Brasil. Em Pereira e Sagalés (2005), há um VAR com a composição de Choleski de ordenamento das variáveis "gasto, produto, receita", equivalente à forma recursiva para as receitas. O procedimento de Blanchard e Perotti (2002) é bastante similar à decomposição de Choleski, sendo um pouco mais flexível também neste caso. Na realidade, os procedimentos se equivalem na estimação do efeito do gasto no produto (pois o gasto é ordenado em primeiro lugar). Na receita, entretanto, há diferença: além de assumirem que a receita responde contemporaneamente ao produto (via elasticidade), Blanchard e Perotti (2002) presumem que o produto também é afetado pela receita, no mesmo período. Já na decomposição de Choleski, algum deles deve vir primeiro. Enquanto em Blanchard e Perotti (2002) considera-se que a receita é afeta contemporaneamente o produto; na abordagem recursiva, o produto é ordenado antes. 
Para o Brasil, poucos estudos estimaram o efeito dos benefícios sociais em uma abordagem do ponto de vista macroeconômico. O estudo de Orair et al (2016) destaca-se por enfatizar o papel multiplicador de renda que os benefícios sociais assumem em períodos de recessão. Com uma abordagem de um VAR não linear para as três esferas de governo no período 2002-2016 com dados de Orair e Gobetti (2017a), inspirado em Auerbach e Gorodnichenko (2012), os autores encontram um efeito multiplicador de pico de 1.51 para este tipo de despesa em uma situação de recessão -cuja magnitude é comparável ao do investimento público (de 1.68). Na recessão, o multiplicador acumulado em quatro anos chega a 8 para os benefícios sociais, e a 6.8 para o investimento público; enquanto que na expansão, esses multiplicadores são não significantes.

Resende (2019) estima, por meio de um VAR linear com dados trimestrais, multiplicadores para benefícios sociais (englobando as mesmas despesas utilizadas neste trabalho: benefícios previdenciários, BPC, Bolsa Família e abono e seguro-desemprego) para o período 1997-2018, utilizando séries fiscais do Tesouro Nacional. O multiplicador de impacto dos benefícios sociais é de 0.72 e chega a 4.37 após oito trimestres. Este valor é alto e, assim como em Orair et al (2016), comparável ao valor do multiplicador de investimento público do governo central, que vale 2.37 (impacto) e 3.37 (acumulado em oito trimestres). A partir desses resultados, Resende (2019) calcula o impulso fiscal a cada ano, utilizando uma desagregação por tipos de despesa. Uma das conclusões da autora é que o ajuste fiscal iniciado em 2015 teve efeitos menos prolongados sobre a demanda agregada em virtude do efeito gerado pelas despesas com benefícios sociais, que suavizaram o impulso contracionista, a despeito do corte de investimentos públicos.

A literatura nacional que utiliza uma abordagem mais microeconômica de análise em painel já apresentou alguns resultados importantes no que diz respeito aos benefícios sociais. Tupy e Toyoshima (2013) apontam para dois canais de transmissão pelos quais as transferências impactam o produto no caso brasileiro. Em primeiro lugar, há a própria redução de desigualdade de renda e pobreza, o que é bem documentado na literatura (Denes et al, 2016; Medeiros et al, 2008). Em segundo lugar, o consumo das pessoas que recebem as transferências é capaz de induzir um efeito multiplicador de renda na economia. O efeito multiplicador de programas de transferência de renda é tratado na literatura sob a perspectiva central de que as transferências levam ao aumento da renda das famílias não só por via direta, mas também com efeitos indiretos: a injeção inicial é capaz de estimular a produção e, logo, a demanda por trabalho, o que resulta em mais renda (Denes et al, 2016).

Esse processo multiplicador é potencializado para os benefícios sociais, em particular, porque as pessoas que recebem esses benefícios possuem alta propensão a consumir. De acordo com Marques e Mendes (2005), quanto mais a população-alvo das transferências de renda se aproxima da pobreza, mais a propensão marginal a consumir se aproxima de 1 
Capítulo 2. Segundo Artigo - Os efeitos estabilizadores dos benefícios sociais: uma análise de multiplicadores fiscais para o Brasil no período 1997-2018

tendo em vista que as pessoas precisam de bens de primeira necessidade. De fato, segundo Ipea (2011), a partir dos dados da Pesquisa de Orçamento Familiar (POF) de 2008/2009, é possível inferir que $80 \%$ dos recursos transferidos pelo programa Bolsa Família foram apropriados pelos $40 \%$ mais pobres, o que acentuou o perfil redistributivo do gasto social no período analisado. Há diversos estudos que enfatizam a boa focalização do PBF, bem como do BPC (Medeiros et al, 2008; Soares et al, 2007; Denes et al, 2016; Souza, 2011). Por exemplo, Medeiros et al (2008) estimam, a partir de dados da PNAD de 2006, que mais de $80 \%$ dos beneficiários dos programas PBF e BPC estão nos primeiros quatro décimos da distribuição de renda per capita familiar.

Além disso, cerca de $70.3 \%$ dos benefícios sociais do Regime Geral de Previdência Social, somados com o Benefício de Prestação Continuada, são de valor até um salário mínimo (Rangel et al, 2009) ${ }^{16}$. Essas informações lançam luz a uma possível causa de um multiplicador alto: as pessoas que recebem os benefícios sociais possuem alta propensão a consumir. Em cenários de crise, como é o que analisamos neste artigo, esse efeito multiplicador fiscal potencializado, como veremos a seguir. A transferência de renda para quem tem maior propensão a consumir ajudaria a manter o consumo durante episódios de crise, o que pode contribuir para a manutenção da demanda agregada e evitar um aprofundamento da recessão.

Ainda assim, o alto efeito multiplicador gerado por transferências não é consenso na literatura. Gomes (2001) (em Tupy e Toyoshima, 2013), por exemplo, argumenta que, embora haja estímulo à demanda agregada, esse estímulo é dissipado tendo em vista que ele ocorre no que o autor chama de "economias sem produção", caracterizada por baixa renda e grande participação de transferências e aposentadorias na renda total dos municípios, bem como grande participação governamental. Essa visão é questionada por estudos que encontram um papel bastante relevante das transferências na dinâmica do produto. Há autores que utilizam uma abordagem de análise em painel para um conjunto de municípios e encontram resultados que vão de encontro à ideia de que os benefícios sociais possuem efeitos multiplicador dissipado pelo "efeito das economias sem produção". Em particular, o aumento de transferências ao PBF e ao BPC teria como efeito o estímulo à renda municipal, sobretudo em regiões mais pobres (Tupy e Toyoshima, 2013; Barros e Athias, 2009; Denes et al, 2016; Neri et al, 2013; Landim Junior, 2009). Em alguns casos, o efeito é maior sobre o PIB agropecuário e, em menor grau, sobre o setor de serviços (Tupy e Toyoshima, 2013); em outros, é o PIB associado a serviços que mais responde a aumentos nos benefícios sociais (Denes et al, 2016).

Neri et al (2013) pontuam que, apesar da importância das transferências sobre a dinâmica da economia, pouco se fala de seus efeitos macroeconômicos. O estudo dos

$\overline{16}$ Os autores chegam à conclusão de que os benefícios do RGPS e do BPC de até um salário mínimo são progressivos em relação ao índice de Gini total, o que mostra seu caráter redistributivo. 
autores é um dos poucos trabalhos que examinam as transferências sob uma ótica de seus efeitos no produto. A partir de uma extensão da metodologia de insumo-produto, com a construção de uma matriz de contabilidade social para o ano de 2009 a partir de dados das Contas Nacionais e da POF de 2008/2009, os autores analisam sete multiplicadores: Bolsa Família (cujo valor foi de 1.78 reais gerados, para cada 1 real gasto no programa), BPC (o multiplicador encontrado foi de 1.19), seguro-desemprego (1.06), abono salarial (1.06), previdência (com efeitos multiplicadores de 0.53 para o RPPS e de 0.52 para o RGPS), FGTS (0.39). Desta forma, Neri et al (2013) encontram um efeito multiplicador bastante expressivo para o Bolsa Família, o BPC, e o seguro-desemprego, que possuem efeitos maiores que a unidade. Já os multiplicadores obtidos para o consumo das famílias mantêm a mesma ordem observada para o multiplicador do produto: o PBF possui o maior efeito, de 2.4, seguido de: BPC (1.54), seguro-desemprego (1.34), abono salarial (1.32), RGPS (0.65), RPPS (0.63) e FGTS (0.47).

\subsection{Metodologia}

A metodologia parte do VAR descrito no Capítulo anterior desta dissertação (Artigo 1), baseado em Blanchard e Perotti (2002), com variáveis fiscais mensais do governo brasileiro central obtidas de Orair e Gobetti (2017a) (dados atualizados) ${ }^{17}$. Para que a hipótese de identificação se sustente, a argumentação está relacionada a duas características: a frequência dos dados e o papel dos estabilizadores automáticos na economia brasileira. A frequência dos dados mensal elimina as respostas possíveis do gasto público ao produto através de política discricionária, mas também ajuda a eliminar as possíveis respostas de transferências ao produto. Peres (2006) destaca que o seguro-desemprego é um importante item sensível ao ciclo e, quanto às transferências previdenciárias, pode-se considerar que elas não possuem regras ou mecanismos de resposta automática ao produto ou ao emprego, dentro de um mês ou de um trimestre. As transferências, seja de aposentadoria ou de programas sociais, estão bastante relacionadas a uma decisão discricionária do governo: o reajuste de salário mínimo, que embora seja influenciado pelo crescimento do produto, está sob controle do governo, conforme apontam Orair e Gobetti (2017b) $)^{18}$. De acordo com Mello e Moccero (2006), o único item da despesa primária sensível ao ciclo econômico

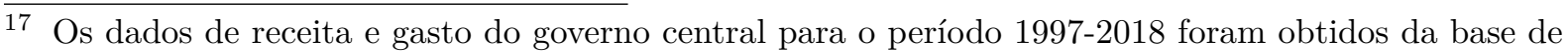
Orair e Gobetti (2017a), em frequência mensal (acima da linha), e ajustados e desagregados como em Orair et al (2016). Além de eliminar inconsistências e ruídos de natureza metodológica das estatísticas oficiais e problemas relativos à composição de receitas e despesas e a operações interorçamentárias, os autores retiraram os efeitos do que ficou conhecido como "pedalada fiscal" (Orair e Gobetti, 2017a).

18 De acordo com Pires e Borges (2019), os reajustes reais de salário mínimo entre 1995 e 2007 eram decididos de forma totalmente discricionária. A partir de 2011, foi criada uma regra em Lei Ordinária, que estabeleceu reajustes para repor a inflação e a média do crescimento do produto dos dois anos anteriores - mas essa regra já era utilizada informalmente entre 2008 e 2010. Esses reajustes são anuais e, logo, demoram certo tempo para que haja uma resposta do próprio gasto ao PIB, não sendo dentro de um trimestre ou de um mês. 

multiplicadores fiscais para o Brasil no período 1997-2018

via estabilizadores automáticos na metodologia da OCDE de estimação de balanço fiscal estrutural são os gastos em seguro-desemprego, assim como na metodologia do FMI, como destaca Andreis $(2016)^{19}$.

Neste trabalho faremos duas versões das estimações dos multiplicadores: uma sem levar em conta o papel estabilizador automático do seguro-desemprego, e outra que fará esse ajuste. Seguimos, desta forma, Orair et al (2016), que empregam a ordenação de Choleski "gasto, receita, produto". Logo, os autores, ao estimarem os multiplicadores associados aos benefícios sociais, ordenam o gasto primeiro, assumindo que não há resposta contemporânea do gasto em relação ao produto. A segunda versão fará o ajuste cíclico no componente de seguro-desemprego para eliminar uma possível endogeneidade associada a respostas de estabilizadores automáticos, como faz a literatura para o cálculo o impacto das transferências sociais no produto. Como o trabalhador tem 120 dias após sua demissão para pedir o benefício, é possível que haja resposta contemporânea dos gastos com esse programa ao produto dentro de um mês ou um trimestre, podendo violar a hipótese de identificação. No entanto, encontramos uma elasticidade positiva do gasto com segurodesemprego em relação ao produto, em acordo com Gobetti el al (2010). De fato, este papel de estabilizador automático deste gasto é questionado. Gobetti et al (2010), por exemplo, não realizam ajustes nos gastos ao estudar o resultado fiscal estrutural. Tanto o seguro-desemprego quanto as demais transferências possuem caráter predominantemente pró-cíclico. Os autores concluem que "embora deva existir um componente cíclico no gasto do seguro-desemprego, ele é de difícil mensuração e, provavelmente, de pouca expressão". De qualquer forma, a estimação que leva em conta o ajuste cíclico, que pondera a resposta contemporânea utilizando a elasticidade (ainda que positiva), alterou de forma mínima os

19 Por fim, realizamos um teste de cointegração entre as variáveis do produto e de transferências (programas sociais, mais aposentadoria). A conclusão é que as variáveis são não estacionárias, mas também não são cointegradas. Neste caso, uma regressão realizada na tentativa de se estimar a elasticidade desse tipo de gasto ao produto apresenta indícios de regressão espúria, como era de se esperar, tendo em vista a ausência de cointegração. Esse resultado de regressão espúria também é encontrado por Gobetti et al (2010). A elasticidade encontrada foi em torno de 1.5, mas esse resultado não é confiável. Os autores Gobetti el al (2010) também encontram uma elasticidade das despesas relacionadas ao seguro-desemprego em relação ao produto alta e positiva, em torno de 3. Para tanto, foi realizada a regressão do logaritmo dos gastos com abono salarial e seguro-desemprego sobre o logaritmo do produto. Nossos resultados apontam para uma elasticidade de 2.35. Apesar de ambas as séries serem não estacionárias, são cointegradas neste caso. Assim, esses resultados reforçam que as transferências de aposentadoria e programas sociais não cointegram com o produto e reforçam a hipótese de que não há resposta contemporânea ou imediata associada a um estabilizador automático. O único item de despesa que isso poderia ocorrer, de acordo Mello e Moccero (2006) e Andreis (2016), é o gasto com seguro-desemprego. Realizamos os testes de cointegração de Johansen, com os testes do Máximo Autovalor e do Traço, bem como o teste de Engle-Granger, para verificar a presença de cointegração entre cada item dos benefícios sociais e o produto e consumo. As transferências de aposentadoria e BPC não cointegram com o produto, nem com o consumo. Desta forma, apenas rejeitamos a hipótese de que não há cointegração nos casos do bolsa família e do seguro-desemprego. No caso do bolsa família, consideramos que, embora a decisão de fixação salário mínimo leve em conta o crescimento da economia, é uma decisão discricionária no sentido de que as despesas com bolsa família não respondam contemporaneamente ao produto, de forma tão imediata. Assim, mantemos a hipótese de identificação. Para o seguro-desemprego, faremos uma versão dos modelos estimados considerando o ajuste cíclico. 
multiplicadores.

Partindo do resultado empírico encontrado por Orair et al (2016) - o de que os benefícios sociais possuem um alto efeito multiplicador, cuja magnitude é até comparável à do investimento público, este artigo apresenta o seguinte resultado: há diferença significante do impacto dos benefícios sociais sobre o produto nas amostras completa (de 1997 a 2018) e pré-crise (de 1997 a 2014) ${ }^{20}$, o que sugere um efeito multiplicador maior sobre o consumo das famílias, sobre o investimento privado e sobre o produto desse tipo de gasto no período de crise. Se a resposta do produto a choques nos benefícios sociais é maior na amostra completa, que inclui a crise, então a resposta (e, consequentemente, os multiplicadores fiscais) somente para o período da crise deve ser ainda maior ${ }^{21}$.

\subsection{Resultados}

\subsubsection{O papel da crise econômica}

O objetivo desta subseção ${ }^{22}$ é apresentar a diferença de resposta do produto aos benefícios sociais nas duas amostras anteriormente mencionadas. Estimamos VARs aos moldes descritos no Capítulo anterior, com o ordenamento: gasto em benefícios sociais, receitas primárias totais e produto. Para os exercícios desagregados em termos de componentes da demanda, substituímos o produto pelo seu componente (consumo das famílias e investimento privado). No caso dos exercícios estimados para cada benefício social, incluímos no VAR tal componente ordenado primeiro, seguido de receitas e produto (ou componentes do produto).

O gráfico da resposta acumulada do produto a um choque nos benefícios sociais nas duas amostras está disponível da Figura 16 a seguir. Os intervalos de confiança ficam separados se considerarmos, ao invés de uma banda de um desvio-padrão, como é usual na literatura, uma banda de 0.8 desvio-padrão. Foi realizado um segundo exercício, similar ao primeiro, mas com os dados trimestralizados. Neste exercício utilizamos a série trimestral do PIB do IBGE e trimestralizamos os dados fiscais de Orair e Gobetti (2017a). No

20 A amostra pré-crise inicia em 1997 e termina no primeiro trimestre de 2014, pois, em acordo com o relatório da CODACE, a recessão teve início no segundo trimestre do ano de 2014.

21 Vale lembrar que o exercício somente para o período de crise 2014-2018 é impossibilitado pelo pequeno número de observações. Essa estratégia de estimação - em duas amostras - para averiguar eventuais alterações no multiplicador durante a crise é similar à de Matheson e Pereira (2016).

22 As variáveis utilizadas neste trabalho são não estacionárias e, logo, foi utilizada a sua primeira- diferença (são integradas de ordem 1), inclusive as variáveis de controle. Assim, os exercícios são realizados em termos de taxa de crescimento. Utilizamos a função impulso-resposta acumulada de forma a obtermos as respostas em nível. O número de lags é escolhido com base nos critérios de informação e no teste de autocorrelação LM (Matteo et al, 2018). Quando se utilizam conjuntamente vários métodos de informação, a literatura recomenda que se escolha aquela defasagem que a maioria dos métodos aponta como sendo mais adequado (Lopes et al, 2012). Os testes para autocorrelação e heterocedasticidade apontaram para a ausência desses problemas na maioria dos modelos. Todos os modelos apresentaram estabilidade. Os testes e os coeficientes dos VAR podem ser disponibilizados sob solicitação. 
Capítulo 2. Segundo Artigo - Os efeitos estabilizadores dos benefícios sociais: uma análise de multiplicadores fiscais para o Brasil no período 1997-2018

exercício mensal, por outro lado, foi utilizada a série do indicador do produto agregado do Banco Central do Brasil (BCB- Depec, série 4380), tal como em Orair et al (2016), que fornece um indicador mensal para o Produto Interno Bruto em valores correntes ${ }^{23}$. A diferença de resposta nas duas amostras persistiu com o uso de dados trimestrais. A resposta acumulada do produto a choques nos benefícios sociais (exercício trimestral) está disponível no gráfico da Figura 17. Note que as funções impulso-resposta das duas amostras ficam estatisticamente diferentes entre si ao consideramos uma banda de um desvio-padrão ${ }^{24}$, no acumulado (a partir do terceiro trimestre).

Figura 16 - Funções Impulso Resposta do produto a choques nos benefícios sociais (exercício mensal)

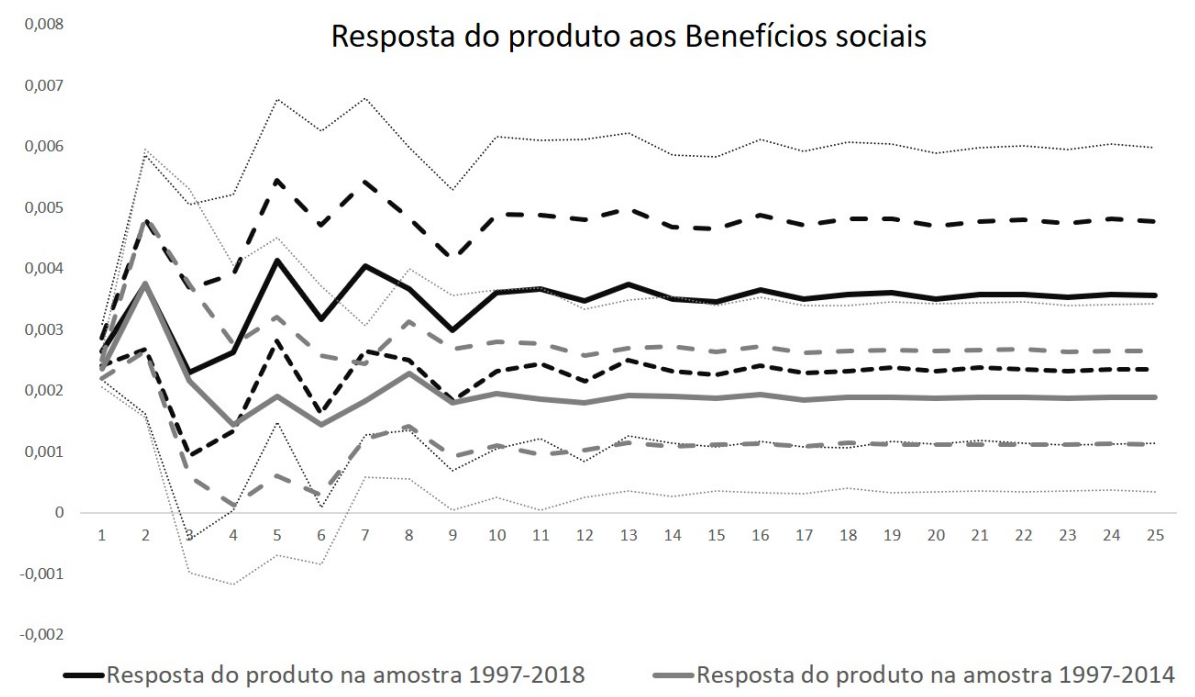

Fonte: Elaboração própria. As linhas tracejada e pontilhada correspondem, respectivamente, ao intervalo de um e de dois desvios-padrão, isto é, níveis de confiança de 68 e $95 \%$.

Como vimos no Capítulo 1, o multiplicador acumulado é uma ferramenta bastante importante para traduzirmos os gráficos em números mais concretos, pois mede a mudança cumulativa no produto após uma mudança cumulativa no gasto do governo em um dado horizonte temporal (Lozano e Rodriguez, 2011; Borg, 2014; Burriel et al, 2010, Spilimbergo et al, 2009).

No exercício mensal encontramos que a cada 1 real gasto em benefícios sociais, há uma geração de renda de quase 3 reais em um período de dois anos para o caso da amostra inteira, que inclui a crise; e de 1.9 reais na amostra pré-crise. Alguns autores já reportaram

23 Esta série é estimada com base em informações divulgadas da produção da indústria de transformação, do consumo de energia elétrica, da exportação de produtos primários e de índices de preços. As estimativas desses índices de volume são ajustadas aos dados de volume do PIB trimestral divulgado pelo IBGE. Essa escolha possui uma desvantagem, que é a utilização de uma série interpolada, mas também possibilita o aumento do número de observações para a estimação -daí a importância de realizarmos os dois exercícios.

24 Mais precisamente, as bandas do intervalo de confiança ficam totalmente separadas ao considerarmos 0.95 desvio-padrão. No caso do exercício mensal, esta separação ocorre considerando 0.8 desvio-padrão. Assim, o exercício trimestral reforça a nossa hipótese de diferença de resposta entre as duas amostras. 
Figura 17 - Funções Impulso Resposta do produto a choques nos benefícios sociais (exercício trimestral).

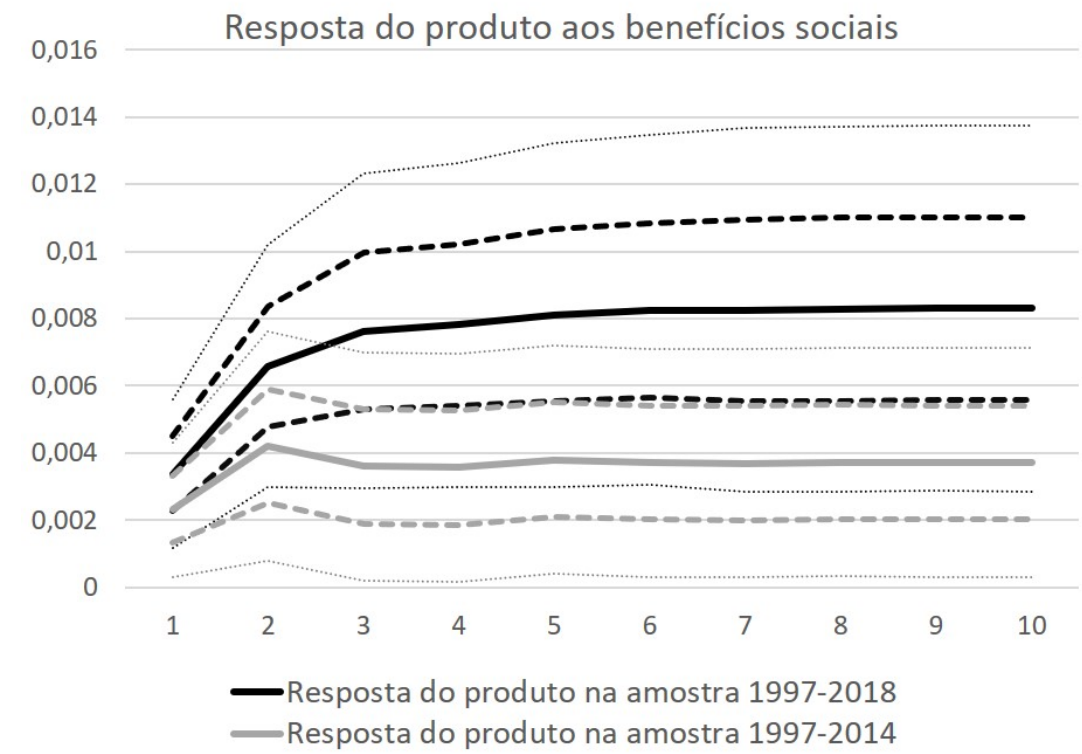

Fonte: Elaboração própria. As linhas tracejada e pontilhada correspondem, respectivamente, ao intervalo de um e de dois desvios-padrão, isto é, níveis de confiança de 68 e $95 \%$.

que os valores dos multiplicadores são sensíveis a alterações pequenas nas especificações do SVAR - daí a importância de testarmos várias especificações, com variáveis dummy, de tendência, uso de dados em diferentes frequências e uso de outro deflator, por exemplo ${ }^{25}$. Segundo Çebi (2015):

25 Por este motivo, testamos o exercício com o uso de dois diferentes deflatores. No caso do exercício mensal, o deflacionamento dos dados foi feito com o IPCA. Para o exercício trimestral, realizou-se um teste de robustez com os resultados obtidos quando o deflacionamento do produto é realizado com o deflator do produto, obtido a partir dos dados do IBGE, como é mais adequado. Não há diferença significativa nos gráficos, que possuem o mesmo padrão de funções de impulso-resposta, mas os multiplicadores ficaram um pouco alterados. No exercício trimestral com todos os dados deflacionados pelo IPCA, o multiplicador acumulado para a amostra inteira é de 3.4, e o de impacto, 1.2; enquanto que na amostra pré-crise os multiplicadores acumulado e de impacto valem em torno de 1.7 e 1.2, respectivamente. Quando todos os dados são deflacionados pelo deflator implícito, o multiplicador acumulado na amostra inteira vale 4.7, e o de impacto, 1.1. Na amostra pré-crise, 1 (impacto) e 3.4 (acumulado). Finalmente, quando os dados do produto são deflacionados pelo deflator implícito e os dados fiscais pelo IPCA, os multiplicadores acumulados para 8 trimestres assumem os valores 4.5 para a amostra inteira e 3.1 para a amostra pré-crise. No impacto, o multiplicador vale 1.3 nas duas amostras. De qualquer forma, a diferença de cerca de 1 real, observada também no exercício mensal, é mantida. Esta diferença é robusta também ao número de lags. Como dito anteriormente, o número de lags é escolhido com base nos critérios de informação e no teste de autocorrelação LM (Matteo et al, 2018). Quando se utilizam conjuntamente vários métodos de informação, a literatura recomenda que se escolha aquela defasagem que a maioria dos métodos aponta como sendo mais adequado (Lopes et al, 2012). Por exemplo, para o caso do exercício para o produto, três dos cinco critérios de informação apontam para o uso de 2 lags (LR, FPE e AIC) e dois para o uso de 1 lag (SC e HQ) - nas duas amostras. Quando estimamos apenas com 1 lag, verificamos forte presença de autocorrelação, pelos testes LM e Portmanteau. Além disso, o teste de exclusão de lags aponta que o segundo lag é importante. Assim, preferimos usar duas defasagens, em ambas as amostras. Quando estimamos apenas com 1 lag, o multiplicador fiscal acumulado para os benefícios sociais vale em torno de 3 reais na amostra inteira e de 2.2 na menor - isto é, ainda há diferença entre amostras. 
Capítulo 2. Segundo Artigo - Os efeitos estabilizadores dos benefícios sociais: uma análise de multiplicadores fiscais para o Brasil no período 1997-2018

"Since VAR models may give different results with small changes in the specification, the main criteria that we focus on are the sign of the expenditure multiplier and whether the point estimate exceeds one" (Çebi, 2015, p.12).

Em nosso caso, o importante é verificar se os padrões de resposta e suas diferenças entre amostras se mantêm ${ }^{26}$.

Os resultados abaixo sumarizam os multiplicadores, de impacto e acumulado de 8 trimestres, utilizando dados mensais e trimestrais. Nota-se que há pouca diferença no impacto, ao compararmos os multiplicadores de impacto das duas amostras. Esse resultado também pode ser visto nos gráficos das Figuras 16 e 17. Entretanto, no acumulado, há diferença:

Para a amostra completa:

\begin{tabular}{|c|c|}
\hline Exercício Mensal & Exercício Trimestral \\
\hline 0.77 e 2.9 & 1.3 e 4.5 \\
\hline
\end{tabular}

Para a amostra pré-crise:

\begin{tabular}{|c|c|}
\hline Exercício Mensal & Exercício Trimestral \\
\hline 0.7 e 1.9 & 1.3 e 3.1 \\
\hline
\end{tabular}

26 Escolhemos apresentar o exercício no qual os dados fiscais foram deflacionados pelo IPCA, e o produto, como é mais adequado, pelo seu deflator implícito. Este foi o exercício que mostrou melhor significância. De acordo com Alves (2017), é mais adequado deflacionar as séries fiscais pelo IPCA devido à alta volatilidade do deflator implícito. Foram feitos testes com a inclusão de variáveis dummy. No caso do exercício trimestral, a variável dummy "dumdate99" foi introduzida de forma a controlar as mudanças ocorridas no modo de operar da economia brasileira em razão da adoção do "tripé macroeconômico". Tal variável assume valor 1 de janeiro de 1999 em diante e 0 nos demais. A justificativa para a introdução dessa variável é que a dinâmica orçamentária do governo se alterou, como explica Andreis (2016). A variável "dum08" assume 1 no período nos últimos dois trimestres de 2008 e no primeiro de 2009, quando houve a queda do produto (que foi bastante transitória durante a crise de 2008), e zero nos demais períodos. Outras dummies testadas foram: dum09, para captar o período de recuperação pós-crise, que foi bastante rápido, e que contou com os benefícios sociais como estímulo à economia. Esta variável assume o valor 1 no terceiro e quarto trimestres de 2009; além de duas variáveis para captar outliers em 2010 e em 2006/2007 (dum10 e dum67). Além disso, foram feitos testes com a inversão da estimação no SVAR: ao invés de considerar "spending-tax", consideramos "tax-spending", assumindo que as decisões de impostos vêm antes das de gasto. Um último teste foi realizado com a incorporação de variável de tendência. Os resultados mostram que a inclusão da variável dummy "dumdate99", além de se mostrar significante, é importante para melhorar a significância, estreitando um pouco os intervalos de confiança. Isto também aconteceu quando incluímos dum08, dum09, dum10 e dum67: houve alterações muito pequenas nos valores dos multiplicadores de impacto e acumulado, mas tais variáveis apresentaram significância de pelo menos 10\%. Particularmente, as variáveis "dum08" e "dum09" apresentaram significância ao nível de 5\%. Tais variáveis melhoraram a significância do modelo como um todo, estreitando um pouco as bandas de desvio-padrão das funções impulso-resposta. Esta conclusão é válida para as duas amostras, e também é válida para o exercício com dados mensais. Por este motivo, o exercício do produto foi feito incluindo tais variáveis. Sua ausência, entretanto, alterou de forma muito marginal dos valores das funções impulso-resposta, em ambas as amostras. Da mesma forma, a inversão das hipóteses para "tax-spending" alterou de forma insignificante os resultados. 


\begin{tabular}{|l|l|l|}
\hline Exercício/ Amostra & $\begin{array}{l}\text { Multiplicadores amostra in- } \\
\text { teira }\end{array}$ & $\begin{array}{l}\text { Multiplicadores amostra pré- } \\
\text { crise }\end{array}$ \\
\hline Exercício baseline & $1.3,3.25(\mathrm{t}=7), 4.5$ & $1.3,2.4(\mathrm{t}=2), 3.1$ \\
\hline $\begin{array}{l}\text { Controle para preço de com- } \\
\text { modities }\end{array}$ & $1.1,2.4(\mathrm{t}=3), 3.5$ & $1,1.86(\mathrm{t}=2), 2.5$ \\
\hline $\begin{array}{l}\text { Controle para taxa de juros } \\
\text { selic }\end{array}$ & $1.2,3(\mathrm{t}=8), 4.2$ & $1.2,2.1(\mathrm{t}=2), 2.78$ \\
\hline Controle para câmbio & $1.19,3.4(\mathrm{t}=6), 4.4$ & $1.3,2.5(\mathrm{t}=6), 3.6$ \\
\hline Com os três controles & $1.1,2.5(\mathrm{t}=3), 3.6$ & $1.1,2(\mathrm{t}=3), 2.8$ \\
\hline
\end{tabular}

Tabela 5 - Multiplicadores fiscais para o exercício do produto (impacto, pico e acumulado)

Tanto os multiplicadores de impacto, quanto os acumulados, são estatisticamente significantes a 5\% - em ambas as amostras e em ambos os exercícios (mensal e trimestral). Também há uma diferença pronunciada, no exercício trimestral, em relação aos multiplicadores de pico, que representa o maior valor do período analisado: vale 3.25 na amostra inteira (e ocorre no sétimo período após o choque) e 2.4 na amostra menor (ocorre no segundo período). Para o exercício mensal, os multiplicadores de pico são semelhantes, mas o período em que eles ocorrem são distintos: 1.25 na amostra inteira (ocorre no quinto período) e 1.2 (ocorre no segundo período após o choque). Essa diferença entre os períodos nos quais há o pico de resposta ilustra que a resposta na amostra inteira possui mais persistência no tempo, dado que seu maior efeito ocorre após um período bem mais longo do que na amostra menor.

Como no Capítulo 1, introduzimos alguns controles nos exercícios econométricos. Vimos, naquele capítulo, que os exercícios mensais foram robustos às especificações. Os exercícios trimestrais, entretanto, apresentaram maior variabilidade. Mas os resultados apontados no texto foram, em certa medida, preservados. A Tabela 5, acima, resume os resultados para a inclusão de controles no caso do exercício estimado para produto, com o vetor "gasto com benefícios sociais, receita primária e produto", e deve ser lida da seguinte maneira: multiplicador de impacto, de pico e acumulado em oito trimestres. O de pico é indicado o período em que ocorre, pela letra t. O exercício baseline refere-se ao exercício sem os controles, apenas com dummies de tempo, explicadas anteriormente. Cada exercício foi testado com a inclusão dos controles separadamente ao exercício baseline $e^{27}$ e, por fim, foi feito um exercício que junta os três controles.

Preço de commodities foi introduzido por meio de um índice, obtido do FMI. Este controle mostrou-se significante a pelo menos $5 \%$. Seu coeficiente positivo foi significativo a $1 \%$ na equação do produto, para as duas amostras, sinalizando a relevância da

27 Para evitar problemas de heterocedasticidade e autocorrelação quando incluímos os controles, foi necessário retirar as dummies de tempo dumdate99, dum10 e dum67 - deixamos apenas dum09 e dum08 (cuja significância foi de 5\% em quase todos os casos). 
Capítulo 2. Segundo Artigo - Os efeitos estabilizadores dos benefícios sociais: uma análise de multiplicadores fiscais para o Brasil no período 1997-2018

demanda externa na renda do país. O exercício trimestral apresentou alguma variação nos multiplicadores quando o índice de preços de commodities foi inserido, embora no mensal quase não tenha tido mudança. Ao retirar a influência dos preços das commodities na economia brasileira, o efeito multiplicador dos benefícios sociais diminuiu. Todavia, as diferenças entre as amostras ficaram preservadas e não houve alteração pronunciada nos multiplicadores, como vemos na tabela acima. Observações similares valem para os efeitos multiplicadores em termos de consumo das famílias e de investimento privado, como veremos adiante. Para este exercício, com o controle do índice de preços de commodities, houve melhora na significância e os intervalos de confiança da função resposta ao impulso ficaram ligeiramente mais estreitos. No caso dos demais controles, descritos a seguir, não houve alteração pronunciada nesse quesito.

Na Tabela 5, "controle para taxa de juros" refere-se à taxa Selic real, acumulada no trimestre. Quando incluímos esta taxa como controle no exercício trimestral, a Tabela 5 indica que houve mudança bastante marginal nos valores, assim como no exercício mensal. Nas duas amostras, seu coeficiente foi negativo na equação do produto. Tal sinal negativo pode ser interpretado como um impacto negativo sobre o consumo, por exemplo, ocasionado por uma distribuição de renda estimulada pelo pagamento de juros destinado aos capitalistas, cujo efeito negativo na demanda agregada desestimula o consumo e, logo, o próprio investimento privado, além de um possível efeito do lado do encarecimento do custo do capital. Contudo, o coeficiente é não significativo.

Quando incluímos a taxa de juros defasada, observamos que seu sinal na equação do produto é negativo - e é significativo a $5 \%$ na amostra menor - embora não seja na amostra maior. Como veremos, o investimento privado é responsivo à taxa de juros defasada. Desta forma, consideramos este exercício como uma possível especificação que inclua taxa de juros ${ }^{28}$. Os multiplicadores foram muito similares ao exercício apenas com o controle contemporâneo, reportado na Tabela 5. Multiplicadores para a amostra inteira: 1.35 (impacto), 4.2 (acumulado), 3 (pico, período 8). Para a amostra pré-crise: 1.4 (impacto), 3.1 (acumulado), 2.5 (pico, período 2).

Outra especificação considerou essa taxa de juros em termos anualizados. Novamente, seu coeficiente foi não significante na equação do produto, porém positivo. Todavia, os multiplicadores foram muito parecidos com o caso de introduzir o controle da taxa de juros real acumulada no trimestre. Para a amostra inteira: 1.2 (impacto), 4.5 (acumulado), 3.1 (pico, período 8). Para a amostra pré-crise: 1.2 (impacto), 2.85 (acumulado), 2.1 (pico, período 2). Considerando o exercício com a taxa de juros anualizada defasada, que foi

28 Para o exercício com o preço de commodities defasado, verificamos multiplicadores iguais aos reportados na tabela 5, que mostra o caso do exercício controlado pela variável apenas contemporânea. O coeficiente do controle defasado afetou o produto de forma positiva, significativo a 10\%, nas duas amostras. No caso do exercício do câmbio, o coeficiente da variável defasada não foi significativo, e também não afetou os multiplicadores. 
significante a $5 \%$ na amostra inteira e a $1 \%$ na menor, com sinal negativo na equação do produto, temos: multiplicadores estimados de 1.4 (impacto), 4.4 (acumulado), 3.1 (pico, período 8) na amostra completa; e 1.4 (impacto), 3.3 (acumulado) e 2.5 (pico, período 2) na amostra menor.

Foi introduzido um índice da taxa de câmbio real efetiva, obtido do Banco Central, como controle, que foi significativo a $5 \%$ nas estimações na equação do produto em ambas as amostras. Seu coeficiente foi negativo em ambos os casos. Como visto no Capítulo 1, uma possível explicação para isso é que, uma desvalorização cambial, por exemplo, deprime salários reais e o consumo e, por conseguinte, o investimento, a despeito do estímulo à demanda por exportações. Os valores dos multiplicadores mudaram ligeiramente na amostra inteira. Para a amostra pré-crise, entretanto, quando tiramos o impacto da taxa de câmbio sobre o produto, obtemos um efeito multiplicador maior para os benefícios sociais (3.6 em termos acumulados). A diferença de pelo menos 1 real entre os multiplicadores acumulados das duas amostras obtida em todas as especificações até aqui apresentadas diminuiu um pouco neste caso, passando a ser de 0.8. Ainda assim, houve uma diminuição tímida, de apenas 20 centavos. Como veremos adiante, essa diferença diminuiu em virtude do efeito multiplicador do investimento privado. Para o consumo, a diferença entre amostras foi totalmente preservada, mas, para o exercício específico do investimento privado, houve diminuição da diferença entre os multiplicadores acumulados nas duas amostras. Ainda assim, os resultados sugerem indícios de um maior efeito multiplicador na amostra que inclui a crise.

Uma diferença um pouco menor entre as amostras também ocorre no exercício que inclui os três controles - taxa de juros selic, preços de commodities e taxa de câmbio de uma vez. O impacto dos preços de commodities predomina - assim como aconteceu no caso do exercício mensal (Capítulo 1). De fato, tal variável apresentou coeficiente positivo e foi significante a $1 \%$ na equação do produto, enquanto os demais controles não apresentaram significância (e mostraram sinal negativo) ${ }^{29}$. Como o preço de commodities foi a variável mais relevante, a Tabela 5 mostra que o exercício ficou parecido com o caso em que controlamos apenas para tal controle.

Uma observação importante é que também foi realizado o exercício aos moldes de Galdon (2013), Adams e Wong (2018), Pereira e Wemans (2013), Baum e Koester (2011), e Hollmayr e Kuckuck (2018); que, como visto na seção de revisão de literatura, estimam o SVAR levando em conta as transferências sociais utilizando o ajuste cíclico para o caso dos gastos com seguro-desemprego ${ }^{30}$. Não houve uma diferença muito pronunciada

$\overline{29}$ Quando incluímos a taxa de juros defasada, seu sinal foi negativo, mas não significante. Os multiplicadores neste caso foram praticamente iguais aos reportados no exercício com os três controles disponível na Tabela 5 .

30 O cálculo da elasticidade dos gastos com seguro-desemprego ao produto foi feito de modo similar ao caso da elasticidade da receita, via MQO, com uma variável dummy para a crise de 2008, a única dummy que se mostrou relevante na regressão, e um termo defasado para o gasto com o seguro. Esta 
Capítulo 2. Segundo Artigo - Os efeitos estabilizadores dos benefícios sociais: uma análise de multiplicadores fiscais para o Brasil no período 1997-2018

nos multiplicadores e as diferenças entre as amostras foram preservadas. Os gráficos das funções impulso-resposta ficaram quase idênticos. No exercício mensal, os multiplicadores obtidos foram de 0.5 (impacto) e 2.2 (acumulado) na amostra inteira; e de 0.4 (impacto) e 1.1 (acumulado) na amostra menor. O exercício trimestral exibiu menor sensibilidade. Para a amostra inteira, os multiplicadores fiscais estimados foram da ordem de 1 (impacto) nas duas amostras. Já o acumulado vale 4.1 reais na amostra inteira e 2.9 na amostra menor.

Se o multiplicador elevado e persistente dos investimentos públicos já é bastante estabelecido na literatura nacional e internacional (No caso da nacional: Pires, 2011; Pires, 2014; Castelo Branco et al, 2015; Orair et al 2016; Dutra, 2016; Peres, 2006; Peres e Ellery, 2009; Cattan, 2017), o resultado para os benefícios sociais só havia aparecido no trabalho de Orair et al (2016) e Resende (2019). Nesse sentido, o crescimento expressivo e estável nesse item do gasto público desde o pacto social de 1988, que sobreviveu em boa medida ao ajuste fiscal iniciado em $2015^{31}$ por seu caráter obrigatório, pode ter evitado flutuações muito maiores do PIB brasileiro ao longo desse período e, em particular, na crise atual.

\subsubsection{O efeito sobre diferentes componentes da demanda agregada}

O objetivo desta subseção é investigar o canal através do qual os benefícios sociais estão elevando o multiplicador, via consumo das famílias ou investimento privado. Partindo da ideia de que os benefícios sociais são importantes para evitar o aprofundamento da crise e que os resultados do SVAR estimado sugerem que a resposta do produto para choques nesse tipo de despesa é maior na amostra que inclui a crise, realizamos o exercício trimestral somente para o consumo das famílias. Esse exercício é obtido a partir do SVAR baseline, com a substituição do produto pelo consumo das famílias (tal como em Burriel et al, 2010) e permite avaliar a função impulso-resposta do consumo das famílias a choques em cada tipo de despesa. O resultado está disponível no gráfico da Figura 18, para o

elasticidade possui sinal positivo. No exercício mensal, seu valor foi de 2.19 para a amostra inteira e 2.3 para a amostra menor. No exercício trimestral, o resultado foi de uma elasticidade de 1.64 na amostra inteira e 1.15 na amostra pré-crise. No exercício para o consumo das famílias, calculamos a elasticidade do seguro-desemprego com relação ao consumo de 1.36 na amostra inteira e de 0.8 na amostra pré-crise. De acordo com a estatística de Durbin Watson, não rejeitamos a hipótese nula de ausência de autocorrelação nestas regressões. Já o teste Breusch Pagan indica ausência de heterocedasticidade. Ademais, antes de realizar a regressão, foram realizados os Testes de Cointegração de Johansen, o do Traço e o do Máximo Autovalor, em ambos as variáveis apresentaram relações de cointegração. Logo, as estimativas das elasticidades não são provenientes de regressões espúrias, dado que as séries são não estacionárias, mas cointegram. O valor da elasticidade é ponderado pela participação das despesas com seguro-desemprego no gasto com benefícios sociais total. Nos exercícios específicos para o seguro-desemprego, essa ponderação não é realizada.

31 A taxa de crescimento dos benefícios sociais permaneceu bastante estável ao longo do período aqui analisado, como resultado do pacto de 1988 e seu caráter obrigatório. Na realidade, a taxa de crescimento anual média dos benefícios sociais permaneceu à frente (ou muito próxima) da taxa de crescimento anual média do produto em todos os subperíodos 1997-2005; 2006-2010; 2011-2014; 2015-2017. No recorte temporal de ajuste fiscal, iniciado em 2015, somente no período de 2014 para 2015 houve corte nesse tipo de despesa. Em 2016 e 2017 houve variação positiva dos benefícios sociais, o que pode ter contribuído para evitar uma recessão mais profunda. 
caso da amostra inteira e para os diferentes componentes da despesa pública primária. Notamos que o consumo responde bastante aos benefícios sociais, como é de se esperar. Como o nosso objetivo é o foco na crise, o gráfico da Figura 19 compara essa resposta com a resposta obtida na amostra pré-crise.

Figura 18 - Funções Impulso Resposta para o consumo das famílias

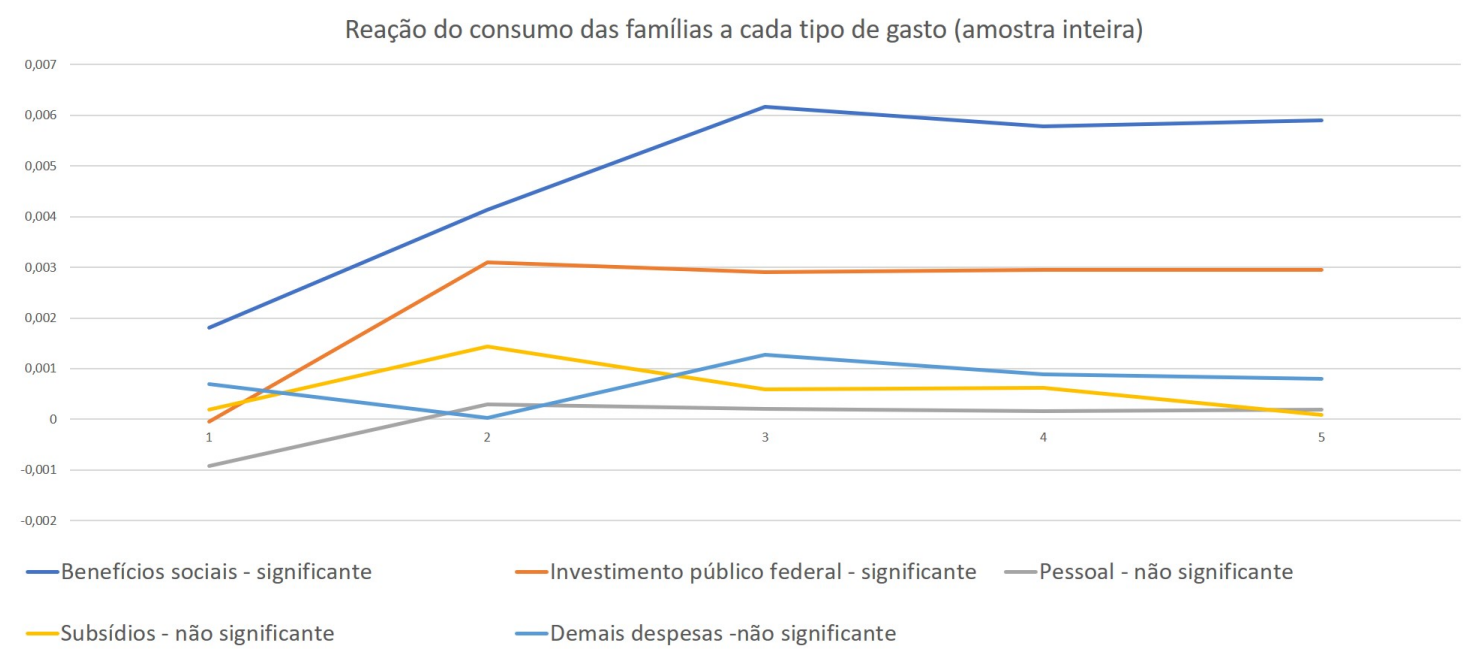

Fonte: Elaboração própria.

As linhas tracejadas indicam que a diferença de resposta é significativa quando consideramos um intervalo de um desvio-padrão no gráfico da Figura $19^{32}$. Nota-se que os padrões das funções impulso-resposta do consumo e do produto são parecidos, assim como em Burriel et al (2010). Enquanto a resposta na amostra pré-crise não é estatisticamente significativa (nem ao nível de $68 \%$ ), a resposta do consumo a choques nos benefícios sociais na amostra inteira não é somente estatisticamente significante a 95\%, como também é maior que na amostra pré-crise. Esse exercício mostra que o componente do produto "consumo das famílias" é bastante responsivo aos benefícios sociais e, além disso, há diferenças significativas entre as amostras ${ }^{33}$. A diferença de resposta é estatisticamente significante

32 Parte significativa da literatura de multiplicadores fiscais considera a banda de um desvio-padrão como intervalo de confiança - como em Blanchard e Perotti (2002). Por este motivo, optou-se por plotar ambas as bandas. Borg (2014) plota apenas a banda a um desvio-padrão por considerar que possui uma amostra pequena na estimação - que é nosso caso no exercício trimestral.

33 Este exercício foi realizado com o deflacionamento do consumo via deflator implícito e com a variável dummy "dumdate99". Outras versões foram estimadas: inclusão das variáveis dummy dum09, dum08, dum67, dum 10; inclusão de tendência; alteração do deflator; alteração da ordem para "tax-spending" e retirada da dummy "dumdate99". Todas essas mudanças resultaram em pequenas diferenças em termos de valores para as funções impulso-resposta e para os multiplicadores, o que é um indício de que o exercício para o consumo é robusto a essas especificações. Em alguns casos, a mudança foi maior, mas as diferenças entre as amostras continuaram. Por exemplo, no caso do consumo, com todos os dados deflacionados pelo IPCA, temos os multiplicadores estimados: 0.3 (impacto) e 1.6 (acumulado) na amostra inteira; e -0.1 (impacto) e -0.57 (acumulado) na amostra pré-crise. Com todos os dados deflacionados pelo deflator implícito do produto, temos: 0.5 (impacto) e 2.5 (acumulado) na amostra completa; e 0.15 (impacto) e 0.5 (acumulado), no caso da amostra menor. Logo, as diferenças entre as amostras foram mantidas, apesar de observarmos alguma alteração nos valores das estimações dos multiplicadores. Para o consumo, mantivemos apenas "dumdate99" no VAR baseline, que melhorou a 
também a $80 \%$ porque as bandas de confiança ainda ficam separadas considerando 1.3 desvios-padrão (com exceção do terceiro período).

Figura 19 - Funções Impulso Resposta para o consumo das famílias aos benefícios sociais em duas amostras

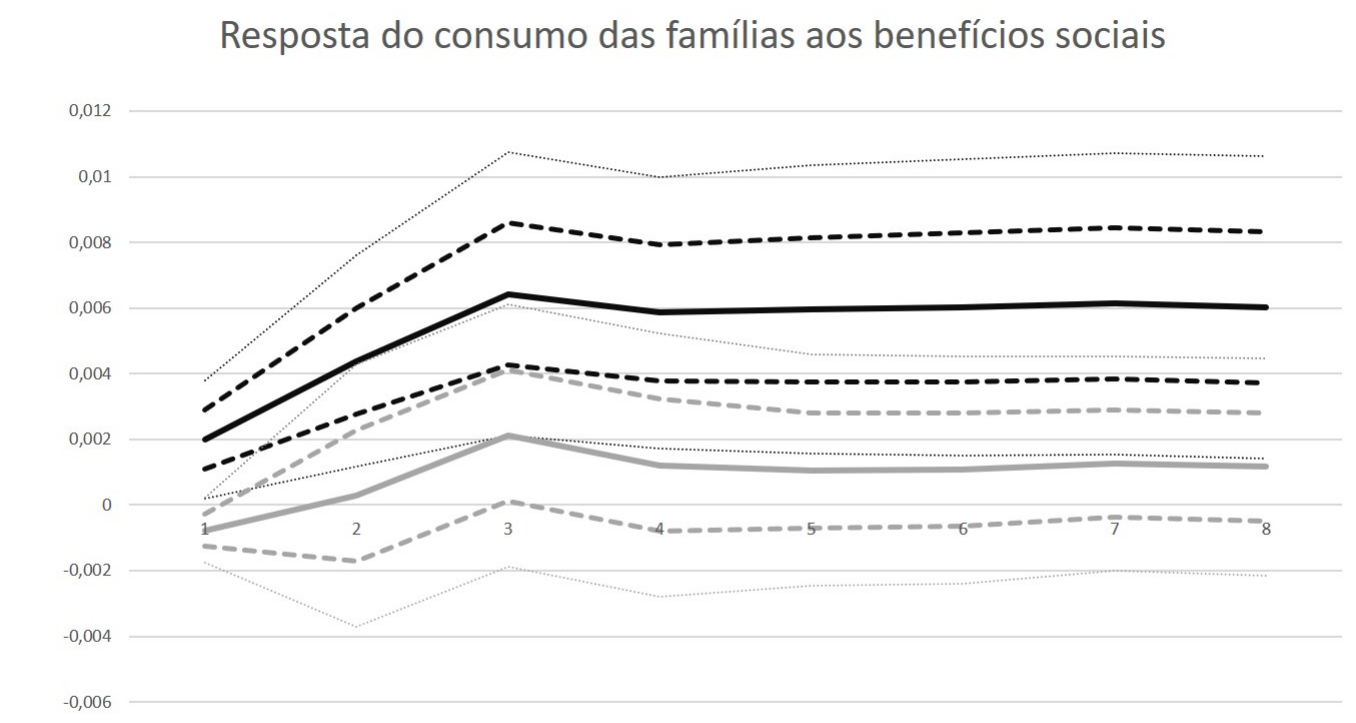

— Resposta do consumo na amostra 1997-2018 —Resposta do consumo na amostra 1997-2014

Fonte: Elaboração própria. As linhas tracejada e pontilhada correspondem, respectivamente, ao intervalo de um e de dois desvios-padrão, isto é, níveis de confiança de 68 e $95 \%$.

Em termos de multiplicadores acumulados de 8 trimestres, a cada aumento de 1 real nos benefícios sociais há 2.3 reais gerados em termos de consumo das famílias na amostra inteira e 0.54 reais na amostra pré-crise (como em Burriel et al (2010), os multiplicadores fiscais de consumo são menores que os do produto). Para os multiplicadores de impacto, isto é, o acréscimo em termos de consumo que ocorre no mesmo período do choque nos benefícios, os valores obtidos foram de 0.5 para a amostra inteira, estatisticamente significante; e negativo para a amostra pré-crise, de -0.27, mas não estatisticamente significante. A diferença de resposta de impacto mostrou-se significante a $95 \%$ de confiança. Os multiplicadores de pico obtidos para o caso do consumo foram: 1.6 na amostra inteira e 0.75 na amostra menor, ambos ocorrendo no terceiro período após o choque. Uma versão utilizando o ajuste cíclico das despesas com seguro-desemprego para o exercício com o

significância do modelo. Estas observações valem também para o exercício para o investimento privado. No caso deste último, entretanto, optou-se por manter as dummies dum09, dum08, dum67 e dum10, além de dumdate99, por apresentarem significância, e por melhorarem a significância do modelo. Sua retirada, entretanto, alterou muito pouco os multiplicadores. Quando alteramos os deflatores, o exercício do investimento, assim como os exercícios do consumo e do produto, foi robusto. Quando deflacionamos todos os dados com o IPCA, estimamos os multiplicadores: 0.32 (impacto) e 1.54 (acumulado) na amostra completa; e 0.2 (impacto) e 0.27 (acumulado) na pré-crise. Com todos os dados deflacionados pelo deflator implícito, temos 0.2 (impacto) e 1.65 (acumulado) na amostra que inclui a crise, bem como 0.03 (impacto) e 0.04 (acumulado) na amostra menor. Logo, as diferenças de resposta aos benefícios sociais entre as amostras foram robustas às mudanças. 
consumo foi estimada e houve preservação das diferenças entre as amostras. Para a amostra inteira, o multiplicador de impacto é de 0.35 e o acumulado, de 2 reais. Para a amostra pré-crise, o de impacto vale -0.4 e o acumulado, 0.3.

Introduzimos algumas variáveis de controle, assim como no caso do produto. A Tabela 6 a seguir apresenta os multiplicadores de impacto, de pico e acumulado, respectivamente, para cada exercício. Quando incluímos o índice de preços de commodities como controle, seu coeficiente positivo foi significante a pelo menos $5 \%$ nas estimações, para a equação do consumo, em ambas as amostras. Este resultado reforça, novamente, a importância do cenário internacional para a economia brasileira no período estudado. Quando retiramos esse efeito positivo sobre o consumo exercido pelo índice de preços de commodities, obtemos multiplicadores fiscais menores -como no caso do exercício para o produto agregado. Apesar dessa mudança, note que a diferença entre as amostras em termos de multiplicador acumulado ao longo do tempo foi mantida.

\begin{tabular}{|l|l|l|}
\hline Exercício/ Amostra & $\begin{array}{l}\text { Multiplicadores amostra in- } \\
\text { teira }\end{array}$ & $\begin{array}{l}\text { Multiplicadores amostra pré- } \\
\text { crise }\end{array}$ \\
\hline Exercício baseline & $0.5,1.6(\mathrm{t}=3), 2.3$ & $-0.27,0.75(\mathrm{t}=3), 0.54$ \\
\hline $\begin{array}{l}\text { Controle para preço de com- } \\
\text { modities }\end{array}$ & $0.41,1.22(\mathrm{t}=3), 1.7$ & $-0.5,0.26(\mathrm{t}=3), 0.08$ \\
\hline $\begin{array}{l}\text { Controle para taxa de juros } \\
\text { selic }\end{array}$ & $0.32,1.3(\mathrm{t}=3), 1.8$ & $-0.41,0.45(\mathrm{t}=3), 0.18$ \\
\hline Controle para câmbio & $0.49,1.6(\mathrm{t}=3), 2.25$ & $-0.26,0.78(\mathrm{t}=3), 0.57$ \\
\hline Com os três controles & $0.25,1(\mathrm{t}=3), 1.4$ & $-0.5,0.003(\mathrm{t}=3),-0.4$ \\
\hline
\end{tabular}

Tabela 6 - Multiplicadores fiscais estimados para o exercício do consumo das famílias

Inserimos um controle para a taxa de juros Selic real acumulada no trimestre. Nesta especificação também houve variação dos valores dos multiplicadores. Seu coeficiente foi negativo em ambas as amostras na equação do consumo, e significante a $5 \%$. Isso pode sugerir um possível efeito de redistribuição de renda para uma classe rentista que possui menor propensão a consumir, por exemplo. Quando controlamos seu efeito, obtemos um efeito multiplicador um pouco menor, mas ainda assim bastante semelhante na amostra inteira, de 1.8 (acumulado). Para a amostra pré-crise, tal multiplicador é de apenas 0.18. Outra especificação testada com a taxa de juros é a inclusão desta taxa anualizada. Houve significância desta variável na equação do produto a 10\%, e seu coeficiente foi negativo em ambas as amostras. Para a amostra inteira, os multiplicadores estimados foram: 0.35 (impacto), 1.85 (acumulado) e 1.33 (pico, período 3). Para a amostra pré-crise: -0.41 (impacto), 0.21 (acumulado) e 0.37 (pico, período 3).

A diferença entre amostras diminuiu bastante marginalmente, mas permaneceu significativa quando olhamos o seu gráfico, similar à Figura 19 (as bandas de um desvio- 
Capítulo 2. Segundo Artigo - Os efeitos estabilizadores dos benefícios sociais: uma análise de multiplicadores fiscais para o Brasil no período 1997-2018

padrão permaneceram separadas no acumulado). No entanto, apesar de observarmos multiplicadores menores nas duas amostras, vimos que a diferença de resposta entre elas foi mantida. Isto pode sugerir que o efeito estabilizador exercido pelos benefícios sociais é bastante relevante na recessão, sendo capaz de compensar o efeito negativo exercido pela taxa de juros, tendo em vista que o multiplicador acumulado na amostra inteira permaneceu alto.

A introdução do índice de taxa de câmbio como controle, entretanto, praticamente não alterou os valores dos multiplicadores. Tal variável exibiu coeficiente negativo na equação do consumo, o que pode refletir que uma desvalorização cambial implica em menores salários reais e menor consumo, mas seu coeficiente não foi significante em nenhuma das duas amostras. Tal índice defasado, no entanto, apresentou coeficiente negativo e com significância a 10\%, nas duas amostras. Multiplicadores estimados: 0.4 (impacto), 2 (acumulado) e 1.45 (pico, período 3) na amostra completa; e -0.5 (impacto), 0.3 (acumulado) e 0.45 (pico, período 3) na amostra pré-crise. As outras duas variáveis de controle defasadas não foram significantes no exercício para o consumo.

Já o exercício controlado pelas três variáveis (taxa selic, câmbio e preço de commodities) apresentou impacto positivo do preço de commodities e bastante relevante, pois houve significância a 5\%, nas duas amostras. Na amostra que inclui a recessão, o controle de taxa de juros apresentou sinal negativo, significante a 5\%, na equação do consumo. $\mathrm{Na}$ amostra menor, por sua vez, tal controle foi significante a 10\%, com sinal negativo. Assim como no caso do produto, nota-se a grande influência do controle de preço de commodities. O câmbio não afetou de forma significante, apesar do coeficiente negativo, em nenhuma das duas amostras ${ }^{34}$. Nota-se que, neste caso, a diferença entre as amostras em termos de resposta acumulada do produto foi até mesmo ampliada, como vemos na Tabela 6 , que mostra os multiplicadores.

Particularmente, podemos observar que, retirado o efeito dos três controles, o multiplicador de benefícios sociais na amostra menor sofreu uma queda mais significativa, em todos os exercícios. Em outras palavras, o multiplicador de benefício social é menos sensível à inclusão de exógenas na amostra inteira do que na pré-crise (para o caso do efeito sobre o consumo), o que pode sugerir que o efeito estabilizador na crise é bastante relevante - e robusto quando controlamos para o efeito de outras variáveis.

Os gráficos ficaram parecidos com o da Figura 19 em todos os casos acima discutidos e, por isso, foram omitidos. Apesar da variação nos valores dos multiplicadores, notamos que as diferenças entre as amostras foram preservadas.

\footnotetext{
$\overline{34}$ No exercício que inclui os três controles, e mais a variável de câmbio defasada - visto que esta foi significante no exercício que controla apenas para o câmbio - os multiplicadores obtidos foram bastante similares - e a variável de câmbio defasada foi significante a 10\%, com sinal negativo na equação do consumo.
} 
Figura 20 - Funções Impulso Resposta para o investimento privado aos benefícios sociais em duas amostras

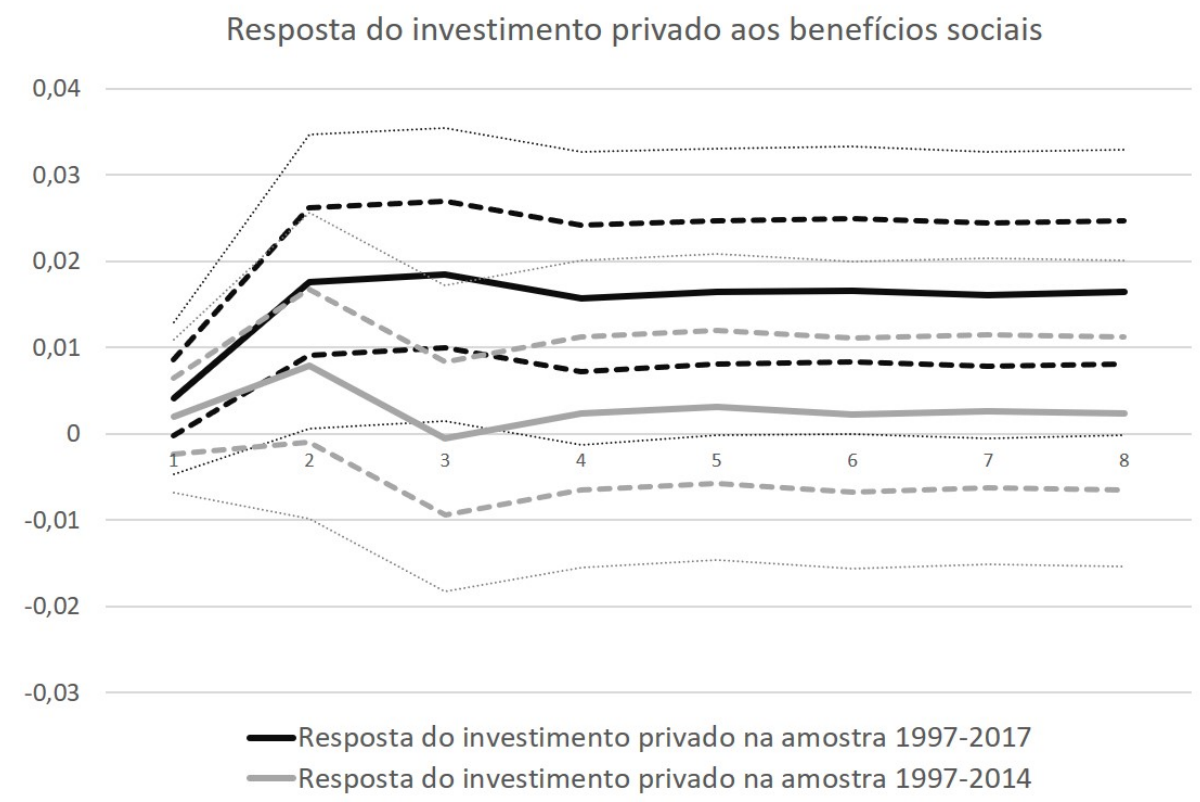

Fonte: Elaboração própria. As linhas tracejada e pontilhada correspondem, respectivamente, ao intervalo de um e de dois desvios-padrão, isto é, níveis de confiança de 68 e $95 \%$.

Foi realizado um exercício também para avaliar a resposta do investimento privado ${ }^{35}$ a choques na variável de benefícios sociais. Como mostra o gráfico da Figura $20^{36}$, o investimento privado se mostrou mais responsivo na amostra que inclui a crise. Apesar de essa diferença entre as respostas ser significante somente quando consideramos bandas de 0.75 desvios-padrão no acumulado da função (a partir do quarto período), o multiplicador acumulado para a amostra que inclui a crise é pouco mais de 1 real maior que o multiplicador acumulado no caso da amostra pré-crise, o que é uma diferença bastante relevante. $\mathrm{O}$ multiplicador de impacto não se mostrou significante para nenhuma das amostras, sendo de 0.27 para a amostra inteira e de 0.2 para a pré-crise. Entretanto, o multiplicador acumulado para 8 trimestres mostrou-se significante para a amostra inteira a $68 \%$, e mesmo a $95 \%$ em alguns períodos (períodos 2 e 3), enquanto que para a amostra pré-crise a função de resposta acumulada não é estatisticamente significante em nenhum dos períodos, nem ao nível de $68 \%$. O valor obtido foi de 1.58 para a amostra inteira, um valor bastante alto, e de 0.45 para a amostra pré-crise. A maior resposta do investimento privado aos benefícios sociais ocorre no terceiro período após o choque, com um multiplicador de pico em torno

35 Os dados de investimento privado foram obtidos da subtração dos dados de investimento público de Orair e Gobetti (2017a) (incluindo as três esferas de governo) da série de investimento obtida das contas nacionais. No entanto, como a série dos investimentos públicos das esferas municipal e estadual só vai até 2017, o exercício com a amostra inteira para avaliar a resposta do investimento privado foi feito com a amostra de 1997 até o último trimestre de 2017, sem incluir os dois primeiros trimestres de 2018, como nos demais exercícios.

36 Para o exercício do investimento privado, a estimação da elasticidade não foi confiável porque as variáveis de seguro-desemprego e de investimento privado não cointegraram. Ainda assim, estimou-se a regressão e o resultado apontou para uma elasticidade muito pequena, em torno de 0.15. Assim, o exercício para o investimento privado não considerou o ajuste cíclico para o seguro-desemprego. 
Capítulo 2. Segundo Artigo - Os efeitos estabilizadores dos benefícios sociais: uma análise de multiplicadores fiscais para o Brasil no período 1997-2018

de 1.22, na amostra que inclui a recessão. Na amostra menor, o multiplicador de pico vale 0.8 , e ocorre no segundo período.

O que o exercício desagregado para os componentes da demanda mostra é que há uma diferença de multiplicadores entre as amostras inteira e pré-crise. Considerando o modelo baseline, para o consumo das famílias, a diferença é de 1.76 reais: a cada 1 real gasto em benefícios sociais, geram-se 1.76 reais a mais em termos de consumo - ao longo de oito trimestres - na amostra que inclui a recessão, se comparamos com a amostra que não a inclui. Esta diferença é estatisticamente significante, como vimos no gráfico da Figura 19. Para o investimento privado, a diferença é de 1.13 reais. O efeito multiplicador ao longo do tempo é $325 \%$ maior na amostra completa para o consumo das famílias e $251 \%$ maior para o investimento privado.

O efeito estabilizador de renda desempenhado pelos benefícios sociais é capaz de estimular o consumo (para compensar o cenário de queda de renda, as famílias consomem uma maior parcela dos benefícios), elevando seu efeito multiplicador. Isto, por sua vez, leva a um aumento das vendas e induz um estímulo ao investimento privado. Portanto, os dois canais são importantes para explicar a diferença de resposta do produto aos benefícios sociais na recessão, com destaque para o consumo das famílias, cuja diferença de magnitude dos multiplicadores foi maior.

Fizemos uma versão com controle para o índice de preços de commodities também para o exercício com investimento privado, e houve diminuição no valor nos multiplicadores, mas a diferença entre amostras foi preservada. A Tabela 7 acima apresenta os resultados para os três controles ${ }^{37}$.

O índice de preços de commodities possui coeficiente positivo na equação do investimento, significativo a $1 \%$ e a $5 \%$, na amostra maior e menor, respectivamente, o que está em consonância com o estudo de Dos Santos et al (2016), explorado no Capítulo 1: o cenário externo favorável poderia, por exemplo, estimular o investimento, elevar o grau de utilização e a taxa de lucro das firmas, dada a importância dos produtos primários na

37 O VAR baseline a partir do qual incluímos os controles não utilizou as dummies de tempo utilizadas no exercício sem controles. Como comentado anteriormente, o exercício para o investimento privado foi feito incluindo as dummies de tempo anteriormente explicadas e que foram utilizadas no exercício realizado sem controles, dum09, dum08, dum10, dum67 e dumdate99 - e que se mostraram significativas a ao menos $10 \%$ em alguma das equações - especialmente dum09 e dum08, cuja significância foi de $5 \%$. O VAR baseline a partir do qual adicionamos controles foi estimado sem as dummies, pois os controles ficaram menos significativos - isto não ocorreu no caso do consumo e do produto, cuja significância dos controles permaneceu a mesma, com ou sem dummies. Para o caso do exercício controlado pelos preços de commodities, o VAR com controles e que inclui tais dummies apresentou resultados muito próximos ao reportado na Tabela 7 , mas o controle de índice de preços de commodities passa a ser significante a $5 \%$ e $10 \%$ somente, nas amostras inteira e pré-crise, respectivamente. Por este motivo, no caso específico do investimento, o VAR baseline não incluiu estas duas dummies, de forma a verificarmos o efeito dos controles apenas. Os multiplicadores estimados na amostra inteira no caso de inclusão de dummies: 0.06 (impacto), 1.05 (acumulado) e 0.93 (pico, período 3). Na amostra menor: -0.1 (impacto), 0.1 (acumulado) e 0.35 (pico, período 3). Nota-se que tais multiplicadores foram bastante semelhantes aos reportados na Tabela 7 . 


\begin{tabular}{|l|l|l|}
\hline Exercício/ Amostra & $\begin{array}{l}\text { Multiplicadores amostra in- } \\
\text { teira }\end{array}$ & $\begin{array}{l}\text { Multiplicadores amostra pré- } \\
\text { crise }\end{array}$ \\
\hline Exercício baseline & $0.27,1.22(\mathrm{t}=3), 1.58$ & $0.2,0.79(\mathrm{t}=2), 0.45$ \\
\hline $\begin{array}{l}\text { Controle para preço de com- } \\
\text { modities }\end{array}$ & $0.03,0.95(\mathrm{t}=3), 1$ & $-0.28,0.2(\mathrm{t}=2), 0.1$ \\
\hline $\begin{array}{l}\text { Controle para taxa de juros } \\
\text { selic }\end{array}$ & $0.41,1.66(\mathrm{t}=3), 1.91$ & $0.22,0.9(\mathrm{t}=2), 1.06$ \\
\hline Controle para câmbio & $0.007,1.46(\mathrm{t}=3), 1.55$ & $-0.08,1.15(\mathrm{t}=2), 1.05$ \\
\hline Com os três controles & $0.2,1.27(\mathrm{t}=3), 1.4$ & $0.04,0.7(\mathrm{t}=2), 0.75$ \\
\hline
\end{tabular}

Tabela 7 - Multiplicadores fiscais estimados para o exercício do investimento privado

estrutura produtiva brasileira, bem como facilitar o ingresso de divisas estrangeiras em seus caixas. Desta forma, possui um impacto positivo no investimento privado.

Para a análise de resposta do investimento privado a choques nos benefícios sociais, especificamente, iremos fazer alguns exercícios adicionais, controlando também para a variável de controle defasada em um período, tendo em vista que, em contraposição com o consumo, tal defasagem foi estatisticamente significante na equação do investimento no caso dos preços de commodities e, especialmente, para a taxa de juros - o que é um indício de que o investimento privado deva responder com certa defasagem. A inclusão do controle de preço de commodities defasado foi significante a 10\%, com coeficiente positivo, nas duas amostras. Na amostra inteira, os multiplicadores estimados são: 0.2 (impacto), 1.2 (acumulado) e 1.1 (pico, período 3). Na amostra menor, 0.17 (impacto), 0.5 (acumulado) e 0.68 (pico, período 2). Neste caso, a diferença entre as amostras em termos de multiplicador acumulado diminuiu um pouco, passando a ser 0.7 , ao invés da diferença de quase 1 real.

Foi estimada uma versão com controle para taxa de juros Selic real acumulada no trimestre. Neste caso, nota-se que a inclusão desta variável de controle defasada também é relevante do ponto de vista de seu impacto na variável de interesse, o investimento. $\mathrm{Na}$ amostra completa, seu coeficiente foi positivo, mas negativo no caso da taxa de juros defasada em um período, ambos significantes a 10\%. Como vimos no Capítulo 1, o efeito da taxa de juros sobre o investimento no arcabouço de modelos neo-Kaleckianos é ambíguo, a depender de fatores como sensibilidade do investimento ao custo do crédito, da elasticidade do mark up das firmas à taxa de juros, bem como da sensibilidade do investimento à taxa de lucro e à participação dos lucros na renda. Nesse sentido, uma interpretação possível é que o investimento poderia responder negativamente à taxa de juros com uma defasagem, o que pode ser um reflexo da sensibilidade ao custo do crédito, por exemplo, sugerindo que o investimento demora um pouco a responder ao aumento do custo do capital. Além disso, como o consumo foi negativamente afetado por tal taxa, de forma estatisticamente significante, o investimento privado também sofre um impacto negativo, por seu caráter induzido. 
Capítulo 2. Segundo Artigo - Os efeitos estabilizadores dos benefícios sociais: uma análise de multiplicadores fiscais para o Brasil no período 1997-2018

$\mathrm{Na}$ amostra menor, o coeficiente da taxa de juros foi positivo, e de sua defasagem, negativo - ambos significantes a $5 \%$. Os valores dos multiplicadores mudaram um pouco, como pode ser visto na Tabela 7. Quando controlamos para a taxa de juros anualizada, o coeficiente deste controle na equação do produto é positivo (e negativo para a variável defasada), ambos significantes a 5\%, nas duas amostras. Os valores estimados para os multiplicadores são muito similares ao caso do exercício controlado com a taxa de juros acumulada no trimestre. Para a amostra inteira: 0.4 (impacto), 1.92 (acumulado) e 1.6 (pico, período 3). Para a amostra pré-crise: 0.23 (impacto), 1.05 (acumulado) e 0.97 (pico, período 2$)^{38}$. Retirando o efeito da taxa de juros, os multiplicadores acumulados sofreram um aumento em relação ao modelo baseline. No entanto, a diferença em termos de multiplicador acumulado permaneceu.

O exercício controlado pela taxa de câmbio apresentou ligeira variação na amostra inteira. Esta variável foi significante a pelo menos $5 \%$. Na equação do investimento, especificamente, seu coeficiente foi negativo e chegou a ser significante a $1 \%$, nas duas amostras. Isto pode sugerir uma concordância com Dos Santos et al (2016) e uma possível explicação enunciada no Capítulo 1 é que o efeito da desvalorização cambial sobre os salários reais poderia diminuir o consumo e desestimular o investimento, apesar dos possíveis ganhos de competitividade. No entanto, há outras explicações, como abordado no Capítulo anterior. Por exemplo, encarecimento de insumos ou restrições de caixa (em firmas que possuem dívida em moeda estrangeira, por exemplo). Para a amostra inteira, o multiplicador acumulado vale 1.55, enquanto que na menor, 1.05. Notamos que houve, neste caso, diminuição da diferença entre as amostras para o multiplicador acumulado: embora tenha permanecido estável na amostra inteira, houve um aumento em tal multiplicador na amostra menor, retirado o efeito negativo do câmbio. A diferença de cerca de 1 real observada nos exercícios anteriores passa a ser de 50 centavos. Portanto, a diferença entre amostras para o investimento privado é menos robusta e deve ser vista com cautela. Ainda assim, os resultados apontam indícios de que o efeito multiplicador seja maior na amostra inteira $^{39}$.

Um último exercício realizado foi feito com a inclusão da variável de controle da taxa de câmbio defasada. Neste caso, a variável defasada (cujo sinal foi negativo na equação do investimento) não foi significante, embora a variável contemporânea continuasse

38 A inclusão das dummies de tempo, que se mostraram significantes no exercício para o investimento, não alterou os multiplicadores estimados de forma substantiva. Neste caso, com o controle da taxa de juros acumulada no trimestre, os multiplicadores estimados para a amostra inteira foram: 0.6 (impacto), 2 (acumulado) e 1.5 (pico, período 3). Para a amostra menor: 0.4 (impacto), 1 (acumulado) e 1.2 (pico, período 2). Os multiplicadores estimados com o controle da taxa anualizada foram praticamente iguais.

39 Se incluirmos no exercício as dummies anteriormente explicadas, utilizadas no exercício sem controles, e que se mostraram relevantes do ponto de vista de significância, ainda obtemos que o efeito da taxa de câmbio é bastante significante, a 1\%, com coeficiente negativo na equação do investimento, mas a diferença entre as amostras é um pouco maior em termos do multiplicador acumulado, valendo pouco mais de 0.8. Para a amostra inteira: 0.06 (impacto), 1.5 (acumulado) e 1.25 (pico, período 3). Amostra menor: 0.03 (impacto), 0.67 (acumulado) e 0.7 (pico, período 2). 
significante a 1\%, com sinal negativo. Os multiplicadores obtidos foram muito similares. Na amostra inteira: 0.05 (impacto), 1.35 (acumulado) e 1.3 (pico, período 3). Na amostra menor: -0.3 (impacto), 0.7 (acumulado) e 0.9 (pico, período 3).

A diferença entre os multiplicadores acumulados das duas amostras também foi um pouco menor no caso do controle para três variáveis. Apenas preço de commodities foi significativa, a 10\%, com sinal positivo na equação do investimento. Os multiplicadores obtidos podem ser vistos na Tabela 7 . Reforçamos que a diferença entre amostras para o investimento privado é menos robusta do que para o consumo das famílias. Todavia, os resultados ainda sugerem alguma diferença em termos de efeito multiplicador ao longo do tempo.

\subsubsection{Desagregação dos benefícios sociais}

Para ter uma ideia das respostas individuais dos componentes dos benefícios sociais, desagregamos os benefícios sociais em suas categorias: Aposentadoria (benefícios do RGPS, urbana e rural), Bolsa Família, Benefício de Prestação Continuada e Seguro-Desemprego (somado com abono salarial). O padrão de resposta do produto a cada uma dessas categorias foi muito similar ao observado no caso do exercício com os benefícios sociais agregados $(\text { Figura } 21)^{40}$.

Novamente, há indícios de diferença de resposta entre as amostras, em termos de multiplicador, como visto nas Figuras 16 e 17. Similar ao caso agregado, a diferença de resposta torna-se significante no acumulado quando consideramos bandas de 0.8 e 0.75 desvios-padrão para o caso da aposentadoria e do Bolsa Família, respectivamente, ao invés da banda tradicional de um desvio-padrão. Para o BPC e para o seguro-desemprego, há diferença se considerarmos 0.85 desvios-padrão. O exercício do seguro-desemprego levou em conta o ajuste cíclico mencionado anteriormente.

Os itens que mais possuem diferença entre as amostras, em termos de efeito multiplicador sobre o produto agregado, são o BPC e o seguro-desemprego. Como veremos nos parágrafos a seguir, o consumo das famílias possui menor diferença entre as amostras em termos de resposta a choques no BPC. No entanto, o BPC revela ter um efeito que acentua as diferenças entre a amostra pré-crise e inteira no caso do investimento privado. Já o seguro-desemprego se mostra bastante relevante para explicar a diferença entre amostras no caso do consumo das famílias, mas menos expressivo do lado do investimento privado.

$\overline{40}$ Assim como na estimação que utiliza os benefícios sociais agregados, consideramos os seguintes exercícios para averiguação da robustez dos modelos desta seção. Todos os exercícios de resposta do produto foram estimados de modo que houvesse a maior significância possível da função impulso-resposta do SVAR. Esse objetivo foi alcançado com o uso do deflator implícito e inclusão das dummies anteriormente explicadas, que foram incluídas caso elas apresentassem significância e se melhorassem a significância do modelo. A retirada ou inclusão dessas variáveis, porém, não alterou os exercícios de maneira substancial. As estimações foram também robustas a outras modificações, como inclusão de tendência, alteração de deflator e mudança para a ordem "tax-spending". 
Capítulo 2. Segundo Artigo - Os efeitos estabilizadores dos benefícios sociais: uma análise de Figura 21 - Funções Impulso Resposta do produto aos benefícios sociais desagregados em duas amostras
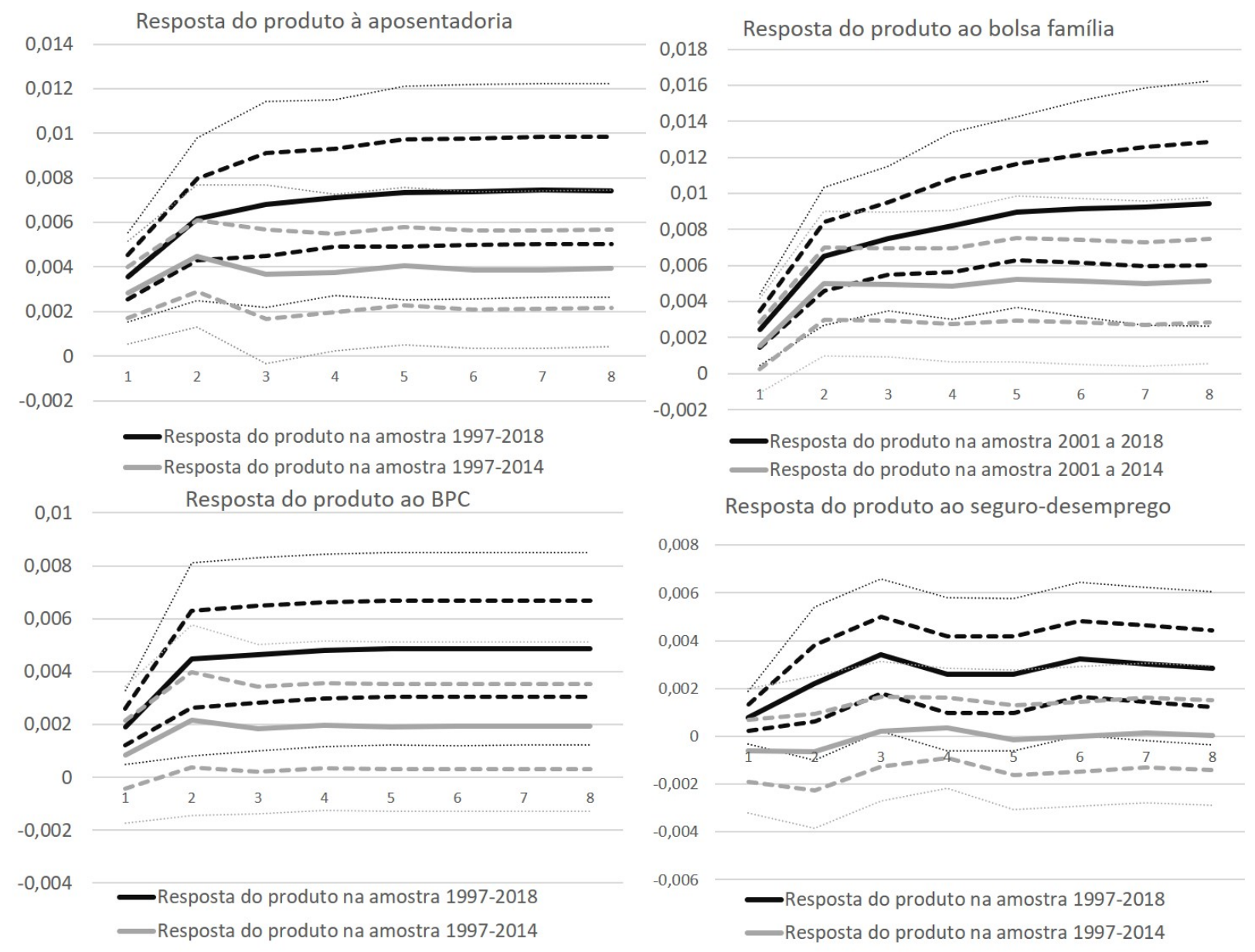

Fonte: Elaboração própria. As linhas tracejada e pontilhada correspondem, respectivamente, ao intervalo de um e de dois desvios-padrão, isto é, níveis de confiança de 68 e $95 \%$.

Na literatura microeconômica abordada na seção de revisão de literatura, há estudos que encontram um efeito maior sobre o produto associado ao PBF, como em Tupy e Toyoshima (2013) e em Neri et al (2013); em outros casos, é o BPC que assume o maior efeito multiplicador (Denes et al, 2016). Assim como em Neri et al (2013), os efeitos multiplicadores, seja em termos do produto agregado ou do consumo, do PBF, do BPC e do seguro-desemprego são os mais relevantes dentre os benefícios sociais. Contudo, em nosso caso, encontramos também uma pronunciada relevância para a aposentadoria.

A Figura 22 ilustra a abordagem desagregada para o consumo das famílias. Para a Aposentadoria e o Bolsa Família, a diferença de resposta nas amostras é significante ao nível de $68 \%$, no acumulado da função, a partir do quarto trimestre. Para os componentes BPC e Seguro-desemprego, a diferença de resposta no acumulado é quase significante ao nível de $68 \%$ (há separação quando consideramos um intervalo de 0.7 desvios-padrão em ambos). Cabe ressaltar que o exercício para o seguro-desemprego levou em consideração seu ajuste cíclico. Novamente, há um padrão das funções impulso-resposta bastante parecido 
Figura 22 - Funções Impulso Resposta do consumo das famílias aos benefícios sociais desagregados em duas amostras

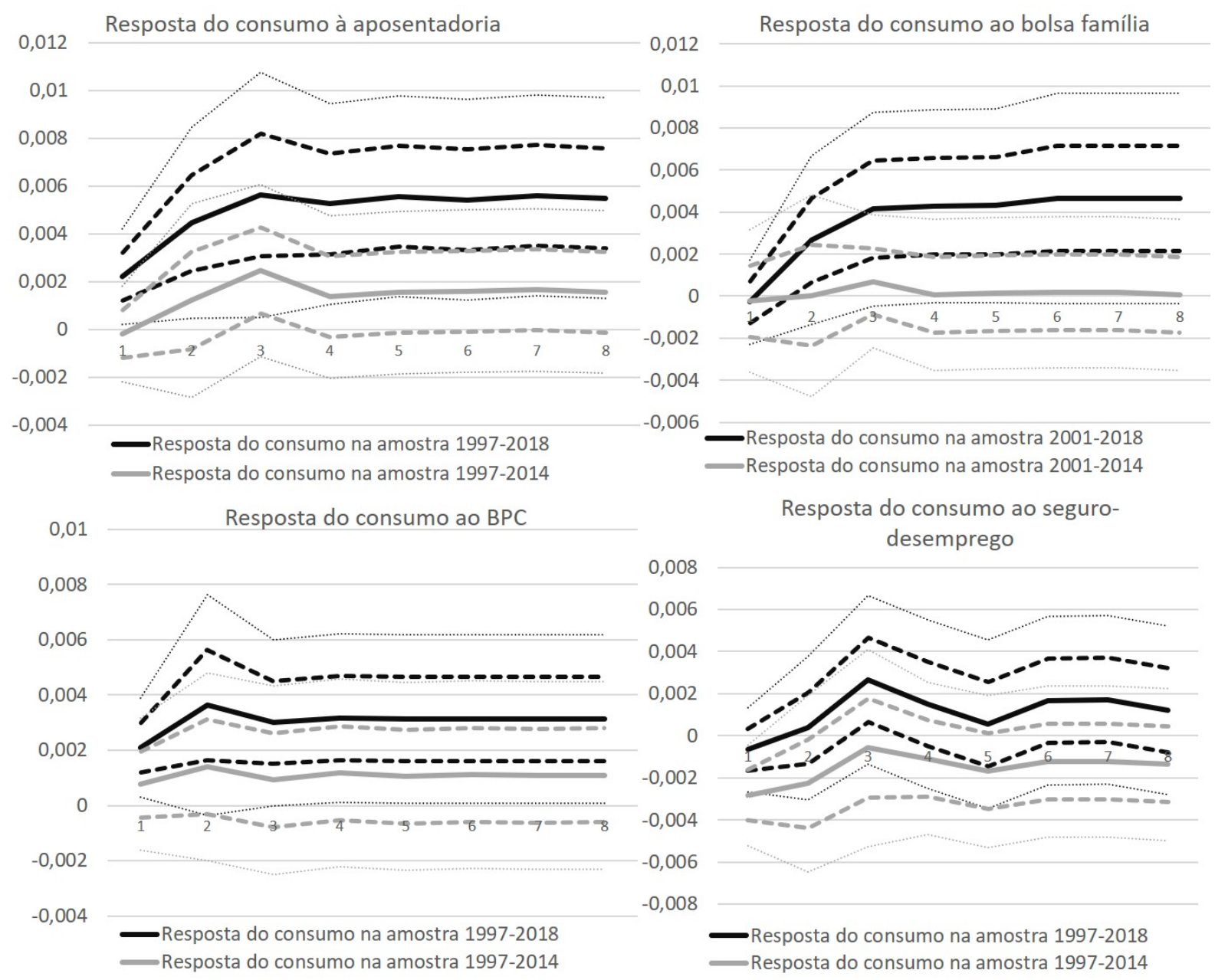

Fonte: Elaboração própria. As linhas tracejada e pontilhada correspondem, respectivamente, ao intervalo de um e de dois desvios-padrão, isto é, níveis de confiança de 68 e $95 \%$.

com o encontrado para o exercício do efeito dos benefícios agregados sobre o consumo, mostrado na Figura 19. Neste exercício, destaca-se que a diferença entre amostras é maior para a aposentadoria e o Bolsa Família. Para o BPC, entretanto, a diferença é um pouco menor e menos significativa, como mencionado anteriormente.

Um outro componente da demanda avaliado é o investimento privado. A Figura 23 mostra as estimações com os benefícios sociais desagregados para este componente. Apesar de a diferença de resposta entre as amostras ser significante para o caso do bolsa família e da aposentadoria apenas ao nível que considera uma banda de 0.65 desvios-padrão, para os demais componentes a diferença é estatisticamente significativa se considerarmos uma banda de quase um desvio-padrão (de 0.9) - para o caso do BPC e seguro-desemprego no acumulado da função. Entretanto, vale destacar que a resposta de impacto é bastante parecida entre as amostras. No caso da aposentadoria, a função impulso-resposta na amostra inteira é significante considerando até mesmo uma banda de dois desvios-padrão em alguns períodos, enquanto que na amostra pré-crise a resposta é significante somente a 
Figura 23 - Funções Impulso Resposta do investimento privado aos benefícios sociais desagregados em duas amostras

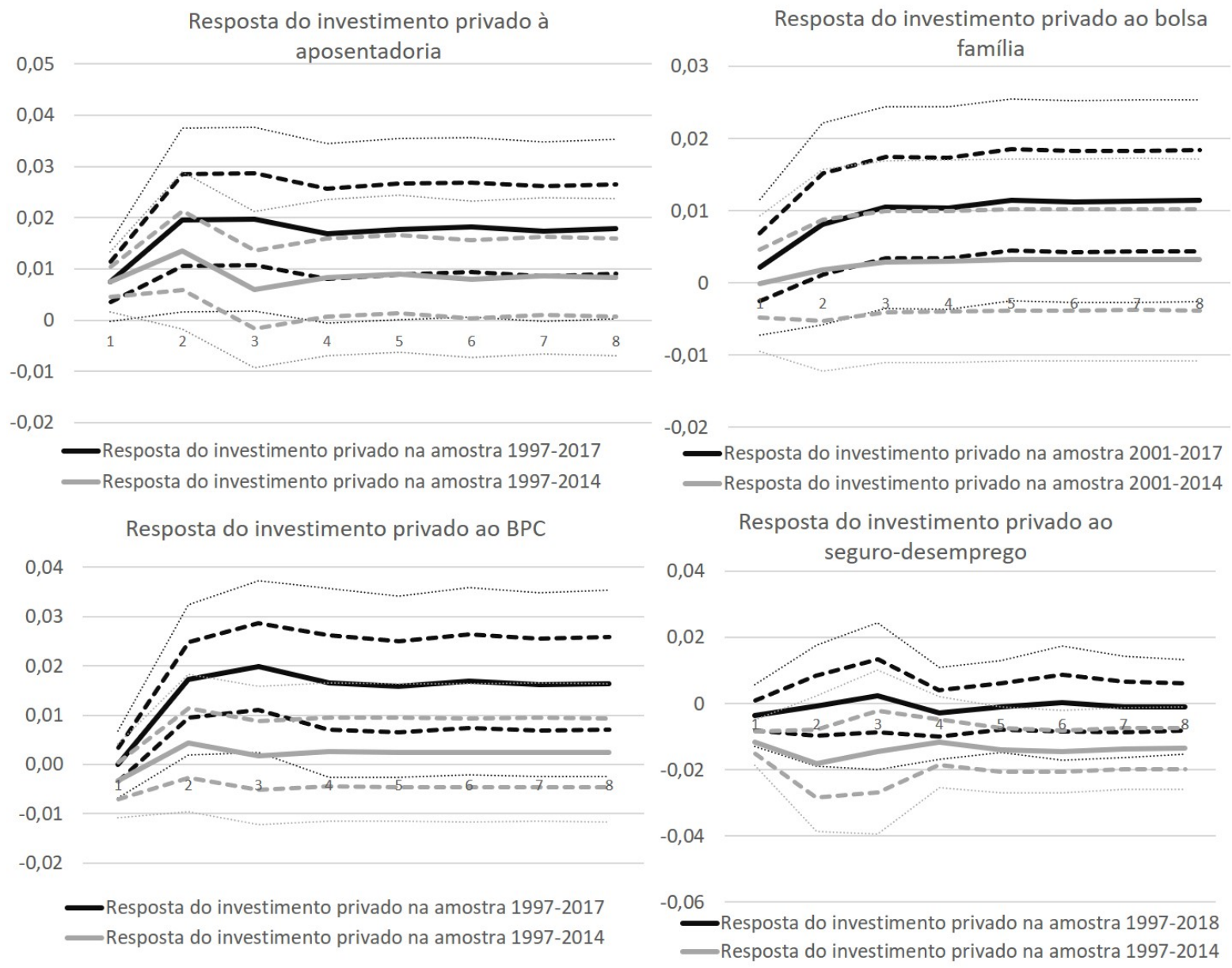

Fonte: Elaboração própria. As linhas tracejada e pontilhada correspondem, respectivamente, ao intervalo de um e de dois desvios-padrão, isto é, níveis de confiança de 68 e $95 \%$.

$68 \%$ (exceto nos períodos três e seis). Para o seguro-desemprego, apesar de a resposta ser negativa, ela não é estatisticamente significante para a amostra inteira, e é para a amostra pré-crise considerando um intervalo de um desvio-padrão.

Ao contrário do exercício com o consumo das famílias, no qual o BPC era um dos componentes que menos apresentava diferença, em termos de resposta do investimento privado o BPC é o componente que apresenta maior diferença entre amostras. Assim, o investimento privado se mostraria mais responsivo ao BPC na crise, uma vez que este programa social está estabelecido na Constituição Federal. Isto deve significar, por exemplo, um acentuado efeito estabilizador para os investimentos privados, tendo em vista que tal programa não está tão sujeito a cortes tão bruscos.

O que o exercício desta subseção mostra é que todos os componentes - em maior ou menor grau - dos benefícios sociais colaboraram para uma diferença de resposta e de efeito multiplicador na amostra que inclui a crise em relação à amostra pré-crise, tanto em termos de consumo das famílias quanto para o investimento privado. Em outras palavras, cada 
um dos componentes dos benefícios sociais apresentou um efeito estabilizador importante de forma a manter a demanda agregada no período da crise e evitar uma recessão ainda maior.

\subsection{Conclusão}

A partir de um VAR estrutural baseado em Blanchard e Perotti (2002), as despesas primárias do governo central com os benefícios sociais (que englobam aposentadorias, BPC, PBF e seguro-desemprego somado com abono salarial) possuem efeito multiplicador sobre a renda maior na amostra que inclui a crise recente (1997-2018), se comparado ao efeito na amostra pré-crise (1997-2014). Esse resultado mostrou-se robusto a várias especificações, como a utilização de dados mensais e trimestrais, inclusão de variáveis dummy, mudança no deflator do produto e ajuste cíclico nas despesas com seguro-desemprego para descontar uma possível resposta de estabilizador automático. A cada 1 real gasto em benefícios sociais, há a geração de quase 3 reais no período de dois anos na amostra inteira, e de 1.9 reais na amostra menor (para o exercício mensal).

Como vimos, há um relativo consenso da literatura, tanto nacional quanto internacional, em torno da importância dos investimentos públicos enquanto um tipo de despesa fundamental para a geração de renda. Este também foi um dos nossos resultados no Artigo 1. Todavia, vimos que, apesar da pouca importância que tem sido dada ao gasto social na literatura sobre multiplicadores fiscais, as despesas com benefícios sociais mostraram um relevante efeito multiplicador, de magnitude comparável ao dos investimentos públicos. Nos estudos para o Brasil, destacam-se dois trabalhos, o de Orair et al (2016), bem como o de Resende (2019). Nossos resultados estão em linha com esses estudos. Cabe ressaltar que, para além de calcular os multiplicadores fiscais associados aos benefícios sociais, nossa contribuição está em analisar especificamente o período da crise recente, isto é, avaliar se o multiplicador fiscal associado aos gastos com benefícios sociais mudou no período da crise, de 2014 a 2018. Como descrito no parágrafo acima, nossos resultados indicam que esse efeito multiplicador foi maior durante a crise. Possivelmente tais resultados estão subestimados, uma vez que calculamos o multiplicador associado ao período da crise utilizando a amostra inteira, e não somente o período 2014-2018, por questões estatísticas. Assim, o efeito exercido pelo gasto com benefícios sociais deve ser ainda maior.

Além disso, nossa contribuição está em desagregar os componentes da demanda agregada, bem como os componentes dos benefícios sociais, no contexto da análise para a crise recente. Constatamos que o consumo das famílias é o mais importante canal pelo qual o efeito multiplicador acima descrito opera - tanto em magnitude como em maior robustez. No entanto, há efeitos relevantes também do lado do investimento privado: o estímulo no consumo induz uma elevação das vendas e, logo, dos investimentos das empresas. De acordo 
Capítulo 2. Segundo Artigo - Os efeitos estabilizadores dos benefícios sociais: uma análise de multiplicadores fiscais para o Brasil no período 1997-2018

com nossos cálculos, considerando o modelo baseline, a cada 1 real gasto geram-se 1.76 reais a mais em termos de consumo e 1.13 reais a mais em investimento privado na amostra inteira, em relação ao que é gerado nas estimações com a amostra pré-crise. Os valores dos multiplicadores, entretanto, estão sujeitos a variações, a depender das estimações com variáveis de controle, como vimos. Contudo, o importante é que as diferenças entre as amostras foram, de um modo geral, robustas às especificações. A desagregação a nível dos benefícios sociais mostra que todas as suas categorias foram importantes para explicar essas diferenças. Em particular, destaca-se a resposta do consumo à aposentadoria e ao Bolsa Família; bem como a resposta do investimento privado ao BPC.

Uma ressalva similar à do Capítulo 1 é válida para este artigo. Os resultados deste estudo possuem um alcance limitado, uma vez que analisamos o papel específico do multiplicador fiscal de gasto público no produto no período analisado, sem considerar outros fatores relevantes (como mudanças na estrutura produtiva, por exemplo). Como vimos no Capítulo 1, entretanto, foi realizada a inclusão de algumas variáveis de controle relevantes para a economia brasileira no período estudado, de forma a endereçar esse problema ao menos parcialmente.

Portanto, do ponto de vista do efeito multiplicador gerado pelo gasto em benefícios sociais - ainda que haja outros fatores em jogo - a manutenção do crescimento das despesas com benefícios sociais na crise, por não serem passíveis de cortes muito expressivos em programas de ajuste, funcionou como um elemento estabilizador da renda na recessão recente e evitou uma queda ainda maior no produto.

\section{Referências do Segundo Artigo}

ADAMS, A.; WONG, M. Quantifying fiscal multipliers in New Zealand: the evidence from SVAR Models. Reserve Bank of New Zealand Analytical Note Series, 2018.

AlESINA, A.; BARBIERO, O.; FAVERO, C.; GIAVAZZI, F.; PARADISI, M. The Effects of Fiscal Consolidations: Theory and Evidence. NBER Working Paper, n.23385, 2017.

ALMEIDA JR, M.; LISBOA, M.; PESSÔA, S. O ajuste inevitável, ou o país que ficou velho antes de se tornar desenvolvido. Artigo publicado na Folha de S. Paulo, julho de 2015 .

ALVES, R. O impacto da política fiscal sobre a atividade econômica ao longo do ciclo econômico: evidências para o Brasil. Dissertação de Mestrado. Instituto de Pesquisas Econômicas. Universidade de São Paulo, 2017.

ANDREIS, A. O comportamento da política fiscal brasileira no período pós-plano real e suas implicações. Dissertação de Mestrado -Universidade do Vale do Rio dos Sinos, 2016.

AUERBACH, A.; GORODNICHENKO, Y. Measuring the output responses to fiscal policy. 
American Economic Journal: Economic Policy, v.4, n.2, p. 1-27, 2012.

BARROS, A.; ATHIAS, D. Salário mínimo, Bolsa Família e desempenho relativo recente da economia do Nordeste. Revista de Economia Política, v.33, n.1(130), p.179-199, 2013.

BAUM, A.; KOESTER, G. The impact of fiscal policy on economic activity over the business cycle -evidence from a threshold VAR analysis. Discussion Paper Series Economic Studies - Deutsche Bundesbank, n.3, 2011.

BEETSMA, R.; GIULIODORI, M. The effects of government purchases shocks: review and estimates for the EU. The Economic Journal, v.121, p.4-32, 2011.

BENETRIX, A.; LANE, P. The Impact of Fiscal Shocks on the Irish Economy. The Economic and Social Review, v. 40, n. 4, p. 407-434, 2009.

BHORAT, H.; CASSIM, A.; EWINYU, A.; STEENKAMP, F. Social Protection and Inequality in Africa: Exploring the interactions. Chapter 8 Social Protection and Inequality in Africa: Exploring the interactions. IN: ODUSOLA, A.; CORNIA, G.; BHORAT, H.; CONCEIÇÃO, P. (Editors). Income Inequality Trends in sub-Saharan Africa: Divergence, determinants and consequences. UNDP, 2017.

BLANCHARD, O.; PEROTTI, R. An empirical characterization of the dynamic effects of changes in government spending and taxes on output. Quarterly Journal of Economics, v.117, n.4, p.1329-1368, 2002.

BOLETIM ESTATÍSTICO DA PREVIDÊNCIA SOCIAL. v. 20, n.1, janeiro de 2015.

BORG, I. Fiscal Multipliers in Malta. Central Bank of Malta Working Papers, n.06, 2014.

BOVA, E.; KLYVIENE, V. Macroeconomic effects of fiscal shocks in Portugal. European Economy Discussion Paper, n.096, 2019.

BRUCKNER, M.; TULADHAR, A. Public Investment as a Fiscal Stimulus: Evidence from Japan's Regional Spending During the 1990s. IMF Working Paper, n.110, 2010.

BURRIEL, P.; CASTRO, F.; GARROTE, D.; GORDO, E.; PAREDES, J.; PEREZ, J. Fiscal policy shocks in the euro area and the US an empirical assessment. Fiscal Studies, v.31, n.2, p. 251-285, 2010.

CARRIÈRE-SWALLOW, Y.; DAVID, A.; LEIGH, D. The macroeconomic effects of fiscal consolidation in emerging economies: evidence from Latin America. International Monetary Fund. IMF Working Papers, n.142, 2018.

CARVAlHO, L. Valsa Brasileira. Do boom ao caos econômico. Editora Todavia, 2018.

CASTElO-BRAnCO, M. A.; LIMA, E. C. R.; PAUlA, L. F. Mudanças de Regime e Multiplicadores Fiscais no Brasil entre 1999-2012: uma avaliação empírica. Anais do XLIII Encontro Nacional de Economia da Anpec, 2015. 
Capítulo 2. Segundo Artigo - Os efeitos estabilizadores dos benefícios sociais: uma análise de multiplicadores fiscais para o Brasil no período 1997-2018

CASTRO, F. The macroeconomic effects of fiscal policy in Spain. Documento de Trabajo Banco de Espana, n.0311, 2003.

CASTRO, F.; FERNANDEZ, L. The Effects of Fiscal Shocks on the Exchange Rate in the Spain. Documentos de Trabajo - Bank of Spain, n.1121, 2011.

CATTAN, R. Política fiscal e crescimento econômico: uma análise do período de metas de inflação no Brasil. Dissertação de Mestrado. Unicamp, 2017.

CAVALCANTI, M.; SILVA, N. Dívida pública, política fiscal e nível de atividade: Uma abordagem var para o brasil no período 1995-2008. Economia Aplicada, v.14, n.4, p.391-418, 2010 .

ÇEBI, C. Government Spending Multiplier in Turkey. Central Bank of the Republic of Turkey (Turkiyes Cumhuriyet Merkez Bankasi) Working Paper, n.15, 2015.

CLAUS, I.; GILL, A.; LEE, B.; MCLELLAN, N. An empirical investigation of fiscal policy in New Zealand. New Zealand Working Paper, n.06/08, 2006.

CLAUS, I.; MARTINEZ-VAZQUEZ, J.; VUlOVIC, V. Government Fiscal Policies and Redistribution in Asian Countries. Asian Development Bank Economics Working Paper Series, n.310, 2012.

COUDRET, N. Fiscal Multipliers in the Netherlands A Structural VAR Approach. Master Thesis in Policy Economics. Erasmus School of Economics, 2013.

COUNCIL ECONOMICS ADVISERS. Estimates of job creation from the american recovery and reinvestment act of 2009, 2009.

DELEIDI, M.; IAFRATE, F.; LEVRERO, E. Public investment fiscal multipliers: an empirical assessment for European countries. Structural Change and Economic Dynamics, v.52, p.354-365, 2019.

DENES, G.; MENEZES-FILHO, N.; KOMATSU, B. Uma avaliação dos impactos macroeconômicos e sociais de programas de transferência de renda nos municípios brasileiros. Insper Policy Paper, n.21, 2016.

DOLLS, M.; FUEST, C.; PEICHL, A. Social Protection as an Automatic Stabilizer. Institute for the Study of Labor (IZA) Policy Paper, n.18, 2010.

DOS SANTOS, C.; MODENESI, A.; SQUEFF, G.; VASCONCELOS, L.; MORA, M.; FERNANDES, T.; MORAES, T.; SUMMA, R.; BRAGA, J. Revisitando a dinâmica trimestral do investimento no Brasil: 1996-2012. Revista de Economia Política, v.36, n. 1 (142), p. 190-213, 2016.

DUFRÉNOT, G.; JAMBOIS, A.; JAMBOIS, L.; KHAYAT, G. Regime-Dependent Fiscal Multipliers in the United States. Open Economies Review, v.27, n.5, 2016.

DUTRA, F. Multiplicadores fiscais no Brasil: estimativas a partir de Modelos STVAR. 
Trabalho de conclusão. Universidade Federal do Rio Grande do Sul, 2016.

ESKESEN, L. The Role for Counter-Cyclical Fiscal Policy in Singapore. IMF Working Paper, n.8, 2009.

FATAS, A.; MIHOV, I. The Effects of Fiscal Policy on Consumption and Employment: Theory and Evidence. Centre for Economic Policy Research (London). CEPR Discussion Paper, n.2760, 2001.

FURCERI, D.; ZDZIENICKA, A. The Effects of Social Spending on Economic Activity: Empirical Evidence from a Panel of OECD Countries. Fiscal Studies, v.33, n.1, p.129-152, 2012.

GALDÓN, C. Are Fiscal Multipliers larger during recessions? Columbia University, 2013. GARCIA, J.; LEMUS, A.; MRKAIC, M. Fiscal Multipliers in the ECCU. IMF Working Paper, n.13/117, 2013.

GECHERT, S.; RANNENBERG, A. Are Fiscal Multipliers Regime-Dependent? A Meta Regression Analysis. IMK working paper, n.139, 2014.

GECHERT, S.; PAETZ, C.; VILlANUEVA, P. The Macroeconomic Effects of Social Security Contributions and Benefits - Evidence from Germany. Macroeconomic Policy Institute (IMK), 2018.

GIORDANO, R.; MOMIGLIANO, S.; NERI, S.; PEROTTI, R. The effects of fiscal policy in Italy: Evidence from a VAR model. European Journal of Political Economy, v.23, p.707-733, 2007.

GOBETTI, S.; GOUVEA, R.; SCHETTINI, B. Resultado fiscal estrutural: um passo para a institucionalização de políticas anticíclicas no Brasil. Texto para discussão IPEA, n.1515, 2010 .

GOMES, G. Velhas secas em novos sertões. Brasília, DF: Ipea, 2001.

GRUDTNER, V.; ARAGON, E. Multiplicador dos gastos do governo em períodos de expansão e recessão: evidências empíricas para o Brasil. Revista Brasileira de Economia, v.71, n.3, p.321-345. 2017.

HAILE, F.; ZARAZÚA, N. Does social spending improve welfare in low-income and middle-income countries? Journal of International Development, v.30, p.367-398, 2018.

HOLLMAYR, J.; KUCKUCK, J. Fiscal multipliers of central, state and local government and of the social security funds in Germany: evidence of a SVAR. Deutsche Bundesbank Discussion Paper, n.28, 2018.

HOLZNER, M. Inequality, growth and public spending in Central, East and Southeast Europe. Society for the Study of Economic Inequality. Working Paper Series, n.221, 2011. 
Capítulo 2. Segundo Artigo - Os efeitos estabilizadores dos benefícios sociais: uma análise de multiplicadores fiscais para o Brasil no período 1997-2018

HUSEYIN, S.; KAYA, A. How large are fiscal multipliers in Turkey? $Z B W-$ Deutsche Zentralbibliothek für Wirtschaftswissenschaften, Leibniz Information Centre for Economics, 2017.

ILZETZKI, E. Fiscal Policy and Debt Dynamics in Developing Countries. Policy Research Working Paper World Bank, n.5666, 2011.

ILZETZKI, E.; MENDOZA, E.; VEGH, C. How Big (Small?) Are Fiscal Multipliers? Journal of Monetary Economics, v.60, p.239-254, 2013.

IPEA. Equidade fiscal no Brasil: impactos distributivos da tributação e do gasto social. Comunicados do IPEA, n. 92, 2011.

IZQUIERDO, A.; LAMA, R.; MEDINA, J.; PUIG, J.; RIERA-CRICHTON, D.; VEGH, C.; VULETIN, G. Is the public investment multiplier higher in developing countries? An empirical investigation. NBER Working paper series, n.26478, 2019.

JEMEC, N.; KASTELEC, A.; DELAKORDA, A. How do fiscal shocks affect the macroeconomic dynamics in the slovenian economy? Delovni Zvezki Banke Slovenije Banck of Slovenia Working Paper, 2013.

KOnStAntinOU, P.; PARTHEnIOU, A. The Effects of Government Spending Over the Business Cycle: A Disaggregated Analysis for OECD and Non-OECD Countries. Quarterly Review of Economics and Finance, 2019.

KOZUHAROV, S.; PETKOVSKI, V. The Impact of Social Transfers on Inequality Measured by Gini Index: The Example of Macedonia. UTMS Journal of Economics, v.9, n.1, p.49-61, 2018.

LANDIM JUNIOR, P. H. Os Efeitos do Programa Bolsa Família sobre a Economia dos Municípios Brasileiros. Relatório Final. Insper, 2009.

LOPES, M.; MOLLO, M.; COLBANO, F. Metas de inflação, regra de Taylor e neutralidade da moeda: uma crítica pós-keynesiana. Revista de Economia Política, v.32, n.2, p.282-304, 2012.

LOZANO, I.; RODRIGUEZ, K. Assessing the macroeconomic effects of fiscal policy in Colombia. Journal of Financial Economic Policy, v.3, n.3, p.206-228, 2011.

MANÇELLARI, A. Macroeconomic effects of fiscal policy in Albania: a SVAR approach. Working paper, Bank of Albania, n.05 (28), 2011.

MARQUES, R.; MENDES, A. Crescimento, desenvolvimento e cidadania. Indic. Econ. FEE, Porto Alegre, v. 33, n. 1, p. 293-316, 2005.

MATHESON, T.; PEREIRA, J. Fiscal multipliers for Brazil. International Monetary Fund, IMF Working papers, n.79, 2016.

MATTEO, D.; VINCENZO, D.; MAZZUCATO, M.; AGNOLUCCI. Fiscal Multipliers: 
a SVAR approach for the US. Associazione Italiana per la Storia dell'Economia Politica (STOREP), 2018.

MEDEIROS, M.; BRITTO, T.; SOARES, F. Targeted cash transfer programmes in Brazil: BPC and the Bolsa Família. International Poverty Centre Working Paper, n.46, 2008.

MELLO, L.; MOCCERO, D. Brazil's fiscal stance during 1995-2005. OECD Economics Department Working Papers, n.485, 2006.

MENDONÇA, D.; MARÇAL, E.; HOLLAND, M. Is fiscal policy effective in Brazil? An empirical analysis. Working paper series, São Paulo School of Economics, 2016.

MERTENS, K.;RAVN, M. A Reconciliation of SVAR and Narrative Estimates of Tax Multipliers. Journal of Monetary Economics, v.68, p.S1-S19, 2014.

NERI, M.; VAZ, F.; SOUZA, P. Efeitos macroeconômicos do programa Bolsa Família: uma análise comparativa das transferências sociais. In: CAMPELLO, T.; NERI, M. (Orgs). Programa Bolsa Família: uma década de inclusão e cidadania. Brasília: IPEA, 2013.

NIEHUES, J. Social Spending Generosity and Income Inequality: A Dynamic Panel Approach. Forschungsinstitut zur Zukunft der Arbeit Institute for the Study of Labor. Discussion Paper, n.5178, 2010.

OCAMPO, J.; ARTEAGA, N. Social protection systems in Latin America: An assessment. Social Protection Department ILO Regional Office for Latin America and the Caribbean. Extension of Social Security. Working Paper, n. 52, 2016.

ORAIR, R. Investimento público no Brasil: trajetórias e relação com o regime fiscal. Texto para discussão - Instituto de Pesquisa Econômica Aplicada (IPEA), n.2215, 2016.

ORAIR, R.; GOBETTI, S. Resultado primário e contabilidade criativa: reconstruindo as estatísticas fiscais acima da linha do governo geral. Texto para discussão - IPEA, n.2288, 2017a.

ORAIR, R.; GOBETTI, S. Brazilian fiscal policy in perspective: from expansion to austerity. Encontro Nacional ANPEC, 2017b.

ORAIR, R.; SIQUEIRA, F.; GOBETTI, S. Política fiscal e ciclo econômico: uma análise baseada em multiplicadores do gasto público. XXI Prêmio do Tesouro Nacional, 2016.

OSPINA, M. The Effect of Social Spending on Income Inequality: An Analysis for Latin American Countries. Documentos de Trabajo Economía y Finanzas. Centro de Investigaciones Económicas y Financieiras (CIEF) - Universidad Eafit, n.10-03, 2010.

PEREIRA, A.; SAGALÉS, O. Long-term effects of fiscal policies in Portugal. College of William and Mary - Working Paper, n.35, 2009.

PEREIRA, M.; WEMANS, L. Output effects of fiscal policy in Portugal: a Structural VAR approach. Banco de Portugal. Economic Bulletin, 2013. 
Capítulo 2. Segundo Artigo - Os efeitos estabilizadores dos benefícios sociais: uma análise de multiplicadores fiscais para o Brasil no período 1997-2018

PERES, M. Os efeitos dinâmicos da política fiscal sobre a atividade econômica: um estudo para o caso brasileiro. Dissertação de Mestrado - Universidade de Brasília, 2006.

PERES, M.; ELLERY, R. Efeitos dinâmicos dos choques fiscais do governo central no pib. Pesquisa e Planejamento Econômico, v.39, n.2, p.159-206, 2009.

PEROTTI, R. Estimating the effects of fiscal policy in OECD countries. IGIER Working Paper, n.276, 2004.

PESSÔA, S. O governo FHC e o gasto social. Artigo publicado no jornal Folha de S.Paulo, em $17 / 08 / 2014$.

PESSÔA, S. Debate dos impactos da nova matriz econômica: a visão mais crítica. Conjuntura Econômica, 2017.

PIRES, M. Controvérsias recentes sobre multiplicadores fiscais. Anais do VII Encontro Internacional da Associação Keynesiana Brasileira, 2011.

PIRES, M. Política fiscal e ciclos econômicos no Brasil. Economia Aplicada, v.18, n.1, p.69-90, 2014.

PIRES, M.; BORGES, B. A Despesa Primária do Governo Central: estimativas e determinantes no período 1986-2016. Estudos Econômicos, v.49, n.2, p.209-234, 2019.

RANGEL, L.; VAZ, F.; FERREIRA, J. Desigualdade na distribuição de renda: enfoque nas aposentadorias e pensões públicas. Informe de Previdência Social, v.21, n.5, 2009.

RAVNIK, R.; ZILIC, I. The use of SVAR analysis in determining the effects of fiscal shocks in Croatia. Financial Theory and Practice, v. 35, n.1, p.35-58, 2010.

REEVES, A.; BASU, S.; MCKEE, M.; MEISSNER, C.; STUCKLER, D. Does investment in the health sector promote or inhibit economic growth? Globalization and Health, v.43, n.9, 2013.

RESENDE, C. Impulso fiscal: Uma abordagem de multiplicadores fiscais com aplicação para a economia brasileira. Dissertação de Mestrado. Escola de Economia de São Paulo. Fundação Getulio Vargas, 2019.

ROMER, C.; ROMER, D. The macroeconomic effects of tax changes: Estimates based on a new measure of fiscal shocks. American Economic Review, v. 100, n.3, p.763-801, 2010. ROMER, C.; ROMER, D. Transfer Payments and the Macroeconomy: The Effects of Social Security Benefit Increases, 1952-1991. American Economic Journal: Macroeconomics, v.8, n.4, p.1-42, 2016.

SANCHÉZ, Á.; PÉREZ, A. Government Social Expenditure and Income Inequalities in the European Union. Review of Public Economics, v.227, n.4, p.133-156, 2018.

SARANGI, N.; BONIN, J. Fiscal policy on public social spending and human development 
in Arab countries. Economic and Social Commission for Western Asia. Technical paper, n.13, 2017.

SILVA, R.; CARVALHO, V.; RIBEIRO, A. How Large are Fiscal Multipliers? A Panel-Data VAR Approach for the Euro Area. FEP Working Papers, n.500, 2013.

SKRBIC, M.; SIMOVIC, H. The size and determinants of fiscal multipliers in Western Balkans: comparing Croatia, Slovenia and Serbia.EFZG Working Paper Series, n.15-10, 2015 .

SOARES, F.; RIBAS, R.; OSÓRIO, R. Avaliando o Impacto do Programa Bolsa Família: uma Comparação com Programas de Transferência Condicionada de Renda de Outros Países. International Poverty Centre, IPC evaluation note, n.1, 2007.

SOUZA, A. Políticas de distribuição de renda no Brasil e o Bolsa Família. Escola de Economia de São Paulo (FGV). Textos para discussão, n.281, 2011.

SPILIMBERGO, A.; SYMANSKI, S.; SCHINDLER, M. Fiscal multipliers. Technical report. IMF Staff Position Note, IMF, 2009.

TENHOFEN, J.; WOLFF, G.; HEPPKE-FALK, K. The Macroeconomic Effects of Exogenous Fiscal Policy Shocks in Germany: A Disaggregated SVAR Analysis. Journal of Economics and Statistics (Jahrbuecher fuer Nationaloekonomie und Statistik), v.230, n.3, p.328-355, 2010.

TUPY, I.; TOYOSHIMA, S. Impactos dos Programas Governamentais de Transferência de Renda sobre a Economia do Vale do Jequitinhonha. XVIII Encontro Regional de Economia, 2013.

ULU, M. The effect of government social spending on income inequality in OECD: a panel data analysis. International Journal of Economics Politics Humanities and Social Sciences, v.1, n.3, 2018.

VALENCIA, F. Fiscal multipliers in Mexico. IMF Mexico Selected Issues. IMF Country Report, n.15/314, p.4-9, 2015.

VAZQUEZ, J. DODSON, B.; VULOVIC, V. The Impact of Tax and Expenditure Policies on Income Distribution: Evidence from a Large Panel of Countries. International Center for Public Policy Working Paper Series, n.77, 2012.

VDOVYCHENKO, A. How does fiscal policy affect gdp and inflation in Ukraine? Visnyk of the National Bank of Ukraine, n. 244, p. 25-43, 2018.

WAGLE, U. How much do social protections matter to poverty and inequality? An insight from Asian experiences. Global Social Policy, p. 1-31, 2016. 



\section{Terceiro Artigo - O efeito dos benefícios sociais na recessão brasileira recente: um modelo Kaleckiano com endividamento das famílias}

\subsection{Introdução}

A exploração do crédito em modelos Kaleckianos foi bastante estimulada pelo fato de que o consumo cresceu consideravelmente nas últimas décadas nos países ricos, em razão de um aumento da participação dos lucros na renda nacional (e, consequentemente, menor participação dos salários na renda), constituindo um puzzle empírico. Nos Estados Unidos, por exemplo, o período a partir de meados da década de 1980 até a crise de 2008 é caracterizado por altas taxas de crescimento do consumo, sobretudo no espectro distributivo dos $96 \%$ mais pobres, seja por meio da facilitação do acesso ao crédito pelo lado da oferta (com inovações financeiras), ou pelo aumento da desigualdade de renda, que exerceu influência nas "normas de consumo" e na demanda por crédito. Tal período é rotulado de Consumer Age por Cynamon e Fazzari (2013). Ryoo e Kim (2014) mostram que o endividamento das famílias em relação ao produto passou de $45 \%$ em 1975 para $100 \%$ em 2006. Já Barba e Pivetti (2008) apresentam que, em 2006, o crédito ao consumidor atingiu $25 \%$ da renda pessoal disponível, o pico de uma trajetória crescente desde a primeira metade da década de 1980, período no qual a média foi por volta de 18\%, embora houvesse oscilações.

A tentativa de preservar uma taxa de crescimento estável do consumo é, na realidade, uma reação à estagnação salarial e ao aumento de desigualdade de renda, e o crédito passa a ser uma espécie de substituto dos salários (Barba e Pivetti, 2008; Cynamon e Fazzari, 2013). O endividamento assume, neste contexto, o papel de fonte alternativa de financiamento das famílias. Se por um lado o aumento do consumo elevou a demanda agregada e estimulou a economia, por outro houve um processo de fragilização financeira que culminou na crise de 2008.

Recentemente, a literatura explorou a possibilidade de haver um efeito de causa também no sentido oposto (em Kim et al, 2018): o próprio aumento do endividamento eleva a desigualdade de renda porque há diminuição do poder de barganha dos trabalhadores no mercado de trabalho, tendo em vista que eles possuem uma dívida para honrar e o custo de perder o emprego se torna ainda mais alto. Isto, por sua vez, eleva a desigualdade, induzindo 
Capítulo 3. Terceiro Artigo - O efeito dos benefícios sociais na recessão brasileira recente: um modelo Kaleckiano com endividamento das famílias

os trabalhadores a tomarem crédito a fim de manter estável sua taxa de crescimento do consumo. Forma-se, deste modo, um círculo vicioso de crescente endividamento e desigualdade de renda, observado no cenário pré-crise de 2008. Cynamon e Fazzari (2013) estimam que $8 \%$ da demanda agregada pré-crise nos Estados Unidos foi baseada em endividamento não sustentável.

No caso brasileiro, a concessão de crédito a pessoas físicas em relação ao produto aumentou rapidamente de 2003 a 2009 e houve um aumento mais suave a partir de 2010 . Essa trajetória crescente do crédito não se deveu ao aumento de desigualdade (embora possa estar relacionada à desigualdade ainda alta) como no caso dos países ricos, mas sim à maior inclusão social do período, caracterizado por altas taxas de crescimento econômico e por políticas de valorização do salário mínimo e formalização do mercado de trabalho. A facilitação do acesso ao crédito foi, neste contexto, bastante estimulada pela institucionalização do crédito consignado, em 2004, e pela expansão do crédito por parte dos bancos desde a crise de 2008 (Carvalho e Rugitsky, 2015; Serrano e Summa, 2012).

Os modelos Kaleckianos que incorporam o endividamento das famílias tipicamente encontram um caráter dual do crédito e seu efeito no crescimento econômico (Dutt, 2006; Palley, 1994; Duman, 2013; Hein, 2011; Kim et al, 2014; Setterfield et al, 2016; Ryoo e Kim, 2014; Marsellou, 2011; Palley, 2010; Pariboni, 2016). Por um lado, o endividamento tem o papel de substituir (ou complementar) os salários, estimulando o consumo e a demanda agregada. Por outro, esse efeito pode ser convertido em estímulo contracionista devido ao caráter concentrador de renda do acúmulo de dívidas por parte das famílias, sobre o qual incide uma taxa de juros. Esse montante (a taxa de juros multiplicada pelo estoque de dívidas) é destinado para a classe capitalista, cuja propensão a poupar é maior. Desta forma, os devedores (ou a classe trabalhadora) - que são mais pobres que os credores (a classe capitalista/rentista) - possuem propensão a consumir maior que a classe rentista. Se o estoque da dívida aumenta, há um estímulo à demanda agregada pela via do estímulo ao consumo, que é interrompido pelo maior pagamento de juros à classe rentista, que poupa mais. Portanto, a presença de classes com diferentes propensões a consumir constitui um elemento fundamental para a construção desses modelos, sendo abordada já por Kaldor (1955). Palley (1994) justifica essa diferença por distinções de classe ou mesmo por questões psicológicas ligadas a um maior otimismo dos devedores.

Assim como em Kapeller e Schutz (2015), partiremos de um resultado empírico para a formulação de nosso modelo. A questão explorada pelos autores procura identificar o porquê do aumento da propensão marginal a consumir nos Estados Unidos, do período 2002-2007, quando foi observada uma expansão significativa do consumo das famílias, embora houvesse uma diminuição da participação dos salários na renda nacional. Segundo os autores, a explicação para uma propensão marginal a consumir maior está relacionada ou a efeitos riqueza (Zezza, 2008) ou ao aumento da desigualdade de renda, que leva ao 
consumo conspícuo e ao endividamento (Kapeller e Schutz, 2015).

Em nosso caso, partiremos do resultado empírico encontrado nos capítulos anteriores. Como vimos nos Artigos 1 e 2, no Brasil os benefícios sociais desempenharam um papel bastante relevante para preservar o produto de variações ainda mais negativas durante a recessão recente. Um canal possível pelo qual isso pode ocorrer é por meio do crédito, uma vez que a concessão de crédito comportou-se de maneira diferente entre trabalhadores aposentados, que recebem o benefícios social da previdência, e trabalhadores ativos. Como veremos, houve queda acentuada na concessão de crédito para esta última classe e estabilidade no caso do crédito ofertado/demandado ao/pelo aposentado. Cabe pontuar que este canal do crédito é um mecanismo indireto, pois, além dele, o benefício social em si já tem um efeito direto em termos de manutenção da demanda agregada e do nível de atividade. O artigo conta com quatro seções, além desta introdução. A segunda seção apresenta a motivação empírica, com dados sobre crédito a pessoa física no Brasil sobretudo nos últimos anos. A seção 3.3 apresenta uma revisão de literatura relacionada. Finalmente, as seções 3.4 e 3.5 incluem o modelo e as conclusões, respectivamente.

\subsection{Motivação empírica}

Esta seção tem como objetivo fundamentar o modelo teórico, que foi inspirado em nossos resultados empíricos. O resultado empírico encontrado no capítulo anterior desta dissertação (Artigo 2) sugere uma diferença significante do impacto dos benefícios sociais sobre o consumo nas amostras completa (de 1997 a 2018) e pré-crise (de 1997 a 2014), o que nos indica que há um efeito multiplicador maior sobre o consumo das famílias e sobre o produto desse tipo de gasto no período de crise. Se a resposta do produto e do consumo das famílias a choques nos benefícios sociais é maior na amostra completa, que inclui a crise, então a resposta (e, consequentemente, os multiplicadores fiscais) somente para o período da crise deve ser ainda maior. Um segundo pilar para a motivação deste modelo é que há uma mudança de composição dos tomadores de crédito consignado no período da crise, o que sugere um possível canal de transmissão para o maior efeito multiplicador de renda, o qual surge de uma maior capacidade de gasto a partir dos benefícios sociais, dado que eles viabilizaram um maior acesso ao crédito no período de crise, como veremos a seguir.

A explicação de multiplicadores maiores na crise frequentemente está associada a um menor efeito crowding out na literatura empírica. Mais recentemente, uma estratégia empírica de modelos não lineares (em Auerbach e Gorodnichenko (2012); Fazzari et al (2015); Orair et al (2016), por exemplo) vem sendo utilizada na tentativa de diferenciar os multiplicadores fiscais durante as recessões e expansões econômicas, o que mostra uma preocupação da literatura com a relação entre multiplicadores fiscais e o ciclo econômico. 
Capítulo 3. Terceiro Artigo - O efeito dos benefícios sociais na recessão brasileira recente: um modelo 144 Kaleckiano com endividamento das famílias

De acordo com Fazzari et al (2015):

"On the one hand, according to equilibrium models in which resources are fully employed a positive shock to government spending affects output only to the extent that it changes inputs or technology. The sign of the effect could go either way. These models often predict some crowding out of private investment or consumption in response to higher government spending. The government spending multiplier could be negative, and if it is positive, it is likely less than unity. [...] On the other hand, Keynesian models predict that the economy will not always fully employ available resources, possibly for extended periods of time, because of insufficient demand. If output is below its potential level, an increase in government spending can directly employ idle resources and raise output" (Fazzari et al, 2015, p.1-2).

Como em períodos de baixo crescimento o tradicional efeito crowding out torna-se pouco aplicável, a política fiscal seria particularmente eficaz durante recessões, quando existe grande capacidade ociosa (FMI 2010, em Pires, 2014).

Este artigo, entretanto, propõe uma explicação para multiplicadores diferentes entre recessão e expansão que não passa pela discussão de restrição de capacidade e, para isso, utilizamos um arcabouço teórico liderado pela demanda. Assumimos que o endividamento das famílias possui um importante papel no estímulo ao consumo, cujo efeito multiplicador é vital inclusive para evitar o aprofundamento da crise.

Nosso resultado é que o consumo reage de forma diferente, dado um choque nos benefícios sociais, em tempos de crise, de modo que o multiplicador de renda para esse tipo de gasto é maior. O modelo aqui explorado propõe um mecanismo no qual o multiplicador fiscal desse tipo de despesa é maior na amostra que contempla o período de recessão devido ao maior acesso ao crédito das famílias que recebem o benefício durante tal período. E esse mecanismo se daria através dos beneficiários da Previdência.

Quando uma família é afligida por uma crise econômica, com perda de empregos, por exemplo, muitas vezes o benefício recebido pelo trabalhador já aposentado ajuda a aliviar a situação financeira dessa família. A propensão a consumir desses trabalhadores já é alta dado que $70 \%$ dos benefícios sociais do Regime Geral da Previdência Social, somados com o Benefício de Prestação Continuada, são de valor até um salário mínimo (Rangel et al, 2009). Os dados da Pesquisa de Orçamento Familiar (POF) de 2017/2018, por exemplo, mostram que a classe que recebe até $\mathrm{R} \$ 1908$ tem uma propensão média a consumir que ultrapassa 1 (sendo próxima a 1.13). Esta faixa de renda é a que tem maior peso dos programas sociais federais, que correspondem a $7.6 \%$ de sua renda total. A aposentadoria do INSS corresponde a $15.7 \%$ de sua renda, sendo também significativa. A faixa de renda de $\mathrm{R} \$ 1908$ a $\mathrm{R} \$ 2862$ possui propensão média a consumir de aproximadamente 0.89 . Do 
rendimento total desta faixa, $3.2 \%$ é proveniente de programas sociais federais e $22 \%$ de aposentadorias do INSS. A terceira faixa, de $\mathrm{R} \$ 2862$ a $\mathrm{R} \$ 5724$, também possui alta propensão a consumir, de cerca de 0.8 . Para este caso, quase $15 \%$ dos rendimentos totais da classe são devidos às aposentadorias do INSS, e 1.3\% aos programas sociais federais. A quarta faixa, de $\mathrm{R} \$ 5724$ a $\mathrm{R} \$ 9540$ - cujo rendimento total possui uma parcela de $11.7 \%$ referente a aposentadorias do INSS e de $0.3 \%$ a programas sociais federais - possui propensão média próxima de 0.73 . A quinta faixa de renda vai de $\mathrm{R} \$ 9540$ a $\mathrm{R} \$ 14310$ e a sexta, de $\mathrm{R} \$ 14310$ a $\mathrm{R} \$ 23850$. As propensões médias para essas duas classes são de 0.64 e 0.6 , respectivamente. Do rendimento total dessas faixas, apenas $8.5 \%$ e $6.2 \%$ são provenientes de aposentadorias do INSS, para as classes 5 e 6, respectivamente. Além disso, a parcela referente a programas sociais federais é de apenas $0.1 \%$, para ambas as classes. A faixa mais rica, com rendimento superior a $\mathrm{R} \$ 23850$, possui propensão média a consumir de 0.43 , ilustrando que o consumo das pessoas de renda mais baixa é de fato bastante relevante para dinamizar a economia.

Os dados da POF realizada em 2008 e 2009 mostram que as propensões a consumir das três primeiras classes são bem parecidas entre as duas pesquisas. Mesmo após a crise recente, tais classes conseguiram manter sua propensão a consumir média, em comparação com as classes mais ricas - embora houvesse uma queda na pesquisa mais recente. As propensões em 2008/2009 para as três primeiras faixas de renda foram próximas de 1.25, 1 e 0.9. Para a quarta faixa tal propensão média também não variou muito, sendo cerca de 0.82. No entanto, para as faixas mais ricas houve uma queda em termos percentuais bem mais relevante. Para as classes 5, 6 e 7, as propensões médias a consumir eram de 0.76 , 0.72 e 0.53 em 2008-2009.

Podemos afirmar que as classes que recebem mais benefícios sociais, as três primeiras faixas de renda, conseguiram manter sua propensão média, de modo que ela caísse menos em comparação com as classes mais ricas, as quais não recebem muito desses benefícios. Em termos percentuais, enquanto as propensões médias a consumir das quatro primeiras faixas de renda caíram cerca de $9 \%$ a $11 \%$, as propensões das três faixas mais ricas apresentaram queda entre, aproximadamente, $16 \%$ e 19\%. Isso também mostra que o benefício social desempenhou um papel estabilizador importante. Vale lembrar que estamos analisando a despesa com consumo média familiar mensal por faixa de renda, que engloba tanto aposentados como ativos. Esta despesa com consumo média familiar é dividida pelo rendimento mensal médio familiar a fim de obter a propensão média a consumir.

Mais especificamente, assumiremos a propensão a consumir da classe de trabalhadores aposentados igual à unidade, no modelo. Essa propensão a consumir é elevada, ou consegue se manter relativamente constante, porque os aposentados obtêm mais crédito na crise, seja pelo lado da demanda, ou pelo lado da oferta - da disposição dos bancos a ofertar. A situação financeira das famílias que sofrem com o desemprego é aliviada por 
Capítulo 3. Terceiro Artigo - O efeito dos benefícios sociais na recessão brasileira recente: um modelo 146 Kaleckiano com endividamento das famílias

meio do uso desses benefícios sociais de forma a se obter crédito e tentar manter o consumo do período anterior à crise. A recente inclusão financeira da base da pirâmide, descrita por Carvalho e Rugitsky (2015), pode ser uma justificativa para esse endividamento (pelo lado da disposição a ofertar dos bancos, pois o risco de inadimplência é menor), sobretudo após a institucionalização do crédito consignado em 2004.

O crédito consignado é uma modalidade de crédito em que desconto da prestação é feito diretamente na folha de pagamento ou de benefício previdenciário do contratante, o que diminui o risco de inadimplência porque o colateral do empréstimo é parte do salário, ou do benefício do INSS. O risco de inadimplência para os bancos nessa modalidade é muito baixo porque o pagamento das parcelas não é uma decisão do devedor, mas constitui uma cobrança compulsória (Brandão, 2019). Isto aumenta a disposição a ofertar crédito por parte do emprestador, tendo em vista a possibilidade de reduzir as taxas de juros e aumentar prazos. De acordo com o Banco Central do Brasil (2018), esta modalidade de crédito é o tipo de empréstimo livre para pessoa física que possui o menor custo. Por exemplo, em outubro de 2017, as taxas de juros dos empréstimos não consignados foram em média cinco vezes maiores do que as dos consignados. Apesar disso, o crédito consignado é uma modalidade lucrativa aos bancos. Mesmo sendo uma das linhas de crédito mais barata do mercado, a sua taxa anualizada ainda é alta. Segundo Brandão (2019), a partir dos dados do Banco Central, a taxa de juros anualizada desse tipo de crédito crédito começou em torno de 30\% de 2004 a 2006, com leve queda a partir daí, embora com flutuações. Em nenhum momento esteve abaixo dos 20\%, mesmo em períodos em que a taxa básica de juros esteve em um dígito - o que é uma taxa bem alta, dado o risco muito baixo de inadimplência.

A modalidade do crédito consignado colaborou para a democratização do acesso ao crédito pela população em geral. De acordo com Carvalho (2018), enquanto o saldo acumulado de operações de crédito representava 25.5\% do PIB em janeiro de 2002, em dezembro de 2012 este número alcançou 49.2\%. Dentro desse total, o saldo da carteira de crédito de pessoas físicas aumentou dez pontos percentuais em relação ao PIB nos últimos dez anos - aumento impulsionado pela modalidade de operações com recursos livres (que englobam as linhas de financiamento ao consumo) - e, em particular, pelo crédito consignado.

Isto pode ser visto no gráfico da Figura 24, que ilustra o saldo total da carteira de crédito consignado pessoal em milhões de reais, com dados mensais deflacionados pelo IPCA. Percebe-se uma evolução crescente no crédito consignado total, que remete, na realidade, a 2004, quando houve sua regulamentação. Há destaque também para o período pós crise de 2008, quando os bancos públicos aumentaram sua oferta de crédito nesta modalidade como forma de evitar a queda no consumo (Brandão, 2019). O gráfico ilustra uma participação bem maior dos trabalhadores do setor público, em relação aos do setor 
Figura 24 - Crédito consignado por categoria (variável estoque)

Saldo da carteira de crédito com recursos livres - Pessoas físicas -

Crédito pessoal consignado

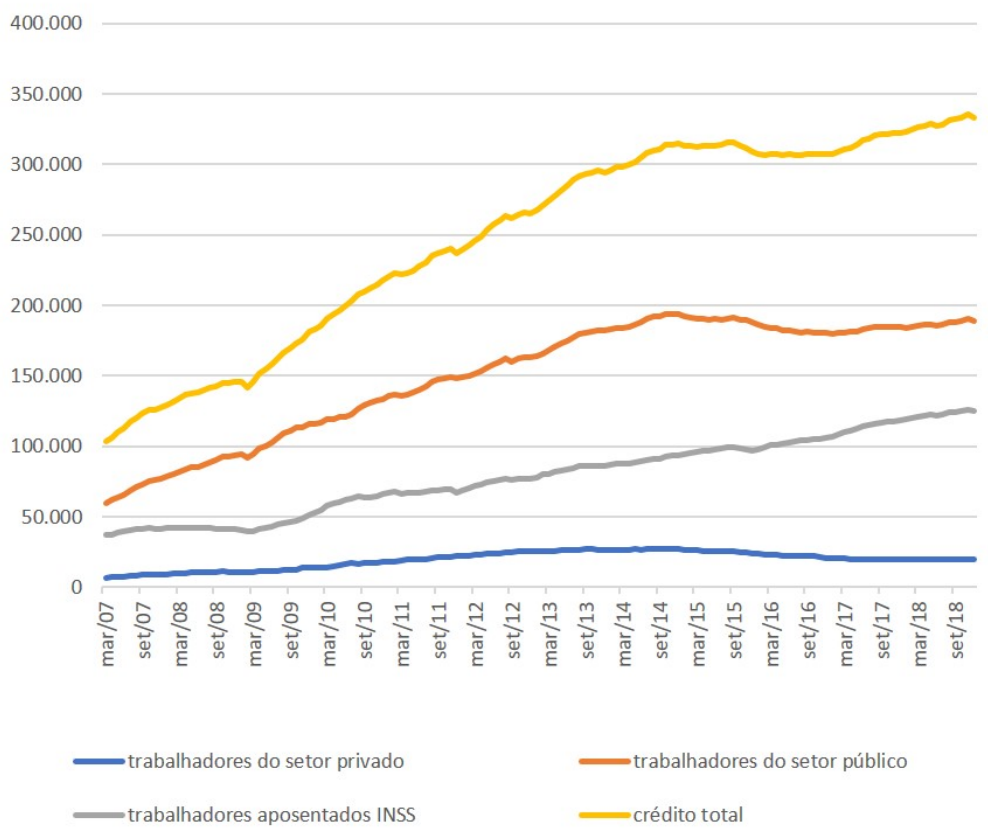

Fonte: Banco Central do Brasil.

privado, neste tipo de crédito. Além disso, percebe-se que nos anos de crise, a partir de 2014, houve reversão da tendência crescente no crédito total, ocasionada pela menor concessão de crédito destinado a trabalhadores ativos (seja do setor público ou privado) e, em grau bem menor, aos trabalhadores aposentados.

Esse movimento de reversão não é visto, no entanto, no saldo da carteira de crédito dos trabalhadores aposentados. Para esta categoria, observamos uma tendência crescente, sobretudo nos anos de recessão. A taxa de variação média do período 2015 a 2018 foi, na realidade, positiva - de 1.87\% ao ano. Esta taxa é positiva devido ao aumento da taxa de variação do saldo de crédito para os trabalhadores aposentados, que foi pouco mais de $8 \%$ ao ano no período, frente a -7.5 e $-0.25 \%$ ao ano para o saldo dos trabalhadores do setor privado e público, respectivamente. Em outras palavras, no período da crise observamos uma contração do crédito aos trabalhadores ativos (sendo que essa contração é bem mais intensa para os trabalhadores do setor privado se comparada à do setor público) e uma expansão do crédito aos trabalhadores aposentados.

No entanto, o saldo da carteira de crédito consignado é uma variável estoque. A variável de fluxo, mais adequada para refletir a oferta de crédito, pode ser vista no gráfico da Figura 25, obtida também do Banco Central, em milhões de reais e deflacionada pelo IPCA. Esta figura ilustra a variável de fluxo do saldo total, que vimos na Figura 24. Trata-se da concessão de crédito consignado por categoria, ou seja, reflete a oferta de 
Capítulo 3. Terceiro Artigo - O efeito dos benefícios sociais na recessão brasileira recente: um modelo 148 Kaleckiano com endividamento das famílias

Figura 25 - Crédito consignado por categoria (variável fluxo)

Concessões de crédito pessoal consignado

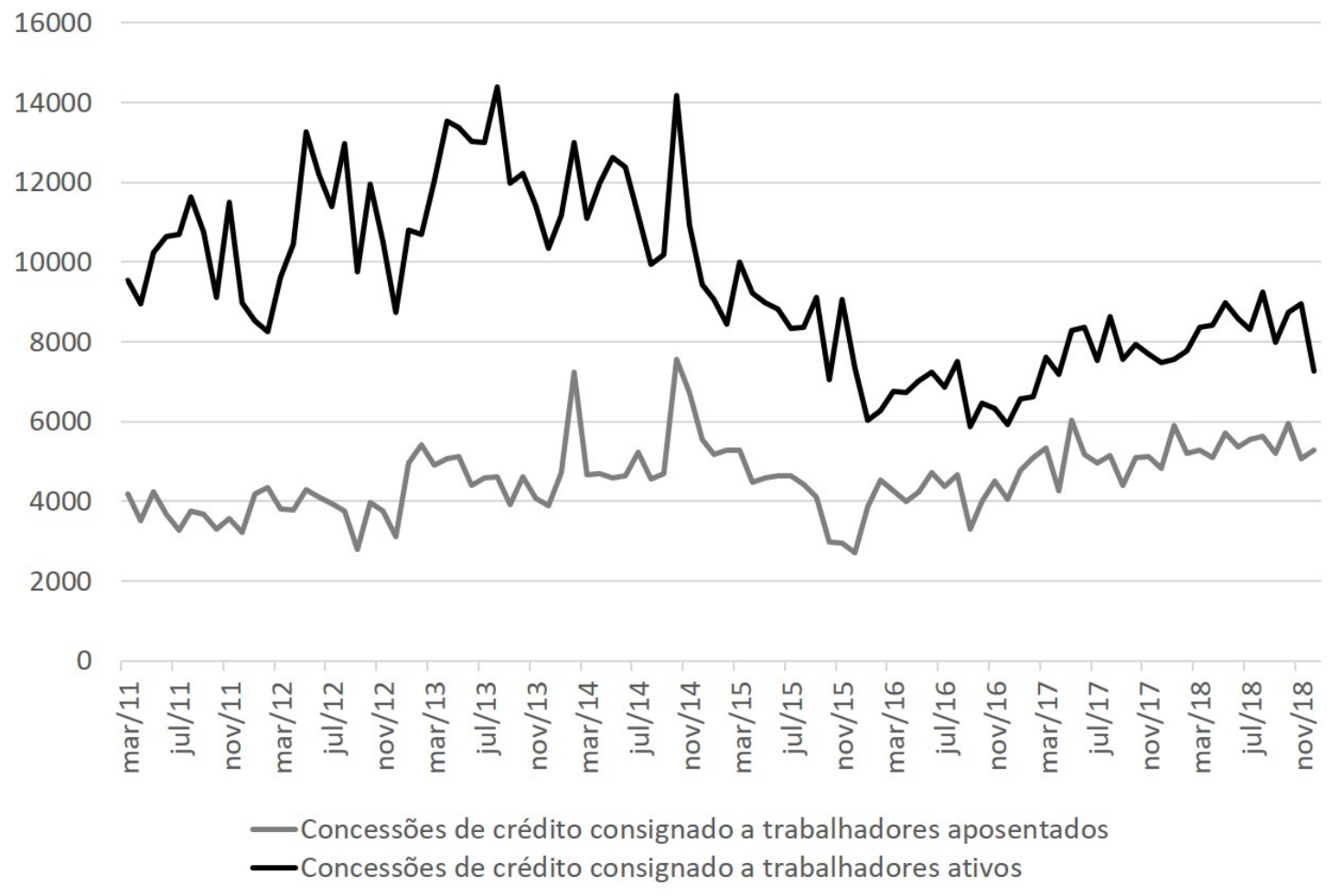

Fonte: Banco Central do Brasil.

crédito, e não o estoque de devedores. Assim, consideramos que esta variável, de fluxo, é uma medida do crédito celebrado no período, que pode ser vista como uma medida de oferta por parte dos bancos, mas também do lado da demanda.

Os dados da Figura 25 ilustram que a concessão total de crédito consignado, incluindo todas as categorias de trabalhadores, caiu no período 2014-2017: sua taxa média de variação ao ano foi de $-5.5 \%$. Todavia, para a categoria de aposentados, houve certa estabilidade na concessão de crédito. A despeito de uma queda significativa em 2015, observada no gráfico da Figura 25, tal queda na concessão de crédito foi menor que a dos ativos, e a sua recuperação foi muito mais rápida, se compararmos à concessão de crédito para os trabalhadores ativos. Vale lembrar que uma queda na concessão de crédito pode significar tanto uma retração da oferta por parte dos bancos, como uma diminuição da própria demanda por crédito. Em nosso modelo, o parâmetro de oferta de crédito irá ter dupla interpretação de forma a comportar isso: pode ser visto pelo lado da oferta por parte dos bancos, e pelo lado dos trabalhadores, que aumentam ou diminuem a sua demanda por crédito durante períodos de queda na atividade econômica, como veremos mais à frente. Vamos considerar alguns subperíodos para termos uma ideia melhor.

Primeiro, quando consideramos o período 2014-2017, a taxa média de variação ao ano da concessão de crédito consignado foi de $2 \%$ ao ano para aposentados e cerca de 
-11\% ao ano para ativos, indicando uma diferença pronunciada. Se estendermos até 2018, observamos uma taxa média de variação positiva de $3.25 \%$ ao ano para os trabalhadores aposentados, e negativa, de $-7.36 \%$ ao ano, para trabalhadores ativos. Se considerarmos apenas o período 2015-2018, ainda observamos queda acentuada para a concessão de crédito aos trabalhadores ativos, de $-7.7 \%$ ao ano, frente a uma estabilidade na taxa média de variação para o caso dos trabalhadores aposentados, de $0.15 \%$ ao ano. Se calcularmos apenas para o período de maior contração do crédito, de 2015 a 2017, encontramos uma taxa de variação média negativa mas muito menor para a concessão de crédito aos aposentados, de $-2.4 \%$, frente a uma taxa de quase $-13 \%$ ao ano para o crédito aos ativos. Calculando para o período de maior recuperação da oferta de crédito, de 2016 a 2018, a taxa média de variação passa a ser muito expressiva e positiva para o crédito aos aposentados, de $8.4 \%$ ao ano e ainda negativa, de $-1.16 \%$, para o caso do crédito ofertado aos ativos.

Em outras palavras, o que o gráfico acima informa é que no período da crise observamos uma contração do crédito aos trabalhadores ativos e uma estabilidade da concessão de crédito aos trabalhadores aposentados. A divisão por subperíodos mostrou que, ao considerar o período da crise, de 2014 a 2017, observamos que a taxa média de variação da concessão de crédito consignado aos trabalhadores ativos foi negativa e bastante expressiva, contrastando com a taxa média de variação do crédito ao aposentado, positiva.

O ideal seria controlar o exercício realizado no Artigo 2, sobre o efeito multiplicador dos benefícios sociais, pela variável de concessão de crédito ao aposentado. Dado que os dados de concessão de crédito consignado estão disponíveis apenas a partir de março de 2011, as amostras (inteira, e sobretudo a pré-crise) ficariam pequenas demais para a realização de um exercício econométrico. Ainda assim, nos valemos de um requisito econométrico bem menos estrito e robusto do que o apresentado no Artigo 2, apenas para tentar avançar um pouco na argumentação, ainda que a significância das estimações não fique adequada. Os resultados, portanto, devem ser vistos com cautela.

Inserindo a variável de controle de crédito consignado aos aposentados no exercício VAR que estima o multiplicador de benefícios sociais, encontramos que, no caso de todos os dados deflacionados pelo IPCA, inclusive os dados de crédito, tal controle foi estatisticamente significante a $5 \%$, apresentando coeficiente positivo na equação do produto, na amostra 2011-2018. Esta variável, no entanto, não é significante na amostra 2011-2014. Esta observação é válida também no caso do exercício do consumo e do investimento privado. Isto é um indício de que o crédito pode ser um fator que colaborou para o resultado do Artigo 2, o efeito multiplicador dos benefícios sociais maior na crise, visto que mesmo com uma amostra pequena, pudemos verificar significância a $5 \%$ da variável ${ }^{1}$.

1 Ao estimar os multiplicadores acumulados em oito trimestres dos benefícios sociais em termos do produto, encontramos que a inserção do controle pouco mudou seu valor na amostra 2011-2014, sendo em torno de 1.9. Na amostra 2011-2018, sem a variável de crédito, estimamos um multiplicador próximo 
Capítulo 3. Terceiro Artigo - O efeito dos benefícios sociais na recessão brasileira recente: um modelo 150 Kaleckiano com endividamento das famílias

Figura 26 - Participação de cada categoria de trabalhador no crédito consignado total

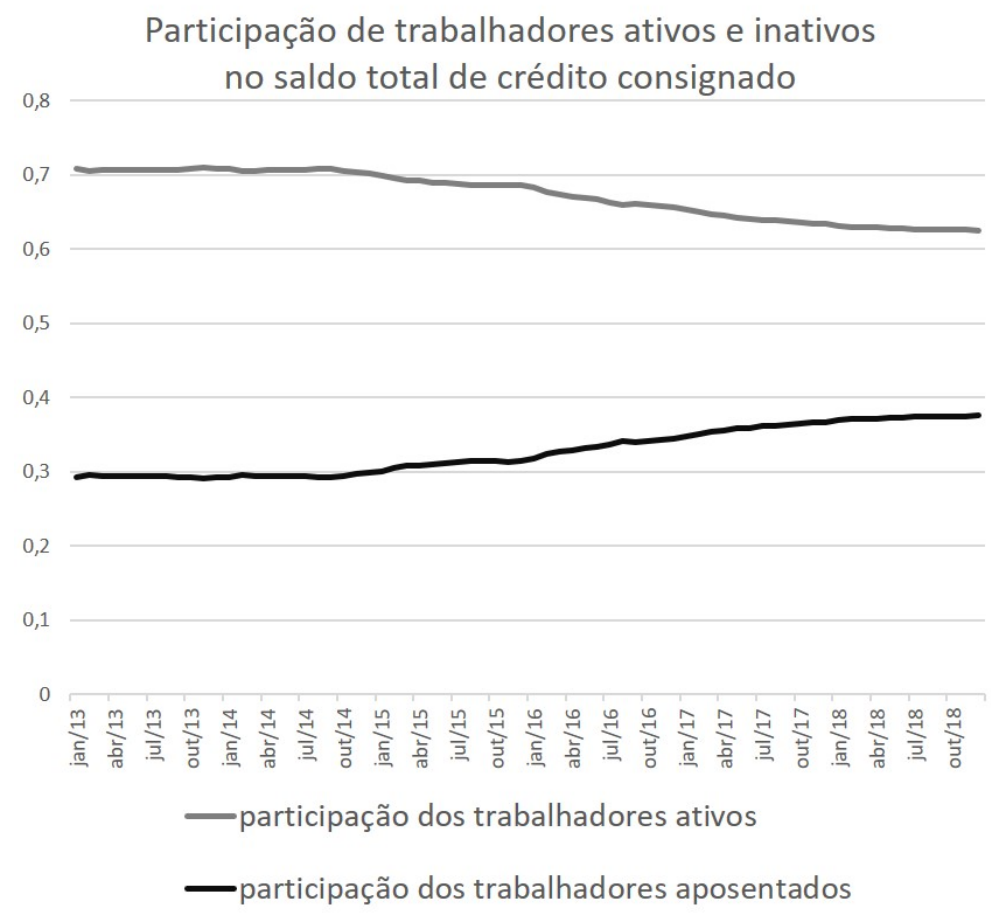

Fonte: Banco Central do Brasil.

O gráfico da Figura $26^{2}$ mostra que a participação ao longo do tempo do trabalhador aposentado no saldo total de crédito consignado pessoal total é relativamente constante a partir de 2010 e se torna crescente nos anos de crise, sobretudo após 2015. Já com relação aos trabalhadores ativos, seja da esfera pública ou privada, observamos uma queda na participação do saldo de crédito total no período de recessão. Percebe-se que até meados de 2014 a participação dos trabalhadores ativos ficava em torno de $70 \%$ no total do saldo de crédito consignado, enquanto que para os inativos esse número era em torno de $30 \%$. A partir de 2014, no período da crise, a participação dos ativos começa a cair, para quase $60 \%$ ao final de 2018; e a parcela dos inativos possui tendência de crescimento, atingindo

de 3, enquanto que uma vez inserido o controle, tal valor passa a ser em torno de 1.5. Em outras palavras, o multiplicador diminuiu quando retiramos o efeito do crédito - mas isso ocorre somente na amostra que inclui a crise - o que pode ser um indício de que o crédito pode ser um fator que colaborou para o resultado do Artigo 2, o efeito multiplicador dos benefícios sociais maior na crise. Com os dados do produto deflacionados pelo deflator implícito, entretanto, não houve significância de tal controle, em nenhuma das duas amostras. Ainda assim, estimamos os multiplicadores, que valem em torno de 5 na amostra que inclui a crise e sem controle, e 4.2 controlando pelo crédito ao aposentado. Na amostra menor, estimamos um multiplicador novamente em torno de 2, que não se alterou substantivamente com a inclusão da variável exógena. Mesmo sem significância da variável de controle, houve diminuição do multiplicador na amostra maior, o que corrobora o resultado encontrado no exercício em que todas as variáveis foram deflacionadas pelo IPCA. Outra evidência é que a inclusão do controle para o crédito consignado para os ativos não teve significância, em nenhuma das duas amostras. Reiteramos que, dado que trabalhamos com uma amostra pequena, os resultados devem ser vistos com cautela.

2 "O Banco Central do Brasil (BCB) divulga, desde 2011, dados sobre os empréstimos consignados em três segmentos distintos: os destinados aos funcionários públicos; aos aposentados e beneficiários do INSS; e aos funcionários do setor privado, regidos pela Consolidação das Leis do Trabalho (CLT)" (Banco Central do Brasil, 2018, p.111). 
quase $40 \%$.

Isto pode ser entendido pelo gráfico da Figura 27, que mostra que a inadimplência da carteira de crédito pessoal consignado é maior para trabalhadores do setor privado, com relativa estabilidade em 2014, um pico em meados de 2015 e após isso uma queda a partir de 2016, talvez motivada pela liberação dos recursos do FGTS. Já a inadimplência dos trabalhadores do setor público é bem menor se comparada à do setor privado e relativamente estável no tempo. Isto explica por que a oferta de crédito é menor a trabalhadores do setor privado (como visto na Figura 24). Para os trabalhadores aposentados, observamos que esta categoria possui a menor inadimplência ${ }^{3}$, com relativa estabilidade no tempo, a despeito de um aumento nos últimos meses.

Figura 27 - Inadimplência no crédito consignado por categoria de trabalhador Inadimplência da carteira de crédito com recursos livres Crédito pessoal consignado (\%)

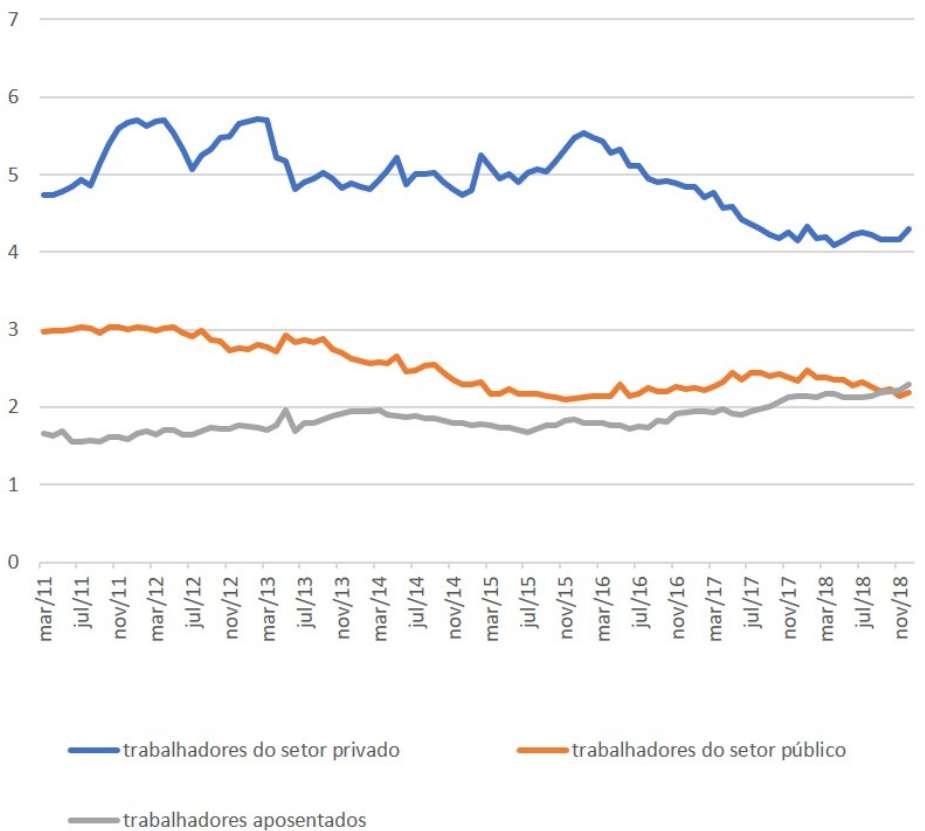

Fonte: Banco Central do Brasil.

Tendo em vista que em um período de queda do nível de atividade econômica a probabilidade de desemprego é maior, nosso modelo vai contemplar o fato de que a

3 "O fato de os juros do INSS serem maiores que os dos servidores públicos não está ligado à inadimplência das operações. Ao contrário do que se poderia esperar, a inadimplência é maior para os servidores públicos do que para o INSS (...). Uma possível explicação para os juros do INSS serem mais altos seria o fato de os funcionários públicos, como dito anteriormente, contratarem empréstimos, em média, mais altos dos que os aposentados do INSS. Como o custo fixo da contratação de um empréstimo é diluído em operação maior, consequentemente cai a cobrança de juros. Outra possível explicação para os aposentados e pensionistas pagarem juros mais altos do que os funcionários públicos pode ser a diferença em termos de educação financeira entre os dois grupos, o que pode levar, por exemplo, o grupo de funcionários públicos a pesquisar e negociar taxas melhores em diferentes bancos" (Banco Central do Brasil, 2018, p.113). 
Capítulo 3. Terceiro Artigo - O efeito dos benefícios sociais na recessão brasileira recente: um modelo 152 Kaleckiano com endividamento das famílias

disponibilidade de crédito aos trabalhadores ativos diminui, na forma de volume -devido à menor disposição dos bancos a ofertar porque o risco de emprestar para alguém que perdeu o emprego e não pode pagar é maior. Aos trabalhadores aposentados, cuja renda não está sujeita ao ciclo de modo tão imediato, há aumento de concessão de crédito - seja pelo lado da oferta porque os bancos possuem maior segurança, seja pelo lado da demanda, pelo efeito de os benefícios sociais funcionarem como alívio em uma família afetada pelo desemprego.

\subsection{Literatura relacionada}

Os modelos neo-Kaleckianos foram bastante desenvolvidos na literatura nas décadas de 1980 e 1990, sendo o principal referencial téorico de modelos liderados pela demanda efetiva. Sua estrutura permite avaliar os impactos da distribuição funcional da renda na demanda efetiva e, por conseguinte, no crescimento econômico, em um contexto com capacidade ociosa e competição imperfeita. Dado o nosso contexto, o de que o multiplicador de benefícios sociais é maior na crise, vamos aplicar um modelo cujo foco é uma situação de excesso de capacidade ociosa em que a distribuição de renda entre classes possui papel relevante para o crescimento econômico.

Embora os benefícios sociais sejam um gasto do governo, a modelagem aqui adotada está mais focada na questão do endividamento dos trabalhadores aposentados na crise, e seus efeitos sobre o crescimento econômico. A literatura que incorpora política fiscal em modelos Kaleckianos geralmente trata dos seguintes aspectos: a) o efeito de gastos autônomos (Hein, 2018; Chang Ko, 2018); b) a estrutura de impostos (Laramie, 1991; Chang Ko, 2018); c) tratamento dos investimentos públicos como crowding in (Commendatore e Pinto, 2011; Tavani e Zamparelli, 2015; Dutt; 2013); d) dívida pública e seus efeitos distributivos (You e Dutt, 1996); e) a questão do debate sobre regras fiscais do tipo teto de gastos e sua falta de eficácia em termos de estabilização da dívida pública (Ribeiro e Lima, 2019). O modelo aqui presente não dará muita ênfase no gasto do governo em si - a suposição de orçamento equilibrado e inexistência de dívida pública será feita. Ademais, o gasto do governo será tratado como duas partes, as transferências referentes aos benefícios sociais (o pagamento de previdência), mais uma parte autônoma.

Os modelos que incorporam endividamento das firmas são bem mais numerosos que os que exploram o endividamento das famílias (Charpe et al, 2012). Após a Crise de 2008 surgiram vários modelos cuja ênfase recaía sobre o papel da dívida familiar. Um dos principais modelos de endividamento familiar, ainda anterior à Crise de 2008, é o de Dutt (2006), que fornece um modelo Steindliano no qual a função consumo da classe trabalhadora depende da renda disponível após pagamento de juros sobre o estoque de dívida, mais um elemento de crédito ao consumidor representado pela variação do estoque 
da dívida a cada período.

$$
C_{w}=\psi Y-i D+\dot{D}
$$

onde $\psi$ é a participação dos salários na renda, $Y$ é o produto, $i$ é a taxa de juros (exógena), $D$ é o estoque de dívida e $\dot{D}$ é a variação de estoque da dívida (derivada da dívida em relação ao tempo, isto é, o quanto de dívida os trabalhadores adquirem a cada momento do tempo). Essa variação, por sua vez, representa o quanto os trabalhadores tomam de crédito e depende fundamentalmente do parâmetro $(\beta)$, que pode ser interpretado como disposição dos bancos a ofertar crédito e também pode ser visto pelo lado da demanda, sendo o quanto os trabalhadores desejam consumir além de sua renda do trabalho. Depende também de sua própria renda disponível $(\psi Y-i D)$ :

$$
B=\beta[\psi Y-i D]
$$

onde $B$ é o nível de empréstimo desejado, que é igual a $\dot{D}$. Observe que a propensão a consumir da classe trabalhadora é dada como 1 nesse modelo e, ao incorporar o endividamento, a propensão a consumir aumenta, tornando-se $1+\beta$ (em relação à renda original, ainda que como proporção da renda disponível total, incluindo dívida, continue sendo 1). O consumo da classe capitalista, por sua vez, é dado por

$$
C_{p}=(1-s)(\pi Y+i D)
$$

onde $(1-s)$ é a propensão a consumir dessa classe e $\pi$ é a participação dos lucros na renda. A renda disponível incorpora, portanto, a transferência de renda da classe trabalhadora para a capitalista através do fluxo de pagamento de juros $i D$.

O curto prazo do modelo chega à conclusão de que um aumento no estoque de dívida dividido pelo estoque de capital e um aumento na taxa de juros possuem efeito negativo sobre o grau de utilização de capacidade instalada pelo mecanismo de transferência de renda para a classe de mais alta propensão a poupar e consequente diminuição da demanda agregada. Já o efeito do parâmetro $\beta$ sobre o grau de utilização no curto prazo é positivo pelo aumento da demanda agregada via consumo. Porém, a um prazo mais longo, o impacto total é ambíguo, dado o efeito contracionista da transferência de renda entre as classes, que deprime o consumo. Esse impacto tende a ser mais negativo quanto mais fraca a demanda autônoma por investimento.

Conclusões similares têm sido encontradas na literatura, que já explorou bastante esse caráter dúbio do crédito às famílias (Palley, 1994; Hein, 2011; Pariboni, 2016; Duman, 2013; Palley, 2010; Marsellou, 2011; Isaac e Kim, 2013). Em geral, podemos resumir as conclusões desses modelos da seguinte forma: um aumento do endividamento das famílias por um lado estimula a demanda agregada e eleva o consumo; por outro, a destinação de juros aos capitalistas, que possuem menor propensão a consumir, diminui a demanda agregada, levando a uma possível instabilidade de longo prazo. A seguir, apresentaremos 
Capítulo 3. Terceiro Artigo - O efeito dos benefícios sociais na recessão brasileira recente: um modelo 154 Kaleckiano com endividamento das famílias

as formas funcionais das funções atribuídas ao consumo e à oferta de crédito. Veremos que em todos os modelos, os parâmetros de oferta/demanda de crédito - o $\beta$ de Dutt (2006) - são exógenos e não dependem diretamente do grau de utilização, apesar de incidirem sobre a renda disponível. Em nosso modelo, iremos endogeneizar esse parâmetro, o qual passará a depender a taxa de emprego e, logo, do grau de utilização.

Uma das primeiras formulações de modelos que partem do diferencial de propensão a consumir para explicar fragilidade financeira está em Palley (1994). Nesta formulação, o autor parte das seguintes equações de funções consumo, similares às de Dutt (2006):

$$
C_{1 t}=a_{1}\left(z Y_{t-1}-S_{t-1}\right)+\dot{D}_{t}
$$

$\mathrm{E}$

$$
C_{2 t}=a_{2}\left((1-z) Y_{t-1}+S_{t}-\dot{D}_{t}\right)
$$

Onde 3.4 é a função consumo do devedor e 3.5, do credor. Nas equações, $z$ é a participação da renda dos devedores na renda nacional, $Y$ é o produto, $S$ é dada pela multiplicação da taxa de juros pelo estoque de dívida. Já $\dot{D}_{t}$ é a variação do nível de dívida - como em Dutt (2006), depende da renda do devedor:

$$
\dot{D}_{t}=D_{t}-D_{t-1}
$$

$\mathrm{E}$

$$
D_{t}=a_{3} z Y_{t-1}
$$

Onde $a_{3}$ pode ser relacionado ao $\beta$ de Dutt (2006) e é explicado pelo autor como um "loan ceiling", que dá o estoque de dívida dividido pela renda do devedor. Considera-se a hipótese da diferença de propensão marginal a consumir, isto é, $a_{1}>a_{2}$. A conclusão de Palley (1994) do modelo básico é que há um efeito multiplicador de renda menor quando $\left(a_{2}-a_{1}\right)$ o diferencial de propensões a consumir - for negativo (isto é, os devedores poupam menos que os emprestadores), pelo efeito da distribuição de renda na direção de quem poupa mais. Já um aumento em $z$ ou em $a_{3}$, por exemplo, tem o efeito de elevar o multiplicador e a demanda agregada, porém ampliando a região instável do modelo.

Entre os artigos mais recentes, após a Crise Global, está o de Hein (2011). O autor assume uma função consumo da classe trabalhadora similar à de Dutt (2006) - equação 3.1 - em que a variação do estoque de dívida no tempo depende da renda disponível não gasta do capitalista, ao invés da renda disponível do consumidor:

$$
\dot{D}=\theta s(\pi Y+i D)
$$

onde $s$ é a propensão a poupar da classe capitalista e $(\pi Y+i D)$ sua renda disponível. O parâmetro $\theta$ possui interpretação muito similar ao $\beta$ de Dutt (2006) e reflete a disposição das famílias ao endividamento, a disposição dos capitalistas a emprestar e a disposição 
das firmas a investir em estoque de capital, dada pelo complemento 1- $\theta$, pois esse capital é financiado pelas firmas e é posse da classe rentista. Nesta configuração, os capitalistas consomem e em seguida decidem como alocar sua poupança entre ações das firmas e títulos da dívida da classe trabalhadora. As conclusões são similares às de Dutt (2006). Por exemplo, um aumento na taxa de juros ou no estoque de dívida normalizado pelo estoque de capital tem efeito contracionista e afeta negativamente a taxa de crescimento do produto e o grau de utilização. Já uma elevação em $\theta$ aumenta o grau de utilização pelo seu efeito positivo sobre o consumo e a demanda agregada, ao transferir renda para os trabalhadores - mas tal efeito torna-se ambíguo a um prazo mais longo.

Duman (2013) parte de um modelo bastante similar ao de Hein (2011) e torna parâmetro $\theta$ uma função, que depende tanto da oferta de crédito pelos bancos (capitalistas) quanto da demanda por crédito pelos trabalhadores. Essa função é dada por $\theta=\theta(\kappa, \xi)$, onde $\kappa$ é home ownership rate, que possui o efeito de menor demanda por crédito e $\xi$ é o spread bancário, o qual aumenta a disposição a ofertar dos bancos. Note que, apesar dessa dependência, tais parâmetros são exógenos.

Há também modelos que incorporam o endividamento das famílias e o endividamento das firmas. É o caso de Marsellou (2011). A função consumo da classe trabalhadora depende da renda disponível líquida do pagamento de serviço da dívida, mais a variação da dívida - como em Dutt (2006), equação 3.1. A equação da variação da dívida neste modelo é dividida em duas partes:

$$
B=\beta_{1}\left(W^{*} L-\psi Y\right)+\beta_{2}\left(\lambda^{*} \psi Y-i D\right)
$$

Marsellou (2011) incorpora a dívida das firmas ao modelo de forma que a função consumo dos capitalistas é dada por:

$$
C_{c}=(1-s)(\pi-i d) Y
$$

onde $i d$ é o pagamento de serviço da dívida das firmas, que subtrai da renda disponível, $B$ é o desejo de empréstimo dos trabalhadores, sendo $B=\dot{D}$. Observe que $W L=\psi Y$. Na equação $3.9, W^{*}$ é o salário "socialmente determinado como padrão de vida": é um salário target, que seria socialmente desejado pelos trabalhadores enquanto $W$ é o salário que eles realmente recebem. $L$ é o número de trabalhadores. Se $W^{*}>W$, então a desigualdade de renda é maior e leva ao estímulo do consumo conspícuo. Isto, por sua vez, aumenta a demanda dos trabalhadores por crédito - o que é captado por $\beta_{1}>0$. Já $\lambda^{*}$ é o serviço da dívida dividido pela renda dos trabalhadores. Quanto maior esse parâmetro, mais propensos ao empréstimos são os trabalhadores. $\lambda^{*}$ é o teto do pagamento de serviço da dívida que os trabalhadores estão dispostos a pagar. Se este teto for maior que o pagamento de juros que eles realmente pagam, então há variação positiva da dívida (tomam crédito) de forma que $\beta_{2} \leq 1$. A conclusão para o equilíbrio de curto prazo é que aumentos em $W^{*}$ ou em $\lambda^{*}$ estimulam a tomada de crédito e a demanda agregada, afetando positivamente o grau de 
Capítulo 3. Terceiro Artigo - O efeito dos benefícios sociais na recessão brasileira recente: um modelo 156 Kaleckiano com endividamento das famílias

utilização. Elevações em $D / K$ ou em $i$ possuem efeito contracionista e diminuem o grau de utilização porque diminuem a renda líquida de quem consome. Um aumento no parâmetro $\beta_{1}$ possui efeito ambíguo e eleva o grau de utilização apenas se $W^{*} L / K>(1-\pi) Y / K$ - o que estimula o endividamento e a demanda agregada. Já um aumento em $\beta_{2}$ possui efeito positivo no grau de utilização no caso em que $\lambda^{*}(1-\pi)>i D / K$, isto é, o efeito é expansionista no caso em que o serviço da dívida não é tão alto.

Em Isaac e Kim (2013), famílias e firmas se endividam, e os rentistas emprestam de tal forma que o consumo desta última classe depende de sua renda disponível, dada pelo pagamento de juros tanto das firmas como dos trabalhadores:

$$
C_{R}=(1-s)\left(i D_{F}+i D_{W}\right)
$$

Onde $D_{F}$ é o estoque de dívida das firmas e $D_{W}$ é o estoque de dívida dos trabalhadores. A função consumo da classe trabalhadora é similar à de Dutt (2006), equação 3.1, em que a variação da dívida é:

$$
\dot{D_{w}}=\theta\left(\overline{D_{W}}-D_{W}\right)
$$

Em que $\theta>0$ é um parâmetro similar ao $\beta$ de Dutt (2006), $\overline{D_{W}}$ é um teto, o qual reflete as condições de crédito ao consumidor. Se esse teto for maior que a dívida realmente contraída $D_{W}$, então há aumento do endividamento por parte dos trabalhadores- nesse sentido, tal teto é similar ao $\lambda^{*}$ de Marsellou (2011).

A solução de curto prazo do modelo resulta em uma economia wage led em que elevações em $i$ possuem efeito ambíguo no grau de utilização, sendo expansionista no caso em que $\left(1-s-\kappa_{r}\right)>0$, isto é, se a propensão a consumir dos capitalistas for maior que $\kappa_{r}$, que é a sensibilidade do investimento da firma à taxa de lucro, a qual depende negativamente da taxa de juros. Elevações no teto da dívida dos trabalhadores normalizado pelo estoque de capital $\overline{D_{W}} / K$ têm o efeito de aumento da demanda agregada e do grau de utilização, ao passo que um estímulo em $D_{W} / K$ tem efeito negativo no grau de utilização. Aumentos em $D_{F} / K$ têm efeito ambíguo, sendo positivo apenas se o pagamento de serviço da dívida não for tão grande e que não é compensado por aumento do consumo da classe rentista.

Em Palley (2010), há um modelo de endividamento das famílias que endogeiniza a distribuição de renda, além de considerar efeito riqueza nas funções consumo, da classe trabalhadora e capitalista, respectivamente:

$$
C_{w}=c_{w}[(1-\pi) Y+(1-z) \pi Y]-z i D+z B
$$

e

$$
C_{c}=c_{\pi} z[\pi Y+i D]
$$

Onde $z$ é a participação dos capitalistas na riqueza e $1-z$ é a parcela de riqueza apropriada pelos trabalhadores. $B$ é a variação da dívida a cada período, como nos modelos anteriores. 
A distribuição de renda é endogeneizada de tal forma que $\pi$ depende positivamente do mark up das firmas, o qual, por sua vez, é uma função positiva do grau de utilização e de um parâmetro que mede o poder de barganha das firmas. A condição de equilíbrio do modelo é dada tanto pela equação de equilíbrio no mercado de bens, quanto pela equação da taxa de lucro, tendo em vista que a distribuição de renda é endógena. Um aumento no estoque de dívida normalizado pelo estoque de capital possui efeito ambíguo, por um lado há estímulo à demanda agregada pelo maior número de empréstimos aos trabalhadores, que elevam seu consumo; por outro, a destinação de juros aos capitalistas, que possuem menor propensão a consumir, diminui a demanda agregada. Elevações em $i$ ou em $z$ elevam a renda disponível dos capitalistas, que tendem a poupar e, logo, deprimem o grau de utilização ${ }^{4}$.

Um outro artigo que incorpora o endividamento dos trabalhadores em um arcabouço Kaleckiano é o de Pariboni (2016), que parte de equações de consumo muito similares às de Dutt (2006) - equações 3.1 e 3.3. A modificação do autor consiste em tratar o modelo como um supermultiplicador. Neste modelo, o $B$, isto é, o crédito tomado pelos trabalhadores a cada momento do tempo, é determinado pela demanda por crédito sujeita às restrições dos bancos, assim como em Dutt (2006). Assim, a demanda por empréstimos aumenta de acordo com a renda do trabalhador. Em Dutt (2006), Palley (2010), Hein (2011), entre outros, o consumo financiado por dívida é induzido pelo próprio produto. Pariboni (2016), por outro lado, propõe que o padrão de consumo financiado por crédito é autônomo, e não induzido pela renda. Esse consumo é autônomo e não está relacionado ao nível de renda corrente, resultante das decisões das firmas. No equilíbrio, a taxa de crescimento da economia é dada pela taxa de crescimento do consumo autônomo. A taxa de variação do estoque da dívida, neste modelo, converge para esta mesma taxa. Aumentos na taxa de juros ou na taxa de amortização possuem efeitos negativos no produto porque o capitalista tende a se apropriar do ganho gerado pelo consumo financiado por crédito. Porém, tais variáveis não afetam a taxa de crescimento da economia, que depende apenas da taxa de crescimento do consumo autônomo.

Kim et al (2017) fazem um modelo cujo ponto de partida são funções consumo da

4 Palley (2010) inclui duas extensões a este modelo baseline. Primeiro, incorpora um "parâmetro de financeirização", que é maior ou igual à razão do pagamento de serviço da dívida pela renda total da classe trabalhadora. O impacto de tal parâmetro, que funciona como um teto de endividamento, é ambíguo no crescimento da economia: por um lado, estimula a demanda agregada pela via do endividamento e maior consumo dos trabalhadores, por outro eleva a poupança da economia ao aumentar a renda disponível da classe capitalista, que tende a poupar e a deprimir a demanda efetiva. Uma outra extensão do autor é no sentido de endogeneizar a moeda bancária, adicionando um termo de efeito riqueza nas funções consumo. Adiciona-se $\gamma_{3}[1-z] M$ na função consumo da classe trabalhadora e $\gamma_{4} z M$ na função consumo do capitalista, onde $M$ é a oferta monetária. Ao fazer isso, a poupança agregada da economia fica reduzida por $\left[\gamma_{3}+\gamma_{4}\right] M$. O autor chega à conclusão de que o crescimento da economia é mais rápido em economias de moeda endógena do que em economias de crédito puro porque há a criação de riqueza monetária, resultando em um efeito positivo no grau de utilização e na taxa de lucro, se comparado ao equilíbrio do modelo base. 
Capítulo 3. Terceiro Artigo - O efeito dos benefícios sociais na recessão brasileira recente: um modelo 158 Kaleckiano com endividamento das famílias

classe trabalhadora e da classe rentista aos moldes de Dutt (2006), mas com variação do estoque da dívida dada pela seguinte função:

$$
\dot{d}=f(d, \psi)
$$

Onde em $d$ já se considera o estoque de dívida normalizado pelo estoque de capital. A equação 3.15 diz que a dívida dos trabalhadores depende de seu comportamento em relação ao seu estoque de dívida já existente e em relação à parcela dos salários na renda $\psi$. Se o acúmulo de dívidas age de forma negativa à acumulação de mais dívida, o trabalhador vai tomar menos empréstimos, levando em conta um "teto" de dívida aceitável, exógeno. Neste caso, $f_{d}<0$. Se, ao contrário, o acúmulo de dívidas leva à variação positiva da dívida, é porque o trabalhador precisa tomar mais empréstimos tendo em vista a elevação do custo do serviço da dívida que ele já tem. Desta forma, ele se endivida ainda mais na tentativa de manter seu consumo, dado por uma meta exógena. Assim, $f_{d}>0$. Já com relação à parcela de salários na renda, um aumento dessa variável pode estimular a tomada de crédito porque os consumidores sentem que eles têm maior poder de compra, inclusive para honrar o serviço da dívida (neste caso, $f_{\psi}>0$ ), ou podem diminuir seus empréstimos assim que eles recebem salários mais altos $\left(f_{\psi}<0\right)$.

No equilíbrio de curto prazo, deve-se levar em conta essas possibilidades, que dependem do comportamento dos trabalhadores com relação à sua dívida. A probabilidade de um aumento em $\psi$ levar a um aumento no grau de utilização (isto é, a economia exibir um comportamento wage led) é maior no caso em que $f_{\psi}>0$. No caso em que $f_{d}>0$, deve haver impacto positivo no grau de utilização, na taxa de lucro e na taxa de crescimento da economia dado um aumento em $d$ - este é o chamado "debt led growth/demand". Esse efeito é negativo, porém, quando $f_{d}<0$, de modo que a economia apresenta "debt burdened growth/demand". A estabilidade de longo prazo também depende do comportamento do consumidor em relação à tomada de crédito.

Alguns autores tratam da questão do endividamento pela via do consumo conspícuo, em que os trabalhadores se endividam devido ao desejo de emulação de consumo dos capitalistas (Kapeller e Schutz, 2015, Cynamon e Fazzari, 2013; Ryoo e Kim, 2014; Setterfield et al, 2016; Barba e Pivetti, 2008; Setterfield e Kim, 2016; Kim et al, 2014). Nesses modelos, torna-se muito relevante o impacto distribuição de renda dos trabalhadores para os rentistas via serviço da dívida, que aumenta o consumo dos rentistas e, portanto, o consumo desejado e a emulação por parte dos trabalhadores, que se endividam ainda mais. De um lado, isso impulsiona o consumo total e a demanda agregada pela via do endividamento. De outro, o aumento do estoque de dívida possui efeito contracionista. Em Setterfield et al (2016), por exemplo, a função consumo da classe trabalhadora e rentista é dada por, respectivamente:

$$
C_{w}=c_{w}\left(W_{p} N-i D\right)
$$


e

$$
C_{R}=c_{\pi}\left(W_{r} M+i D+\Pi\right)
$$

Onde $c_{w}$ é a propensão a consumir dos trabalhadores e $c_{\pi}$, a dos rentistas. D é o estoque da dívida; i, a taxa de juros; $\Pi$ é a massa de lucros; $W_{p}$ é o salário do trabalhador; $W_{r}$ é o salário do gerente; $N$ é o número de trabalhadores; $M$ é o número de gerentes. Nesse modelo, a classe rentista é composta não apenas pelos capitalistas, mas também pelos trabalhadores da classe de gerentes, que possuem massa salarial dada por $W_{r} M$, com $W_{r}=\phi W_{p}$, onde $\phi>1$, que é o prêmio salarial da classe de gerentes em relação à classe dos trabalhadores. Além disso, $M=\alpha N$, onde $\alpha<1$ (que vem de uma função de produção do tipo Leontief).

Os trabalhadores se endividam para imitar o consumo da classe rentista. Consomem sua renda dos salários e depois escolhem se endividar. A poupança dos trabalhadores, neste modelo, é tratada como um resíduo:

$$
S_{w}=\left(1-c_{w}\right)\left(W_{p} N-i D\right)
$$

Já a variação da dívida a cada momento do tempo, $\dot{D}$, aparece somando no equilíbrio macroeconômico e sua equação é dada por:

$$
\dot{D}=\beta\left(C_{T}-C_{w}\right)
$$

Onde $\beta>0$ é um parâmetro parecido com o de Dutt (2006), $C_{w}$ é a função consumo da classe trabalhadora e $C_{T}$ é o consumo target, estimulado pelo desejo de emulação por parte dos trabalhadores - sendo uma parcela $\eta$ do consumo da classe rentista:

$$
C_{T}=\eta C_{R}
$$

O endividamento contribui positivamente para o grau de utilização se o impacto positivo da distribuição de renda dos trabalhadores para os rentistas via serviço da dívida que aumenta o consumo dos rentistas e, portanto, o consumo target e a emulação por parte dos trabalhadores, que se endividam ainda mais - superar o impacto negativo causado pela menor propensão a consumir dos capitalistas (a quem se destina a renda que redistribuída por meio do pagamento de juros) $)^{5}$.

Em Setterfield e Kim (2016) há um modelo parecido, mas com algumas diferenças nos resultados finais. A modificação dos autores é tratar a função poupança da classe trabalhadora da seguinte forma:

$$
S_{w}=\left(1-c_{w}\right) W_{p} N-i D
$$

5 Comparando com o modelo de Dutt (2006), observamos que naquele não há ambiguidade: o aumento do estoque da dívida normalizado pelo capital possui efeito negativo sobre a taxa de crescimento da economia. Isto ocorre porque não há emulação modelada como em Setterfield et al (2016), no qual o aumento do consumo rentista, estimulado por sua maior renda proveniente do serviço da dívida, estimula a tomada de crédito. 
Capítulo 3. Terceiro Artigo - O efeito dos benefícios sociais na recessão brasileira recente: um modelo 160 Kaleckiano com endividamento das famílias

A equação 3.21 difere da 3.18 no sentido de que, enquanto o pagamento de serviço da dívida é um gasto realizado a partir do resíduo que sobra após a decisão do trabalhador sobre o quanto consumir de sua renda bruta do trabalho na equação 3.21, na equação 3.18 esse pagamento de juros é visto como dedução da renda disponível, isto é, o trabalhador consome a fração do que sobra de sua renda após essa dedução. Assim, na equação 3.21, o trabalhador consome parte do salário e usa o resíduo ou para pagar o serviço da dívida, ou para alocar em poupança. Nesse sentido, a alocação em poupança e o pagamento de juros sobre a dívida são substitutos perfeitos. Uma implicação importante dessa modificação é que o impacto de uma elevação da taxa de juros ou do estoque de dívida em relação ao estoque de capital possuem efeito expansionista no curto prazo sobre o grau de utilização, dado que a transferência de renda na direção dos rentistas é de uma renda não gasta pelos trabalhadores. Assim, tal renda vai para os rentistas não como uma vazamento, mas como uma injeção (desde que $c_{\pi}>0$ ).

Kim et al (2014) partem de equações muito parecidas às de Setterfield et al (2016), mas mantêm $C_{T}$ na equação 3.19, sem substitui-lo pela equação dada em 3.20. Os autores advertem que $C_{T}$ pode ser interpretado como um efeito emulação ou como um nível de consumido atingido em algum momento do passado. Um aumento de $C_{T}$ impulsiona o consumo total e a demanda agregada pela via do endividamento; enquanto que o aumento do estoque de dívida possui efeito contracionista. O efeito final vai depender da propensão a poupar do capitalista.

Ryoo e Kim (2014) tratam o endividamento das famílias por meio de uma modelagem a la Kaldor, em que a distribuição de renda é a variável de ajuste, ao invés do grau de utilização. O formato da função consumo dos trabalhadores é bem parecido ao de Dutt (2006), em que o endividamento é afetado pela disposição dos bancos à oferta de crédito. A tomada de crédito (ou a variação do estoque de dívida) é dada por:

$$
\dot{D}=\phi\left(Y_{w}(t), z(t)\right)
$$

Com $\phi_{1}>0$ e $\phi_{2}>0$. Isto é, a variação da dívida possui dois elementos. Primeiro, a oferta de crédito pelos bancos depende positivamente da renda do trabalho (líquida de pagamento de juros sobre o estoque da dívida) $Y_{w}$. O segundo elemento é via lado da demanda: é dado pelo desejo de emulação por parte dos trabalhadores acomodado pelos bancos, captado por z. A conclusão do modelo é que a desigualdade de renda inicial estimula o desejo de emulação do consumo, que aumenta o crédito e a demanda agregada. Esse processo redistribui renda em favor dos rentistas, ocasionando a queda da participação salarial na renda e diminuindo o consumo dos trabalhadores. Há, desta forma, aumento da desigualdade que age como estímulo ao desejo de emulação do consumo ${ }^{6}$.

6 Um aspecto novo deste modelo é a ênfase ao papel dos bancos. O longo prazo do modelo chega a um equilíbrio instável no qual $\phi_{2}$ diferente de zero é pré-condição para instabilidade, isto é, há um efeito de emulação que é atendido sem restrições pelos bancos. Isto, somado ao um $\phi_{1}$ pequeno, resulta em 
Os modelos de endividamento das famílias citados nesta seção consideram que o consumo financiado por dívida depende da renda disponível, como vimos na equação 3.1, de Dutt (2006), e consequentemente do próprio produto. Essa dependência, no entanto, se dá por um parâmetro exógeno (o beta da equação 3.1), que possui uma dupla interpretação: pode ser visto pelo lado da disposição dos bancos a ofertarem crédito e pelo lado da disposição dos trabalhadores a tomarem crédito a fim de consumir além da sua renda do trabalho. O que propomos aqui é fazer com que essa oferta de crédito seja dependente da taxa de emprego e, logo, do próprio grau de utilização, endogeneizando o parâmetro beta. Em Duman (2013), por exemplo, torna tal parâmetro uma função, que depende da home ownership rate, que possui o efeito de menor demanda por crédito e do spread bancário, o qual aumenta a disposição a ofertar dos bancos. Mas essa função depende de parâmetros que são exógenos. Assim, nosso modelo levará em conta a endogeneização da oferta de crédito para contemplar a sua dependência em relação ao ciclo econômico, aos moldes do que discutimos na motivação empírica. Isto, por sua vez, já levará a consequências importantes em termos do efeito multiplicador, como veremos a seguir.

É importante pontuar que a literatura já explorou bastante a questão do duplo caráter do crédito, como acima discutido. Nosso intuito aqui não é construir um modelo que evidencie isto - ainda que as consequências do endividamento familiar sejam muito relevantes para o crescimento econômico em um prazo mais longo. Isto porque nosso foco específico é a mudança de efeito multiplicador na recessão recente. Como nosso recorte temporal é restrito ao período da crise, construiremos um modelo que vai contemplar apenas o curto prazo, com foco direcionado para a questão do efeito multiplicador.

\subsection{Modelo}

\subsubsection{Estrutura}

O mecanismo de formação de preços da economia é tradicional Kaleckiano, em que os preços são formados por um mark up sobre o custo unitário do trabalho, o qual é constante enquanto existir capacidade ociosa (Harris, 1974; Dutt, 1984; Asimakopoulos, 1975):

$$
P=(1+m) \frac{W L}{Y}
$$

Onde $m$ é o mark up; $W$ é o salário real; $L$ é o número de trabalhadores, $Y$ é o produto. A participação dos lucros na renda total $\pi$ é dada por:

$$
\pi=\frac{m}{1+m}
$$

um equilíbrio em que o elo entre oferta de crédito dos bancos e renda do trabalho é muito fraco. O papel dos bancos para a estabilidade do equilíbrio, portanto, é fundamental. 
Capítulo 3. Terceiro Artigo - O efeito dos benefícios sociais na recessão brasileira recente: um modelo 162 Kaleckiano com endividamento das famílias

A participação dos salários na renda chamamos de $\psi=1-\pi$. Portanto, consideramos que a distribuição de renda é exógena. A taxa de lucro $r$ :

$$
r=\pi \frac{Y}{Y^{*}} \frac{Y^{*}}{K}=\pi u \frac{1}{v}
$$

onde $K$ é o estoque de capital, $Y^{*}$ é o produto de pleno emprego, $u$ é o grau de utilização $\frac{Y}{Y^{*}}$ e $v$ é a razão capital produto. Para simplificação, consideramos $v=1$. Desta forma, o grau de utilização $u$ é dado por $u=\frac{Y}{K}$.

O ponto de partida é uma estrutura de classes similar à de Setterfield et al (2016). Porém, a interpretação aqui abordada é distinta. Existem quatro classes: os trabalhadores ativos, os trabalhadores aposentados, os capitalistas, e os trabalhadores desempregados (para os quais não modelaremos funções consumo, por simplificação). Na literatura, a divisão entre capitalistas e trabalhadores é justificada pela diferença de propensão a consumir entre tais classes. Além disso, enquanto uma classe toma crédito, a outra empresta e recebe pagamento de juros da dívida (Charpe et al, 2012; Palley, 1994; Setterfield e Kim, 2016). Essa dinâmica proporciona transferência de renda, em um primeiro momento, da classe que mais poupa para a que mais consome via crédito (isto é, dos capitalistas para os trabalhadores), enquanto que deve haver distribuição de renda do sentido contrário conforme os trabalhadores acumulam dívidas e precisam pagar os juros para os credores, os capitalistas (Dutt, 2006).

A divisão entre trabalhadores, entre ativos e aposentados, é justificada pela seção 3.2 e busca modelar a questão empírica de que a propensão a consumir é maior na crise para a classe dos trabalhadores que recebe o benefício social, de forma que o multiplicador é maior em momentos de crise. Como visto na seção 3.2, isto é justificado pelo exercício empírico apresentado: o efeito dos benefícios sociais na amostra que inclui a crise é maior, seja em termos de resposta do produto ou, sobretudo, em termos de resposta somente do consumo das famílias. Além disso, os dados sobre o crédito consignado apresentados na seção 3.2 nos dão respaldo empírico. Como aponta o relatório do Banco Central do Brasil (2018), em um cenário de maior incerteza econômica na crise, tanto as condições de oferta quanto as de demanda por crédito podem ser afetadas adversamente. No lado da oferta, os bancos e as instituições financeiras possuem maior dificuldade em precificar o risco de inadimplência, diminuindo a oferta de crédito aos trabalhadores ativos, sobretudo os do setor privado. Pelo lado da demanda, tais trabalhadores podem se tornar mais avessos ao endividamento devido ao receio de perder o emprego.

Assim, a classe dos trabalhadores ativos é formada por $L$ trabalhadores, que recebem salário real $W$, pagam impostos sobre sua renda do trabalho $\theta_{w} W L$ com alíquota $\theta_{w}$ e pagam contribuição previdenciária - que incide sobre sua renda $W L: \lambda_{w} b_{w} W L$. Onde seguimos Silva e Kappes (2018): $\lambda_{w}$ é a proporção de trabalhadores formais e $b_{w}$ é a alíquota de contribuição dos trabalhadores formais ativos ao sistema previdenciário de repartição. Embora não haja distinção entre trabalhadores formais e informais no modelo 
(vamos assumir que há apenas formais), iremos manter $\left(\lambda_{w} b_{w}\right)$ como a contribuição total que incide sobre a renda do trabalho. A renda disponível da classe trabalhadora ativa é dada por:

$$
Y_{d}=\alpha_{1}\left[W L\left(1-\theta_{w}-\lambda_{w} b_{w}\right)\right]
$$

A equação 3.26 fornece a renda disponível dos trabalhadores ativos, que se endividam em um momento de elevação do nível de atividade econômica, isto é, quando estão empregados e recebendo salários. Essa renda é multiplicada por um fator, $\alpha_{1}$, que poderia ser interpretado como um teto de pagamento de serviço da dívida que os trabalhadores estão dispostos a pagar. Quando esse alfa multiplicado pela renda do trabalho for maior que o pagamento de juros, então os trabalhadores ainda tomam crédito (na equação 3.42 isso fica mais claro).

Essa renda disponível, entretanto, está sujeita a mudanças no nível de atividade econômica. Como o foco deste artigo é a crise brasileira recente, o trabalhador ativo corre risco de perder seu emprego. Se ele perde o emprego, ele se torna incapaz de tomar novo crédito e sua renda disponível torna-se zero. Desta forma, o consumo da classe trabalhadora ativa é condicional à parcela de empregados, dada pela taxa de emprego:

$$
C_{w}=c_{w}(E)\left[\alpha_{1} W L\left(1-\theta_{w}-\lambda_{w} b_{w}\right)-i D_{w}\right]+B_{w}
$$

Onde $D_{w}$ é o estoque de dívida da classe dos trabalhadores ativos, $i$ é a taxa de juros, $B_{w}$ é o quanto tomam de crédito a cada período de tempo (é a variação de sua dívida). A propensão a consumir $c_{w}(E)$ depende positivamente da taxa de emprego $E$ : quanto maior a parcela de desempregados, mais os trabalhadores poupam e reduzem sua propensão a consumir por medo de perder o emprego. Similarmente, quanto maior a parcela de empregados na economia, em uma situação de aumento do nível de atividade, maior a propensão a consumir desses trabalhadores. Essa relação entre a propensão a consumir e as expectativas de desemprego pode ser justificada por uma evidência que tem sido tratada na literatura econométrica (em Silveira e Lima (2019) há uma formalização teórica), empregando efeitos fixos ou VAR, de que as mudanças nas expectativas com relação ao desemprego - e seu grau de pessimismo - contribuem para elevar o desemprego efetivo, utilizando surveys europeia e norte-americana (Michigan Survey) (Girardi, 2014; Leduc e Sill, 2013; Dickerson e Green, 2012). Por exemplo, em Leduc e Sill (2013), o VAR estimado pelos autores encontra que um choque que reduza a taxa de desemprego esperada em 1 ponto percentual leva a uma diminuição parecida na taxa de desemprego efetiva. Desta forma, uma expectativa de desemprego por parte dos trabalhadores ativos leva a uma propensão a consumir menor e a um impacto negativo no produto e na taxa de emprego em nosso modelo.

Mais à frente, vamos considerar que essa dependência na propensão a consumir dos trabalhadores ativos em relação à parcela de empregados não é tão forte, porque, como é 
Capítulo 3. Terceiro Artigo - O efeito dos benefícios sociais na recessão brasileira recente: um modelo 164 Kaleckiano com endividamento das famílias

comum em modelos Kaleckianos, os trabalhadores gastam tudo o que ganham. Aqui, apesar de ainda haver a possibilidade de termos uma propensão a consumir menor que um para os trabalhadores ativos, esta propensão não é tão responsiva à taxa de emprego porque os trabalhadores ativos, que não ganham muito, precisam gastar suas rendas (estando ou não em situação de queda na atividade econômica). Este será um dos resultados do modelo, como veremos na seção 3.4.4. Além disso, veremos que o trabalhador desempregado tem dificuldade de obter crédito, na forma como modelaremos $B_{w}$, porque os bancos não estão dispostos a ofertar crédito para eles.

A classe dos trabalhadores aposentados, por sua vez, possui renda disponível dada por:

$$
Y_{d}=\alpha_{2}\left[B N\left(1-\theta_{a}\right)\right]
$$

onde $B$ é o valor do benefício de aposentadoria, $N$ é o número de beneficiários, $\theta_{a}$ é a alíquota de impostos. Os aposentados já recebem sua remuneração descontada da parcela que fica como colateral (e como o próprio pagamento de serviço da dívida) no crédito consignado. Desta forma, recebem uma parcela $\alpha_{2}$ do benefício total. Considerando que o benefício recebido é uma proporção do salário médio (Silva e Kappes, 2018), isto é, os trabalhadores aposentados não recebem integralmente, com $\phi<1$ :

$$
B=\phi W
$$

Além disso, o número de aposentados é uma proporção constante $\alpha<1$ do número de trabalhadores ativos (Silva e Kappes, 2018):

$$
N=\alpha L
$$

A proporção de ativos e inativos não muda, por hipótese, por tratar-se de um modelo cujo foco é a crise, isto é, é elaborado em termos de curto prazo. A oferta de trabalho não é, por hipótese, uma restrição.

A função consumo dos trabalhadores aposentados fica:

$$
C_{a}=c_{a}\left(\alpha_{2} \alpha \phi W L\left(1-\theta_{a}\right)-i D_{a}\right)+B_{a}
$$

Repare que esta função independe da parcela de desempregados porque o beneficiário não corre o risco de perder seu emprego. Logo, tem sua renda do trabalho garantida pelo sistema previdenciário, independente do ciclo econômico. Como justificado na seção 3.2, propomos um modelo no qual os trabalhadores aposentados se endividam quando há uma queda no nível de atividade econômica de tal forma que isso aumente sua propensão a consumir. Assim, consideramos $D_{a}$ o estoque de sua dívida e $B_{a}$ a tomada de crédito a cada instante de tempo. Para simplificação, consideramos a propensão marginal a consumir $c_{a}$ igual à unidade. 
A classe capitalista recebe renda do lucro distribuído (dividendos), que não é reinvestido nas firmas. Esse lucro é uma proporção $\xi$ dos lucros totais. Os capitalistas são donos das firmas e dos bancos e, logo, recebem duas modalidades de lucro. O lucro resultante das atividades produtivas das firmas é dado pela diferença entre receita e custo:

$$
\text { Lucrofirmas }_{\text {firm }}=Y-\theta_{c} Y-W L-W L \lambda_{c} b_{c}
$$

A renda proveniente dos lucros das firmas está sujeita à tributação cuja alíquota é $\theta_{c}$ e ao pagamento da previdência $\lambda_{c} b_{c}$, onde $\lambda_{c}$ é a proporção de capitalistas contribuintes e $b_{c}$ é a alíquota de contribuição dos capitalistas à previdência - seguimos Silva e Kappes (2018), que colocam as firmas como contribuintes.

Além da renda dos lucros das firmas, a classe capitalista é rentista e dona dos bancos, recebendo os juros dos empréstimos concedidos aos trabalhadores, ativos e aposentados. No entanto, a parcela de desempregados deve afetar esse lucro porque quanto mais trabalhadores desempregados existem, em uma situação de queda do nível de atividade, maior o risco de default da dívida. Embora os bancos contraiam seu crédito para os trabalhadores desempregados, há o risco do não pagamento do trabalhador que tomou o crédito enquanto estava empregado. Desta forma, considera-se que o lucro dos bancos é afetado negativamente pelo default - como em Allain (2014) - quanto maior o parâmetro $\theta_{\text {default }}$, que é a taxa de default sobre o estoque de dívida e depende negativamente da parcela de empregados $E$. Em outras palavras, $\theta_{\text {default }}$ é a parcela da dívida $D_{w}$ que não é paga. Essa parcela depende positivamente da taxa de desemprego. Essa "taxa de default" incide sobre o estoque de dívida - tal como em Charpe e Flaschel (2013). Repare que não existe default por parte dos aposentados, por hipótese. O lucro dos bancos torna-se:

$$
\text { Lucro }_{\text {bancos }}=i\left(D_{w}+D_{a}\right)-\theta_{\text {default }}(E) D_{w}
$$

A função consumo da classe capitalista leva em conta esses dois tipos de lucro e é dada pela equação 3.34 .

$$
C_{c}=c_{c}\left\{\xi\left[\left(Y\left(1-\theta_{c}\right)-W L\left(1+\lambda_{c} b_{c}\right)\right]+i\left(D_{w}+D_{a}\right)-\theta_{\text {default }}(E) D_{w}\right\}\right.
$$

Consideramos $c_{a}=1>c_{w}>c_{c}$, a hipótese usual Kaleckiana de divisão de classes.

A renda total dessa economia, portanto, é dada pela soma da massa de salários e de lucros:

$$
W L+\Pi=Y
$$

Em termos de participação na renda: $\psi=1-\pi$.

Considerando que o modelo não incorporará dívida pública, supomos que há orçamento equilibrado:

$$
T=G
$$


Capítulo 3. Terceiro Artigo - O efeito dos benefícios sociais na recessão brasileira recente: um modelo 166 Kaleckiano com endividamento das famílias

onde $T$ é a receita e $G$, o gasto, em termos primários. A receita arrecadada pelo governo é composta por tributação e por contribuição previdenciária:

$$
T=W L\left(\theta_{w}+\theta_{a} \alpha \phi+\lambda_{w} b_{w}\right)+\left(\theta_{c} Y+W L \lambda_{c} b_{c}\right)
$$

O gasto do governo é dado pelo pagamento de aposentadoria (transferências) e a parte exógena $G_{0}$ :

$$
G=\alpha \phi W L+G_{0}
$$

A função investimento, $I / K$, é a tradicional do modelo Kaleckiano canônico, que depende do grau de utilização $\left(\operatorname{com} \gamma_{u}>0\right)$ e de uma parte autônoma que reflete o espírito animal.

$$
\frac{I}{K}=\gamma_{0}+\gamma_{u} u
$$

Esta parte autônoma do investimento, que chamamos de $\gamma_{0}$, pode ser interpretada como um grau de otimismo dos empresários (Kim et al, 2017), ligada às expectativas sobre a futura tendência da taxa de crescimento das vendas, por exemplo (Lavoie, 2014). Isto é, este parâmetro está bastante relacionado com as fases do ciclo econômico.

O equilíbrio da previdência se dá a partir da equação a seguir, tendo em vista que o RGPS é um regime de repartição simples:

$$
\left(b_{w}+b_{c}\right) \frac{W}{B}=\frac{N}{L}
$$

Isto é, $\left(b_{w}+b_{c}\right) W L=B N$. Ou ainda, $b_{w}+b_{c}=\alpha \phi$. Na equação, $b_{w}$ e $b_{c}$ são as alíquotas de contribuição (do trabalhador e do capitalista, respectivamente), $W / B$ é a taxa de reposição, e $N / L$ é a razão de dependência (Silva e Kappes, 2018). Um aumento no número de aposentados em relação aos que estão na ativa, ou no valor do benefício em relação ao salário médio $(\phi)$, requer um aumento da alíquota de contribuição do trabalhador na ativa ou na alíquota do capitalista para manter o equilíbrio do sistema.

\subsubsection{Inserção do crédito no modelo}

Tal como em Charpe et al (2012), os bancos precisam assumir papel central no racionamento de crédito, que depende também da renda disponível dos trabalhadores (Dutt, 2006). O crédito é dependente do ciclo, assim como a renda disponível dos trabalhadores ativos. Em momentos de expansão, os bancos tendem a ter lucros maiores e tomam mais riscos, ofertando mais crédito (Heuvel, 2002). Em Charpe et al (2012), $\dot{D}$ é uma função de oferta de crédito que depende de duas partes. A primeira parte é parecida com a de Dutt (2006): o crédito depende da renda disponível do tomador e é totalmente acomodado pelos bancos. A segunda parte depende do diferencial da taxa de lucro do banco em relação a uma taxa de lucro de estado estacionário, estabelecendo um elo direto entre a lucratividade bancária e a demanda agregada. 
Em nosso modelo, trataremos da heterogeneidade de tomadores de crédito da seguinte forma: a função oferta de crédito possui uma parte que é acomodada pelos bancos e independe da etapa do ciclo econômico. Esta parte é dependente da renda dos trabalhadores já aposentados, cuja renda disponível não depende do ciclo. Os bancos acomodam essa demanda, tendo em vista esta não-dependência da fase do ciclo econômico: é mais seguro emprestar para quem não tem risco de perder o emprego. A oferta dos bancos para essa classe de trabalhadores depende de um $\beta_{1}$, assim como vimos na literatura em geral, na seção 3.3, que independe do ciclo econômico: esse crédito é ofertado de qualquer maneira - quando o nível de atividade aumenta ou cai - tendo em vista que o aposentado não tem risco de perder o emprego e o valor da aposentadoria está dado em termos reais no curto prazo.

Quando há uma situação de queda no nível de atividade econômica, o parâmetro de oferta e demanda de crédito é aumentado por um $\beta^{*}, \operatorname{com} \beta^{*}>0$. Esse $\beta^{*}$ é uma função do grau de utilização $u$. Isto significa que, quando o nível de atividade sobe, os bancos acomodam a demanda da classe trabalhadora aposentada segundo um parâmetro $\beta_{1}>0$ - parâmetro que reflete também a disposição desta classe a se endividar. Quando o nível de atividade cai, entretanto, esta classe está mais propensa ao endividamento, tendo em vista que as pessoas usam o benefício social para tomar emprestado e tentar manter seu consumo, visto que sua renda disponível foi diminuída (pela própria diminuição das transferências e da arrecadação). Os inativos estão dispostos a aumentarem sua demanda por crédito porque sua renda não está sujeita a variações do ciclo de forma tão imediata, como é o caso dos ativos (não perdem o emprego); e os bancos estão dispostos a emprestar mesmo na crise para esta classe porque o risco é baixo. A inadimplência dos aposentados é a mais baixa entre as categorias de trabalhadores para o caso do consignado - como vimos na seção 3.2. Desta forma, o parâmetro $\beta_{1}$ é acrescido por um $\beta^{*}>0$ quanto mais o nível de atividade da economia diminui. A sensibilidade da tomada de crédito dos aposentados à parcela de empregados é capturada por esta função. A equação de tomada de crédito para a classe de trabalhadores aposentados torna-se:

$$
B_{a}=\beta_{1}\left[\alpha_{2} \alpha \phi W L\left(1-\theta_{a}\right)-i D_{a}\right]+\beta^{*}(u)\left[\alpha_{2} \alpha \phi W L\left(1-\theta_{a}\right)-i D_{a}\right]
$$

Onde a derivada $\beta_{u}^{*}<0$, pois quanto maior (menor) o grau de utilização, menor (maior) a oferta/demanda de crédito para os aposentados.

Para a classe de trabalhadores na ativa, os bancos contraem a oferta de crédito quanto mais a economia se aproxima de uma queda no nível de atividade, ao contrário do que acontece com os aposentados. Neste caso, os bancos não emprestam para os desempregados. Assim, $\beta_{2}$ reflete as condições de demanda e de oferta de crédito para os trabalhadores ativos empregados. Este beta é função da parcela de empregados -ou taxa de emprego - de maneira que $\beta_{2_{E}}>0$ : isto é, o beta depende positivamente de $E$, e, logo, do grau de utilização, ao contrário do que ocorre com o caso dos aposentados. 
Capítulo 3. Terceiro Artigo - O efeito dos benefícios sociais na recessão brasileira recente: um modelo 168 Kaleckiano com endividamento das famílias

Em uma situação de queda do nível de atividade econômica, menos pessoas estão empregadas e, logo, a tomada de crédito diminui. O efeito dessa queda é capturado também pela menor disposição dos bancos a ofertarem crédito mesmo para o trabalhador empregado, visto que ele corre o risco de perder o emprego e não honrar sua dívida. Pelo lado da demanda, o próprio trabalhador empregado deverá assumir menos riscos, contraindo sua demanda por crédito ao temer perder o emprego. Assim, o parâmetro $\beta_{2}$ sofre uma redução quanto maior a parcela de desempregados, e consequentemente menor a parcela de empregados.

$$
B_{w}=\beta_{2}(E)\left[\alpha_{1} W L\left(1-\theta_{w}-\lambda_{w} b_{w}\right)-i D_{w}\right]+\beta_{3}\left(\frac{1}{\alpha \phi}\right)
$$

O último elemento da equação 3.42 reflete que a oferta de crédito aos trabalhadores da classe ativa está condicionada à distribuição dos dois tipos de renda na renda total da economia, isto é, à divisão da massa de salários pela massa de benefícios $\frac{W L}{B N}$, que pode ser interpretada como uma razão de dependência do sistema previdenciário. Note que isso equivale a $\frac{1}{\alpha \phi}$. Consideramos $\beta_{3}>0$, pois se os trabalhadores ativos detiverem uma parcela maior da renda, os bancos estarão mais interessados em emprestar a eles. Se, por outro lado, a distribuição favorecer os aposentados, com um aumento em $\alpha$ ou em $\phi$, ou mesmo com uma diminuição direta na participação na renda por parte dos trabalhadores ativos em uma situação de queda no nível de atividade, a oferta de crédito aos trabalhadores ativos contrai.

Note que a propensão a consumir dos trabalhadores aposentados é dada por $\left(1+\beta_{1}\right)$ no caso limite quando o grau de utilização é muito alto. No caso contrário, há um aumento da propensão a consumir, que fica $\left(1+\beta_{1}+\beta^{*}(u)\right)$-sendo tanto maior quanto menor $u$. Para os trabalhadores ativos, a propensão a consumir é $\left(c_{w}(E)+\beta_{2}(E)\right)$, sendo maior quando a parcela de empregados sobe (quando $u$ sobe). Isto é, a disposição a ofertar dos bancos depende da renda disponível dos trabalhadores na ativa, que, por sua vez, depende do ciclo econômico. Quando há um aumento no nível de atividade econômica, os bancos ofertam crédito para esta classe segundo um $\beta_{2}(E)>0$. Quando há uma queda no nível de atividade econômica, os bancos contraem crédito para esta classe, com redução na disposição a ofertar segundo a função $\beta_{2}(E)$. A oferta total de crédito é dada pela soma de $B_{a}$ com $B_{w}$ e sua formulação enfatiza o papel dos bancos na restrição de crédito. Repare que, enquanto a oferta/demanda de crédito dos ativos depende da taxa de emprego (e, logo, do grau de utilização), a oferta/demanda de crédito dos aposentados depende do grau de utilização. Isto porque o trabalhador ativo deve levar em conta a taxa de emprego quando pensa em tomar empréstimos. Já o aposentado leva em consideração o próprio grau de utilização diretamente, pois uma diminuição deste significa uma diminuição das próprias transferências de aposentadoria e um aumento da demanda por crédito por parte deles. 
Tendo em vista que a taxa de inadimplência dos trabalhadores aposentados é baixa, como visto na seção 3.2 (e, em nosso modelo, é zero) assume-se a hipótese de que o crédito consignado para os trabalhadores aposentados é amortizado inteiramente, pela parcela $1-\alpha_{2}$ de sua renda disponível. Essa parcela da renda disponível é suficiente para cobrir sua dívida total de modo que o aposentado honre o principal e os juros de sua dívida. A equação 3.43 abaixo diz que o estoque da dívida do aposentado é igual à parcela fixa de sua renda disponível que é abatida quando ele faz o empréstimo consignado. Em outras palavras, o que ele guarda é suficiente para o pagamento de amortização e dos juros de sua dívida. Repare que, embora sua propensão a consumir seja 1, esta propensão diz respeito à proporção $\alpha_{2}$ de sua renda.

$$
D_{a}=\left(1-\alpha_{2}\right) \alpha \phi W L\left(1-\theta_{a}\right)-i D_{a}
$$

Para os trabalhadores ativos, por outro lado, assume-se que nem toda a sua dívida é amortizada. Neste caso, há uma parcela de default. A parte da dívida que é amortizada vem de sua renda disponível - mais especificamente da parcela $1-\alpha_{1}$ de sua renda disponível, embora sua propensão a consumir do restante $\alpha_{1}$ não seja 1 , como no caso do aposentado. Vimos que a parcela da dívida que sofre default depende negativamente da taxa de emprego: $\theta_{\text {default }}(E)$. A parcela $1-\theta_{\text {default }}(E)$ da dívida, por outro lado, é amortizada. A parte da renda dos trabalhadores ativos que ficou como lastro ao empréstimo consignado corresponde a $1-\alpha_{1}$ de sua renda do trabalho líquida, como vimos. Entretanto, esses trabalhadores correm risco de perder o emprego quando a economia sofre uma queda no nível de atividade, e ainda terão uma dívida herdada, que não necessariamente eles vão conseguir honrar. Assim, a parcela da dívida $D_{w}$ que é honrada e amortizada depende da parcela de empregados. Desta forma, nem toda a renda "guardada" como lastro do empréstimo (isto é, a proporção $1-\alpha_{1}$ da renda do trabalho líquida), será utilizada para pagamento de principal - diferentemente do que ocorre com os aposentados. Os trabalhadores que perdem o emprego poderiam recorrer a essa renda, por exemplo, deixando de pagar a amortização. Assim, assume-se que uma parte $\alpha_{3}$ da renda "guardada" como lastro é destinada à amortização da dívida $D_{w}$, cuja parcela $1-\theta_{\text {default }}(E)$ é paga. Este $\alpha_{3}$ depende de $E$, positivamente: quanto maior a parcela de empregados, maior a renda destinada à amortização de dívidas.

$$
D_{w}\left(1-\theta_{\text {default }}(E)\right)=\alpha_{3}(E)\left(1-\alpha_{1}\right)\left[W L\left(1-\theta_{w}-\lambda_{w} b_{w}\right)\right]-i D_{w}
$$

A parcela restante de $D_{w}$ sofre default, diminuindo o lucro dos bancos: $D_{w} \theta_{\text {default }}(E)$.

O modelo aqui desenvolvido tem como objetivo explicar o maior efeito multiplicador das transferências do governo com benefícios sociais no período da recessão recente. Assim, nosso contexto é de curto prazo, de modo que o longo prazo não é o nosso escopo - como mencionado anteriormente. O crédito pode se tornar um mecanismo de transferência de renda para a classe capitalista tal que, no longo prazo, há efeitos estagnacionistas 
Capítulo 3. Terceiro Artigo - O efeito dos benefícios sociais na recessão brasileira recente: um modelo 170 Kaleckiano com endividamento das famílias

- como tipicamente os modelos mostram. No entanto, este não é nosso objeto. Aqui, o que nos interessa é explicar o maior efeito multiplicador da política fiscal que ocorre a partir das transferências com benefícios sociais no contexto de uma diminuição do nível de atividade econômica, e um canal possível pelo qual isso ocorreu é o crédito consignado. Há a possibilidade de que os aposentados simplesmente começaram a consumir mais quando o nível de atividade caiu. Porém, isto não elimina a possibilidade de o crédito consignado ter desempenhado um papel relevante neste processo, dado que sua concessão ficou estável durante o período da crise - contrastando com a oferta de crédito aos ativos, cuja variação média ao ano foi consideravelmente negativa.

\subsubsection{Modelo simplificado}

A seguir apresentaremos dois modelos. O simplificado, que busca entender o efeito do crédito no multiplicador. Este efeito é similar ao de um aumento na propensão a consumir, como em Dutt (2006). O modelo que apresentaremos posteriormente parte dessa análise para endogeneizar a oferta de crédito, que passará a depender do grau de utilização, aos moldes do que descrevemos na seção 3.4.2.

Neste modelo simplificado, vamos considerar que as propensões a consumir e o coeficiente de oferta de crédito são exógenos, de maneira que não dependam da taxa de emprego, nem do grau de utilização. A função consumo dos trabalhadores ativos torna-se:

$$
C_{w}=c_{w}\left[\alpha_{1} W L\left(1-\theta_{w}-\lambda_{w} b_{w}\right)-i D_{w}\right]+B_{w}
$$

Em que:

$$
B_{w}=\beta_{2}\left[\alpha_{1} W L\left(1-\theta_{w}-\lambda_{w} b_{w}\right)-i D_{w}\right]+\beta_{3}\left(\frac{1}{\alpha \phi}\right)
$$

A função consumo dos trabalhadores aposentados é:

$$
C_{a}=\alpha_{2} \alpha \phi W L\left(1-\theta_{a}\right)-i D_{a}+B_{a}
$$

Onde já consideramos a propensão a consumir igual à 1. Repare que:

$$
B_{a}=\beta_{1}\left[\alpha_{2} \alpha \phi W L\left(1-\theta_{a}\right)-i D_{a}\right]+\beta^{*}\left[\alpha_{2} \alpha \phi W L\left(1-\theta_{a}\right)-i D_{a}\right]
$$

O consumo do capitalista:

$$
C_{c}=c_{c}\left\{\xi\left[\left(Y\left(1-\theta_{c}\right)-W L\left(1+\lambda_{c} b_{c}\right)\right]+i\left(D_{w}+D_{a}\right)-\theta_{\text {default }} D_{w}\right\}\right.
$$

Isto é, consideramos $c_{w}, \beta_{2}, \theta_{\text {default }}$, e $\beta^{*}$ exógenos (não dependem da taxa de emprego e, logo, também não dependem do grau de utilização). Além disso, consideramos as funções investimento e gasto do governo anteriormente apresentadas. 
O equilíbrio de curto prazo é dado pelo equilíbrio no mercado de bens ${ }^{7}$. Colocamos $B=B_{a}+B_{w}$ na equação porque o consumo é acrescido da tomada de crédito, assim como faz a literatura em geral. O grau de utilização de equilíbrio é dado pela seguinte equação:

$$
\begin{gathered}
u^{*}=Y / K=C_{w} / K+C_{a} / K+C_{c} / K+I / K+G / K+B / K \\
u^{*}=\frac{A}{B}
\end{gathered}
$$

Onde o numerador $A$ é:

$$
A=\gamma_{0}+g_{0}+c_{c} i\left(d_{w}+d_{a}\right)+\beta_{3}\left(\frac{1}{\alpha \phi}\right)-\left(c_{w}+\beta_{2}\right) i d_{w}-\left(1+\beta_{1}+\beta^{*}\right) i d_{a}-c_{c} \theta_{d e f a u l t} d_{w}
$$

E o denominador $B$ :

$$
\begin{aligned}
& B=1-\left(c_{w}+\beta_{2}\right) \alpha_{1}(1-\pi)\left(1-\theta_{w}-\lambda_{w} b_{w}\right)-\left(1+\beta_{1}+\beta^{*}\right) \alpha_{2} \alpha \phi(1-\pi)\left(1-\theta_{a}\right) \\
& \quad-c_{c} \xi\left[\left(1-\theta_{c}\right)-(1-\pi)\left(1+\lambda_{c} b_{c}\right)\right]-\gamma_{u}-\alpha \phi(1-\pi)(3.53)
\end{aligned}
$$

Sabemos que $A>0$ (condição 1) para que o equilíbrio $u^{*}$ faça sentido econômico $\left(u^{*}>0\right)$ e $B>0$ (condição 2), pela condição Keynesiana de estabilidade. Isto significa que temos as seguintes condições.

Condição 1:

$$
\gamma_{0}+g_{0}+c_{c} i\left(d_{w}+d_{a}\right)+\beta_{3}\left(\frac{1}{\alpha \phi}\right)>\left(c_{w}+\beta_{2}\right) i d_{w}+\left(1+\beta_{1}+\beta^{*}\right) i d_{a}+c_{c} \theta_{\text {default }} d_{w}
$$

Condição 2:

$$
\begin{aligned}
& 1>\left(c_{w}+\beta_{2}\right) \alpha_{1}(1-\pi)\left(1-\theta_{w}-\lambda_{w} b_{w}\right)+\left(1+\beta_{1}+\beta^{*}\right) \alpha_{2} \alpha \phi(1-\pi)\left(1-\theta_{a}\right) \\
& +\mathrm{c}_{c} \xi\left[\left(1-\theta_{c}\right)-(1-\pi)\left(1+\lambda_{c} b_{c}\right)\right]+\gamma_{u}+\alpha \phi(1-\pi)(3.55)
\end{aligned}
$$

Outra forma de enxergarmos essas condições é em termos das curvas $g_{s}$, dada pela poupança agregada dividida pelo estoque de capital; e $g_{i}$, dada pela soma do investimento e do gasto do governo, ambos divididos pelo estoque de capital.

$$
\begin{gathered}
g_{s}=S / K=Y / K-C / K=u-C / K \text { é dada por: } \\
g_{s}=u\left\{1-\left(c_{w}+\beta_{2}\right) \alpha_{1}(1-\pi)\left(1-\theta_{w}-\lambda_{w} b_{w}\right)-\left(1+\beta_{1}+\beta^{*}\right) \alpha_{2} \alpha \phi(1-\pi)\left(1-\theta_{a}\right)\right. \\
\left.-c_{c} \xi\left[\left(1-\theta_{c}\right)-(1-\pi)\left(1+\lambda_{c} b_{c}\right)\right]\right\}-\beta_{3} \frac{1}{\alpha \phi}+\left(c_{w}+\beta_{2}\right) i d_{w}+i d_{a}\left(1+\beta_{1}+\beta^{*}\right)-c_{c} i\left(d_{w}+\right. \\
\left.d_{a}\right)+c_{c} \theta_{\text {default }} d_{w}(3.56)
\end{gathered}
$$$$
\text { Já } g_{i}=I / K+G / K \text { vale: }
$$$$
g_{i}=\gamma_{0}+g_{0}+u\left[\gamma_{u}+\alpha \phi(1-\pi)\right]
$$

$\overline{7}$ O estoque de dívida dividido pelo estoque de capital chamamos de $d_{a}$ e $d_{w}$. 
Capítulo 3. Terceiro Artigo - O efeito dos benefícios sociais na recessão brasileira recente: um modelo

A condição Keynesiana de estabilidade requer que a sensibilidade da poupança a variações no grau de utilização, ou derivada com relação a $u$ (termo entre chaves na equação 3.56) supere a sensibilidade do investimento a esta mesma variável $\left(\gamma_{u}+\alpha \phi(1-\pi)\right)$. Repare que os parâmetros de oferta de crédito desempenham um papel contrário à condição, isto é, se forem muito altos, a condição pode não se sustentar (pois contribuem para injeções de demanda). Limitamos $\beta_{2}$ e $\beta_{1}+\beta^{*}$ entre zero e um, assim como as propensões a consumir.

Além disso, da condição 1, podemos afirmar que o intercepto de $g_{i}$ é mais alto que do da $g_{s}$ : os parâmetros de espírito animal e de gasto autônomo precisam ser maiores que as interações dos estoques de dívida, das duas classes trabalhadoras, com a taxa de juros, as propensões a consumir e os parâmetros de oferta de crédito. A propensão a consumir do capitalista, bem como a parte do crédito que não depende da renda disponível para ser demandado ou ofertado $\left(\beta_{3}\right)$ também precisam ser altos o suficiente. Assim, percebe-se que, embora o crédito tenha uma importância significativa na sustentação da demanda agregada, proporcionando uma propensão a consumir maior e estimulando o efeito multiplicador, como veremos a seguir, os estoques de dívida e a taxa de juros não podem ser muito altos.

O multiplicador derivado de um aumento no gasto autônomo é derivado a partir de:

$$
\frac{\partial u^{*}}{\partial g_{0}}=\frac{1}{B}>0
$$

Onde $B$ é dado por 3.53 .

Na equação 3.53, destaca-se que um aumento na oferta e na demanda de crédito aos aposentados na situação de diminuição do nível de atividade econômica, captado por um maior $\beta^{*}$, aumenta o multiplicador, porque equivale a um incremento na propensão a consumir. Uma diminuição na oferta de crédito aos ativos, ou mesmo uma diminuição em sua propensão a consumir, atua de forma a diminuir o multiplicador. Desta forma, o efeito final para que se eleve o multiplicador quando há queda no nível de atividade deve ser tal que a propensão a consumir maior dos aposentados, possibilitada pelo acesso ao crédito (conforme nossa hipótese), compense a retração do consumo dos trabalhadores ativos. Isso ajudaria a economia a sustentar o consumo das famílias, funcionando como um elemento estabilizador e impedindo uma recessão ainda mais profunda, conforme argumentamos no Artigo 2. Ou seja, para que o multiplicador (dado por $\frac{1}{B}$ ) seja maior quando o nível de atividade econômica se retrai, a condição necessária é que os trabalhadores aposentados estejam muito dispostos a tomar crédito e os bancos igualmente dispostos a ofertá-lo, isto é, precisamos de $\beta^{*}$ relativamente alto. Esta é nossa hipótese construída a partir da motivação empírica da seção 3.2, e pode ser justificada pelo atrelamento do crédito consignado à aposentadoria, do lado da oferta. Do lado da demanda, os trabalhadores desta classe de fato estão bem mais dispostos a se endividarem em um cenário de redução da renda disponível das famílias afetadas pelo desemprego. A situação financeira das famílias que sofrem com o desemprego é aliviada por meio do uso desses benefícios sociais de forma 
a se obter crédito.

Repare que, na equação do multiplicador, não aparecem os parâmetros de espírito animal, nem os estoques de dívida, que são termos autônomos. Tal como em Charles et al (2015), a ausência do parâmetro de investimento autônomo reflete a independência do multiplicador, na configuração abordada no que chamamos de modelo simplificado, do estado da economia. Um menor parâmetro de espírito animal poderia significar uma redução no nível de atividade econômica, por exemplo. Além disso, repare que o multiplicador independe dos estoques de dívida. Em nosso contexto, os estoques de dívida também podem ser vistos como indicadores do estado da economia. Um maior estoque de dívida dos aposentados, por exemplo, poderia indicar um contexto de queda do grau de utilização. O que chamamos a atenção é que não há nada, na equação do multiplicador, que indique o estado da economia, com base no que desenvolvemos da estrutura do modelo até aqui.

Apesar das nossas considerações anteriores, por enquanto tanto as propensões a consumir quanto os parâmetros da oferta de crédito foram considerados exógenos e independentes da taxa de emprego e, logo, do grau de utilização. Adicionalmente, repare que as equações das curvas $g_{s}$ e $g_{i}$ são lineares, com a primeira mais inclinada que a segunda, pela condição Keynesiana de estabilidade. Uma política fiscal que implique em deslocamento da $g_{i}$ resulta em um efeito multiplicador e aumento do grau de utilização que independe da fase do ciclo econômico, ou seja, independe de um grau de utilização que seja maior ou menor. Tal incremento de renda é o mesmo a qualquer nível de atividade econômica. Por este motivo, vamos elaborar um modelo na próxima seção que permita distinção entre os efeitos multiplicadores ao longo dos níveis do grau de utilização de capacidade instalada. Isso é possível quando surge uma curva $g_{s}$ convexa, como veremos adiante.

\subsubsection{Modelo com endogeneização da oferta de crédito}

A seção anterior apresentou o modelo simplificado, no qual os parâmetros que representam as condições de oferta e demanda de crédito, bem como as propensões a consumir e a taxa de default, eram exógenos, não dependiam do grau de utilização. Nesta seção, vamos incorporar os efeitos da taxa de emprego e do grau de utilização sobre essas variáveis, como já discutido quando apresentamos a estrutura do modelo (nas seções 3.4.1 e 3.4.2). Naquelas seções argumentamos que as propensões a consumir e os parâmetros que refletem as condições de oferta e demanda por crédito (os betas) dependem da taxa de emprego $E$ e do grau de utilização $u$, da seguinte forma:

$1) c_{w}(E)$ depende positivamente de $E$ : quanto maior a taxa de emprego (e o grau de utilização), maior a propensão a consumir dos trabalhadores ativos. A propensão a consumir dos aposentados não varia, e seu valor é igual à unidade independente da fase do ciclo econômico, como vimos (por hipótese); 
Capítulo 3. Terceiro Artigo - O efeito dos benefícios sociais na recessão brasileira recente: um modelo

2) $\beta_{2}(E)$ depende positivamente de $E$ : quanto maior o grau de utilização e a taxa de emprego, temos uma oferta de crédito maior na direção dos trabalhadores ativos, bem como uma demanda maior por parte desses trabalhadores, cuja chance de perder o emprego diminui quando a economia está operando em alto grau de utilização;

3) $\beta^{*}(u)$, a parte do crédito dos aposentados sensível ao ciclo, depende negativamente do grau de utilização $u$. Em cenários de redução no nível de atividade nos quais o grau de utilização diminui, os bancos escolhem ampliar sua oferta de crédito aos aposentados em detrimento dos ativos. Além disso, os aposentados, para sustentarem sua renda (tendo em vista que a própria renda das transferências diminui com a queda do grau de utilização), também demandam mais crédito. Assim, quando o grau de utilização cai, o beta aumenta. Em outras palavras, essas variáveis, que antes eram exógenas, tornam-se dependentes do grau de utilização (pois a taxa de emprego também depende do grau de utilização).

Como a taxa de emprego é dada por $E=\frac{L}{X}$, considerando que há $X$ pessoas nessa economia, das quais $L$ são trabalhadores ativos empregados, e dado que o produto dessa economia é $Y=a L$, isto é, $u=a \frac{L}{K}$, então temos que $E=\frac{L}{X}=\frac{L}{Y} \frac{Y}{K} \frac{K}{X}=\frac{1}{a} u k$. Como vimos, nosso modelo está restrito ao curto prazo. Desta forma, vamos considerar que o inverso da produtividade do trabalho $\frac{1}{a}$ multiplicado pelo estoque de capital per capita $k$ é igual a 1 . Ou ainda, a produtividade do trabalho é igual ao estoque de capital per capita. Portanto, $E=u$, de modo que a taxa de emprego é igual ao grau de utilização.

Para a função consumo dos trabalhadores ativos, vamos considerar que, como tanto $c_{w}$ quanto $\beta_{2}$ dependem positivamente de $u\left(c_{w}+\beta_{2}=c\right.$, que depende de $\left.u\right)$ de modo que propomos a seguinte relação linear:

$$
c=c_{w u} u
$$

Com $c_{w u}>0$, que pode ser interpretado como um parâmetro que captura a sensibilidade da propensão a consumir e, principalmente, da oferta (ou demanda) de crédito dos trabalhadores ativos em relação ao grau de utilização.

A função consumo dos trabalhadores ativos torna-se (já considerando dividida pelo estoque de capital):

$$
C_{w} / K=c_{w u} u\left[\alpha_{1} u(1-\pi)\left(1-\theta_{w}-\lambda_{w} b_{w}\right)-i d_{w}\right]+\beta_{3}\left(\frac{1}{\alpha \phi}\right)
$$

A função consumo dos trabalhadores inativos continua com a propensão a consumir igual a 1, independente da fase do ciclo econômico, já que os aposentados possuem renda estando em situações de aumento ou de diminuição do nível de atividade econômica (não correm risco de perder o emprego). Sua oferta de crédito, entretanto, é endogeneizada da seguinte maneira: $\beta^{*}$ torna-se uma função linear com uma parte que independe do grau de utilização, $\beta_{1}$, e outra parte que depende negativamente do grau de utilização:

$$
\beta^{*}=\beta_{1}+\beta^{u} u
$$


Com $\beta^{u}<0$, que indica a sensibilidade da oferta de crédito (ou demanda) para os aposentados em relação ao grau de utilização.

Vamos considerar uma queda na atividade econômica, isto é, uma queda em $u$. Temos que, considerando os valores em termos de antes e depois desta queda:

$$
\beta_{\text {depois }}^{*}-\beta_{\text {antes }}^{*}=\beta^{u}\left[u_{\text {depois }}-u_{\text {antes }}\right]
$$

Repare que uma queda em $u$ leva a um aumento na oferta de crédito aos aposentados, segundo o coeficiente, que é negativo, $\beta^{u}$. Logo, há variação positiva no crédito. Se a sensibilidade da oferta e demanda de crédito dos aposentados ao grau de utilização $\beta^{u}$ for muito alta, então este incremento no crédito será maior. Raciocínio similar vale para o parâmetro $c_{w u}$ : quanto mais alta for esta sensibilidade, uma queda no grau de utilização leva a uma maior diminuição no crédito para a classe de ativos.

A função consumo dos aposentados torna-se, já dividida pelo estoque de capital:

$$
C_{a} / K=\left(1+\beta_{1}-\beta^{u} u\right)\left[\alpha_{2} \alpha \phi u(1-\pi)\left(1-\theta_{a}\right)-i d_{a}\right]
$$

Onde já levamos em conta o sinal negativo de $\beta^{u}$.

A função consumo do capitalista é alterada apenas no que se refere à taxa de default, que passa a ser função linear negativa do grau de utilização:

$$
\theta_{\text {default }}=\theta_{\text {def }} u
$$

Onde $\theta_{\text {def }}<0$.

As funções de investimento e gasto do governo em relação ao estoque de capital permanecem inalteradas em relação ao modelo simplificado.

O equilíbrio de curto prazo no mercado de bens resulta na seguinte equação:

$$
u^{2}[A]-u[B]-C=0
$$

Onde:

$$
\begin{aligned}
& A=(1-\pi)\left[-c_{w u} \alpha_{1}\left(1-\theta_{w}-\lambda_{w} b_{w}\right)+\beta^{u} \alpha_{2} \alpha \phi\left(1-\theta_{a}\right)\right] \\
& B=\left\{-1-i d_{w} c_{w u}+\alpha_{2} \alpha \phi(1-\pi)\left(1-\theta_{a}\right)\left(1+\beta_{1}\right)+\beta^{u} i d_{a}+c_{c} \xi\left[\left(1-\theta_{c}\right)-(1-\pi)\left(1+\lambda_{c} b_{c}\right)\right]\right. \\
& \left.+\mathrm{c}_{c} \theta_{d e f} d_{w}+\alpha \phi(1-\pi)+\gamma_{u}\right\}(3.67) \\
& C=\left[\gamma_{0}+g_{0}+c_{c} i\left(d_{w}+d_{a}\right)+\beta_{3} \frac{1}{\alpha \phi}-i d_{a}\left(1+\beta_{1}\right)\right]
\end{aligned}
$$

A solução desta equação requer a raiz positiva:

$$
u^{*}=\frac{B+\left(B^{2}+4 A C\right)^{1 / 2}}{2 A}
$$


Capítulo 3. Terceiro Artigo - O efeito dos benefícios sociais na recessão brasileira recente: um modelo

A condição Keynesiana de Estabilidade ${ }^{8}$ requer que a derivada da curva de poupança agregada dividida pelo estoque de capital com relação ao grau de utilização (que vale $\frac{\partial g_{s}}{\partial u}=2 u A-B^{\prime}$, onde $\left.B^{\prime}=B-\left(\gamma_{u}+\alpha \phi(1-\pi)\right)\right)$ seja maior que a derivada da curva investimento mais gastos do governo, também dividida pelo estoque de capital, com relação ao grau de utilização $\left(\frac{\partial g_{i}}{\partial u}=\gamma_{u}+\alpha \phi(1-\pi)\right)$. Em outras palavras, a condição requer que a resposta a uma variação em $u$ dos vazamentos de demanda seja maior que a das injeções. Aplicando esta condição, chegamos à seguinte equação:

$$
\left[B^{2}+4 A C\right]^{1 / 2}>0
$$

Ou seja, a Condição Keynesiana de Estabilidade requer que o discriminante da equação de segundo grau seja positivo. Sabemos que o termo ao quadrado é sempre positivo. Vamos considerar $\gamma_{0}+g_{0}+c_{c} i\left(d_{a}+d_{w}\right)+\beta_{3}\left(\frac{1}{\alpha \phi}\right)>i d_{a}\left(1+\beta_{1}\right)$. Ou seja, $C>0$. Esta condição é parecida com a Condição 1, do modelo simplificado. Como naquele modelo, vamos impor que o estoque de dívida dos aposentados multiplicado pela taxa de juros não é tão alto a ponto de comprometer a estabilidade.

Se a sensibilidade da propensão a consumir dos ativos e da sua disponibilidade de crédito multiplicada por parâmetros que afetam a sua renda disponível for muito alta a ponto de superar a sensibilidade do crédito ao aposentado ao ciclo $\left(c_{w u} \alpha_{1}\left(1-\theta_{w}-\lambda_{w} b_{w}\right)\right.$ muito alto), então $A$ seria negativo e a condição Keynesiana acima poderia não ser atendida (a menos que a parte positiva supere a negativa). Mas para além disso, se $A<0$, note que a inclinação da curva $g_{s}$ poderia ser negativa, a menos que $B^{\prime}$ fosse negativo e superasse em módulo seu valor. Se a inclinação for negativa, a curva $g_{s}$ dependeria negativamente do grau de utilização: a propensão a consumir dos ativos e sua disponibilidade de crédito são tão sensíveis ao grau de utilização que um aumento neste último faz a propensão a consumir subir muito a ponto de diminuir a poupança agregada dividida pelo estoque de capital. Neste caso, o efeito multiplicador de uma política fiscal (deslocamento da $g_{i}$ ) ocorreria em uma curva $g_{s}$ decrescente e côncava (pois a segunda derivada da curva $g_{s}$ vale $2 A$, sendo negativa), atuando no sentido oposto, de redução do grau de utilização e do produto. Desta forma, vamos excluir este caso, pois não é condizente com nossas observações empíricas.

A segunda opção, ainda considerando o caso de alta sensibilidade da propensão a consumir dos ativos e de sua disponibilidade de crédito, seria uma curva crescente em $u$, porém ainda côncava. Neste caso um efeito multiplicador ocasionado por política fiscal (deslocamento da curva $g_{i}$ ) seria maior quando o grau de utilização fosse mais alto,

8 A equação da curva de poupança agregada normalizada pelo estoque de capital é dada por $g_{s}=$ $u^{2} A-u B^{\prime}+i d_{a}\left(1+\beta_{1}\right)-c_{c} i\left(d_{w}+d_{a}\right)-\beta_{3} \frac{1}{\alpha \phi}$. A equação da curva do investimento mais os gastos do governo normalizada pelo estoque de capital é $g_{i}=\gamma_{0}+g_{0}+\gamma_{u} u+\alpha \phi u(1-\pi)$. Poderíamos, alternativamente, supor o investimento exógeno - tendo em vista que o modelo não apresenta dinâmica por ser focado no curto prazo. A única mudança maior neste caso é que a curva $g_{i}$ apresentaria uma inclinação menor, dada apenas por $\alpha \phi(1-\pi)$. 
isto é, quando há elevações no nível de atividade econômica. Portanto, podemos derivar um primeiro resultado importante do nosso modelo, que é uma condição para que o multiplicador fiscal seja mais alto quando há uma queda no nível de atividade: $A>0$, ou seja

$$
c_{w u} \alpha_{1}\left(1-\theta_{w}-\lambda_{w} b_{w}\right)<\beta^{u} \alpha_{2} \alpha \phi\left(1-\theta_{a}\right)
$$

Em palavras, a condição nos diz que o efeito do crédito sobre o consumo do aposentado durante o período de queda no grau de utilização mais do que compensa a redução do crédito e da propensão a consumir dos trabalhadores ativos. Esta é uma condição de convexidade para a curva $g_{s}$, de modo que sua concavidade seja para cima, como veremos adiante graficamente (Gráfico 28). Esta característica de convexidade será importante para explicarmos o maior efeito multiplicador em uma situação de queda no nível de atividade. Desta forma, o crédito ao aposentado e o seu consumo assumem um papel estabilizador.

Podemos afirmar que esse resultado nos diz que o consumo dos ativos não está sujeito a variações tão grandes, bem como o consumo dos aposentados possui papel estabilizador e aumenta quando o grau de utilização é baixo (isto é, $c_{w u}$ não é tão alto e $\beta^{u}$ não é muito baixo) a ponto de a curva $g_{s}$ ser negativamente inclinada: quanto maior o $u$, menor a poupança agregada porque os ativos gastam muito mais. Assim, podemos pensar que os trabalhadores ativos, na realidade, já gastam quase tudo o que ganham. Na situação de um menor grau de utilização, sua propensão a consumir, que já está próxima de 1, sofre uma pequena redução (trabalhadores já consomem boa parte do que ganham, estando em situação de alto ou baixo nível de atividade econômica). Sua oferta de crédito também sofre redução, mas esta redução não é tão sensível a ponto de comprometer a estabilidade.

Portanto, a parte anticíclica do crédito (que é a parte demandada /ofertada pelos/para os aposentados) mais do que compensa a contração do crédito para a classe de ativos de modo que esta parte anticíclica assume o papel estabilizador da renda quando o grau de utilização sofre uma queda. Dentro de nosso contexto, vimos que os benefícios sociais no Brasil no período da recessão recente contribuíram para a estabilização da renda, por meio de um efeito multiplicador maior e de magnitude até mesmo comparável ao efeito do investimento público. Podemos interpretar o resultado da equação 3.71 como sendo, dentro desse contexto de queda na atividade econômica, a condição para esse efeito multiplicador maior. De um lado, o maior acesso ao crédito possibilitado sobretudo após a regulamentação do crédito consignado pode ter contribuído para elevar a sensibilidade do crédito aos trabalhadores aposentados em relação ao grau de utilização (elevar o parâmetro $\left.\beta^{u}\right)$. De outro, esta maior inclusão financeira pode funcionar como um impedimento para que o parâmetro $c_{w u}$ não seja muito alto de modo que as restrições ao crédito aos trabalhadores ativos em situações de diminuição do grau de utilização não fossem tão 
Capítulo 3. Terceiro Artigo - O efeito dos benefícios sociais na recessão brasileira recente: um modelo 178 Kaleckiano com endividamento das famílias

fortes a ponto de diminuir drasticamente sua propensão a consumir. Em outras palavras, o maior acesso ao crédito funcionou como um elemento importante para estabilização da renda durante o período recente de crise.

Como vimos nos parágrafos acima, $A>0$, em que a renda do aposentado e seu crédito ofertado possuem caráter estabilizador. Esta é a condição para que a curva $g_{s}$ seja convexa e que o efeito multiplicador de uma política fiscal seja maior quando o grau de utilização for menor. Em suma, a curva $g_{s}$ possui as seguintes características: é crescente em $u$ e mais inclinada que a $g_{i}$, como de costume, mas assume a configuração de uma parábola com concavidade voltada para cima - tal como em Charles et al (2015). Neste artigo, os autores propõem um modelo para explicar o maior multiplicador durante recessões a partir do papel do consumo do capitalista: os capitalistas aumentam a propensão a poupar conforme o grau de utilização aumenta, o que significa que, quando há queda do grau de utilização, eles tentam suavizar seu consumo e diminuem tal propensão. Isto dá o formato de parábola com concavidade voltada para cima para a curva $g_{s}$, porque a propensão a poupar do capitalista é uma função linear positiva do grau de utilização.

Aqui, o modelo resulta em uma configuração parecida, mas por canais diferentes: é o crédito ao aposentado e seu aumento da propensão a consumir que assumem o papel de estabilizar o consumo quando o grau de utilização diminui. Quando endogeneizamos a propensão a consumir e as condições de crédito, que passaram a ser funções diretas da taxa de emprego, e, logo, do grau de utilização, a função $g_{s}$ assume o formato de parábola. Desta forma, nosso modelo é uma extensão do de Dutt (2006), considerando duas classes de trabalhadores e que o parâmetro que reflete as condições de oferta e demanda por crédito é endógeno.

O multiplicador resultante a partir de um choque exógeno no gasto do governo assume a forma:

$$
\frac{\partial u^{*}}{\partial g_{0}}=\frac{1}{\Delta}
$$

Onde:

$$
\Delta=\left[B^{2}+4 A C\right]^{1 / 2}
$$

Que é sempre maior que zero. Além disso, vemos que o multiplicador depende de parâmetros que indicam o estado da economia, como o espírito animal, que pode ser visto como um grau de otimismo por parte das firmas e, logo, intrinsecamente ligado ao ciclo econômico. Isto é um indicativo de que o multiplicador agora responde ao ciclo, tal como em Charles et al (2015). Repare ainda que no multiplicador encontrado no modelo simplificado, onde não havia endogeneização da oferta de crédito, os estoques de dívida não exerciam nenhum papel no multiplicador. Aqui, em contraste, o multiplicador depende dos estoques de dívida (que também possuem relação com o próprio ciclo econômico), bem como de outros parâmetros, como $\beta_{3}$, e a sensibilidade da taxa de default ao grau de utilização $\theta_{d e f}$. Além da fundamental dependência em relação às sensibilidades do crédito ao aposentado 
(captada por $\left.\beta^{u}\right)$ e da propensão a consumir dos ativos e de seu crédito ofertado $\left(c_{w u}\right)$ ao ciclo econômico.

Antes de analisar como o multiplicador se comporta, vamos realizar alguns exercícios de estática comparativa para entender a dinâmica do modelo. Da equação do equilíbrio, podemos achar a taxa de crescimento da economia: $g^{*}=\gamma_{0}+u^{*} \gamma_{u}$. Para a análise que se segue, nota-se que $\frac{\partial g^{*}}{\partial \chi}=\gamma_{u} \frac{\partial u^{*}}{\partial \chi}$, onde $\chi$ é a variável a qual tiramos a derivada para avaliar seus impactos. Assim, o impacto na taxa de crescimento da economia dada uma variação em $\chi$ vai na mesma direção (possui o mesmo sinal) do impacto no grau de utilização. Nas equações abaixo, consideramos $D=\frac{1}{2}\left(B^{2}+4 A C\right)^{-1 / 2}>0$. Lembre-se, além disso, que $A>0$ e $C>0$.

Considere um aumento na sensibilidade da oferta de crédito aos aposentados em relação ao grau de utilização $\left(\beta^{u}\right)$ :

$$
\frac{\partial u^{*}}{\partial \beta^{u}}=\left[i d_{a}+D 2 B i d_{a}+4 D C(1-\pi) \alpha_{2} \alpha \phi\left(1-\theta_{a}\right)\right] \frac{1}{2 A}-\frac{u^{*}(1-\pi) \alpha_{2} \alpha \phi\left(1-\theta_{a}\right)}{A}
$$

Repare que o efeito positivo é maior quanto menor é o grau de utilização. Não sabemos o sinal de $B$, que pode ser positivo ou negativo. Mas repare que aumentos em $\beta^{u}$ (e mesmo em $d_{a}$ ) colaboram para que o sinal da derivada seja positivo (para que $B$ seja positivo) - assim como $\gamma_{u}, c_{c} \alpha, \phi, \beta_{1}, \alpha_{2}$, isto é, parâmetros que estão ligados à renda disponível do aposentado e à sua propensão a consumir, bem como a sensibilidade do investimento ao grau de utilização, por exemplo. Já $c_{w u}$, que, como resultado do modelo, é baixo, e também $d_{w}$, atuam de forma negativa sobre $B$ e sobre o sinal da derivada. Usando nosso resultado anterior, argumentamos que a inclusão financeira possibilitada pela regulamentação do crédito consignado contribuiu para uma elevação da sensibilidade do crédito do aposentado ao ciclo $\beta^{u}$, e para uma diminuição da sensibilidade da propensão a consumir dos ativos (que inclui também a propensão a consumir possibilitada pelo acesso ao crédito), $c_{w u}$. Este foi o resultado obtido do nosso modelo para que o multiplicador fosse maior quando o grau de utilização é mais baixo (equação 3.71). Desta forma, é razoável supor uma chance maior de o sinal de $B$ ser positivo, tendo em vista que o parâmetro $\beta^{u}$ é bem mais sensível que $c_{w u}$.

Na equação acima, o pagamento de juros atua de forma positiva (embora possua sinal negativo em $C$ ), devido ao caráter anticíclico da dívida contraída. O pagamento de juros diminui a renda disponível. Como a oferta/demanda de crédito ao aposentado depende negativamente de sua renda disponível (pelo seu caráter anticíclico), uma redução nesta última pelo maior pagamento de juros estimula nova tomada de crédito e o consumo. Assim, o papel do crédito à classe que recebe benefícios sociais fica bastante evidenciado como elemento estabilizador quando há queda no nível de atividade econômica. Nesta situação, o efeito positivo do aumento da sensibilidade do crédito ao aposentado sobre o grau de utilização é reforçado. 
Uma elevação na sensibilidade da propensão a consumir total (a propensão a consumir somada com a oferta de crédito) dos ativos ao grau de utilização $\left(c_{w u}\right)$ possui efeito mais negativo quando há um baixo grau de utilização, porque a queda do consumo da classe dos trabalhadores ativos é acentuada quando o nível de atividade econômica se reduz, pela contração de sua propensão a consumir e de sua oferta de crédito - isso é ilustrado na equação abaixo. O efeito negativo é reforçado por um alto estoque de dívida desta classe, cujo pagamento de juros desempenha o papel contracionista tradicional em modelos Kaleckianos ${ }^{9}$. Como anteriormente, $\beta^{u}, \gamma_{u}, \alpha, \phi, \beta_{1}$ e $\alpha_{2}$ mais altos colaboram para que o sinal de $B$ seja positivo, bem como $c_{w u}$ e $d_{w}$ mais baixos ${ }^{10}$.

$$
\frac{\partial u^{*}}{\partial c_{w u}}=\left[-i d_{w}-D 2 B i d_{w}-4 D C(1-\pi) \alpha_{1}\left(1-\theta_{w}-\lambda_{w} b_{w}\right)\right] \frac{1}{2 A}+\frac{u^{*}(1-\pi) \alpha_{1}\left(1-\theta_{w}-\lambda_{w} b_{w}\right)}{A}
$$

O efeito do aumento dos estoques de dívida:

$$
\frac{\partial u^{*}}{\partial d_{a}}=\frac{\beta^{u} i+D 2 B \beta^{u} i+D 4 A i\left(c_{c}-1-\beta_{1}\right)}{2 A}
$$

O efeito do estoque de dívida dos aposentados sobre a taxa de crescimento da economia é positivo se a propensão a poupar do capitalista não é tão alta, porque a dívida transfere recursos, via pagamento de juros, da classe de propensão a consumir maior (aposentados) para a classe de propensão a consumir menor (capitalistas). Além disso, como nos casos anteriores, repare que, como não sabemos o sinal de $B, \beta^{u}$ colabora para que o sinal da derivada seja positivo (assim como $\gamma_{u}, \alpha, \phi, \beta_{1}, \alpha_{2}$ ). Já $c_{w u}$ e $d_{w}$ atuam de forma negativa. Se o efeito anticíclico da dívida dos aposentados compensar o efeito adverso da distribuição de renda aos capitalistas e o efeito contracionista do consumo dos ativos, o efeito final será positivo.

$$
\frac{\partial u^{*}}{\partial d_{w}}=\frac{-i c_{w u}-D 2 B i c_{w u}+D 4 A c_{c} i}{2 A}
$$

Para simplificar consideramos que $\theta_{\text {def }}=0$. Esse efeito negativo do estoque de dívida dos ativos sobre o grau de utilização é menos negativo se a propensão a consumir do capitalista for alta $^{11}$.

9 O pagamento de juros diminui a renda disponível. Como a propensão a consumir e a oferta de crédito desta classe dependem positivamente da renda disponível, pelo seu caráter pró-cíclico, uma redução nesta renda disponível resulta em menor propensão a consumir da classe dos ativos e em efeito negativo sobre o grau de utilização.

10 Aqui devemos ter um cuidado extra ao analisar essa derivada. Quando olhamos a equação, fica claro que um maior estoque de dívida $d_{w}$ leva a um efeito mais negativo no grau de utilização. No entanto, um $d_{w}$ maior, ou um $c_{w u}$ maior levam à maior chance de $B$ tornar-se negativo. Assim, poderia haver um elemento positivo na equação, onde $D 2 B i d_{w}$ torna-se positivo, suavizando o efeito negativo sobre o grau de utilização. Um $c_{w u}$ muito alto poderia indicar uma curva $g_{s}$ côncava onde o efeito multiplicador é maior quando o grau de utilização é alto porque a propensão a consumir dos ativos é pró-cíclica, neutralizando o efeito negativo da derivada. Como vimos, entretanto, um dos nossos resultados, explorado na equação 3.71, é que $c_{w u}$ não é tão alto (e é compensado pelo efeito de $\beta^{u}$ ).

11 A condição para $B$ ser positivo ou negativo também vale aqui: por exemplo, $\beta^{u}$ colabora para $B$ ser 
Vejamos o efeito de um aumento da taxa de juros:

$$
\frac{\partial u^{*}}{\partial i}=\frac{-d_{w} c_{w u}+\beta^{u} d_{a}+D 2 B\left(-d_{w} c_{w u}+\beta^{u} d_{a}\right)+D 4 A\left[d_{a}\left(c_{c}-1-\beta_{1}\right)+d_{w} c_{c}\right]}{2 A}
$$

Repare que $\beta^{u} d_{a}>d_{w} c_{w u}$ colabora para derivada positiva - é o caso também da propensão a consumir do capitalista. Em $B$ e $A, \beta^{u}$ e $d_{a}$ também colaboram para que a derivada seja positiva, ao contrário de $c_{w u}$ e $d_{w}$. Isto é, se o consumo ocasionado pelo endividamento dos aposentados for tal que compense a distribuição de renda aos capitalistas ocasionada pela própria dívida e o efeito da sensibilidade da propensão a consumir dos trabalhadores ativos ao ciclo, há um efeito positivo da taxa de juros porque a dívida contraída por parte dos aposentados possui caráter anticíclico. A redução de renda disponível dos aposentados -ocasionada por uma taxa de juros maior - poderia levar, por exemplo, a uma nova tomada de empréstimos por parte deles.

Para ter uma ideia dos demais parâmetros, apresentamos seus efeitos no apêndice. De um modo geral, tais efeitos evidenciam bastante como estão conectadas as rendas dos dois tipos de trabalhadores ao ciclo econômico. As derivadas do grau de utilização com relação aos parâmetros que alteram a renda disponível dos trabalhadores ativos, como $\alpha_{1}$, $\theta_{w}, \lambda_{w} b_{w}$, tendem a ser mais positivas (em uma situação em que há aumento da renda disponível - aumento em $\alpha_{1}$ e redução em $\theta_{w}$ ou em $\lambda_{w} b_{w}$, por exemplo) em situações de aumento do grau de utilização, dado que o consumo desses trabalhadores possui caráter pró-cíclico - seja via oferta e demanda por crédito, seja via propensão a consumir direta.

Já alterações em parâmetros que afetam a renda dos trabalhadores aposentados $\left(\alpha_{2}\right.$, $\theta_{a}, \phi, \alpha$ ), no sentido de elevar sua renda disponível (aumento em $\alpha_{2}, \alpha, \phi$, ou diminuição em $\theta_{a}$ ), tendem a ter impactos mais positivos sobre o grau de utilização e a taxa de crescimento da economia em situações de diminuição do nível de atividade econômica, evidenciando que a renda desses trabalhadores funciona como um estabilizador em tempos de diminuição no grau de utilização, pelo efeito de sua propensão a consumir se elevar. Os parâmetros que afetam a renda do capitalista, bem como a parte do crédito que não depende do ciclo, possuem efeitos muito parecidos com os do modelo Kaleckiano tradicional - e podem ser vistos no apêndice.

Vamos agora analisar como o multiplicador fiscal se comporta por meio de alguns exercícios de estática comparativa. Tendo em vista sua dependência em relação ao ciclo econômico, se o valor do multiplicador aumenta, é um indicativo de que estamos indo em direção a um grau de utilização menor. Vamos chamar esse efeito de "efeito pró-cíclico". Já se ocorrer uma diminuição do valor desse multiplicador, é sinal de que estamos nos movendo em direção a um grau de utilização maior. Este é o efeito que vamos chamar

positivo (reforçando o sinal negativo da derivada) e $c_{w u}$, colabora pra $B$ ser negativo, amenizando o sinal negativo do efeito do estoque de dívida $d_{w}$ sobre o grau de utilização. Aqui há uma interpretação parecida, portanto, com o caso da derivada do grau de utilização em relação ao $c_{w u}$, que vimos anteriormente. 
Capítulo 3. Terceiro Artigo - O efeito dos benefícios sociais na recessão brasileira recente: um modelo 182 Kaleckiano com endividamento das famílias

de "efeito anticíclico". Um bom exemplo para ilustrar isso é analisar o que ocorre com o multiplicador quando há alterações nas sensibilidades do crédito e da propensão a consumir em relação ao grau de utilização.

Figura 28 - Efeito multiplicador com alto e baixo grau de utilização

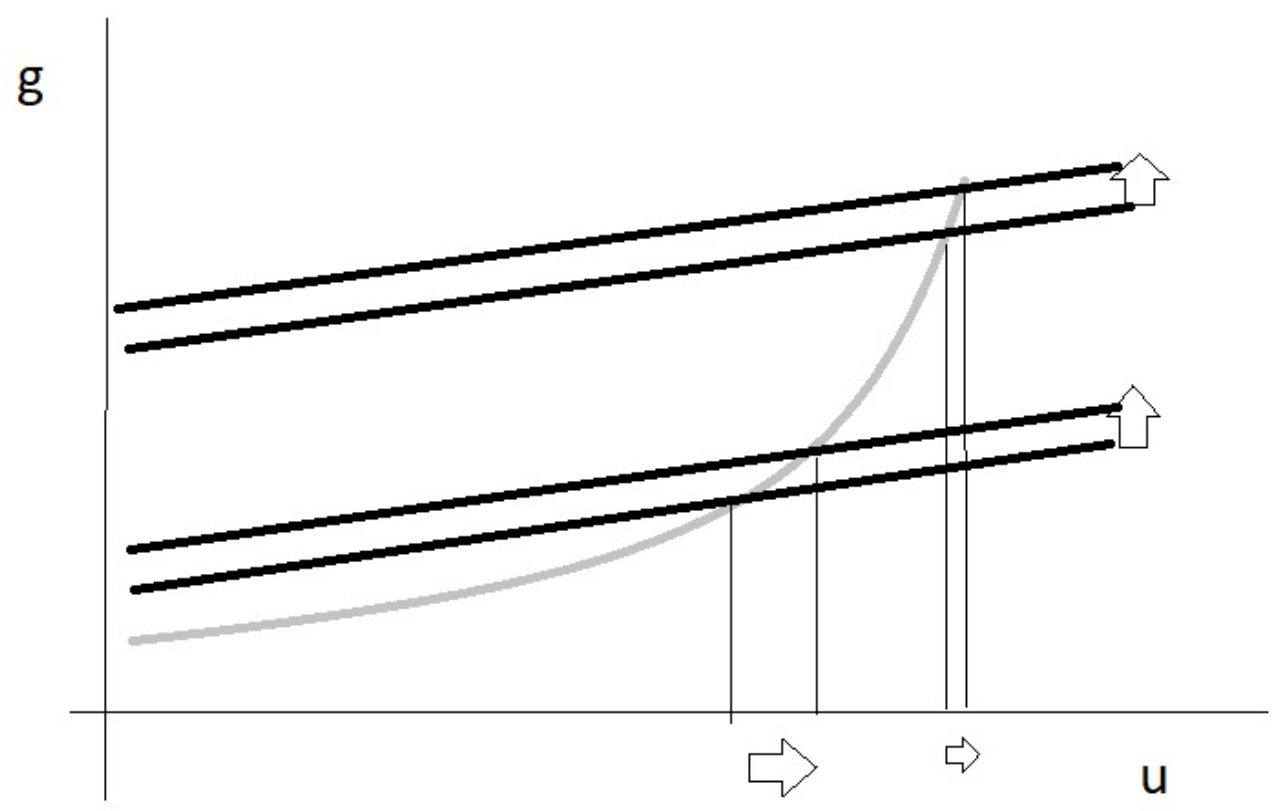

Fonte: Elaboração própria. A linha cinza refere-se à curva $g_{s}$ que, como vimos, apresenta um formato de parábola com concavidade para cima. Como de costume, o eixo vertical representa a poupança agregada dividida pelo estoque de capital (ou o investimento agregado dividido pelo estoque de capital). O eixo horizontal, o grau de utilização de capacidade instalada $(u)$. A linha preta representa a curva $g_{i}$. Repare que a curva $g_{s}$ é mais inclinada, pela condição Keynesiana de estabilidade. Pela condição $C>0$, o intercepto da $g_{i}$ é mais alto. O deslocamento da linha preta é a representação de um aumento no gasto público (parte exógena), com alto e baixo grau de utilização. O efeito do multiplicador fiscal é maior em valor quando o grau de utilização for baixo. Conforme vamos avançando na direção de um $u$ maior, o valor desse incremento de renda diminui.

Primeiro, suponha uma elevação no parâmetro $\beta^{u}$, isto é, a variação do crédito aos aposentados é acentuada quando ocorre diminuição do grau de utilização, de modo que a variação (positiva) em $\beta^{*}$ é maior. Neste caso, este incremento maior em $\beta^{*}$ implica em maior propensão a consumir dos aposentados, que possuem maior acesso ao crédito. Isto eleva o efeito multiplicador, como vimos no modelo simplificado. No entanto, o multiplicador cresce, mas seu valor (o valor do incremento) diminui porque, conforme o grau de utilização aumenta, $\beta^{*}$ reduz. Estamos nos movendo em direção a um grau de utilização maior, onde o valor do efeito multiplicador é diminuído. Este efeito surge devido à endogeneização do parâmetro de crédito $\beta^{*}$, que garante um formato de parábola com concavidade voltada para cima para a função $g_{s}$, assim como em Charles et al (2015): quando o grau de utilização é baixo, um deslocamento na curva $g_{i}$ devido a um choque na parte exógena dos gastos públicos causa um grande efeito no grau de utilização (Gráfico 28, acima). Conforme o grau de utilização aumenta (isto é, a economia se aproxima de um nível de atividade econômica maior), esse incremento é menor. O gráfico acima 
ilustra esse mecanismo: o multiplicador é maior em valor quando o grau de utilização for baixo. Similarmente, conforme vamos avançando na direção de um $u$ maior, o valor do multiplicador diminui.

Podemos ver isso pela seguinte derivada, onde chamamos $F=\frac{1}{2}\left(B^{2}+4 A C\right)^{\frac{-3}{2}}>0$ :

$$
\frac{\partial \text { multiplicador }}{\partial \beta^{u}}=-F\left[2 \text { Bid }_{a}+4 C(1-\pi) \alpha_{2} \alpha \phi\left(1-\theta_{a}\right)\right]
$$

Repare que $B$ positivo colabora para o sinal negativo da derivada, assim como na equação 3.74, na qual colaborava para o efeito de esse beta sobre o grau de utilização ser positivo. Chamamos de "efeito anticíclico" porque um aumento em $\beta^{u}$ ocasiona uma maior queda (um maior aumento) em $\beta^{*}$ quando o grau de utilização aumenta (diminui). A derivada em 3.79 é negativa porque estamos indo em direção a um grau de utilização mais alto, como indica a derivada do grau de utilização com relação a $\beta^{u}$, calculada na equação 3.74. Quando a derivada em 3.74 é positiva (cuja chance é maior quando o grau de utilização é baixo), estamos aumentando o grau de utilização pelo efeito do maior crédito ao aposentado e sua maior propensão a consumir e, logo, pela propriedade de convexidade da curva $g_{s}$, o valor do multiplicador diminui - por isso a equação 3.79 é negativa - estamos nos direcionando a um grau de utilização maior.

Desta forma, o efeito multiplicador é bastante relevante no período de queda do nível de atividade, e é possibilitado pelo consumo da classe que recebe benefícios sociais. Similarmente, considere um aumento em $c_{w u}$. Se $u$ sofre uma redução, o aumento em $c_{w u}$ eleva a diminuição em $c$. Neste caso, há uma diminuição ainda maior da propensão a consumir dos trabalhadores ativos, o que faz com que o multiplicador decresça (vide multiplicador do modelo simplificado), mas o seu valor aumenta. O efeito negativo da derivada da equação 3.75 é maior quando o grau de utilização é baixo, pelo efeito da contração do crédito aos ativos, e de sua propensão a consumir, diminuindo ainda mais o grau de utilização. Assim, estamos nos movendo em direção a um grau de utilização menor, o que faz com que o valor do incremento de renda (o valor do multiplicador) seja maior. Isso pode ser visto na equação positiva:

$$
\frac{\partial \text { multiplicador }}{\partial c_{w u}}=-F\left[2 B\left(-i d_{w}\right)-4 C(1-\pi) \alpha_{1}\left(1-\theta_{w}-\lambda_{w} b_{w}\right)\right]
$$

Repare, mais uma vez, que $B$ positivo colabora para o sinal positivo. Chamamos de "efeito pró-cíclico" porque um aumento em $c_{w u}$ leva a uma queda maior na propensão a consumir total $c$ quando o grau de utilização cai. Como vimos em 3.75, o efeito negativo de $c_{w u}$ sobre o grau de utilização é maior quando o grau de utilização for baixo. Assim, estamos nos movendo em direção a um grau de utilização menor, o que significa que o valor do multiplicador é maior, por isso a equação 3.80 tende a ser positiva.

Podemos ilustrar essa estática comparativa por meio de um gráfico. Um aumento em $\beta^{u}$ fortalece uma inclinação menor da curva $g_{s}$ (cuja inclinação é $2 u A-B^{\prime}$ ) quando $u$ 
Capítulo 3. Terceiro Artigo - O efeito dos benefícios sociais na recessão brasileira recente: um modelo 184 Kaleckiano com endividamento das famílias

é pequeno (pois há um aumento tanto de $B^{\prime}$ quanto de $A$ ). O intercepto desta curva não muda. Também não há alteração em $g_{i}$. Neste caso, quando o grau de utilização é baixo, $g_{s}$ tende a se deslocar para baixo, diminuindo sua inclinação. O Gráfico 29, ilustrado a seguir, mostra esta situação. Note que um deslocamento de $g_{i}$ (política fiscal) possui efeito multiplicador menor na nova curva $g_{s}$, dado que estamos nos movendo em direção a um grau de utilização maior e, como tal curva é convexa, o incremento de renda devido à política fiscal se reduz, como vimos acima. Considere um aumento em $c_{w u}$. Neste caso, há o fortalecimento de uma inclinação maior para $g_{s}$ se o grau de utilização for baixo, de modo que há o seu deslocamento para cima. O intercepto não muda. A figura abaixo ilustra o que ocorre também neste caso, mas na direção oposta: nos movemos em direção a um $u$ menor, onde o valor do multiplicador fiscal é maior.

Figura 29 - Efeito de um aumento em $\beta^{u}$ e efeito multiplicador com alto e baixo grau de utilização

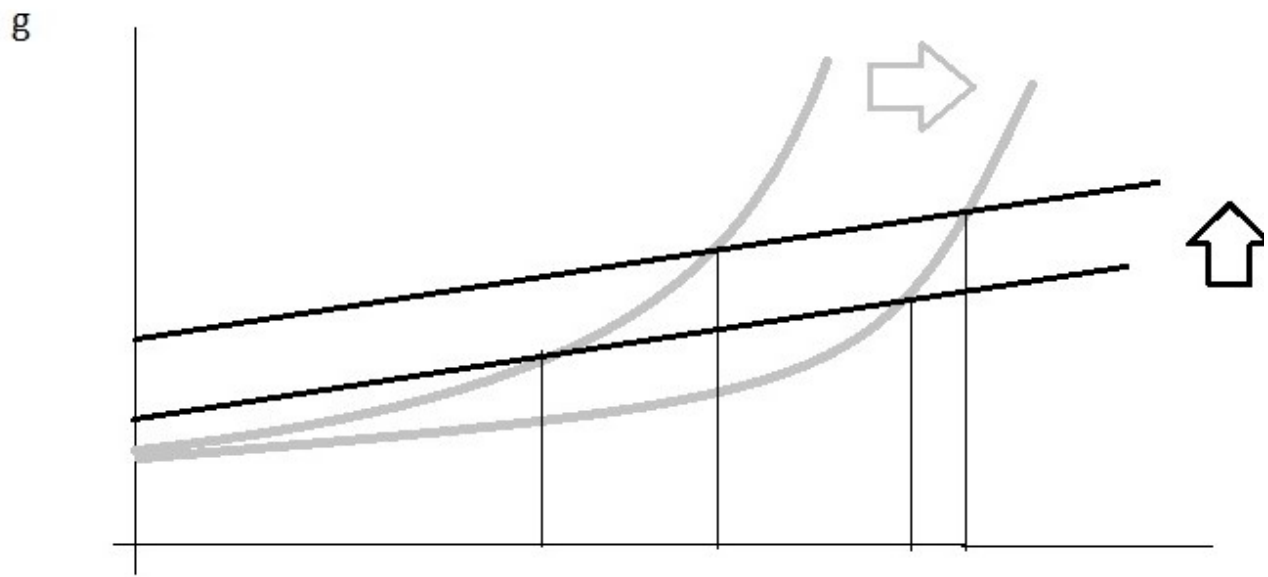

$\mathrm{u}$

Fonte: Elaboração própria. A linha cinza refere-se à curva $g_{s}$ que, como vimos, apresenta um formato de parábola com concavidade para cima. Como de costume, o eixo vertical representa a poupança agregada dividida pelo estoque de capital (ou o investimento agregado dividido pelo estoque de capital). O eixo horizontal, o grau de utilização de capacidade instalada $(u)$. A linha preta representa a curva $g_{i}$. Repare que a curva $g_{s}$ é mais inclinada, pela condição Keynesiana de estabilidade. Pela condição $C>0$, o intercepto da $g_{i}$ é mais alto. O giro da curva $g_{s}$ representa um aumento em $\beta^{u}$. O deslocamento da linha preta é a representação de um aumento no gasto público (parte exógena), com alto e baixo grau de utilização. O efeito do multiplicador fiscal é maior em valor quando o grau de utilização for baixo. Conforme vamos avançando na direção de um $u$ maior, o valor desse incremento de renda diminui.

Podemos considerar também como o multiplicador se comporta em relação aos estoques de dívida. Como vimos na equação 3.76, o aumento do estoque de dívida dos aposentados em relação ao estoque de capital tende a ter um efeito positivo sobre o grau de utilização - e $B$ positivo colabora para isso - se o seu efeito anticíclico compensar o efeito adverso da distribuição de renda aos capitalistas e o efeito contracionista do consumo dos ativos. Assim, o efeito de $d_{a}$ sobre o multiplicador tende a ser negativo se isso ocorrer, pois 
estamos nos movendo para um grau de utilização mais alto:

$$
\frac{\partial \text { multiplicador }}{\partial d_{a}}=-F\left[2 B\left(\beta^{u} i\right)+4 A i\left(c_{c}-1-\beta_{1}\right)\right]
$$

Similarmente, vimos na equação 3.77 que o efeito de $d_{w}$ sobre o grau de utilização tende a ser negativo - e $B$ positivo colabora para isso. Também há um correspondente para isso em termos do efeito multiplicador, que tende a ser positivo se isso ocorrer, pois nos movemos para um $u$ menor:

$$
\frac{\partial \text { multiplicador }}{\partial d_{w}}=-F\left[2 B\left(-i c_{w u}\right)+4 A\left(i c_{c}\right)\right]
$$

Interpretação semelhante vale para a taxa de juros, cujo efeito sobre o multiplicador é mais negativo se o efeito anticíclico da dívida for maior ( $\beta^{u}$ maior e $c_{w u}$ menor) pois nesse caso o impacto sobre o grau de utilização é positivo (equação 3.78) e, logo, o valor do multiplicador diminui:

$$
\frac{\partial \text { multiplicador }}{\partial i}=-F\left[2 B\left(-d_{w} c_{w u}+\beta^{u} d_{a}\right)+4 A\left(c_{c} d_{w}+d_{a}\left(c_{c}-1-\beta_{1}\right)\right)\right]
$$

A estática comparativa neste caso, dos estoques de dívida e da taxa de juros, fica similar à da Figura 29, porém há um deslocamento do intercepto da curva $g_{s}$. Mas a interpretação dos gráficos é parecida e, por este motivo, não iremos desenhá-los ${ }^{12}$.

Vamos considerar também o efeito de $\gamma_{0}$, parâmetro que está presente no multiplicador e está muito ligado ao ciclo econômico:

$$
\frac{\partial \text { multiplicador }}{\partial \gamma_{0}}=-4 A F
$$

Que é negativo, pois um aumento em $\gamma_{0}$ desloca a curva $g_{i}$ para cima, aos moldes da Figura 28, e eleva o grau de utilização, diminuindo o valor do multiplicador.

Por fim, vamos considerar uma mudança na distribuição de renda, por meio de uma variação positiva em $\pi$, a participação dos lucros na renda:

$$
\frac{\partial u^{*}}{\partial \pi}=\left\{-\alpha_{2} \alpha \phi\left(1-\theta_{a}\right)\left(1+\beta_{1}\right)+c_{c} \xi\left(1+\lambda_{c} b_{c}\right)-\alpha \phi+D 2 B(.)+4 D C\left[-A^{\prime}\right]\right\} \frac{1}{2 A}+\frac{u^{*}\left(A^{\prime}\right)}{A}
$$

Onde $A^{\prime}=\left[-c_{w u} \alpha_{1}\left(1-\theta_{w}-\lambda_{w} b_{w}\right)+\beta^{u} \alpha_{2} \alpha \phi\left(1-\theta_{a}\right)\right]$ e $()=.-\alpha_{2} \alpha \phi\left(1-\theta_{a}\right)\left(1+\beta_{1}\right)+$ $c_{c} \xi\left(1+\lambda_{c} b_{c}\right)-\alpha \phi$. Esta expressão diz que, se $c_{c}$ não for muito alta (como é o caso, por hipótese de modelos Kaleckianos), o termo entre chaves é negativo. Repare, como de praxe,

12 Por exemplo, se $d_{a}$ aumenta, e se o grau de utilização for baixo, há o fortalecimento de uma inclinação menor, com um giro parecido ao da Figura 29, com a diferença de que o intercepto tende a subir. Há tanto um giro quanto um deslocamento da curva. Se $d_{w}$ aumenta, e se o grau de utilização for baixo, fortalece uma inclinação maior (indo em direção a um $u$ menor), com deslocamento do intercepto para baixo. Interpretação parecida é válida para o efeito de $i$. Se tal efeito for predominantemente positivo, de modo que aumentamos $u$, há um giro da curva $g_{s}$ como na Figura 29, bem como um deslocamento. 
Capítulo 3. Terceiro Artigo - O efeito dos benefícios sociais na recessão brasileira recente: um modelo 186 Kaleckiano com endividamento das famílias

que $B>0$ colabora para isso - isto é $\beta^{u}$ mais alto e $c_{w u}$ mais baixo. O segundo termo, multiplicado por $u^{*}$ é positivo. Assim, a economia tende a exibir um comportamento wage led ${ }^{13}$ quanto mais o termo positivo for menor, isto é, quando o grau de utilização for pequeno. Portanto, a tendência wage led é reforçada em situações de queda do nível de atividade econômica, pois a renda do trabalhador aposentado é sustentada pela parte anticíclica da oferta de crédito, atuando de forma a mitigar os efeitos contracionistas via maior efeito multiplicador.

\subsection{Conclusão}

O modelo aqui desenvolvido buscou inspiração no resultado empírico abordado nos Artigos 1 e 2. Deve-se frisar que nosso modelo é uma representação possível dos resultados que encontramos anteriormente. Embora nossos resultados anteriores tenham nos inspirado, a construção de um modelo teórico requer a simplificação de vários aspectos da realidade. Nossa hipótese para o surgimento de um multiplicador fiscal para as despesas com benefícios sociais que aumenta em períodos de queda no nível de atividade econômica passa pelo endividamento das pessoas que recebem o benefício social - os trabalhadores aposentados - cujo consumo aumenta em um cenário de redução no nível de atividade econômica porque há maior disponibilidade de crédito. Esse incremento do consumo é possibilitado pela tomada de crédito maior, a qual ocorre por duas vias: aumento da oferta de crédito dos bancos aos trabalhadores aposentados - com diminuição do crédito aos trabalhadores na ativa - e aumento da demanda por crédito por parte dos trabalhadores aposentados, que pode funcionar como um alívio financeiro para a família durante um período difícil. O aumento da oferta de crédito aos trabalhadores aposentados é justificado pela regulamentação do crédito consignado, de 2004, que oferece menos riscos ao emprestador. Como motivação empírica, apresentamos os dados sobre o crédito consignado no Brasil, que apontam que, no período da crise recente, o crédito concedido aos trabalhadores aposentados apresentou uma queda bem menor no início e uma recuperação muito mais rápida, relativamente ao crédito concedido aos trabalhadores ativos. O crédito, assim, é visto como um possível canal indireto pelo qual o efeito estabilizador da renda dos gastos com benefícios sociais ocorre.

Nosso modelo sugere que o maior efeito multiplicador em situações de queda no nível de atividade econômica decorre do fornecimento de crédito aos aposentados durante tal período. Esta parte anticíclica do crédito mais do que compensa a contração do consumo (via propensão a consumir direta ou via contração de crédito) dos ativos, levando a um multiplicador fiscal que se eleva em períodos de baixo grau de utilização de capacidade instalada, e diminui conforme a economia se aproxima de um nível de atividade

13 Não se trata do sentido usual do termo wage led - podemos pensar que a aposentadoria refere-se a uma renda do trabalho pretérita. Neste sentido, utilizamos tal termo com esta qualificação. 
econômica maior. Isso pode ser justificado pela regulamentação do crédito consignado, pois a maior inclusão financeira, sobretudo da base da pirâmide (que tem maior propensão a consumir), pode ser um elemento poderoso para dinamizar a economia e resultar em um multiplicador de renda mais alto, até mesmo impedindo um agravamento da crise econômica recente. Vimos que um aumento da sensibilidade do crédito ofertado/demandado para/pelos aposentados, por exemplo, leva a um aumento no grau de utilização quanto mais a economia está em situação de baixo grau de utilização, o que é coerente com um multiplicador maior em períodos de queda na atividade econômica. Similarmente, um aumento na sensibilidade da propensão a consumir total dos ativos (incluindo a oferta/demanda de crédito) leva a efeitos mais negativos quanto mais baixo o grau de utilização.

De um modo geral, observamos que a dívida do aposentado contribui para efeitos positivos no grau de utilização se o consumo ocasionado por ela for tal que compense a distribuição de renda aos capitalistas e o efeito da sensibilidade da propensão a consumir e oferta de crédito aos ativos. Outro resultado bastante importante é que um menor grau de utilização fortalece a tendência wage led da economia, tendo em vista que quando há queda no nível de atividade econômica o efeito do crédito ao aposentado sobre o consumo é no sentido de aumentá-lo a ponto de compensar variações negativas no consumo dos trabalhadores ativos.

Para além de modelar uma situação empírica em um contexto específico, a crise brasileira recente, a contribuição do artigo está em fazer uma releitura da estrutura de classes de Setterfield et al (2016), com um modelo Kaleckiano que inclui previdência e trabalhadores de dois tipos, ativos e inativos. Esta ótica permitiu a modelagem de uma função de oferta de crédito que leva em conta a heterogeneidade dos trabalhadores, especialmente durante períodos de queda no nível de atividade, sendo uma extensão da oferta de crédito modelada por Dutt (2006). Nossa extensão incluiu a endogeneização do parâmetro que reflete as condições de oferta/demanda de crédito, que passou a depender do grau de utilização. Também nos inspiramos em Charles et al (2015), que construíram um modelo cujo multiplicador fiscal em recessões era maior porque os capitalistas decidem consumir mais quando há queda no nível do grau de utilização. Nosso canal de transmissão, porém, é a propensão a consumir dos trabalhadores por meio do crédito. Como resultado, obtemos que o multiplicador aumenta quando o grau de utilização é baixo porque existe uma parte anticíclica do crédito que mais do que compensa o efeito negativo da contração de consumo das famílias durante o período de queda do nível de atividade. Portanto, sugerimos uma formalização possível do caráter estabilizador da renda da classe que recebe os benefícios sociais.

Uma limitação de nosso modelo é que ficamos restritos ao curto prazo, tendo em vista que nosso interesse específico é na crise brasileira recente e nas ferramentas 
Capítulo 3. Terceiro Artigo - O efeito dos benefícios sociais na recessão brasileira recente: um modelo 188 Kaleckiano com endividamento das famílias

de se combater uma recessão ainda maior. Os modelos Kaleckianos de endividamento das famílias geralmente apontam para o duplo caráter do crédito: apesar de o efeito do crédito ser positivo no curto prazo, com aumento da propensão a consumir, elevação da demanda agregada e estímulo ao crescimento econômico, seu efeito a longo prazo pode ser desestabilizador, pois fortalece uma distribuição de renda dos trabalhadores, que mais consomem, aos capitalistas (cuja propensão a poupar é maior) e explicita o efeito estagnacionista do endividamento das famílias. O longo prazo, porém, não é o nosso escopo neste artigo. Desta forma, elaborar um modelo que incorpore endogeneização da oferta de crédito e analise seus efeitos a longo prazo é uma possibilidade de pesquisa futura.

\section{Referências do Terceiro Artigo}

ALLAIN, O. Macroeconomic effects of consumer debt: three theoretical essays. Centre d'Economie de la Sorbonne Working Paper, n.87 2014.

ASIMAKOPULOS, A. A Kaleckian theory of income distribution. Canadian Journal of Economics, v.8, n.3, p.313-333, 1975.

AUERBACH, A.; GORODNICHENKO, Y. Measuring the output responses to fiscal policy. American Economic Journal: Economic Policy, v.4, n.2, p. 1-27, 2012.

BANCO CENTRAL DO BRASIL. Empréstimo consignado: características, acesso e uso. Departamento de Promoção da Cidadania Financeira (Depef), 2018.

BARBA, A.; PIVETTI, M. Rising household debt: its causes and macroeconomic implications - a long period analysis. Cambridge Journal of Economics, v.33, n.1, p.113-137, 2008.

BRANDÃO, V. Crédito consignado e crise no Brasil: uma via de mão dupla. Encontro Nacional de Economia Politica, 2019.

CARVALHO, L.; RUGITSKY, F. Growth and distribution in Brazil the 21st century: revisiting the wage-led versus profit-led debate. Working paper series. Department of Economics FEA/USP, n.25, 2015.

CARVAlHO, L. Valsa Brasileira. Do boom ao caos econômico. Editora Todavia, 2018.

CATTAN, R. Política fiscal e crescimento econômico: uma análise do período de metas de inflação no Brasil. Dissertação de Mestrado. Unicamp, 2017.

CHANG KO, M. Fiscal policy, government debt, and economic growth in the Kaleckian model of growth and distribution. Journal of Post Keynesian Economics, v.42, n.2, p.215$231,2018$.

CHARLES, S.; DALLERY, T.; MARIE, J. Why the Keynesian multiplier increases during hard times: a theroretical explanation based on rentiers' saving behaviour. Metroeconomica, 
v.66, n.3, p.451-473, 2015.

CHARPE, M.; FLASCHEL, P. Workers' debt, default and the diversity of financial fragilities. Structural Change and Economic Dynamics, v.27, p.48-65, 2013.

CHARPE, M.; FLASCHEL, P.; PROANO, C. Income distribution, credit rationing and households' debt. Metroeconomica, v.63, n.3, p.458-492, 2012.

COMMENDATORE, P.; PINTO, A. Public expenditure composition and growth: a neo-Kaleckian analysis. Cahiers D'Economie Politique, v.61, p.187-222, 2011.

CYNAMON, B.; FAZZARI, S. Inequality and household finance during the consumer age. Levy Economics Institute Working Paper, n.752, 2013.

DICKERSON, A.; GREEN, F. Fears and realisations of employment insecurity. Labour Economics, v.19, n.2, p.198-210, 2012.

DUMAN, A. Household debt in Turkey: the critical threshold for the next crisis. ECOMOD Prague, 2013.

DUTT, A. Stagnation, income distribution and monopoly power. Cambridge Journal of Economics, v.8, n.1, p.25-40, 1984.

DUTT, A. K. Maturity, stagnation and consumer debt: a steindlian approach. Metroeconomica, v.57, n.3, p.339-364, 2006.

DUTT, A. K . Government spending, aggregate demand and economic growth. Review of Keynesian Economics, v.1, n.1, p.105-119, 2013.

FAZZARI, S.; MORLEY, J.; PANOVSKA, I. State-dependent effects of fiscal policy. Studies in Nonlinear Dynamics and Econometrics, v.19, n.3, p.285-315, 2015.

GIRARDI, A. Expectations and macroeconomic fluctuations in the euro area. Economics Letters, v.125, n.2, p.315-318, 2014.

HARRIS, J. The price policy of firms, the level of employment and distribution of income in the short run. Australian Economic Papers, v.13, p.144-151, 1974.

HEIN, E. Finance-dominated capitalism, re-distribution, household debt and financial fragility in a Kaleckian distribution and growth model. IN: The Macroeconomics of Finance-Dominated Capitalism - and its Crisis. Edward Elgar Publishing, 2011.

HEIN, E. Autonomous government expenditure growth, deficits, debt, and distribution in a neo-Kaleckian growth model. Journal of Post Keynesian Economics, v.41, n.2, p.316-338, 2018.

HEUVEL, S. Does bank capital matter for monetary transmission. Federal Reserve Bank of New York Economic Policy Review, v.15, p.256-65, 2002.

ISAAC, A.; KIM, Y. Consumer and corporate debt: a Neo-Kaleckian synthesis. Metroeco- 
Capítulo 3. Terceiro Artigo - O efeito dos benefícios sociais na recessão brasileira recente: um modelo 190 Kaleckiano com endividamento das famílias

nomica, v.64, n.2, p.244-271, 2013.

KALDOR, N. Alternative theories of distribution. The Review of Economic Studies, v.23, n.2, p.83-100, 1955.

KAPELLER, J.; SCHUTZ, B. Conspicuous consumption, inequality and debt: The nature of consumption-driven profit-led regimes. Metroeconomica, v.66, n.1, p.51-70, 2015.

KIM, Y. SETTERFIELD, M.; MEI, Y. A theory of aggregate consumption. European Journal of Economics and Economic Policies: Intervention, v.11, n.1, p.31-49, 2014.

KIM, Y.; LIMA, G.; SETTERFIELD, M. Political aspects of household debt. The New School for Social Research Working Paper, n.24, 2017.

KIM, Y.; LIMA, G.; SETTERFIELD, M. Political aspects of household finance: debt, wage bargaining, and macroeconomic (in)stability. Journal of Post Keynesian Economics, v.42, n.1, p.16-38, 2018.

LARAMIE, A. J. Taxation and Kalecki's Distribution Factors. Journal of Post Keynesian Economics, v.13, n.4, p.583-594, 1991.

LAVOIE, M. Post-Keynesian Economics: new foundations. [S.1.]: Edward Elgar Publishing, 2014.

LEDUC, S.; SILL, K. Expectations and economic flutuations: an analysis using survey data. The Review of Economics and Statistics, v.95, n.4, p.1352-1367, 2013.

MARSELLOU, E. Consumer and corporate debt in a basic Post Keynesian Model of growth and income distribution. 15th annual conference of the Macroeconomic Policy Institute (IMK) at the Hans-Boeckler-Foundation, Research Network Macroeconomics and Macroeconomic Policies (FMM), 2011.

ORAIR, R.; SIQUEIRA, F.; GOBETTI, S. Política fiscal e ciclo econômico: uma análise baseada em multiplicadores do gasto público. XXI Prêmio do Tesouro Nacional, 2016.

PALlEY, T. Debt, Aggregate Demand, and The Business Cycle: an Analysis in the Spirit of Kaldor and Minsky. Journal of Post Keynesian Economics, v.16, n.3, p.371-390, 1994.

PALLEY, T. Inside debt and economic growth: a neo- Kaleckian analysis. In: SETTERFIELD, M. Handbook of Alternative Theories of Economic Growth. Edward Elgar, 2010.

PARIBONI, R. Household consumer debt, endogenous money and growth: A supermultiplierbased analysis. PSL Quarterly Review, v.69, n.278, p. 211-233, 2016.

PIRES, M. Política fiscal e ciclos econômicos no Brasil. Economia aplicada, v.18, n.1, p.69-90, 2014.

RANGEL, L.; VAZ, F.; FERREIRA, J. Desigualdade na distribuição de renda: enfoque 
nas aposentadorias e pensões públicas. Informe de Previdência Social, v.21, n.5, 2009.

RIBEIRO, R.; LIMA, G. Government expenditure ceiling and public debt dynamics in a demand-led macromodel. Journal of Post Keynesian Economics, v.42, n.3, p.363-389, 2019 .

RYOO, S.; KIM, Y. Income distribution, consumer debt and keeping up with the Joneses. Metroeconomica, v.65, n.4, p.585-618, 2014.

SERRANO, F.; SUMMA, R. A desaceleração rudimentar da economia brasileira desde 2011. OIKOS, v.11, n.2, p.166-202, 2012.

SETTERFIELD, M.; KIM, Y. Debt servicing, aggregate consumption and growth. Structural Change and Economic Dynamics, v.36, p.22-33, 2016.

SETTERFIELD, M.; KIM, Y.; REES, J. Inequality, Debt Servicing and the Sustainability of Steady State Growth. Review of Political Economy, v.28, n.1, p.45-63, 2016.

SILVA, D; KAPPES, S. A Previdência Social Brasileira em um Modelo de Consistência de Estoques e Fluxos. XI Encontro da Associação Keynesiana Brasileira, 2018.

SILVEIRA, J.; LIMA, G. Can workers' increased pessimism about the labor market conditions raise unemployment? Working Paper Series FEA USP, n.38, 2019.

TAVANI, D; ZAMPARELLI, L. Government spending composition, aggregate demand, growth and distribution. Institut für Makroökonomie und Konjunkturforschung (IMK) Working Paper, n.158, 2015.

TAYLOR, L. A stagnationist model of economic growth. Cambridge Journal of Economics, v.9, n.4, p. 383-403, 1985.

YOU, J.; DUTT, A. Government debt, income distribution and growth. Cambridge Journal of Economics, v.20, n.3, p.335-351, 1996.

ZEZZA, G. U.S. growth, the housing market, and the distribution of income. Journal of Post Keynesian Economics, v.30, n.3, p.375-401, 2008.

\subsection{Apêndice do Terceiro Artigo}

Vejamos os efeitos dos demais parâmetros no modelo com endogeneização da oferta de crédito.

A derivada do grau de utilização com relação à parte do crédito ofertada ao aposentado cuja oferta independe do ciclo é positiva se o fluxo de pagamento de juros sobre a dívida não for muito alto, sendo compensado por seu efeito positivo sobre o consumo, como nos modelos Kaleckianos tradicionais de crédito. Note que, novamente, $B>0$ possui papel para o sinal da derivada: 


$$
\frac{\partial u^{*}}{\partial \beta_{1}}=\left[\alpha_{2} \alpha \phi(1-\pi)\left(1-\theta_{a}\right)+D 2 B\left(\alpha_{2} \alpha \phi(1-\pi)\left(1-\theta_{a}\right)\right)+4 A D\left(-i d_{a}\right)\right] \frac{1}{2 A}
$$

A parte do crédito cuja oferta está condicionada à distribuição dos dois tipos de renda, de aposentados e ativos, possui efeito positivo sobre o grau de utilização. Sua magnitude depende dos parâmetros que indicam a proporção de aposentados e da proporção de sua renda:

$$
\frac{\partial u^{*}}{\partial \beta_{3}}=\frac{2 D}{\alpha \phi}
$$

Agora vamos derivar com relação aos parâmetros que indiquem a renda disponível dos trabalhadores ativos.

$$
\frac{\partial u^{*}}{\partial \alpha_{1}}=-D 4 C(1-\pi) c_{w u}\left(1-\theta_{w}-\lambda_{w} b_{w}\right) \frac{1}{2 A}+\frac{u^{*}(1-\pi) c_{w u}\left(1-\theta_{w}-\lambda_{w} b_{w}\right)}{A}
$$

Um aumento na renda disponível dos trabalhadores ativos por meio de $\alpha_{1}$ é mais positivo quanto maior o grau de utilização, tendo em vista que o crédito ofertado a eles, bem como sua propensão a consumir, são pró-cíclicos. Quando o grau de utilização é baixo, o efeito negativo é maior. O efeito da renda desses trabalhadores, portanto, é no sentido pró-cíclico. Ambos os efeitos, na direção positiva e negativa, dependem da sensibilidade da propensão total a consumir $c_{w u}$.

Raciocínio similar vale para o aumento na alíquota de imposto e de contribuição previdenciária para os trabalhadores ativos:

$$
\begin{gathered}
\frac{\partial u^{*}}{\partial \theta_{w}}=D 4 C(1-\pi) c_{w u} \alpha_{1} \frac{1}{2 A}-\frac{u^{*}(1-\pi) c_{w u} \alpha_{1}}{A} \\
\frac{\partial u^{*}}{\partial \lambda_{w} b_{w}}=D 4 C(1-\pi) c_{w u} \alpha_{1} \frac{1}{2 A}-\frac{u^{*}(1-\pi) c_{w u} \alpha_{1}}{A}
\end{gathered}
$$

Em um cenário de aumento do grau de utilização, o efeito do aumento dessas alíquotas é mais negativo, pois diminui a renda disponível da classe que possui renda pró-cíclica, cuja propensão a consumir aumenta conforme o grau de utilização se eleva.

Um aumento na renda disponível do aposentado, por outro lado, age no sentido contrário. Seu efeito positivo sobre o grau de utilização e a taxa de crescimento da economia é maior quando o grau de utilização for menor (em recessões, por exemplo), o que ilustra mais uma vez o caráter anticíclico da renda do aposentado:

$$
\frac{\partial u^{*}}{\partial \alpha_{2}}=\left[\left(1+\beta_{1}\right) \alpha \phi(1-\pi)\left(1-\theta_{a}\right)+D 2 B(.)+D 4 C(1-\pi) \beta^{u} \alpha \phi\left(1-\theta_{a}\right)\right] \frac{1}{2 A}-\frac{u^{*}(1-\pi) \beta^{u} \alpha \phi\left(1-\theta_{a}\right)}{A}
$$


Onde $()=.\left(1+\beta_{1}\right) \alpha \phi(1-\pi)\left(1-\theta_{a}\right)$.

Similarmente, cobrar uma alíquota maior de impostos ao aposentado quando há queda no nível de atividade econômica possui efeito mais negativo sobre o grau de utilização (efeito positivo é menor quando o grau de utilização é baixo):

$\frac{\partial u^{*}}{\partial \theta_{a}}=\left[-\left(1+\beta_{1}\right) \alpha_{2} \alpha \phi \alpha(1-\pi)+D 2 B()-.D 4 C(1-\pi) \beta^{u} \alpha_{2} \alpha \phi\right] \frac{1}{2 A}+\frac{u^{*}(1-\pi) \beta^{u} \alpha_{2} \alpha \phi}{A}$

Onde(.)=-(1+ $\left.\beta_{1}\right) \alpha_{2} \alpha \phi \alpha(1-\pi)$.

Um aumento da proporção de aposentados em relação aos ativos $\alpha$ e um aumento da proporção do valor da aposentadoria em relação ao salário dos ativos $\phi$ possuem efeitos muito parecidos:

$$
\frac{\partial u^{*}}{\partial \alpha}=[(.)+D 2 B(.)+D 4 C(. .)+D 4 A(. .)] \frac{1}{2 A}-\frac{u^{*}(1-\pi) \beta^{u} \alpha_{2} \phi\left(1-\theta_{a}\right)}{A}
$$

Onde $()=.\left(1+\beta_{1}\right) \alpha_{2} \phi(1-\pi)\left(1-\theta_{a}\right)+\phi(1-\pi) ;(.)=.(1-\pi) \beta^{u} \alpha_{2} \phi\left(1-\theta_{a}\right) ;(.)=.-\beta_{3} \frac{1}{\phi \alpha^{2}}$.

$$
\frac{\partial u^{*}}{\partial \phi}=[(.)+D 2 B(.)+D 4 C(. .)+D 4 A(. .)] \frac{1}{2 A}-\frac{u^{*}(1-\pi) \beta^{u} \alpha_{2} \alpha\left(1-\theta_{a}\right)}{A}
$$

Onde: $()=.\left(1+\beta_{1}\right) \alpha_{2} \alpha(1-\pi)\left(1-\theta_{a}\right)+\alpha(1-\pi) ;(.)=.(1-\pi) \beta^{u} \alpha_{2} \alpha\left(1-\theta_{a}\right) ;(.)=.-\beta_{3} \frac{1}{\alpha \phi^{2}}$.

Quando o grau de utilização é menor, o efeito negativo nas derivadas acima é menor, colaborando para que a derivada seja positiva. Repare o papel de $\beta^{u}$ e $c_{w u}$, novamente, em $B$. Em situações de queda do nível da atividade econômica, o aumento da renda do trabalhador aposentado - seja via maior valor do benefício, ou por uma maior proporção de aposentados - tende a elevar o grau de utilização, dado o seu caráter anticíclico.

Um aumento da sensibilidade da função investimento ao grau de utilização possui efeito positivo (e $B>0$ colabora) na taxa de crescimento da economia:

$$
\frac{\partial u^{*}}{\partial \gamma_{u}}=\frac{1+D 2 B}{2 A}
$$

Agora, vejamos o efeito dos parâmetros que dizem respeito à renda do capitalista. Um aumento da propensão a consumir do capitalista possui efeito positivo sobre o grau de utilização. Uma maior participação dos lucros na renda ou uma menor alíquota de contribuição patronal à previdência contribuem para isso:

$$
\frac{\partial u^{*}}{\partial c_{c}}=\left\{\xi\left[\left(1-\theta_{c}\right)-(1-\pi)\left(1+\lambda_{c} b_{c}\right)\right]+\theta_{d e f} d_{w}+D 2 B(.)+D 4 A i\left(d_{w}+d_{a}\right)\right\} \frac{1}{2 A}
$$

Onde $()=.\xi\left[\left(1-\theta_{c}\right)-(1-\pi)\left(1+\lambda_{c} b_{c}\right)\right]+\theta_{d e f} d_{w}$.

Um aumento na sensibilidade da taxa de default ao grau de utilização possui efeito positivo sobre o grau de utilização. Tal efeito é maior quanto mais alta a propensão a 
consumir do capitalista e o estoque de dívida dos ativos. Isto porque, se a sensibilidade desta taxa for alta, conforme o grau de utilização aumenta, há uma grande redução no default. Na função consumo do capitalista, $C_{c}=c_{c}\left\{\xi\left[\left(Y\left(1-\theta_{c}\right)-W L\left(1+\lambda_{c} b_{c}\right)\right]+i\left(D_{w}+\right.\right.\right.$ $\left.\left.D_{a}\right)-\theta_{\text {default }} D_{w}\right\}=c_{c}\left\{\xi\left[\left(Y\left(1-\theta_{c}\right)-W L\left(1+\lambda_{c} b_{c}\right)\right]+i\left(D_{w}+D_{a}\right)+\theta_{\text {def }} D_{w} u\right\}\right.$. Isto é, como a taxa de default depende negativamente do grau de utilização, a sua sensibilidade entra com sinal positivo na função consumo do capitalista. Conforme $u$ aumenta, maior é o consumo desta classe porque há menos default. Repare o papel de $B$ novamente (nesta e nas próximas derivadas).

$$
\frac{\partial u^{*}}{\partial \theta_{d e f}}=\left[c_{c} d_{w}+D 2 B\left(c_{c} d_{w}\right)\right] \frac{1}{2 A}
$$

Elevações na alíquota de contribuição patronal possuem efeito mais negativo conforme a propensão a consumir do capitalista (ou sua proporção dos lucros), por exemplo, for mais alta:

$$
\frac{\partial u^{*}}{\partial \lambda_{c} b_{c}}=\left[-c_{c} \xi(1-\pi)+D 2 B\left(-c_{c} \xi(1-\pi)\right)\right] \frac{1}{2 A}
$$

Um aumento na alíquota de impostos do capitalista possui efeito negativo quanto maior a propensão a consumir do capitalista (ou sua proporção dos lucros):

$$
\frac{\partial u^{*}}{\partial \theta_{c}}=\left[-c_{c} \xi+D 2 B\left(-c_{c} \xi\right)\right] \frac{1}{2 A}
$$

Elevações na parcela de lucros distribuídos causam efeito positivo no grau de utilização de acordo com a propensão a consumir do capitalista e os parâmetros que afetam a sua renda disponível:

$$
\frac{\partial u^{*}}{\partial \xi}=\left[c_{c}\left[\left(1-\theta_{c}\right)-(1-\pi)\left(1+\lambda_{c} b_{c}\right)\right]+D 2 B(.)\right] \frac{1}{2 A}
$$

Onde $()=.c_{c}\left[\left(1-\theta_{c}\right)-(1-\pi)\left(1+\lambda_{c} b_{c}\right)\right]$. 